
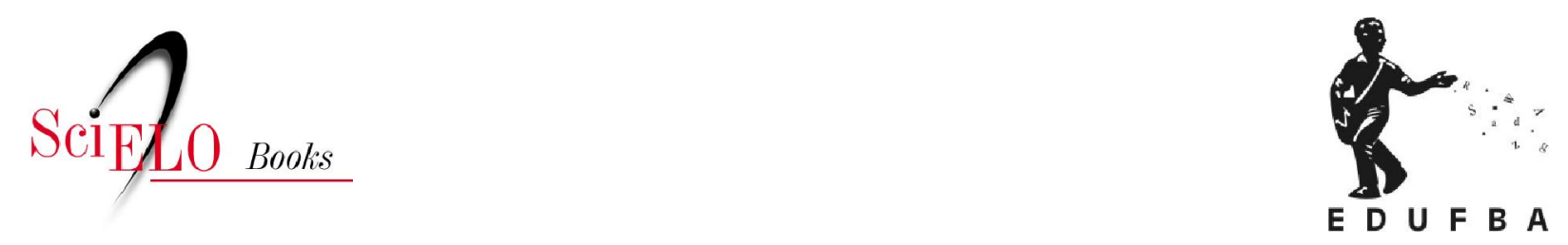

\title{
Práticas investigativas em atividade física e saúde
}

\author{
Helio José Bastos Carneiro de Campos \\ Francisco José Gondim Pitanga \\ (orgs.)
}

CAMPOS, HJC., and PITANGA, FJG., orgs. Práticas investigativas em atividade física e saúde [online]. Salvador: EDUFBA, 2013, 207 p. ISBN 978-85-232-1220-9. Available from SciELO Books $<\underline{\text { http://books.scielo.org }>\text {. }}$

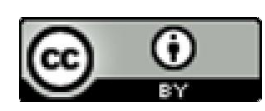

All the contents of this work, except where otherwise noted, is licensed under a Creative Commons Attribution $\underline{4.0 \text { International license. }}$

Todo o conteúdo deste trabalho, exceto quando houver ressalva, é publicado sob a licença Creative Commons Atribição 4.0.

Todo el contenido de esta obra, excepto donde se indique lo contrario, está bajo licencia de la licencia Creative Commons Reconocimento 4.0. 


\section{Práticas investigativas em atividade física e saúde}


Dilma Roussef

PRESIDENTE DA REPÚBLICA

Aloísio Mercadante

MINISTRO DA EDUCAÇÃO

Sistema Universidade Aberta do Brasil

Jorge Guimarães

PRESIDENTE DA CAPES

João Teatini

DIRETOR DE EDUCAÇÃO A DISTÂNCIA DA CAPES

Governo do Estado da Bahia

Jacques Wagner

GOVERNADOR

Otto Roberto Mendonça de Alencar

VICE-GOVERNADOR

Osvaldo Barreto Filho

SECRETÁRIO DA EDUCAÇÃO

Universidade do Estado da Bahia - UNEB

Lourisvaldo Valentim da Silva

REITOR

Adriana dos Santos Marmori Lima

VICE-REITORA

José Bites de Carvalho

PRÓ-REITOR DE ENSINO DE GRADUAÇÃO

Silvar Ferreira Ribeiro

COORDENADOR UAB/UNEB

André Magalhães

COORDENADOR UAB/UNEB ADJUNTO
Universidade Federal da Bahia

Dora Leal Rosa

REITORA

Luiz Rogério Bastos Leal

VICE-REITOR

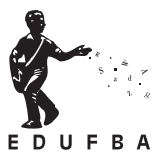

Editora da Universidade Federal da Bahia

Flávia Goulart Mota Garcia Rosa

DIRETORA

Alberto Brum Novaes

Angelo Szaniecki Perret Serpa

Caiuby Álves da Costa

Charbel Niño El Hani

Cleise Furtado Mendes

Dante Eustachio Lucchesi Ramacciotti

Evelina de Carvalho Sá Hoisel

José Teixeira Cavalcante Filho

Maria Vidal de Negreiros Camargo

CONSELHO EDITORIAL

\section{PAIS RICO E PAIS SEM POBREZA}

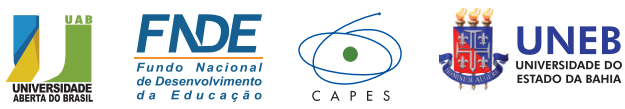




\section{Práticas investigativas em atividade física e saúde}

Helio José Bastos Carneiro de Campos

Francisco José Gondim Pitanga

Organizadores 
2013. Autores

Direitos para esta edição cedidos à Edufba.

Feito o depósito legal.

Grafia atualizada conforme o Acordo Ortográfico da Língua

Portuguesa de 1990, em vigor no Brasil desde 2009.

Raíssa Ribeiro Silva Santos

PROJETO GRÁFICO, CAPA E EDITORAÇÃO

Ana Virginia Carneiro de Campos

FOTO HELIO CAMPOS

Flávia Garcia Rosa

NORMALIZAÇÃO

Claudia Vega

REVISÃO

Sistema de Bibliotecas - UFBA

Práticas investigativas em atividade física e saúde / Helio José Bastos Carneiro de Campos, Francisco José Gondim Pitanga (Organizadores) ; [apresentação], Helio José Bastos Carneiro de Campos ; [prefácio], Francisco Pitanga ; [posfácio], Luiz Alberto Bastos de Almeida. - Salvador : EDUFBA, 2013.

$207 \mathrm{p}$.

ISBN 978-85-232-1061-8

1. Exercícios físicos. 2. Exercícios terapêuticos. 3. Hábitos de saúde. I. Campos, Helio José Bastos Carneiro de. II. Pitanga, Francisco José Gondim. III. Almeida, Luiz Alberto Bastos de.

CDD - 613.7

Editora filiada à

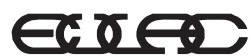

ASOCIACION DE EDITORIALES UNIVERSITARIAS DE AMERICA LATINA Y EL CARIBE

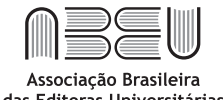

das Editoras Universitárias

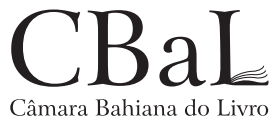

EDUFBA

Rua Barão de Jeremoabo, s/n

Tel.: (71) 3283-6160 / 3283-6164

Campus Ondina, 40.170-115

Salvador - Bahia

edufba@ufba.br 


\section{Apresentação}

A presente coletânea sobre as práticas investigativas na área da atividade física e saúde é uma aspiração antiga dos profissionais baianos de Educação Física que veem se debruçando cotidianamente nas pesquisas relacionadas à promoção da saúde, atividade física, qualidade de vida, estilo de vida, bem-estar e saúde coletiva.

A ideia deste projeto nasceu de sucessivas conversas entre os professores Francisco Pitanga, Luiz Alberto Tourinho e Helio Campos. O desdobramento dessas reuniões informais levou à iniciativa de organizar uma coletânea a partir da experiência vivenciada nas reuniões do curso de Licenciatura em Educação Física do EAD da Universidade Aberta do Brasil (UAB) e da Universidade do Estado da Bahia (UNEB), onde a maioria dos autores desta obra é docente.

Os artigos aqui apresentados são oriundos de um grande esforço pela qualificação profissional. São textos resultantes de investigação científica em cursos de pós-graduação stricto-sensu, lato sensu e da iniciação científica. Salientamos que os artigos, na sua quase totalidade, são inéditos e apenas dois deles foram publicados anteriormente, um na Revista Associação Médica Brasileira, em 2008, e o outro na Revista Brasileira de Cineantropometria e Desenvolvimento Humano, em 2011. 
Foram vários os fatores que nos motivaram a executar esse projeto da organização da coletânea. O primeiro refere-se à enorme carência de livros que tratem do assunto com seriedade e propósito científico. O segundo diz respeito ao fato de que a totalidade dessas obras pertencem a autores e editoras do sul do país, sendo que, na maioria das vezes, o produto está esgotado, além de ser de difícil acesso aos baianos. O terceiro refere-se à importância dos resultados das pesquisas realizadas pelos autores cuja significância é enorme por se tratar do banco de dados referente à população baiana, o que torna imperioso a divulgação na comunidade científica e na sociedade. O quarto, que esse livro poderá ser um instrumento de enorme valia para os profissionais e estudantes da área da atividade física e da saúde, especialmente os da Educação Física.

A seleção dos artigos teve como critério a proveniência das dissertações de mestrado, tese de doutorado e artigo produzidos no curso de especialização em Condicionamento Físico Aplicado a Cardiologia da União Metropolitana de Educação e Cultura (UNIME). Também foram contemplados artigos produzidos em grupos de pesquisa de duas universidades públicas baianas Universidade do Estado da Bahia (UNEB) - Campus de Alagoinhas e a Universidade Estadual de Feira de Santana (UEFS).

Portanto, os artigos aqui publicados estão organizados em três partes: na primeira, contemplamos os textos referentes aos trabalhos originais, na segunda, encontram-se os artigos de revisão bibliográfica, e na terceira, os trabalhos produzidos nos grupos de pesquisa.

Os artigos dessa coletânea apresentam temas bastante abrangentes e diversificados, porém, de importância vital para estudos na área da atividade física e da saúde. Eles tratam sobremodo dos seguintes assuntos: "Concepções da imagem corporal entre praticantes e instrutores de musculação, fisiculturista e estudantes de Educação Física da região metropolitana de Salvador-BA: uma análise sobre os níveis de satisfação com a forma física e a autopercepção corporal"; "Atividade física como fator de proteção para co-morbidades cardiovasculares em mulheres obesas"; "Razão cintura/estatura comparado a outros indicadores antropométricos de obesidade como preditor de risco coronariano elevado"; "Prevalência 
e fatores associados à inatividade física em adultos na cidade de Lauro de Freitas-BA"; "Mecanismos de atuação do exercício nos níveis de fadiga de pacientes com câncer”; "Contribuição do exercício resistido para prevenção e controle da osteoporose em mulheres adultas"; "Fatores associados à inatividade física em adolescentes: um artigo de revisão"; "Participação do sistema nervoso autônomo nas alterações cardiorrespiratórias e metabólicas durante a prática competitiva do surf"; "Estudo quantitativo da produção científica sobre atividade física para a promoção da saúde no banco de teses da Capes no ano de 2008"; "Práticas corporais desenvolvidas com idosas participantes do Projeto Educar para a Atividade Física (EPAF) da Universidade do Estado da Bahia e variáveis da aptidão física”.

Ao finalizar esta apresentação, quero registrar os meus agradecimentos a todos os colegas professores pesquisadores que atenderam prontamente ao convite, para aqui deixar sua contribuição nesta obra que abre uma nova perspectiva na publicação científica da Educação Física na Bahia e especialmente na temática da Atividade Física e da Saúde.

Aos leitores, convido-os para uma leitura acurada e generosa, o que, por certo, significa ter um olhar atento, criterioso e crítico, no sentido de propiciar um melhor entendimento sobre a importância da atividade física regular e planejada na promoção da saúde.

Boa leitura! Prof. Dr. Helio José Bastos Carneiro de Campos 



\section{Prefácio}

Fazer o prefácio da coletânea Práticas investigativas em atividade física e saúde é motivo de muito orgulho e satisfação. Orgulho em virtude de ter participado da formação acadêmica de diversos autores desta obra literária no momento em que fizemos a orientação das suas respectivas dissertações de mestrado. Satisfação porque vemos que mesmo na região Nordeste do Brasil, quando as sementes são plantadas, frutos de alta qualidade acabam sendo colhidos.

Além disto, congratulo-me com a Universidade Aberta do Brasil (UAB) e com a Universidade do Estado da Bahia (UNEB) que viabilizaram a revisão, normalização e parceria com a Editora da UFBA (Edufba), visando a publicação desta importante coletânea, que sem dúvida alguma muito irá contribuir para o crescimento acadêmico dos alunos da Educação Física à distância.

O livro está didaticamente dividido com a apresentação de artigos científicos, todos eles com conteúdos de grande relevância para a área de atividade física e saúde no Brasil. É importante ressaltar que entre os artigos apresentados encontram-se textos originais oriundos de tese de doutorado e dissertações de mestrado. Os temas são sobremaneira interessantes, oportunos e atualizados, e ainda destacamos o caráter inédito dos trabalhos. 
O primeiro artigo desta obra aborda de forma muito interessante as concepções da imagem corporal entre praticantes e instrutores de musculação, fisiculturistas e estudantes de Educação Física da região metropolitana de Salvador-Bahia.

No segundo artigo os autores comentam sobre a atividade física como fator de proteção para comorbidades cardiovasculares demonstrando que o comportamento ativo fisicamente pode prevenir agravos metabólicos e cardiovasculares em mulheres obesas.

No terceiro artigo compara-se a razão cintura-estatura a outros indicadores antropométricos de obesidade como preditores de risco coronariano elevado demonstrando a importância da utilização da antropometria como instrumento de triagem para agravos metabólicos e cardiovasculares na população da cidade de Salvador-Bahia.

O quarto artigo do livro aborda de forma bastante pertinente a prevalência e fatores associados a inatividade física em adultos na cidade de Lauro de Freitas-Bahia-Brasil trazendo contribuições para a implantação de políticas públicas para promoção de atividades físicas na região Nordeste do Brasil

No quinto artigo os autores comentam sobre os mecanismos de atuação do exercício nos níveis de fadiga de pacientes com câncer.

No sexto artigo os autores abordam as contribuições do exercício resistido para prevenção e controle da osteoporose em mulheres adultas.

No sétimo artigo os autores tratam, por meio de estudo de revisão, dos fatores associados a inatividade física em adolescentes considerando que o conhecimento sobre a prática da atividade física, e seus determinantes, nesta faixa etária é fundamental para a adoção de hábitos ativos fisicamente.

No oitavo artigo os autores comentam sobre a participação do sistema nervoso autônomo nas alterações cardiorrespiratórias e metabólicas durante a prática competitiva do surf.

No nono artigo os autores fazem um estudo quantitativo sobre a produção científica a respeito da atividade física para promoção da saúde no banco de teses da CAPES no ano de 2008. 
Finalmente, no décimo artigo os autores discutem sobre as práticas corporais desenvolvidas com idosas participantes do projeto "Educar para a atividade física" da UNEB.

Aproveito esta oportunidade para parabenizar o professor Helio Campos por ter se debruçado exaustivamente sobre o projeto desta coletânea, no firme propósito de apresentar para a comunidade científica e a sociedade baiana resultados de pesquisas importantes realizadas por pesquisadores baianos e colaboradores sobre a temática da atividade física e saúde.

Portanto, recomendo a leitura detalhada do livro, considerando que isto proporcionará um melhor entendimento da real contribuição científica dos pesquisadores sobre a íntima relação da atividade física, saúde e qualidade de vida dos baianos e da região Nordeste do Brasil.

Prof. Dr. Francisco Pitanga 



\section{Sobre os autores}

ALINE DA SILVA ADÃES MOTTA

Graduada em Educação Física pela Universidade Estadual de Feira de Santana (UEFS), Núcleo de Estudos e Pesquisas em Atividade Física e Saúde (NEPAFIS/UEFS).

E-mail: asa_motta@yahoo.com.br

\section{ALINE MENDONÇA DE SÁ}

Fisioterapeuta. Especialista em Clínica da Dor. Formação em Pilates Sttot Pilates Canadá. Diretora Técnica do Curso de Formação em Pilates ActivePilates Brasil.

E-mail: aline@activepilates.com.br

ANA CRISTINA RODRIGUES MENDES

Graduada em Nutrição (UNEB) e em Educação Física (UCsal). Especialização em Psicopedagogia (Univ. Gama Filho). Especialista em Nutrição nos Esportes (ASBRAN). Mestre em Nutrição (UFPE). Doutora em Psicologia, Saúde, Educação e Qualidade de Vida (AWU/LAD). Docente da Universidade do Estado da Bahia (UNEB), Departamento de Ciências da Vida - Cursos de Graduação e Pós-Graduação em Nutrição.

E-mail: acrismendes@gmail.com 
ANA LUİZA COELHO RUBINI

Possui graduação em Psicologia pela Universidade Federal da Bahia (1992) e mestrado em Desenvolvimento Humano e Responsabilidade Social pela Fundação Visconde de Cairu (2006). Atualmente é professor titular da União Metropolitana de Educação e Cultura e Unime Salvador e concursada da Prefeitura Municipal de Salvador, lotada no Centro de Atenção Psicossocial (CAPS) Prof. Aristides Novis.

E-mail: analuizarubini@gmail.com

ANTONIO DANTAS JÚNIOR

Graduado em Odontologia (1985) e em Educação Física (2007) ambas pela Universidade Federal da Bahia (UFBA). Especialista em Atividade Física e Saúde pela União Metropolitana de Educação e Cultura (UNIME - Lauro de Freitas - 2010). Presidente da Cooperativa de Assistência à Saúde e Atividades Afins LTDA (COPAS).

E-mail: hisd_06@yahoo.com.br

\section{CARLOS FERNANDO DE AMORIM ALVES}

Graduado em Educação Física pela Universidade Católica do Salvador (UCSAL). Mestre em Alimentos, Nutrição e Saúde pela Universidade Federal da Bahia (UFBA). Professor do Centro Universitário Jorge Amado (UNIJORGE) e União Metropolitana de Educação e Cultura (UNIME). Bolsista da CAPES/ UAB/UNEB. Docente do Curso de Licenciatura em Educação Física EAD/ UNEB.

E-mail: camorimalves@uol.com.br

CÍNTIA GUIMARÃES ROSÁRIO

Graduanda do curso de Licenciatura em Educação Física pela UNEB Alagoinhas, atualmente é uma das monitoras do projeto de extensão Educar para a Atividade Física da referida universidade e professora voluntária na Universidade Aberta a Terceira Idade (UATI). Bolsista de iniciação cientifica pela Fundação de Apoio a Pesquisa do Estado da Bahia (Fapesb).

E-mail: cintia_rosario@yahoo.com.br 


\section{CIRO OLIVEIRA QUEIROZ}

Graduado em Educação Física pela UESB. Especialista em Atividade Física Adaptada e Saúde pela UGF, Núcleo de Estudos em Atividade Física e Saúde - NEAFIS/UESB. Mestrando em biotecnologia da saúde e medicina investigativa pela FIOCRUZ.

E-mail: ciroedfisica@gmail.com

\section{CLOUD KENNEDY COUTO DE SÁ}

Graduado em Educação Física pela Universidade Federal da Bahia (1997), Mestre em Nutrição pela Universidade Federal da Bahia (2004) e doutor em Medicina e Saúde Humana pela Escola Bahiana de Medicina e Saúde Pública (2012). Professor adjunto na Universidade Estadual de Feira de Santana e na Escola Bahiana de Medicina e Saúde Pública. Integrante do Núcleo de Estudos e Pesquisas em Atividade Física e Saúde - NEPAFIS/ UEFS. Concentra suas atividades de pesquisa sobre mecanismos, respostas e adaptações dos sistemas corporais frente ao exercício e a nutrição. E-mail: sacloud@yahoo.com.br

\section{CRISTIANO PENAS SEARA PITANGA}

Possui graduação em Educação Física pela Universidade Católica do Salvador (UCSAL). Especialização em condicionamento físico aplicado à cardiologia pela União Metropolitana de Educação e Cultura (Unime). Mestrado em Avaliação das Atividades Física e Desportiva pela Universidade de Trás-os-Montes e Alto Douro. Atualmente é professor da Faculdade Regional da Bahia (UNIRB) e do Centro Universitário Jorge Amado (UNIJORGE). Bolsista da CAPES/UAB/UNEB. Docente do Curso de Licenciatura em Educação Física EAD/UNEB e doutorando em Educação Física na UTAD/Portugal.

E-mail: cpspitanga@gmail.com

DANILO RAMOS HAUN

Graduação em Educação Física pela Universidade Católica do Salvador (UCSAL) e Mestrado em Educação Física e Desporto pela Universidade de Trás-os-Montes e Alto Douro. Atualmente é líder do setor de pós-reabilitação 
e reabilitação esportiva do Instituto Baiano de Reabilitação. Personal trainer da Academia Villa Forma e da Academia Julião Catello e fisiologista da ATP Run - Assessoria Esportiva. Atua principalmente nos seguintes temas: avaliação física, condicionamento físico e saúde.

E-mail: danilohaun@gmail.com

FRANCISCO JOSÉ GONDIM PITANGA

Graduação em Educação Física pela Universidade Católica do Salvador (UCSAL). Mestrado em Ciência do Movimento Humano pela Universidade Federal de Santa Maria (UFSM). Doutorado em Saúde Coletiva pela Universidade Federal da Bahia (UFBA) e pós-doutorado pela Universidade Federal de Santa Catarina (UFSC). Atualmente é Professor Adjunto da Universidade Federal da Bahia, Professor Titular da Universidade do Estado da Bahia, Coordenador do Curso de Educação Física do Centro Universitário Jorge Amado e Coordenador do Curso de Licenciatura em Educação Física EAD/ $\mathrm{UNEB} / \mathrm{UAB}$.

E-mail: pitanga@lognet.com

HELIO JOSÉ BASTOS CARNEIRO DE CAMPOS

Formado em Educação Física pela UCSAL, doutor em Educação pela UFBA, Livre Docente pela AWU/USA, professor Aposentado da UFBA e UCSAL. Professor Integrante do Núcleo Docente Estruturante da UNIJORGE. Coordenador Editorial da Revista Corpo, Movimento e Saúde da UNIJORGE. Bolsista da Capes/UAB/UNEB. Docente do Curso de Licenciatura em Educação Física EAD/UNEB. Membro do Instituto Geográfico e Histórico da Bahia (IGHB). Escritor, autor de quatro livros na área da Educação e Capoeira.

E-mail: helliocampos@gmail.com

\section{INES LESSA}

Graduação em Medicina pela Universidade Federal da Bahia (1966), mestrado em Saúde Pública pela Universidade Federal da Bahia (1977) e doutorado em Medicina pela Universidade Federal da Bahia (1982). Atualmente é professora aposentado da Universidade Federal da Bahia, atuando na pós- 
-graduação. Faz parte do corpo editorial das Revistas Brasileira de Hipertensão, de Saúde Pública/Journal of Public Health e dos Arquivos Brasileiros de Cardiologia. ad hoc das Revista Brasileira de Epidemiologia, Cadernos de Saúde Pública, Arquivos de Neuropsiquiatria e Revista de Saúde Pública da OPS. Tem experiência na área de Saúde Coletiva, com ênfase em Epidemiologia das doenças crônicas não transmissíveis (DCNT), atuando também na área de serviços de saúde para os mesmos temas: epidemiologia das doenças cardiovasculares, incluindo as cerebrovasculares, diabetes mellitus, obesidade, doença renal crônica, dislipidemias, síndrome metabólica e envelhecimento. Desenvolveu e executou vários projetos para o Ministério da Saúde e para a Secretaria de Saúde do Estado da Bahia.

E-mail: Ines@lessa.org

JOÃO MARCELO MIRANDA

Graduação em Educação Física pela Universidade Federal da Bahia (UFBA). Participou do Intercâmbio - FCDEF - UC - PT. Especialista em Biomecânica, Avaliação Física e Prescrição de Exercícios (UniFMU). Mestre em Educação Física pela Universidade São Judas Tadeu (USJT). Área de Concentração: Atividade Física, Esporte e Saúde. Linha de Pesquisa: Biodinâmica da Atividade Física. Pós-graduando em Docência no Ensino Superior (UNICID). Atualmente é docente do curso de graduação em Educação Física da Universidade Cidade de São Paulo e da Uninove.

E-mail: jmdqm@hotmail.com

\section{MARCELA MOTA FREITAS}

Licenciada em Educação Física pela UFBA. Mestre em Educação Física pela Universidade Trás-os-Montes e Alto Douro (UTAD) - Portugal. Professora e integrante do Núcleo Docente Estruturante (NDE) da UNIJORGE). Coordenadora e avaliadora física da Academia Sports Authority. Professora do Instituto Federal da Bahia (IFBA) e bolsista da Capes/UAB/UNEB. Docente do Curso de Licenciatura em Educação Física EAD/UNEB.

E-mail: profmarcelafreitas@yahoo.com.br 
MARCUS VINÍCIUS PALMEIRA

Mestre em Educação Física pela Universidade São Judas Tadeu (USJT/SP) (2007). Licenciatura plena em Educação Física (1999), e pós-graduado em nível de especialização em Treinamento Desportivo (2002), ambos curso realizados na Universidade Federal da Bahia (UFBA). Licenciado em Pedagogia (2012) pelo Centro Universitário Nove de Julho (UNINOVE); Pós-graduando em Educação Física Escolar pela Universidade Estadual de Campinas (UNICAMP). Experiência docente na área de Educação Física, Esporte, Saúde e Educação. Atuando principalmente nos seguintes temas: educação física escolar, treinamento desportivo, movimento na educação infantil, e esportes radicais, na natureza e de aventura.

E-mail: mvpalmeira@yahoo.com.br

MARIA CECILIA SĀ PINTO RODRIGUES DA COSTA

Possui graduação em Nutrição pela Universidade Federal da Bahia (UFBA). Especialização em Alimentos (UFBA). Mestrado em Nutrição e Doutorado em Saúde Pública (UFBA). Atualmente é professora adjunta da UFBA. Tem experiência na área de Saúde Coletiva, com ênfase em doenças crônicas não-transmissíveis, e nutrição, atuando principalmente nos seguintes temas: obesidade e práticas alimentares.

E-mail: marcosta@superig.com.br

MAURÍCIO MALTEZ RIBEIRO

Graduado em Educação Física pela UCSAL. Especialista em reabilitação cardiovascular pelo Instituto do coração (InCor) da USP. Mestre em Fisiologia pelo Instituto de Ciências Biomédicas (ICB) da USP. Doutor em Ciências pela Faculdade de Medicina da USP e professor da Universidade do Estado da Bahia (UNEB). Bolsista da CAPES/UAB/UNEB e Docente do Curso de Licenciatura em Educação Física EAD/UNEB.

E-mail: mmaltez@usp.br

RICARDO JACÓ DE OLIVEIRA

Natural de Uberlândia-MG, concluiu o doutorado em Neurologia/Neurociências pela Universidade Federal de São Paulo em 1996. Atualmente é pro- 
fessor adjunto da Universidade de Brasília (UnB). Publicou diversos artigos em periódicos especializados e em anais de eventos. Possui 12 capítulos de livros e 4 livros publicados. Orientou dissertações de mestrado, teses de doutorado e trabalhos de iniciação cientifica nas áreas de Educação Física, Fisioterapia, Medicina e Psicologia. Em suas atividades profissionais interagiu com 200 colaboradores e em seu currículo Lattes os termos mais freqüentes na contextualização da produção científica, tecnológica e artístico-cultural são: idosas, envelhecimento, idosos, Força, exercício, genética, Treinamento resistido, Atividade Física, Composicão Corporal, Densidade Mineral óssea e depressão.

E-mail: fefpg@unb.br

\section{RITA DE CÁSSIA RIBEIRO SILVA}

Possui graduação em Nutrição pela Universidade Federal da Bahia (1989), mestrado em Nutrição Humana Aplicada pela Universidade de São Paulo (1994), doutorado em Saúde Coletiva pela Universidade Federal da Bahia (2001) e Pós doutorado pela London School of Hygiene and Tropical Medicine (LSHTM). Atualmente é professor associado II da Universidade Federal da Bahia. Tem experiência na área de Saúde Coletiva, com ênfase em Epidemiologia, atuando principalmente nos seguintes temas: Disturbios nutricionais, doenças crônicas/DCNT, doenças parasitárias, desenvolvimento cognitivo, crianças e adolescentes.

E-mail: ritaribeiroufba@gmail.com

ROGÉRIO BRANDÃO WICHI

Graduado em Educação Física pela Universidade Estadual Paulista, Campus Rio Claro. Mestre em Farmacologia pela Faculdade de Ciências Médicas da Universidade Estadual de Campinas. Realizou doutorado sanduíche na Wright State University School of Medicine, Dayton, Ohio, EUA, doutorando-se em Ciências pela Escola Paulista de Medicina da Universidade Federal de São Paulo. Recebeu da Sociedade Interamericana de Hipertensão o prêmio Jovem Pesquisador. Professor Adjunto da Universidade Federal de Sergipe (UFS).

E-mail: rbwichi@hotmail.com 
ROGÉRIO TOSTA DE ALMEIDA

Graduado em Educação Física pela UFBA. Especialista em Metodologia do Ensino da Educação Física pela UESB. Mestre em Saúde Coletiva pela UEFS. Professor assistente da Universidade Estadual de Feira de Santana. Membro do Núcleo de Estudos e Pesquisas em Atividade Física e Saúde (NEPAFIS). Email: rogertosta@yahoo.com.br

VALTER ABRANTES PEREIRA DA SILVA

Graduado em Educação Física pela UCSAL em 1997, Professor Auxiliar da Universidade do Estado da Bahia (UNEB). Mestre em Educação Física pela Universidade Católica de Brasília. Especialista em Condicionamento Físico Aplicado à Prevenção Cardiológica Primária e Secundária pela Faculdade de Medicina e Instituto do Coração da Universidade São Paulo (FMUSP-InCor). Professor a UNIME. Fisiologista do Esporte Clube Vitória. Coordenador de tutoria do Curso de Licenciatura em Educação Física EAD/UNEB/UAB e Bolsista da CAPES/UAB/UNEB.

E-mail: vabrantes@bol.com.br 


\section{Sumário}

23 Concepções da imagem corporal entre praticantes e instrutores de musculação, fisiculturistas e estudantes de educação física da região metropolitana de Salvador-Ba: uma análise sobre os níveis de satisfação com a forma física e a autopercepção corporal ANA CRISTINA RODRIGUES MENDES, HELIO JOSÉ BASTOS DE CARNEIRO CAMPOS EANA LUİZA COELHO RUBINI

49 Atividade física como fator de proteção para co-morbidades cardiovasculares em mulheres obesas

CRISTIANO PENAS SEARA PITANGA, RICARDO JACÓ DE OLIVEIRA, INES LESSA, MARIA CECILLIA COSTA E FRANCISCO JOSÉ GONDIM PITANGA

63 Razão cintura/estatura comparado a outros indicadores antropométricos de obesidade como preditor de risco coronariano elevado

DANILO RAMOS HAUN, FRANCISCO JOSÉ GONDIM PITANGA E INES LESSA

79 Prevalência e fatores associados à inatividade física em adultos na cidade de Lauro de Freitas-Ba-Brasil MARCELA MOTA FREITAS E FRANCISCO JOSÉ GONDIM PITANGA 
103 Mecanismos de atuação do exercício nos níveis de fadiga de pacientes com câncer

ALINE DA SILVA ADÃES MOTTA, ALINE MENDONÇA DE SÁ E CLOUD KENNEDY COUTO DE SÁ

113 Contribuição do exercício resistido para prevenção e controle da osteoporose em mulheres adultas

ANTONIO DANTAS JÚNIOR E HELIO JOSÉ BASTOS CARNEIRO DE CAMPOS

129 Fatores associados à inatividade física em adolescentes: um artigo de revisão

CARLOS FERNANDO DE AMORIM ALVES E RITA DE CÁSSIA RIBEIRO SILVA

153 Participação do sistema nervoso autônomo nas alterações cardiorrespiratórias e metabólicas durante a prática competitiva do surfe

MARCUS VINICIUS PALMEIRA, ROGÉRIO BRANDÃO WICHI, HELIO JOSÉ BASTOS CARNEIRO DE CAMPOS E JOÃO MARCELO MIRANDA

165 Estudo quantitativo da produção científica sobre atividade física para promoção da saúde no banco de teses da CAPES no ano de 2008

CIRO OLIVEIRA QUEIROZ E ROGÉRIO TOSTA DE ALMEIDA

191 Práticas corporais desenvolvidas com idosas participantes do projeto Educar Para a Atividade Física (EPAF) da Universidade do Estado da Bahia e variáveis da aptidão física

CINNTIA GUIMARÃES ROSÁRIO, MAURÍCIO MALTEZ RIBEIRO E VALTER ABRANTES PEREIRA DA SILVA

205 Posfácio

LUIZ ALBERTO BASTOS DE ALMEIDA 


\section{Concepções da imagem corporal entre praticantes e instrutores de musculação, fisiculturistas e estudantes de educação física da região metropolitana de Salvador-Ba: uma análise sobre os níveis de satisfação com a forma física e a autopercepção corporal}

Ana Cristina Rodrigues Mendes Helio José Bastos de Carneiro Campos

Ana Luíza Coelho Rubini

\section{INTRODUÇÃO}

Nas últimas décadas, o tema imagem corporal vem despertando um interesse cada vez maior no Brasil e em diversos países, especialmente entre adolescentes e jovens, uma vez que comumente estes indivíduos associam a sua identidade à autoimagem corporal. O conceito de imagem corporal não necessariamente representa o reflexo do espelho, como ressalta Courtine (1995): “[...] ter uma boa aparência não significa ter uma imagem corporal positiva; a imagem corporal é, na verdade, um estado de espírito".

Segundo Adami e colaboradores (2005), a busca de uma imagem corporal adequada aos anseios estereotipados de corpo 
é um dos fenômenos mais impressionantes na sociedade atual, existindo neste contexto, uma grande influência cultural sobre a imagem do corpo, o que pode criar aspectos distorcidos relacionados ao universo corporal.

A crescente valorização do corpo e da estética nas sociedades de consumo, refletida nos meios de comunicação de massa, que expõem como modelo ideal e de masculinidade - um corpo inflado de músculos - pode estar contribuindo para que um número crescente de jovens envolva-se com o uso de esteróides anabolizantes, dentre outras práticas arriscadas, na intenção de rapidamente desenvolver massa muscular. (COURTINE, 1995)

Conceitualmente, a imagem corporal é a forma pela qual o corpo se apresenta para si mesmo, ou seja, é o conjunto de sensações cinestésicas construídas pelos sentidos (audição, visão, tato, paladar), oriundos de experiências vivenciadas pelo indivíduo, que conduzem à construçãode um referencial do seu corpo, para o seu corpo e para o outro, sobre o objeto elaborado. (RUSSO, 2005; MATARUNA, 2004; TAVARES, 2003; SCHILDER, 1999)

Segundo Adami e colaboradores (2005), a imagem corporal é um complexo fenômeno que envolve aspectos cognitivos, afetivos, socioculturais e motores, e está intrinsecamente associada com o conceito de si próprio, sendo influenciável pelas dinâmicas interações entre o ser e o meio em que vive. Corroborando com estes autores, Tavares (2003, p. 29), afirma que a imagem mental "integra várias modalidades sensoriais e diversos processos psíquicos que estão continuamente em intercâmbio”, sendo, deste modo, formadas imagens de objetos externos e internos. Segundo o autor, o ser humano constrói a sua visão do eu e da imagem do seu corpo, intimamente associados, ambos dependentes do desenvolvimento do sistema sensorial/neurológico, da percepção e das relações socioculturais que o indivíduo estabelece com o seu meio. Desenvolve-se desde o nascimento até a morte, dentro de uma estrutura complexa e subjetiva, sofrendo modificações ao longo da vida, que implicam na construção e reconstrução contínuas, resultante do processamento de estímulos.

Durante os anos pré-escolares, a criança desenvolve de forma acentuada o seu conceito a respeito da imagem corporal. (MONTARDO, 2009; MATARUNA, 2004). Sua formação pode ser influenciada por fatores como sexo, idade, meios de comunicação, bem como por uma relação entre 
processos cognitivos, como crenças, valores e atitudes provenientes de sua cultura. Além disto, envolve fatores emocionais, de atitude e perceptuais, relacionando-se diretamente com a autoestima, com o amor próprio e com a satisfação pessoal. (ALMEIDA et al., 2005; BARROS, 2005; CAMARGO et al., 2008)

A autopercepção do peso é um aspecto importante quando se fala de imagem corporal, podendo ser influenciada por diversos fatores, incluindo a cultura e os padrões sociais. (COSTA et al., 2007; VEGGI et al., 2004) Em artigo de revisão, Camargo e colaboradores (2007), citando Saikali e colaboradores (2004) afirmam que a autoavaliação da imagem corporal pode ocorrer de três formas: (1) o indivíduo pensa em extremos relacionados à sua aparência ou é muito crítico em relação a ela; (2) o indivíduo compara a aparência com padrões extremos da sociedade; e (3) o indivíduo concentra-se em um aspecto de sua aparência.

A enfática estratégia do estímulo à prática de exercícios físicos e da alimentação visando o rendimento e as medidas corporais, associada abadass de1995(açm o que afirma o incansável desejo de "ter um corpo" adequado aos padrões culturalmente impostos, reforçam as analogias que comumente são feitas entre o corpo humano em movimento ao padrão de uma máquina, nas quais ambos - exercício e alimentação - são executados de um modo irrefletido e irresponsável, repetitivo e mecânico. (ADAMI et al., 2005; RIZZO PINTO, 1997)

Cohane e Pope (2001) realizaram uma revisão sobre aspectos relacionados à imagem corporal em indivíduos do sexo masculino. Em termos gerais, o estudo aponta que alterações de imagem corporal no sexo masculino, ao contrário do que se pensava, são considerados relativamente comuns, e diferem do padrão de distorção tipicamente feminino. As mulheres apresentam níveis bem maiores de insatisfação que os homens e descrevem sempre corpos mais magros como objetivo. No caso dos homens, há aqueles que seguem o padrão feminino, mas a maioria considera um corpo mais musculoso como representação da imagem corporal masculina ideal. Sabe-se hoje que o excesso de vaidade e a obsessão para manter um corpo escultural não são características exclusivas das mulheres, tendo-se revelado frequentemente entre os homens, que estão cada vez mais preocupados 
com a aparência. Entretanto, o que inicialmente parecia ser um cuidado com a saúde corporal vem se transformando em problema, que tende a agravar-se quando a busca pela perfeição extrapola os limites do corpo, originando um transtorno psíquico conhecido como transtorno dismórfico muscular.

Se a imagem culturalmente dominante e socialmente valorizada remete ao estereótipo do sujeito forte e musculoso, esta provavelmente tornar-se-á a busca incessante de muitos insatisfeitos com o próprio corpo. Aqueles que não conseguem alcançar esse padrão desejado, podem desencadear um processo de sofrimento patológico que passa a exercer um impacto negativo sobre a autoimagem e sobre a vida do sujeito, interferindo nas suas relações, no seu comportamento social e afetivo. De acordo com o que afirma Becker (1999), "esta imagem corporal negativa pode determinar o aparecimento de baixa autoestima e depressão, ou seja, sofrimento".

Em academias de ginástica e em muitas faculdades de Educação Física, historicamente sempre houve algum planejamento e/ou incentivo para a adoção de estratégias de homogeneização e controle do corpo, como por exemplo, exercícios de ginástica geral, a prática de esportes, com formações e movimentos executados sempre numa mesma direção, orientadas a partir de um modelo (corpo do professor) e grupo homogêneo de ações (corpo dos alunos). Em função dessa realidade, há que se reconhecer que praticantes e instrutores de musculação, lutadores e fisiculturistas, dentre outros, constituem grupos potencialmente susceptíveis à ocorrência de distúrbios de distorção de imagem corporal, como a vigorexia, por exemplo.

Nesse sentido, ainda que preliminar, este estudo remete-nos à investigação de questões de relevância na área do comportamento humano, a saber: se existem e quais são os níveis de satisfação com imagem corporal e níveis de preocupação com a forma física (silhueta) e com a aparência como potenciais sinalizadores de risco para transtornos dismórficos corporais.

Este artigo tem como objetivo analisar a concepção da imagem corporal entre praticantes e instrutores de musculação, lutadores e atletas-fisiculturistas nas academias de ginástica e estudantes de Educação Física da região metropolitana de Salvador-BA, identificando níveis de preocupação 
com a forma física (silhueta) e com a aparência, e avaliando a autopercepção da imagem corporal nos grupos pesquisados.

\section{MATERIAL E MÉTODOS}

\section{Modelo de Estudo}

Pesquisa de abordagem quali-quantitativa e natureza descritiva na qual técnicas de observação, registro, análise e correlação entre fatos ou fenômenos (variáveis) foram utilizadas para a coleta das informações e dados, investigando a frequência com que determinado fenômeno ocorreu, sem manipulação de variáveis. (MARTINS; SANTOS, 2003)

\section{Amostra}

A amostra envolveu 637 indivíduos adultos, do sexo masculino, fisicamente ativos, na faixa etária de 18 a 45 anos, residentes da Região Metropolitana de Salvador-BA, levando em consideração os seguintes critérios para a inclusão na pesquisa:

a) praticantes regulares de exercícios físicos, incluindo atividade de musculação há, pelo menos, seis meses anteriores à pesquisa;

b) frequentadores habituais de academias de ginástica (pelo menos 3 vezes por semana);

c) com disponibilidade de tempo para responder aos questionários.

O estudo foi realizado em uma amostra probabilística e estratificada, levando-se em consideração o perfil atlético dos respondentes, incluindo: atletas de fisiculturismo, lutadores e/ou levantadores de peso que participem de competições regionais, nacionais ou internacionais, praticantes de musculação e instrutores de musculação. Considerando que a população-alvo do estudo apresenta características específicas e está sujeita aos critérios de inclusão anteriormente citados, existiram limitações importantes em relação à quantidade de indivíduos constituintes da amostra. 


\section{Instrumentos de Avaliação}

Foram utilizados dois instrumentos de avaliação, incluindo escalas e questionários autoaplicáveis validados na literatura científica, a saber:

1. BISQ-22 Body Image Satisfaction Questionnaire (LUTTER et al., 1990): Este questionário apresenta 22 itens a serem avaliados, tais como partes do corpo e fatores de ordem física que podem ser classificados em cinco opções de resposta: 1- Não gosto nada e desejaria ser diferente; 2- Não gosto, mas tolero; 3- É indiferente, não me importo; 4- Estou satisfeito(a); 5- Considero-me favorecido(a). Foi utilizado para verificar o grau de satisfação dos pesquisados em relação a 22 parâmetros corporais.

2. Escala de Silhuetas (STUNKARD et al., 1983): Utilizada para a verificação da imagem corporal atual e ideal através de um conjunto de 9 silhuetas variando entre a magreza e a obesidade. Para verificar o grau de satisfação ou insatisfação corporal foi avaliada a diferença entre a Percepção da Imagem Corporal Real (PICR), equivalente à silhueta atual, e a Percepção da Imagem Corporal Ideal (PICI), equivalente à silhueta desejada apontada pelo indivíduo.

CLASSIFICAÇÃO DA AUTOPERCEPÇÃO DA IMAGEM CORPORAL (APIC)

Diferença (PICR - PICI) igual a zero = satisfeito

Diferença (PICR - PICI) diferente de zero = insatisfeito

- Silhueta 1 - Baixo peso (magro);

- Silhuetas 2-5 - Peso normal (eutrofia);

- Silhuetas 6-7 (sobrepeso);

- Silhueta 8-9 (obesidade)

\section{Procedimentos/Coleta de Dados}

A partir de um estudo-piloto que envolveu a aplicação de 150 questionários autopreenchíveis em academias de ginástica, respondidos individualmente, os instrumentos foram submetidos a análise e discussão de 
uma comissão de profissionais mestres e doutores (psicólogo, estatístico, nutricionista e professor de Educação Física) após as quais foram remodelados e padronizados para a pesquisa.

Depois do estudo-piloto, seguido da análise e padronização dos questionários, a coleta de dados foi realizada em 08 faculdades de Educação Física (públicas e particulares) e 35 academias de ginástica localizadas na Região Metropolitana de Salvador-BA, incluindo a capital (Salvador) e os municípios de Lauro de Freitas, Camaçari e Dias D’ávila, no período de março de 2008 a janeiro de 2009. Essa coleta foi realizada a partir da autorização prévia dos coordenadores das academias de ginásticas e coordenadores dos cursos de Educação Física, e após consentimento dos participantes do estudo. Utilizou-se como critério para a escolha das academias: a localização em grandes bairros, o tamanho das academias - particularmente as de médio e grande porte - (mínimo de duzentos alunos), os horários de funcionamento em três turnos e a disponibilidade/oferta das modalidades de musculação e lutas ou artes marciais.

\section{Análise Estatística}

A avaliação estatística dos dados foi feita a partir da Análise descritiva e exploratória dos dados e foram realizadas no Laboratório de Estatística da Universidade Federal da Bahia-UFBA, a partir do software Statistical Package for the Social Sciences (SPSS) Release 11.0. Na análise descritiva conjunta entre duas ou três variáveis, foram calculadas as frequências absolutas e as percentagens. Em algumas tabelas com o cruzamento de duas variáveis foi avaliado o grau de associação entre elas através do Teste Qui-Quadrado de Associação.

\section{RESULTADOS E DISCUSSÃO}

Após aplicação da metodologia estatística, foi feita a análise descritiva e exploratória dos dados, apresentada como um resumo das variáveis quantitativas que nos permitiram traçar um perfil geral da população pesquisada.

A Tabela 01 com as medidas-resumo da população estudada, mostra que o informante, em média, tinha 26,3 anos de idade, pesava $78,1 \mathrm{~kg}$, com 
estatura de 177,2 cm e IMC de 24,8. Em relação à variabilidade, medida pelo coeficiente de variação de Pearson, a idade foi a variável que apresentou maior dispersão relativa, porém, com um valor que não pode ser considerado alto (24\%). A distribuição das estaturas foi bastante próxima à forma simétrica $(0,13)$, no entanto, o grau de achatamento foi de 0,78 menor do que a da distribuição Normal-Padrão, corroborando à informação de existência de pequena variabilidade nos dados. A variável que apresentou maior grau de assimetria (à direita) foi a idade, e a maioria dos informantes apresentou idade igual ou menor do que 29 anos. Com respeito ao Índice de Massa Corporal (IMC), os dados apresentaram pequena variabilidade, alguma assimetria à direita (coeficiente igual a 0,81) e foi o maior coeficiente de curtose registrado (2,81); verificou-se ainda que $50 \%$ dos informantes têm IMC igual ou menor do que 24,7. O valor mínimo para esta variável foi 16,7 e o máximo 42,5; evidenciou-se também que metade dos informantes tem o IMC entre 23,0 e 26,4.

TABELA 1. Medidas-resumo para as variáveis: Idade, Peso, Estatura e IMC - Salvador-BA, 2009

\begin{tabular}{|c|c|c|c|c|c|}
\hline \multicolumn{2}{|l|}{ Medidas-resumo } & $\begin{array}{l}\text { Idade } \\
\text { (em anos } \\
\text { completos) }\end{array}$ & $\begin{array}{l}\text { Peso } \\
\text { (em kg) }\end{array}$ & $\begin{array}{l}\text { Estatura } \\
\text { (em cm) }\end{array}$ & IMC \\
\hline \multirow{2}{*}{ No de observações } & Válidas & 635 & 633 & 633 & 633 \\
\hline & Não válidas & 2 & 4 & 4 & 4 \\
\hline \multicolumn{2}{|l|}{ Média aritmética } & 26,3 & 78,1 & 177,2 & 24,8 \\
\hline \multicolumn{2}{|l|}{ Mediana } & 25,0 & 77,0 & 177,0 & 24,7 \\
\hline \multicolumn{2}{|l|}{ Desvio padrão } & 6,25 & 10,97 & 6,95 & 2,88 \\
\hline \multicolumn{2}{|c|}{ Coef. variação de Pearson } & 0,24 & 0,14 & 0,04 & 0,12 \\
\hline \multicolumn{2}{|l|}{ Assimetria } & 1,10 & 0,68 & 0,13 & 0,81 \\
\hline \multicolumn{2}{|l|}{ Curtose } & 0,77 & 1,69 & 0,78 & 2,81 \\
\hline \multicolumn{2}{|l|}{ Mínimo } & 17 & 50 & 152 & 16,7 \\
\hline \multicolumn{2}{|l|}{ Máximo } & 47 & 130 & 205 & 42,5 \\
\hline \multirow{2}{*}{ Percentil } & 25 & 22 & 71 & 173 & 23,0 \\
\hline & 75 & 29 & 85 & 182 & 26,4 \\
\hline
\end{tabular}

Ao se analisar o nível de satisfação com a imagem corporal, observou-se que $47,4 \%$ dos entrevistados revelaram-se satisfeitos; do total de $52,6 \%$ dos 
insatisfeitos, 28,1\% gostariam de ser mais fortes ou mais gordos ao passo que $24,5 \%$ gostariam de ser mais magros (Tabela 02 ).

TABELA 2. Distribuição dos entrevistados segundo os níveis de satisfação (autopercepção da imagem corporal) - Salvador-BA, 2009

\begin{tabular}{l|c|c}
\hline Autopercepção da imagem corporal (níveis de satisfação) & N $^{\circ}$ de obs. & $\%$ \\
\hline Satisfeito & 302 & 47,4 \\
\hline Insatisfeito (gostariam de ser mais fortes ou mais gordos) & 179 & 28,1 \\
\hline Insatisfeito (gostariam de ser mais magros) & 156 & 24,5 \\
\hline TOTAL & 637 & 100,0 \\
\hline
\end{tabular}

Damasceno e colaboradores (2005), estudando o tipo físico ideal e o nível de insatisfação com a imagem corporal entre 186 praticantes de caminhada, sendo 87 mulheres e 98 homens, verificou-se que as mulheres tendem a escolher silhuetas menores que a atual; no caso dos homens, a tendência é desejar desenvolver um corpo com maior massa muscular e menor quantidade de gordura corporal, assim como relatado por Araújo e Araújo(2003), que demonstram diferentes expectativas em relação ao corpo entre os sexos.

Entretanto, segundo Graham e colaboradores (2000), a preocupação com a imagem corporal parece ser uma marca feminina, sobretudo na adolescência, quando o corpo estabelece seu formato. Os autores afirmam que os garotos adolescentes não sofrem tanta pressão social, tendendo a apresentar melhor aceitação da sua autoimagem. No entanto, contrariamente ao que afirmam os autores, os resultados deste estudo revelam um elevado índice de insatisfação dos entrevistados, todos do sexo masculino, com a sua imagem corporal, particularmente aqueles mais jovens. Esses achados são semelhantes aos de outros estudos relatados na literatura científica (DAMASCENO et al. 2005; VEGGI et al., 2004; IRIART et al., 2002; POPE et al., 2000) reafirmando que a pressão social, fatores ambientais, socioculturais, dentre outros já referidos anteriormente, afetam de modo significativo os indivíduos de ambos os sexos, embora este estudo não tenha envolvido indivíduos do sexo feminino. 
A partir da análise das tabelas 03, 04 e 05, com respeito aos itens cabelo, dentes, olhos, orelhas, nariz, testa, pele, face, braços, peitoral, ombros, abdômen, porte físico e nível de energia, constantes no questionário BISQ observou-se que, no mínimo, 70\% dos entrevistados encontram-se nas categorias "satisfeito" ou "muito satisfeito" com essas partes do corpo. Quanto à opinião "não gosto nada e desejaria ser diferente", os maiores percentuais encontram-se para os itens cabelo, dentes, nariz e nível de energia, que apresentaram, respectivamente, 3,6\%, 3,3\%, 3,3\% e 3,6\%.

TABELA 3. Distribuição dos níveis de satisfação (autopercepção da imagem corporal) para os itens cabelo, dentes, olhos, orelhas e nariz - Salvador-BA, 2009

\begin{tabular}{|c|c|c|c|c|c|c|c|c|c|c|}
\hline \multirow[b]{2}{*}{ Nível de satisfação } & \multicolumn{2}{|c|}{ Cabelo } & \multicolumn{2}{|c|}{ Dentes } & \multicolumn{2}{|c|}{ Olhos } & \multicolumn{2}{|c|}{ Orelhas } & \multicolumn{2}{|c|}{ Nariz } \\
\hline & $\begin{array}{l}\mathrm{N}^{0} \\
\text { obs. }\end{array}$ & $\%$ & $\begin{array}{l}\mathrm{N}^{\circ} \\
\text { obs. }\end{array}$ & $\%$ & $\begin{array}{l}\mathrm{N}^{\circ} \\
\text { obs. }\end{array}$ & $\%$ & $\begin{array}{l}\mathrm{N}^{\circ} \\
\text { obs. }\end{array}$ & $\%$ & $\begin{array}{l}\mathrm{N}^{\circ} \\
\text { obs. }\end{array}$ & $\%$ \\
\hline $\begin{array}{l}\text { Não gosto nada e } \\
\text { desejaria ser diferente }\end{array}$ & 23 & 3,6 & 21 & 3,3 & 07 & 1,1 & 10 & 1,6 & 21 & 3,3 \\
\hline Não gosto, mas tolero & 66 & 10,4 & 59 & 9,3 & 16 & 2,5 & 20 & 3,1 & 66 & 10,4 \\
\hline $\begin{array}{l}\text { É indiferente, } \\
\text { não me importo }\end{array}$ & 87 & 13,7 & 71 & 11,2 & 51 & 8,0 & 87 & 13,7 & 104 & 16,3 \\
\hline Estou satisfeito & 310 & 48,7 & 321 & 50,5 & 291 & 45,8 & 319 & 50,1 & 281 & 44,1 \\
\hline $\begin{array}{l}\text { Considero-me } \\
\text { muito satisfeito }\end{array}$ & 151 & 23,7 & 164 & 25,8 & 271 & 42,6 & 201 & 31,6 & 165 & 25,9 \\
\hline TOTAL & 637 & 100,0 & 636 & 100,0 & 636 & 100,0 & 637 & 100,0 & 637 & 100,0 \\
\hline
\end{tabular}

TABELA 4. Distribuição dos níveis de satisfação (autopercepção da imagem corporal) para os itens testa, pele, face, braços e peitoral - Salvador-BA, 2009

\begin{tabular}{|c|c|c|c|c|c|c|c|c|c|c|}
\hline \multirow{2}{*}{$\begin{array}{l}\text { Autopercepção da } \\
\text { imagem corporal } \\
\text { (níveis de satisfação) }\end{array}$} & \multicolumn{2}{|c|}{ Testa } & \multicolumn{2}{|c|}{ Pele } & \multicolumn{2}{|c|}{ Face } & \multicolumn{2}{|c|}{ Braços } & \multicolumn{2}{|c|}{ Peitoral } \\
\hline & $\begin{array}{l}\mathrm{N}^{\circ} \\
\text { obs. }\end{array}$ & $\%$ & $\begin{array}{l}\mathrm{N}^{\circ} \\
\text { obs. }\end{array}$ & $\%$ & $\begin{array}{l}\mathrm{N}^{\circ} \\
\text { obs. }\end{array}$ & $\%$ & $\begin{array}{l}\mathrm{N}^{\circ} \\
\text { obs. }\end{array}$ & $\%$ & $\begin{array}{l}\mathrm{N}^{0} \\
\text { obs. }\end{array}$ & $\%$ \\
\hline $\begin{array}{l}\text { Não gosto nada e } \\
\text { desejaria ser diferente }\end{array}$ & 11 & 1,7 & 11 & 1,7 & 07 & 1,1 & 17 & 2,7 & 18 & 2,8 \\
\hline Não gosto, mas tolero & 28 & 4,4 & 29 & 4,6 & 16 & 2,5 & 49 & 7,7 & 48 & 7,5 \\
\hline $\begin{array}{l}\text { É indiferente, } \\
\text { não me importo }\end{array}$ & 100 & 15,7 & 60 & 9,4 & 48 & 7,5 & 54 & 8,5 & 73 & 11,5 \\
\hline Estou satisfeito & 335 & 52,6 & 295 & 46,3 & 352 & 55,3 & 327 & 51,4 & 326 & 51,3 \\
\hline $\begin{array}{l}\text { Considero-me } \\
\text { muito satisfeito }\end{array}$ & 163 & 25,6 & 242 & 38,0 & 214 & 33,6 & 189 & 29,7 & 171 & 26,9 \\
\hline TOTAL & 637 & 100,0 & 637 & 100,0 & 637 & 100,0 & 636 & 100,0 & 636 & 100,0 \\
\hline
\end{tabular}


O item abdômen destacou-se dos demais por apresentar os maiores percentuais para as categorias "não gosto nada e desejaria ser diferente" e "não gosto, mas tolero". As respostas estão distribuídas da seguinte maneira: 12,9\% não gostam nada e desejariam ser diferentes; $20,1 \%$ não gostam, mas toleram; 36,3\% estão satisfeitos; e 20,3\% estão muitos satisfeitos.

TABELA 5. Distribuição dos níveis de satisfação (autopercepção da imagem corporal) para os itens ombros, porte físico e nível de energia - Salvador-BA, 2009

\begin{tabular}{|c|c|c|c|c|c|c|c|c|}
\hline \multirow{2}{*}{$\begin{array}{l}\text { Autopercepção } \\
\text { da imagem corporal } \\
\text { (níveis de satisfação) }\end{array}$} & \multicolumn{2}{|c|}{ Ombros } & \multicolumn{2}{|c|}{ Porte físico } & \multicolumn{2}{|c|}{ Nível de energia } & \multicolumn{2}{|c|}{ Abdômen } \\
\hline & $\begin{array}{l}\mathrm{N}^{\circ} \\
\text { obs. }\end{array}$ & $\%$ & $\begin{array}{l}\mathrm{N}^{0} \\
\text { obs. }\end{array}$ & $\%$ & $\begin{array}{l}\mathrm{N}^{0} \\
\text { obs. }\end{array}$ & $\%$ & $\begin{array}{l}\mathrm{N}^{0} \\
\text { obs. }\end{array}$ & $\%$ \\
\hline $\begin{array}{l}\text { Não gosto nada e } \\
\text { desejaria ser diferente }\end{array}$ & 16 & 2,5 & 19 & 3,0 & 23 & 3,6 & 82 & 12,9 \\
\hline Não gosto, mas tolero & 45 & 7,1 & 51 & 8,0 & 44 & 6,9 & 128 & 20,1 \\
\hline $\begin{array}{l}\text { É indiferente, } \\
\text { não me importo }\end{array}$ & 61 & 9,6 & 56 & 8,8 & 49 & 7,7 & 67 & 10,5 \\
\hline Estou satisfeito & 347 & 54,6 & 335 & 52,6 & 307 & 48,2 & 231 & 36,3 \\
\hline $\begin{array}{l}\text { Considero-me } \\
\text { muito satisfeito }\end{array}$ & 167 & 26,3 & 176 & 27,6 & 214 & 33,6 & 129 & 20,3 \\
\hline TOTAL & 636 & 100,0 & 637 & 100,0 & 637 & 100,0 & 637 & 100,0 \\
\hline
\end{tabular}

Os demais itens avaliados apresentaram percentuais acima de $60 \% \mathrm{com}$ respeito às duas categorias que representam os maiores níveis de satisfação. Entretanto, em relação à categoria "não gosto nada e desejaria ser diferente", as maiores percentagens ocorreram para os itens peso (7,7\%), cintura $(6.3 \%)$, coxas $(6,1 \%)$, pernas $(5,7 \%)$ e postura $(5,5 \%)$. Para os outros itens (quadris, estatura e resistência física) a percentagem de informantes variou entre 4,1\% e 4,4\% nesta categoria. As proporções referentes à categoria "não gosto, mas tolero" variam entre 7,8\% (quadris) e 16,5\% (pernas), sendo a segunda maior frequência para o item coxas (15,9\%) (Tabelas 6 e 07).

Alguns estudos demonstram que a supervalorização do corpo como expressão de um narcisismo exacerbado evidencia-se no discurso dos indivíduos pesquisados, no qual se dá ênfase ao prazer na contemplação do próprio corpo no espelho. (SAIKALI et al., 2004; ASSUNÇÃO, 2002). Esse fato expressa-se no próprio ato de exercitar-se, em que o praticante não se relaciona com o corpo como um todo, mas com partes do mesmo. 
São exercitados individualmente o peitoral, os braços, as pernas, as coxas, o abdômen, e às vezes apenas determinados grupos musculares; reforça-se a idéia do corpo dividido, e se estabelecem parâmetros para cada parte.

TABELA 6. Distribuição da autopercepção da imagem corporal segundo os níveis de satisfação para os itens quadris, cintura, coxa e pernas - Salvador-BA, 2009

\begin{tabular}{l|c|c|c|c|c|c|c|c}
\hline \multirow{2}{*}{$\begin{array}{l}\text { Autopercepção da } \\
\text { imagem corporal } \\
\text { (níveis de satisfação) }\end{array}$} & $\begin{array}{l}|c| \\
\text { Qu } \\
\text { obs. }\end{array}$ & $\%$ & $\begin{array}{l}\text { No } \\
\text { obs. }\end{array}$ & $\%$ & $\begin{array}{l}\text { No } \\
\text { obs. }\end{array}$ & $\%$ & $\begin{array}{l}\mathrm{N}^{0} \\
\text { obs. }\end{array}$ & $\%$ \\
\hline $\begin{array}{l}\text { Não gosto nada e } \\
\text { desejaria ser diferente }\end{array}$ & 26 & 4,1 & 40 & 6,3 & 39 & 6,1 & 36 & 5,7 \\
\hline Não gosto, mas tolero & 50 & 7,8 & 68 & 10,7 & 101 & 15,9 & 105 & 16,5 \\
\hline $\begin{array}{l}\text { É indiferente, } \\
\text { não me importo }\end{array}$ & 117 & 18,4 & 122 & 19,2 & 79 & 12,4 & 81 & 12,7 \\
\hline Estou satisfeito & 302 & 47,4 & 275 & 43,2 & 266 & 41,8 & 264 & 41,4 \\
\hline $\begin{array}{l}\text { Considero-me } \\
\text { muito satisfeito }\end{array}$ & 142 & 22,3 & 132 & 20,7 & 152 & 23,9 & 151 & 23,7 \\
\hline TOTAL & 637 & 100,0 & 637 & 100,0 & 637 & 100,0 & 637 & 100,0 \\
\hline
\end{tabular}

TABELA 7. Distribuição dos níveis de satisfação (autopercepção da imagem corporal) para os itens postura, peso, estatura e resistência física - Salvador-BA, 2009.

\begin{tabular}{|c|c|c|c|c|c|c|c|c|}
\hline \multirow{2}{*}{$\begin{array}{l}\text { Autopercepção da } \\
\text { imagem corporal } \\
\text { (níveis de satisfação) }\end{array}$} & \multicolumn{2}{|c|}{ Postura } & \multicolumn{2}{|c|}{ Peso } & \multicolumn{2}{|c|}{ Estatura } & \multicolumn{2}{|c|}{ Resistência física } \\
\hline & $\begin{array}{l}\mathrm{N}^{\circ} \\
\text { obs. }\end{array}$ & $\%$ & $\begin{array}{l}\mathrm{N}^{\circ} \\
\text { obs. }\end{array}$ & $\%$ & $\begin{array}{l}\mathrm{N}^{\circ} \\
\text { obs. }\end{array}$ & $\%$ & $\begin{array}{l}\mathrm{N}^{0} \\
\text { obs. }\end{array}$ & $\%$ \\
\hline $\begin{array}{l}\text { Não gosto nada e } \\
\text { desejaria ser diferente }\end{array}$ & 35 & 5,5 & 49 & 7,7 & 26 & 4,1 & 28 & 4,4 \\
\hline Não gosto, mas tolero & 59 & 9,3 & 83 & 13,0 & 83 & 13,0 & 76 & 11,9 \\
\hline $\begin{array}{l}\text { É indiferente, } \\
\text { não me importo }\end{array}$ & 75 & 11,8 & 69 & 10,8 & 61 & 9,6 & 56 & 8,8 \\
\hline Estou satisfeito & 312 & 49,0 & 325 & 51,0 & 290 & 45,5 & 284 & 44,6 \\
\hline $\begin{array}{l}\text { Considero-me } \\
\text { muito satisfeito }\end{array}$ & 156 & 24,5 & 111 & 17,4 & 177 & 27,8 & 193 & 30,3 \\
\hline TOTAL & 637 & 100,0 & 637 & 100,0 & 637 & 100,0 & 637 & 100,0 \\
\hline
\end{tabular}

Na análise do perfil atlético dos entrevistados, segundo a "autopercepção da imagem corporal” (Tabela 8), observa-se que para os fisiculturistas, instrutores de musculação e lutadores há uma percentagem maior de 
entrevistados satisfeitos com a imagem corporal. Os praticantes de musculação foram os que apresentaram as maiores proporções nas categorias "insatisfeito, gostaria de ser mais magro" $(27,4 \%)$ e "insatisfeito, gostaria de ser mais forte ou mais gordo" (31,3\%). Os praticantes de fisiculturismo foram os que apresentaram as menores proporções de insatisfação (12,5\% e $20,0 \%$, respectivamente). Avaliando a existência de associação entre estas variáveis, o teste $x^{2}$ indicou associação entre o perfil atlético e a autopercepção da imagem corporal, uma vez que existem evidências nos dados para rejeitar a hipótese de independência formulada no referido teste (p-valor $=0,015<5 \%)$.

TABELA 8. Distribuição do perfil atlético segundo níveis de satisfação (autopercepção da imagem corporal) - Salvador-BA, 2009

\begin{tabular}{|c|c|c|c|c|c|}
\hline \multirow[b]{2}{*}{ Perfil atlético } & \multirow[b]{2}{*}{ Frequência } & \multicolumn{4}{|c|}{ Níveis de satisfação (Autopercepção da imagem corporal) } \\
\hline & & Satisfeito & $\begin{array}{l}\text { Insatisfeito, } \\
\text { gostaria de ser mais } \\
\text { forte ou mais gordo }\end{array}$ & $\begin{array}{l}\text { Insatisfeito, } \\
\text { gostaria de ser } \\
\text { mais magro }\end{array}$ & Total \\
\hline \multirow{2}{*}{ Fisiculturista } & Abs. & 27 & 08 & 05 & 40 \\
\hline & $\%$ & 67,5 & 20,0 & 12,5 & 100,0 \\
\hline \multirow{2}{*}{$\begin{array}{l}\text { Praticante de } \\
\text { musculação }\end{array}$} & Abs. & 166 & 126 & 110 & 402 \\
\hline & $\%$ & 41,3 & 31,3 & 27,4 & 100,0 \\
\hline \multirow{2}{*}{$\begin{array}{l}\text { Instrutor de } \\
\text { musculação }\end{array}$} & Abs. & 31 & 13 & 11 & 55 \\
\hline & $\%$ & 56,4 & 23,6 & 20,0 & 100,0 \\
\hline \multirow{2}{*}{ Lutador } & Abs. & 62 & 23 & 24 & 109 \\
\hline & $\%$ & 56,9 & 21,1 & 22,0 & 100,0 \\
\hline \multirow{2}{*}{ Outros } & Abs. & 15 & 09 & 06 & 30 \\
\hline & $\%$ & 50,0 & 30,0 & 20,0 & 100,0 \\
\hline \multirow{2}{*}{ TOTAL } & Abs. & 301 & 179 & 156 & 636 \\
\hline & $\%$ & 47,3 & 28,1 & 24,5 & 100,0 \\
\hline
\end{tabular}

Dentre os entrevistados fisiculturistas, destacam-se as seguintes observações: $100 \%$ dos entrevistados com idade entre 41 e 45 anos estão satisfeitos com a imagem corporal (autopercepção positiva), porém, o número de informante é muito pequeno; cerca de $60 \%$ das observações que se encontram na faixa de idade entre 18 e 24 anos estão insatisfeitos, mas que 
gostariam de ser mais fortes ou mais gordos; aqueles com mais de 30 anos na grande maioria está satisfeita com sua imagem (a menor percentagem observada foi 75\%). Entretanto, para os fisiculturistas com idade entre 30 e 35 anos, $18,8 \%$ estão insatisfeitos e gostariam de ser mais magros. Daqueles que se encontram na faixa de idade entre $25-29$ anos, 37,5\% gostariam de ser mais fortes e $25,0 \%$ mais magros $^{12}$ (Tabela 9).

TABELA 9. Distribuição da idade segundo níveis de satisfação (autopercepção da imagem corporal) - Salvador-BA, 2009

PERFIL ATLÉTICO: FISICULTURISTA

\begin{tabular}{|c|c|c|c|c|c|}
\hline \multirow[b]{2}{*}{$\begin{array}{l}\text { Idade } \\
\text { (em anos) }\end{array}$} & \multirow[b]{2}{*}{ Freqüência } & \multicolumn{3}{|c|}{ Níveis de satisfação (Autopercepção da imagem corporal) } & \multirow[b]{2}{*}{ Tota } \\
\hline & & Satisfeito & $\begin{array}{l}\text { Insatisfeito, mas } \\
\text { gostaria de ser mais } \\
\text { forte ou mais gordo }\end{array}$ & $\begin{array}{l}\text { Insatisfeito, mas } \\
\text { gostaria de ser } \\
\text { mais magro }\end{array}$ & \\
\hline \multirow{2}{*}{$18-24$} & Abs. & 02 & 03 & - & 05 \\
\hline & $\%$ & 40,0 & 60,0 & - & 100,0 \\
\hline \multirow{2}{*}{$25-29$} & Abs. & 03 & 03 & 02 & 08 \\
\hline & $\%$ & 37,5 & 37,5 & 25,0 & 100,0 \\
\hline \multirow{2}{*}{$30-35$} & Abs. & 12 & 01 & 03 & 16 \\
\hline & $\%$ & 75,0 & 6,3 & 18,8 & 100,0 \\
\hline \multirow{2}{*}{$36-40$} & Abs. & 06 & 01 & - & 07 \\
\hline & $\%$ & 85,7 & 14,3 & - & 100,0 \\
\hline \multirow{2}{*}{$41-45$} & Abs. & 04 & - & - & 04 \\
\hline & $\%$ & 100,0 & - & $\mathrm{v}$ & 100,0 \\
\hline \multirow{2}{*}{ TOTAL } & Abs. & 27 & 08 & 05 & 40 \\
\hline & $\%$ & 67,5 & 20,0 & 12,5 & 100,0 \\
\hline
\end{tabular}

Pope Jr. e Katz (1994), analisando uma amostra de cento e oito fisiculturistas, identificou nove indivíduos $(8,3 \%)$ que se descreviam como muito fracos e pequenos, quando na verdade eram extremamente fortes e musculosos, revelando sinais de distorção da imagem corporal e altos níveis de insatisfação com a aparência. Além disso, o estudo refere que todos

12 Não foi possível verificar a existência de associação entre a idade e a autopercepção da imagem devido ao pequeno número de informantes. 
relatavam uso de esteróides anabolizantes e dois tinham histórico anterior de anorexia nervosa.

Entre os praticantes de musculação foi possível verificar elevado grau de insatisfação com respeito à imagem corporal nas diversas faixas etárias. Entre os mais jovens (de 18 a 24 anos), aproximadamente 60\% estão insatisfeitos (40,6\% gostariam de ser mais fortes ou mais gordos e $19,8 \%$ mais magros); entre 25 e 29 anos, cerca de $50 \%$ estão insatisfeitos, com percentuais similares entre as duas categorias. Os praticantes de musculação com idade entre 30 e 35 anos e os mais velhos (41-45 anos) foram os que apresentaram os maiores percentuais de insatisfação quanto ao fato de serem mais magros (50\% e 46,7\%, respectivamente). O teste $x^{2}$ para independência, em três categorias da variável "idade” (de 18 a 24 anos; de 25 a 29 anos; e 30 ou mais) e nível de significância de 5\%, indicou que existe associação entre as variáveis "idade" e "autopercepção da imagem corporal” (p-valor $=0,000)$ dentre os praticantes de musculação (Tabela 10).

TABELA 10. Distribuição da idade segundo níveis de satisfação (autopercepção da imagem corporal) - Salvador-BA, 2009

PERFIL ATLÉTICO: PRATICANTE DE MUSCULAÇÃO

\begin{tabular}{|c|c|c|c|c|c|}
\hline \multirow[b]{2}{*}{$\begin{array}{l}\text { Idade } \\
\text { (em anos) }\end{array}$} & \multirow[b]{2}{*}{ Frequência } & \multicolumn{3}{|c|}{ Níveis de satisfação (Autopercepção da imagem corporal) } & \multirow[b]{2}{*}{ Total } \\
\hline & & Satisfeito & $\begin{array}{l}\text { Insatisfeito, mas } \\
\text { gostaria de ser mais } \\
\text { forte ou mais gordo }\end{array}$ & $\begin{array}{l}\text { Insatisfeito, mas } \\
\text { gostaria de ser } \\
\text { mais magro }\end{array}$ & \\
\hline \multirow{2}{*}{$18-24$} & Abs. & 82 & 84 & 41 & 207 \\
\hline & $\%$ & 39,6 & 40,6 & 19,8 & 100,0 \\
\hline \multirow{2}{*}{$25-29$} & Abs. & 54 & 23 & 29 & 106 \\
\hline & $\%$ & 50,9 & 21,7 & 27,4 & 100,0 \\
\hline \multirow{2}{*}{$30-35$} & Abs. & 14 & 10 & 24 & 48 \\
\hline & $\%$ & 29,2 & 20,8 & 50,0 & 100,0 \\
\hline \multirow{2}{*}{$36-40$} & Abs. & 13 & 01 & 08 & 22 \\
\hline & $\%$ & 59,1 & 4,5 & 36,4 & 100,0 \\
\hline \multirow{2}{*}{$41-45$} & Abs. & 03 & 05 & 07 & 15 \\
\hline & $\%$ & 20,0 & 33,3 & 46,7 & 100,0 \\
\hline \multirow{2}{*}{ TOTAL } & Abs. & 166 & 123 & 109 & 398 \\
\hline & $\%$ & 41,7 & 30,9 & 27,4 & 100,0 \\
\hline
\end{tabular}


Achados similares ao nosso estudo foram relatados por McCreary e Sasse (2000), em estudo citado por Cohane e Pope Jr. (2001) realizado com noventa e seis jovens, com média de idade de 18 anos, onde a maioria deles referia o desejo de serem mais pesados e musculosos em relação ao seu corpo atual.

Entre os instrutores de musculação foi possível verificar que existe uma maior proporção de satisfeitos do que insatisfeitos em todas as classes de idade. $100 \%$ dos entrevistados que se encontram na faixa de idade entre 36 a 45 anos estão satisfeitos com a imagem corporal. Aqueles com idade entre 18 e 29 anos apresentaram percentuais elevados com respeito a cada categoria de insatisfação, com percentuais variando entre $20,8 \%$ e $25 \%$. Dentre aqueles com idade de 30 a 35 anos, um terço dos informantes estão insatisfeitos, mas gostariam de ser mais fortes ou mais gordos, não havendo informantes na outra categoria de insatisfação (Tabela 11).

TABELA 11. Distribuição da idade segundo níveis de satisfação (autopercepção da imagem corporal) - Salvador-BA, 2009

PERFIL ATLÉTICO: INSTRUTOR DE MUSCULAÇÃO

\begin{tabular}{l|c|c|c|c|c}
\hline \multirow{2}{*}{$\begin{array}{l}\text { Idade } \\
\text { (em anos) }\end{array}$} & Frequência & Satisfeito & $\begin{array}{c}\text { Níveis de satisfação (Autopercepção da imagem corporal) } \\
\text { Insatisfeito, mas } \\
\text { gostaria de ser mais } \\
\text { forte ou mais gordo }\end{array}$ & $\begin{array}{l}\text { Insatisfeito, } \\
\text { mas gostaria de } \\
\text { ser mais magro }\end{array}$ & Total \\
\hline \multirow{2}{*}{$18-24$} & Abs. & 13 & 06 & 05 & 24 \\
\cline { 2 - 6 } & $\%$ & 54,2 & 25,0 & 20,8 & 100,0 \\
\hline \multirow{2}{*}{$25-29$} & Abs. & 13 & 06 & 06 & 25 \\
\cline { 2 - 6 } & $\%$ & 52,0 & 24,0 & 24,0 & 100,0 \\
\hline \multirow{2}{*}{$30-35$} & Abs. & 02 & 01 & - & 03 \\
\cline { 2 - 6 } & $\%$ & 66,7 & 33,3 & - & 100,0 \\
\hline \multirow{2}{*}{$36-40$} & Abs. & 01 & - & - & 01 \\
\cline { 2 - 6 } & $\%$ & 100,0 & - & - & 100,0 \\
\hline \multirow{2}{*}{$41-45$} & Abs. & 02 & - & 11 & 02 \\
\cline { 2 - 6 } & $\%$ & 100,0 & - & 20,0 & 100,0 \\
\hline \multirow{2}{*}{ TOTAL } & Abs. & 31 & 13 & - \\
\cline { 2 - 6 } & $\%$ & 56,4 & 23,6 & - & 100,0 \\
\hline
\end{tabular}


Estudo realizado por Antunes (2000) revelou que o número de instrutores de musculação é crescente até 30 anos, e de 30 a 35 anos ocorre frequentemente uma diminuição na quantidade de instrutores em atividade. Esses dados apontam para uma valorização da condição física e aspecto jovial para esse mercado de trabalho, o que reforça as evidências de que existe ênfase exagerada na aparência física, principalmente no ambiente das academias, que é muito influenciado pela mídia e pelo culto ao corpo em nossa sociedade.

No perfil lutadores, pode-se observar que aqueles com idade entre 30 e 35 anos foram os que apresentaram maior nível de satisfação com a imagem corporal. Os lutadores com idade entre 18 e 24 anos e 25 e 29 anos apresentam uma proporção de insatisfação acima de 40\%. Para verificar o grau de associação para as variáveis "idade" e "autopercepção da imagem corporal" entre os lutadores, o teste $x^{2}$ para independência apresentou o p-valor igual a 0,499 ( $\alpha=5 \%)$, indicando que existe independência entre estas variáveis, ao restringir para três categorias da variável "idade” (18-24; 25-29; 30 ou mais) (Tabela 12).

A interpretação desses dados podem ser respaldadas por um estudo de Beiras e colaboradores (2007) no qual os autores discutiram as formas de representação do corpo masculino analisando personagens das histórias em quadrinhos de super-heróis (lutadores) que ganham vida na imaginação dos leitores, estabelecendo fortes ligações com seu cotidiano. Um corpo musculoso e viril vem historicamente se tornando o referencial de corporeidade masculina, enquanto corpos que desviam desse modelo são comumente satirizados ou excluídos da mídia. 
TABELA 12. Distribuição da idade segundo níveis de satisfação (autopercepção da imagem corporal) - Salvador-BA, 2009

PERFIL ATLÉTICO: LUTADOR

\begin{tabular}{|c|c|c|c|c|c|}
\hline \multirow[b]{2}{*}{$\begin{array}{l}\text { Idade } \\
\text { (em anos) }\end{array}$} & \multirow[b]{2}{*}{ Frequência } & \multicolumn{3}{|c|}{ Níveis de satisfação (Autopercepção da imagem corporal) } & \multirow[b]{2}{*}{ Total } \\
\hline & & Satisfeito & $\begin{array}{l}\text { Insatisfeito, mas } \\
\text { gostaria de ser mais } \\
\text { forte ou mais gordo }\end{array}$ & $\begin{array}{l}\text { Insatisfeito, } \\
\text { mas gostaria de } \\
\text { ser mais magro }\end{array}$ & \\
\hline \multirow{2}{*}{$18-24$} & Abs. & 26 & 14 & 09 & 49 \\
\hline & $\%$ & 53,1 & 28,6 & 18,4 & 100,0 \\
\hline \multirow{2}{*}{$25-29$} & Abs. & 20 & 06 & 08 & 34 \\
\hline & $\%$ & 58,8 & 17,6 & 23,5 & 100,0 \\
\hline \multirow{2}{*}{$30-35$} & Abs. & 14 & 02 & 04 & 20 \\
\hline & $\%$ & 70,0 & 10,0 & 20,0 & 100,0 \\
\hline \multirow{2}{*}{$36-40$} & Abs. & - & 01 & 01 & 02 \\
\hline & $\%$ & - & 50,0 & 50,0 & 100,0 \\
\hline \multirow{2}{*}{$41-45$} & Abs. & 01 & - & 02 & 03 \\
\hline & $\%$ & 33,3 & - & 66,7 & 100,0 \\
\hline \multirow{2}{*}{ TOTAL } & Abs. & 61 & 23 & 24 & 108 \\
\hline & $\%$ & 56,5 & 21,3 & 22,2 & 100,0 \\
\hline
\end{tabular}

TABELA 13. Distribuição da classificação da silhueta atual segundo níveis de satisfação (autopercepção da imagem corporal) - Salvador-BA, 2009

PERFIL ATLÉTICO: FISICULTURISTA

\begin{tabular}{|c|c|c|c|c|c|}
\hline \multirow[b]{2}{*}{ Silhueta atual } & \multirow[b]{2}{*}{ Frequência } & \multicolumn{3}{|c|}{ Níveis de satisfação (Autopercepção da imagem corporal) } & \multirow[b]{2}{*}{ Total } \\
\hline & & Satisfeito & $\begin{array}{l}\text { Insatisfeito, mas } \\
\text { gostaria de ser mais } \\
\text { forte ou mais gordo }\end{array}$ & $\begin{array}{l}\text { Insatisfeito, mas } \\
\text { gostaria de ser } \\
\text { mais magro }\end{array}$ & \\
\hline \multirow{2}{*}{$\begin{array}{l}\text { Peso normal } \\
\text { (eutrofia) }\end{array}$} & Abs. & 26 & 08 & 04 & 38 \\
\hline & $\%$ & 68,4 & 21,1 & 10,5 & 100,0 \\
\hline \multirow{2}{*}{ Sobrepeso } & Abs. & 01 & - & 01 & 02 \\
\hline & $\%$ & 50,0 & - & 50,0 & 100,0 \\
\hline \multirow{2}{*}{ TOTAL } & Abs. & 27 & 08 & 05 & 40 \\
\hline & $\%$ & 67,5 & 20,0 & 12,5 & 100,0 \\
\hline
\end{tabular}


Entre os praticantes de musculação classificados como eutróficos, dentre os insatisfeitos com a imagem corporal, $34,7 \%$ gostariam de ser mais fortes ou gordos e 19,2\% mais magros. Para os praticantes com sobrepeso, 95,5\% gostariam de ser mais magros e somente $4,5 \%$ estão satisfeitos com a imagem corporal. Ao reduzir as categorias de ambas variáveis para duas (variável silhueta atual em baixo peso/normal (eutrófico) e sobrepeso/obesidade e a variável "autopercepção da imagem corporal (em satisfeito e insatisfeito), o teste $x^{2}$ para independência indica que existe alguma associação entre a silhueta atual e a autopercepção da imagem corporal entre aqueles que praticam musculação (p-valor $=0,000 ; \alpha=5 \%$ ) (Tabela 14).

TABELA 14. Distribuição da classificação da silhueta atual segundo níveis de satisfação (autopercepção da imagem corporal) - Salvador-BA. 2009

PERFIL ATLÉTICO: PRATICANTE DE MUSCULAÇÃO

\begin{tabular}{|c|c|c|c|c|c|}
\hline \multirow[b]{2}{*}{ Silhueta atual } & \multirow[b]{2}{*}{ Frequência } & \multicolumn{3}{|c|}{ Níveis de satisfação (Autopercepção da imagem corporal) } & \multirow[b]{2}{*}{ Total } \\
\hline & & Satisfeito & $\begin{array}{l}\text { Insatisfeito, mas } \\
\text { gostaria de ser mais } \\
\text { forte ou mais gordo }\end{array}$ & $\begin{array}{l}\text { Insatisfeito, } \\
\text { mas gostaria de } \\
\text { ser mais magro }\end{array}$ & \\
\hline \multirow{2}{*}{$\begin{array}{l}\text { Baixo peso } \\
\text { (magro) }\end{array}$} & Abs. & 01 & 03 & - & 04 \\
\hline & $\%$ & 25,0 & 75,0 & - & 100,0 \\
\hline \multirow{2}{*}{$\begin{array}{l}\text { Peso normal } \\
\text { (eutrofia) }\end{array}$} & Abs. & 163 & 123 & 68 & 354 \\
\hline & $\%$ & 46,0 & 34,7 & 19,2 & 100,0 \\
\hline \multirow{2}{*}{ Sobrepeso } & Abs. & 02 & - & 42 & 44 \\
\hline & $\%$ & 4,5 & - & 95,5 & 100,0 \\
\hline \multirow{2}{*}{ TOTAL } & Abs. & 166 & 126 & 110 & 402 \\
\hline & $\%$ & 41,3 & 31,3 & 27,4 & 100,0 \\
\hline
\end{tabular}

A maioria dos instrutores de musculação entrevistados (90,5\%) são eutróficos, porém, 38,0\% revelaram estar insatisfeitos com a imagem corporal: 26,0\% gostariam de ser mais gordos ou mais magros; e $12,0 \%$ gostariam de ser mais magros. Para outros cinco informantes, a silhueta atual foi classificada como sobrepeso e 100,0\% estão insatisfeitos e gostariam de ser mais magros ${ }^{2}$ (Tabela 15). 
TABELA 15. Distribuição da classificação da silhueta atual segundo níveis de satisfação (autopercepção da imagem corporal) - Salvador-BA, 2009

PERFIL ATLÉTICO: INSTRUTOR DE MUSCULAÇÃO

\begin{tabular}{l|c|c|c|c|c}
\hline \multirow{2}{*}{ Silhueta atual } & \multirow{2}{*}{ Frequência } & Satisfeito & $\begin{array}{l}\text { Níveis de satisfação (Autopercepção da imagem corporal) } \\
\text { Insatisfeito, mas } \\
\text { gostaria de ser mais } \\
\text { forte ou mais gordo }\end{array}$ & $\begin{array}{l}\text { Insatisfeito, } \\
\text { mas gostaria de } \\
\text { ser mais magro }\end{array}$ & Total \\
\hline \multirow{2}{*}{$\begin{array}{l}\text { Peso normal } \\
\text { (eutrofia) }\end{array}$} & Abs. & 31 & 13 & 06 & 50 \\
\cline { 2 - 6 } & $\%$ & 62,0 & 26,0 & 12,0 & 100,0 \\
\hline \multirow{2}{*}{ Sobrepeso } & Abs. & - & - & 05 & 05 \\
\cline { 2 - 6 } & $\%$ & - & - & 100,0 & 100,0 \\
\hline \multirow{2}{*}{ TOTAL } & Abs. & 31 & 13 & 11 & 55 \\
\cline { 2 - 6 } & $\%$ & 56,4 & 23,6 & 20,0 & 100,0 \\
\hline
\end{tabular}

Estudo de Russo (2005) analisou a percepção corporal de 102 estudantes de Educação Física de uma cidade do interior de São Paulo, sendo 47 do sexo feminino e 55 do sexo masculino, a fim de identificar distorções da imagem corporal. Os resultados revelaram que um grande percentual dos respondentes do sexo masculino traz relatos significativos no que diz respeito ao tédio, medo de ficar gordo ou mais gordo, preocupação com o corpo não ser "firme" e uma excessiva preocupação com a gordura corporal.

Os lutadores com peso normal, $37,3 \%$, encontram-se insatisfeitos $(23,2 \%$ gostariam de ser mais fortes ou mais magros e 14,1\% mais magros). Entre aqueles com sobrepeso, 100,0\% estão insatisfeitos e gostariam de ser mais $\operatorname{magros}^{2}$ (Tabela 16).

Segundo Veggi e colaboradores (2004), citando Blowers e colaboradores (2003), as discrepâncias entre o índice de massa corporal e o peso corporal "ideal" podem levar a estados emocionais negativos, tais como desapontamento e insatisfação, colocando os indivíduos em risco de terem transtornos psiquiátricos. Os indivíduos que tiveram a percepção de estarem com sobrepeso ou peso abaixo do normal podem, muitas vezes, sentir-se isolados ou discriminados por seus colegas, potencializando o sentimento de inadequação e de baixa autoestima. 
TABELA 16. Distribuição da classificação da silhueta atual segundo níveis de satisfação (autopercepção da imagem corporal) - Salvador-BA, 2009

PERFIL ATLÉTICO: LUTADOR

\begin{tabular}{l|c|c|c|c|l}
\hline \multirow{2}{*}{ Silhueta atual } & Frequência & Satisfeito & $\begin{array}{l}\text { Níveis de satisfação (Autopercepção da imagem corporal) } \\
\text { gostaria de ser mais } \\
\text { forte ou mais gordo }\end{array}$ & $\begin{array}{l}\text { Insatisfeito, mas } \\
\text { gostaria de ser } \\
\text { mais magro }\end{array}$ & Total \\
\hline \multirow{2}{*}{$\begin{array}{l}\text { Peso normal } \\
\text { (eutrofia) }\end{array}$} & Abs. & 62 & 23 & 14 & 99 \\
\cline { 2 - 6 } & $\%$ & 62,6 & 23,2 & 14,1 & 100,0 \\
\hline \multirow{2}{*}{ Sobrepeso } & Abs. & - & - & 09 & 09 \\
\cline { 2 - 6 } & $\%$ & - & - & 100,0 & 100,0 \\
\hline \multirow{2}{*}{ Obesidade } & Abs. & - & - & 01 & 01 \\
\cline { 2 - 6 } & $\%$ & - & - & 100,0 & 100,0 \\
\hline \multirow{2}{*}{ TOTAL } & Abs. & 62 & 23 & 24 & 109 \\
\cline { 2 - 6 } & $\%$ & 56,9 & 21,1 & 100,0 \\
\hline
\end{tabular}

Estudo realizado por Branco e colaboradores (2006) demonstrou que a insatisfação com a imagem corporal foi mais prevalente entre os adolescentes com sobrepeso e obesidade, com destaque para o sexo feminino. Entre os adolescentes do sexo masculino, verificou-se que, dos 443 eutróficos, 85 (19,2\%) acharam-se em sobrepeso; dos 95 em sobrepeso, 25 (26,3\%) consideraram-se eutróficos; dos 35 em obesidade, 15 (42,8\%) identificaram-se com as figuras (silhuetas) de sobrepeso e $1(2,8 \%)$ em eutrofia.

\section{CONCLUSÃO}

Com base na análise descritiva e exploratória dos dados e discussão dos resultados da pesquisa, pode-se afirmar ainda que:

I. Mais da metade dos indivíduos pesquisados revelam estar insatisfeitos com a sua imagem corporal;

II. ao se analisar o nível de satisfação com partes específicas do corpo, cerca de 1/3 dos respondentes consideram-se satisfeitos em relação aos itens pesquisados; 
III. os maiores níveis de insatisfação associada a partes específicas do corpo relacionam-se ao abdômen que representa o item referido por 1/3 dos entrevistados;

IV. entre aqueles que afirmam não gostar de alguma parte do corpo ou medida corporal, ou aqueles que desejariam ser diferentes, os maiores percentuais referem-se ao peso, à postura e a partes específicas do corpo, como: cintura, coxas e pernas;

V. os fisiculturistas que apresentaram os menores percentuais de insatisfação com relação à percepção da imagem corporal encontravam-se na faixa entre 41 a 45 anos, revelando $100 \%$ de satisfação ao passo que $60 \%$ daqueles com idade entre 18 a 24 anos gostariam de ser mais fortes;

VI. entre os praticantes de musculação, verificou-se um elevado grau de insatisfação com relação à imagem corporal, ressaltando-se que, dentre os mais jovens (entre 18 e 24 anos), mais de 40\% gostariam de ser mais fortes ou mais gordos, e cerca de $20 \%$ gostariam de ser mais magros; aproximadamente metade dos indivíduos entre 30 e 35 anos demonstraram estar insatisfeitos em relação à autopercepção da imagem corporal, pois gostariam de ser mais magros;

VII. a maior parte dos instrutores de musculação parecem estar satisfeitos com a imagem corporal, ressaltando-se que, entre os mais jovens, houve um maior percentual de insatisfação revelando o desejo de serem mais fortes ou mais gordos;

VIII. os fatores como faixa etária e medidas corporais influenciam a percepção da imagem corporal e os níveis de satisfação com a aparência, forma física e autoimagem.

Cabe destacar que vários aspectos relacionados à identidade, gênero, relações de poder e autoafirmação do sujeito em relação à sua imagem corporal que não foram alvo de investigação deste estudo devem ser considerados na análise do perfil dos grupos de risco para o desenvolvimento de transtornos de autoimagem em estudos posteriores.

Vale ressaltar ainda a necessidade de pesquisas direcionadas ao estudo da imagem corporal e suas distorções. Isto se realizaria no sentido de 
propor ações educativas e preventivas aos transtornos corporais e intervenções de caráter multiprofissional que possam contribuir para o controle e diminuição nas estatísticas ligadas a estes distúrbios psíquicos e emocionais. Estes que, por sua vez, estão intimamente associados a um estilo de vida pautado na cultura do exagero e do imediatismo que vigora na sociedade atual, e particularmente associados a uma busca desenfreada e ilimitada de um padrão ou um ideal de perfeição inalcançável.

\section{REFERÊNCIAS}

ADAMI, F. et al. Aspectos da construção e desenvolvimento da imagem corporal e implicações na Educação Física. Revista DigitalBuenos Aires, v. 10, n. 83, 2005. Disponível em: <http://www.efdeportes.com/>. Acesso em: 17 jul. 2007.

ALMEIDA, G. A. N. et al.. Percepção de tamanho e forma corporal de mulheres: estudo exploratório. Psicologia em Estudo, v. 10, n. 1, p. 27-35, 2005. ANTUNES, A.C. Academias de ginástica e musculação: preparação de recursos humanos. Rio Claro: UNESP, 2000.

ARAÚJO, D. S. M. S.; ARAÚJO, C. G. S. Self-perception and dissatisfaction with weight does not depend on the frequency of physical activity. Arq. Bras. Cardiol., v. 80, n. 3, p. 243, 2003.

ASSUNÇÃO, S.S.M. Dismorfia muscular. Rev .Bras. Psiquiatria, v. 24 (supl III), p. 80-4, 2002.

BARROS, D. D. Imagem corporal: a descoberta de si mesmo. Hist. Cienc. Saúde-Manguinhos, Rio de Janeiro, v. 12, n. 2, p. 547-554, 2005.

BEIRAS, A. et al. Gênero e super-heróis: o traçado do corpo masculino pela norma. Psicol. Soc, v. 19, n. 3, p. 62-67, 2007.

BECKER, J. R. B. Manual de psicologia aplicada ao exercício \& esporte. Porto Alegre: Eldelbra, 1999.

BLOWERS L.C.; LOXTON, N.J.; GRADY-FLESSER, M.; OCCHIPINT, S.; DAWE, $\mathrm{S}$. The relationship between sociocultural pressure to be thin and body dissatisfaction in preadolescent girls. Eat Behav., v. 4, n. 3, p. 29-44, 2003. 
BRANCO, L. M.; HILÁRIO, M. O. E.; CINTRA, I. P. Percepção e satisfação corporal em adolescentes e a relação com seu estado nutricional. Rev. Psiq. Clín., v. 33, n. 6, p. 292-296, 2006.

CAMARGO, Tatiana P. Pires de et al. Vigorexia: revisão dos aspectos atuais deste distúrbio de imagem corporal. Rev. bras. psicol. Esporte, v. 2, n. 1, p. 01-15, 2008.

COHANE G., POPE Jr. H. G. Body image in boys: a review of the literature. Int J. Eat Disord, v. 29, p. 373-9, 2001.

COURTINE, J. Stakhanovistas do narcisismo: body-building e puritanismo ostentatório na cultura americana do corpo. In: SANT’ANNA, D. B. (Org.). Políticas do corpo. São Paulo: Estação Liberdade, 1995.

DAMASCENO, V. O.; LIMA, J. R. P.; VIANNA, J. M.; VIANNA, V. R. A.; NOVAES, J. S. Tipo físico ideal e satisfação com a imagem corporal de praticantes de caminhada. Rev Bras Med Esporte, v. 11, n. 3, p. 181-186. maio./jun., 2005. IRIART, J. A. B.; ANDRADE, T. M. de M. Musculação, uso de esteróides anabolizantes e percepção de risco entre jovens fisiculturistas de um bairro popular de Salvador-BA, Brasil. Cad. Saúde Pública, Rio de Janeiro,v. 18, n. 5, set./out., 2002.

GRAHAM, M.A.; EICH, C.; KEPPHART, B.; PETERSON, D. Relationship among body image, sex and popularity of high school students. Percept Mot Skills. v. 90, p. 1187-1193, 2000.

LUTTER, J. et al. Representações de homens e mulheres sobre a prática da musculação em academia. Revista Digital Buenos Aires v. 12, n. 11, agos., 2007. Disponível em: <http://www.efdeportes.com/>. Acesso em: 17 abr. 2009.

MCCREARY, D. R.; SASSE, D. K. An exploration of the drive for muscularity in adoles-cent boys and girls. Journal of American College Health, 48, p. 297-304. 2000 .

MARTINS, J. P.; SANTOS, G.P. Metodologia da pesquisa científica: trabalho direcionado. Rio de Janeiro: Palestra Editora, 2003. 242 p.

MATARUNA, Leonardo. Imagem Corporal: noções e definições. Revista Digital Buenos Aires, v. 10, n. 71, abr., 2004. Disponível em: <http://www.efdeportes. com/efd71/imagem.htm>. Acesso em: 07 abr. 2009. 
MONTARDO, J.L. Aprendendo a Vida. 2004.Disponível em:

<http://planeta.terra.com.br/saude/montardo/desenvolvimento/ epensamento2.htm>. Acesso em: 17 abr. 2009.

POPE, H. G. Jr; KATZ D. L. Psychiatric and medical effects of anabolicandrogenic use: a controlled study of 160 athletes. Arch Gen Psychiatric 51: 375-382, 1994.

POPE, H. G. Jr; et al. Body image perception among men in three countries. Am J. Psychiatric:, v. 157, n. 80, p. 1297-301, aug., 2000.

POPE, H.G.; OLIVARDIA; R. PHILLIPS K. A. O complexo de Adônis: a obsessão masculina pelo corpo. Rio de Janeiro: Campus, 2000. 320p.

RUSSO, R. Imagem corporal: construção através da cultura do belo. Revista Movimento \& Percepção, Espírito Santo do Pinhal-SP, v. 5, n. 6, jan/jun., p. 80-90, 2005.

SAIKALI, C. J., et al. Imagem corporal nos transtornos alimentares. Rev. Psiq. Clin. v. 31, n. 4, p. 164-166, 2004.

SCHILDER, P. A imagem do corpo: as energias construtivas da Psique. São Paulo: Martins Fontes, 1999.

STUNKARD A. J.; SORENSON T.; SCHLUSINGER F. Use of the Danish Adoption Register for the study of obesity and thinness. In: KETY, S.S.; ROWLAND, L.P.; SIDMAN, R.L.; MATTHYSSE, S.W. (Editor). The genetics of neurological and psychiatric disorders. New York: Raven, 1983. 20-115 p. TAVARES, M.C.C. Imagem corporal: conceito e desenvolvimento. São Paulo: Manole, 2003.

VEGGI, A. B et. al. Índice de massa corporal, percepção do peso corporal e transtornos mentais comuns entre funcionários de uma universidade no Rio de Janeiro. Rev. Bras. Psiquiatr. v. 26, n. 4, p. 242-24, 2004. 



\title{
Atividade física como fator de proteção para co-morbidades cardiovasculares em mulheres obesas
}

\author{
Cristiano Penas Seara Pitanga \\ Ricardo Jacó de Oliveira \\ Ines Lessa \\ Maria Cecília Costa \\ Francisco José Gondim Pitanga
}

\section{INTRODUÇÃO}

De acordo com as mais recentes estimativas globais, a partir de estudo em 106 países, em 2005 havia 937 milhões de pessoas com sobrepeso e 396 milhões de pessoas obesas no mundo. As projeções para 2030 estimam em 2,16 bilhões de pessoas com sobrepeso e 1,12 bilhões com obesidade e co-morbidades associadas. (KELLY et al., 2005)

No Brasil, de acordo com dados do Instituto Brasileiro de Geografia e Estatística (IBGE, 2004) a obesidade atinge 11\% da população, correspondendo a 10,5 milhões de pessoas. Estudos de caráter epidemiológico têm demonstrado que a obesidade está associada com morbidade e mortalidade cardiovascular. 
(HUBERT et al. 1983; HARRIS et al. 1993) Outrossim, estudos sugerem que a atividade física proporciona significativa melhoria da função cardíaca de mulheres climatéricas (PASCHOAL; POLESSI; SIMIONI, 2008), com importante redução do risco de doenças cardiovasculares, com impactos significativos em todas as causas de mortalidade. (ERLICHMAN; KERBEY; JAMES, 2002) A atividade física tem demonstrado uma relação inversa com a morbidade e mortalidade cardiovascular, assim como também altos níveis de atividade física no tempo livre está associada ao aumento da longevidade. (BLAIR et al., 1989) Recentes trabalhos têm verificado que a prática regular da atividade física está associada a menores índices de mortalidade em obesos ativos quando comparados a obesos sedentários. (GIACOMINI; SANTOS; GIACOMINI, 2007)

Por outro lado, já há algum tempo tem-se verificado a existência de sub-grupo de obesos não expostos às co-morbidades cardiovasculares (CMCV) normalmente encontradas em pessoas com diagnóstico de obesidade, como por exemplo: hipertensão arterial, diabetes mellitus e dislipidemias, especulando-se que a atividade física poderia exercer importante papel na prevenção destes agravos metabólicos e cardiovasculares em indivíduos obesos. (BROCHU et al., 2001)

Contudo, ao se tentar verificar qual seria a associação da atividade física com as CMCV em mulheres obesas, verifica-se que existe uma escassez de estudos que avaliam esta relação. Assim, o objetivo do presente estudo foi analisar o efeito protetor da atividade física para as CMCV em mulheres obesas.

\section{MÉTODOS}

\section{Amostra}

Participaram do estudo 387 mulheres residentes na cidade de Salvador-Ba, com faixa etária de 21 a 75 anos, com índice de massa corporal (IMC) $\geq 30 \mathrm{~kg} / \mathrm{m}^{2}$ que estavam em tratamento para obesidade, matriculadas no ambulatório de obesidade do Hospital Universitário Professor 
Edgar Santos (HUPES) da Universidade Federal da Bahia (UFBA) e no Centro de Referência Estadual para Assistência a Diabetes e Endocrinologia (CEDEBA) da Secretaria de Saúde do Estado da Bahia (SESAB), na cidade de Salvador-BA. O estudo foi aprovado pelo Comitê de ética do conselho Regional de Medicina do Estado da Bahia, parecer/resolução nº 110/2005.

Os voluntários foram esclarecidos sobre o estudo, sendo que todos assinaram termo de autorização de acordo à resolução 196/1996 do Conselho Nacional de Saúde, em concordância com os princípios éticos contidos na Declaração de Helsinki (1964, reformulada em 2000), do World Medical Association.

\section{Variáveis de estudo}

Foram estudadas as seguintes variáveis: nível de atividade física (variável independente), CMCV, representada pela hipertensão arterial, diabetes mellitus e dislipidemias (variável dependente), etnia, estado civil e IMC (covariáveis).

\section{Coleta de dados}

Os dados foram coletados por uma equipe de estudantes de medicina da UFBA que foram devidamente treinados para executar os seguintes protocolos: o IMC foi determinado pela divisão da massa corporal pela estatura, sendo a massa corporal expressa em quilogramas (kg), e a estatura, em metros (m). Adotou-se como critério para obesidade o valor $\geq 30 \mathrm{~kg} / \mathrm{m}$.

Para aferição da estatura, foi empregado um estadiômetro vertical da própria balança, com $210 \mathrm{~cm}$ de comprimento e escala de $0,1 \mathrm{~cm}$, enquanto que para a avaliação da massa corporal foi utilizada uma balança de plataforma (Filizola, Brasil), calibrada, graduada de zero a $150 \mathrm{~kg}$ e com precisão de $0,1 \mathrm{~kg}$.

Para determinação dos níveis de atividade física foi utilizado o International Physical Activity Questionnaire (IPAQ), na versão curta com aplicação de entrevista referente à semana anterior, contendo perguntas em relação à frequência e duração das atividades físicas moderadas, vigorosas e da caminhada. Inicialmente os participantes do estudo foram classificados como sedentários, insuficientemente ativos, ativos e muito ativos. 
Os indivíduos classificados como sedentários foram aqueles que não realizaram nenhuma atividade física por pelo menos 10 minutos contínuos durante a semana. Os classificados como insuficientemente ativos foram aqueles que realizavam atividades físicas por pelo menos 10 minutos por semana, porém, em quantidade insuficiente para serem classificados como ativos. Foram classificados como ativos aqueles que cumpriram as recomendações de praticar atividades físicas leves ou moderadas por 5 dias ou mais por semana e acumular 150 minutos de atividades físicas por semana; e/ou praticar atividades físicas vigorosas $\geq 3$ dias por semana e $\geq 20$ minutos por sessão. Os indivíduos classificados como muito ativos foram aqueles que cumpriram com as recomendações de praticar atividades vigorosas $\geq 5$ dias por semana $\geq$ que 30 minutos por sessão; ou praticar atividades vigorosas $\geq 3$ dias por semana e $\geq 20$ minutos por sessão somadas à prática de atividades leves e/ou moderadas $\geq 5$ dias por semana e $\geq 30$ minutos por sessão. Em seguida, a classificação da atividade física foi dicotomizada em inativos fisicamente (sedentários e insuficientemente ativos) e ativos fisicamente (ativos e muito ativos).

Para determinação dos níveis de lipídios plasmáticos e glicemia foi realizada coleta de sangue após 12 horas de jejum no laboratório de Patologia Clínica (LPC) na cidade de Salvador-Ba. Para a determinação dos níveis de HDL-C foi utilizado o método COD-ANA ENZIMÁTICO, enquanto que para determinação dos níveis de colesterol e triglicerídios utilizou-se o método ENZIMÁTICO TRINDER. Os níveis de LDL-C e VLDL-C foram calculados de acordo com a fórmula de Friedewald. Para a caracterização do quadro de dislipidemia foi adotado o critério de apresentar pelo menos uma das lípidas com o valor fora do limite recomendado pelas diretrizes brasileiras para Dislipidemia da Sociedade Brasileira de Cardiologia. Foram incluídos também os indivíduos dislipidêmicos em tratamento atual com medicamentos.

Para a determinação dos níveis de glicose sanguínea foi utilizado o método OXIDASE GOD-ANA ENZIMÁTICO. Para a caracterização da Hiperglicemia, adotou-se como referência a glicemia de jejum $\geq 126 \mathrm{mg} / \mathrm{dl}$. Foram incluídos também os indivíduos diabéticos em tratamento atual com medicamentos, mesmo com a glicemia controlada. 
A medida da pressão arterial (PA) foi efetuada duas vezes, após repouso de 10 minutos, com o mesmo aparelho (OMRON $705 \mathrm{CP}$ ), usando braçadeira adequada (Large). Para a caracterização da hipertensão arterial foi adotado o critério de pressão arterial sistólica (PAS) $\geq 140 \mathrm{mmHg}$ e/ou pressão arterial diastólica $(\mathrm{PAD}) \geq 90 \mathrm{mmHg}$. A PA foi mensurada no braço direito posicionado à altura do coração, com o indivíduo relaxado na posição sentada. A PAS foi determinada ao aparecimento dos ruídos, fase I de Korotkoff e a PAD no desaparecimento dos ruídos, fase V de Korotkoff. Foram incluídos também os indivíduos hipertensos em tratamento atual com medicamentos, mesmo com PA controlada.

Os indivíduos classificados com presença de CMCV foram aqueles que apresentaram uma ou mais das variáveis, lipídeos plasmáticos, pressão arterial e glicemia fora das referências de normalidade, ou aqueles que estavam em uso de medicamentos. Os indivíduos classificados com ausência de CMCV foram aqueles que apresentaram as variáveis analisadas dentro dos valores de referências normais.

\section{Análise estatística}

Inicialmente foi realizada estratificação para análise de modificação de efeito e confundimento. A análise para modificação de efeito foi realizada através da observação das medidas pontuais estrato-específicas e seus intervalos de confiança. Foi utilizado intervalo de confiança de $95 \%$. A análise para confundimento foi feita comparando-se a Odds Ratio (OR) entre a associação bruta e ajustada pelos possíveis confundidores. Utilizou-se como parâmetro para identificar a diferença entre as associações o valor de $20 \%$. Logo após, foi realizada a análise através de regressão logística. A modelagem foi realizada com procedimento backward, partindo-se do modelo completo e retirando-se uma a uma as possíveis variáveis de confundimento que, quando suprimidas do modelo, causaram alteração igual ou superior a $20 \%$ na medida pontual de associação entre atividade física e CMCV. Finalmente, estimou-se a OR entre atividade física e CMCV através do modelo que melhor explicou esta associação.

Foram considerados como potenciais modificadores de efeito e confundimento da associação entre atividade física e $\mathrm{CMCV}$ as variáveis idade, 
etnia, estado civil e índice de massa corporal, todas introduzidas na modelagem de forma estratificada, exceto a idade que foi analisada de forma contínua. Para as demais variáveis utilizou-se a seguinte estratificação: etnia $=1$ se branco, etnia $=2$ se pardo e etnia $=3$ se negra; estado civil $=1$ se solteiro, estado civil $=2$ se casado e estado civil $=3$ se viúvo; $I M C=0$ se $<40$ e IMC $=1$ se $>40 ; \mathrm{CMCV}=0$ se apresentaram ausência das doenças metabólicas e CMCV = 1 se apresentaram presença de uma ou mais das doenças metabólicas analisadas; nível de atividade física $=0$ se classificado como ativo fisicamente e nível de atividade física $=1$ se classificado como inativo.

Após análise para confundimento e modificação de efeito, a idade foi considerada como confundimento e a etnia, o estado civil e IMC como modificadores de efeito. Assim, o melhor modelo para explicar a associação entre atividade física e CMCV foi o ajustado por idade e estratificado por etnia, estado civil e IMC. Foi também analisado o efeito dose resposta do nível de atividade física para proteção das CMCV. Para esta análise foram criadas variáveis DUMMIES para comparação entre o grupo de referência (inativos) e cada um dos outros extratos da variável atividade física. Foi utilizado o teste de Mantel Haenzel para testar a homogeneidade dos valores do OR entre os estratos de cada variável com nível de significância de 0,05. O intervalo de confiança foi estabelecido em 95\%. Empregou-se o programa estatístico "STATA" versão 7.0. 


\section{RESULTADOS}

TABELA 1. Caracterização da amostra

A CARACTERIZAÇÃO DA AMOSTRA PODE SER

\begin{tabular}{l|l|l}
\hline Variável & M DP & IC (95\%) \\
\hline Idade (anos) & $44,1 \pm 10,4$ & $(21-75)$ \\
\hline Peso $(\mathrm{kg})$ & $107,7 \pm 18,3$ & $(142-201)$ \\
\hline Estatura (cm) & $158 \pm 0,06$ & $(31,2-70,5)$ \\
\hline IMC $\left(\mathrm{kg} / \mathrm{m}^{2}\right)$ & $42,79 \pm 6,32$ & \\
\hline Etnia (\%) & & $(25,7-34,7)$ \\
\hline Branco & 30,2 & $(41,9-50,8)$ \\
\hline Pardo & 45,9 & $(19,5-28,0)$ \\
\hline Negro & 23,8 & $(28,4-37,6)$ \\
\hline Estado civil (\%) & & $(55,6-65,2)$ \\
\hline Solteiro & 33,1 & $(4,1-8,7)$ \\
\hline Casado & 60,5 & \\
\hline Viúvo & 6,5 & \\
\hline
\end{tabular}

$M=$ Média; DP = Desvio Padrão; IC = Intervalo de Confiança

Na Tabela 2 pode ser observado o nível de atividade física da população estudada e a prevalência das CMCV.

TABELA 2. Classificação nível de atividade física e prevalência de comorbidades cardiovasculares

\begin{tabular}{l|c|c}
\hline Variáveis & Percentual & IC (95\%) \\
\hline Atividade física & & \\
\hline Ativo & 31,52 & $(28,1-34,9)$ \\
\hline Inativo & 68,48 & $(63,8-73,0)$ \\
\hline CMCV & & \\
\hline Presença & 73,90 & $(69,6-78,2)$ \\
\hline Ausência & 26,10 & $(21,8-30,4)$ \\
\hline
\end{tabular}

IC = Intervalo de Confiança; $\mathrm{CMCV}=$ Co-Morbidades Cardiovasculares 
Pode-se observar que a maioria das mulheres estavam inativas fisicamente. Já em relação às CMCV foi observado que a maioria das mulheres apresentaram as referidas CMCV.

A Tabela 3 demonstra a associação bruta e ajustada por idade entre a atividade física e CMCV em mulheres obesas.

TABELA 3. Associação bruta e ajustada por idade entre atividade física e co-morbidades cardiovasculares em mulheres obesas

\begin{tabular}{l|l|l}
\hline Atividade Física & $\begin{array}{l}\text { Associação Bruta } \\
\text { OR (IC 95\%) }\end{array}$ & $\begin{array}{l}\text { Ajuste por idade } \\
\text { OR (IC 95\%) }\end{array}$ \\
\hline Inativos & 1,00 & 1,00 \\
\hline Ativos & $0,11(0,04-0,24)$ & $0,11(0,04-0,25)$ \\
\hline
\end{tabular}

OR = Odds Ratio; IC = Intervalo de Confiança

A atividade física apresentou associação com as CMCV na associação bruta e quando ajustado por idade, demonstrando efeito protetor para as CMCV em mulheres obesas.

A tabela 4 demonstra a associação entre atividade física e CMCV ajustado por idade e estratificado por etnia, IMC e estado civil.

TABELA 4. Atividade Física e co-morbidades cardiovasculares ajustado por idade e estratificado por etnia, estado civil e IMC

\begin{tabular}{l|c|c|c}
\hline Variáveis & OR & IC (95\%) & P \\
\hline Etnia & & & \\
\hline Branca & 0,19 & $(0,05-0,71)$ & \\
\hline Parda & 0,04 & $(0,01-0,20)$ & 0,10 \\
\hline Negra & 0,16 & $(0,03-0,78)$ & \\
\hline Estado Civil & & & \\
\hline Solteiro & 0,22 & $(0,07-0,63)$ & \\
\hline Casado & 0,04 & $(0,01-0,20)$ & \\
\hline Viúvo & 1,01 & $(0,91-1,13)$ & \\
\hline IMC & & & 0,04 \\
\hline$<40$ & 0,12 & $(0,03-0,43)$ & \\
\hline$>40$ & 0,09 & $(0,03-0,28)$ & \\
\hline
\end{tabular}

OR = Odds Ratio; IC = Intervalo de Confiança

56 Cristiano Pitanga, Ricardo de Oliveira, Ines Lessa, Maria Costa e Francisco Pitanga 
A atividade física apresentou associação com as CMCV quando estratificado por etnia, IMC e estado civil, exceto entre as viúvas.

A tabela 5 demonstra o efeito dose resposta entre o nível de atividade física CMCV.

TABELA 5. Efeito dose resposta do nível de atividade física e co-morbidades cardiovasculares em obesas

\begin{tabular}{l|l|l}
\hline Nível de Atividade Física & OR & IC (95\%) \\
\hline Inativos & 1,00 & \\
\hline Insuficiente ativo & 0,90 & $(0,83-0,97)$ \\
\hline Ativos & 0,65 & $(0,59-0,71)$ \\
\hline Muito ativo & 0,50 & $(0,29-0,84)$ \\
\hline
\end{tabular}

OR = Odds Ratio; IC = Intervalo de Confiança

Foi observado que quanto maior o nível de atividade física maior a proteção para as CMCV. As mulheres obesas classificadas como muito ativas fisicamente apresentaram maior proteção para a presença das CMCV.

\section{DISCUSSÃO}

Os resultados do presente estudo demonstraram que a atividade física promoveu proteção para as CMCV em mulheres obesas na associação bruta e quando ajustado por idade e estratificado por etnia, IMC e estado civil, exceto para viúvas. Foi evidenciado que a atividade física contribui para a ausência das CMCV, independente dos valores atribuídos ao IMC, demonstrando que mulheres obesas que praticam atividades físicas regularmente diminuem o risco para o desenvolvimento das CMCV.

Em estudo longitudinal (PAFFENBARGER et al., 1986) realizado durante o período de 12 a 16 anos, com uma amostra de 1413 indivíduos, com faixa etária de 35 a 74 anos, demonstrou-se que um gasto calórico acima de $2000 \mathrm{kcal}$ por semana diminui significativamente os índices de mortalidade por doenças cardiovasculares. Nesse sentido, Blair e Mccloy (1993) estudaram a associação entre atividade física e mortalidade em 25.433 mulheres, demonstrando que a atividade física apresentou uma associação inversa com a mortalidade. 
No presente estudo não foi realizado um acompanhamento longitudinal da população, podendo ser um fator limitante, já que foi analisada apenas a última semana de cada indivíduo em relação à prática de atividades físicas. A literatura tem recomendado que adultos para adquirir proteção para as CMCV devem acumular pelo menos trinta minutos de atividades físicas em intensidade moderada na maioria dos dias da semana, com um gasto calórico de 200 calorias por dia (CDC - ACSM, 1995).

Indivíduos com risco aumentado para o desenvolvimento da síndrome metabólica que praticam atividades físicas nos momentos de lazer adquirem uma maior proteção para esse distúrbio quando comparados a indivíduos que são sedentários nos momentos de lazer. (LAAKSONEN et al., 2002) A atividade física está associada à proteção para o desenvolvimento do diabetes mellitus, bem como a redução dos riscos das doenças causadas em pacientes diabéticos. Estudo recente realizado por Jonker e colaboradores (2006) demonstrou que indivíduos que praticavam atividades físicas em moderada intensidade apresentaram uma maior expectativa de vida e maior proteção para o diabetes mellitus quando comparados a indivíduos que praticavam atividades físicas em baixa intensidade. Já os indivíduos que praticavam atividades físicas em baixa intensidade, apresentaram uma maior expectativa de vida e maior proteção para o diabetes mellitus, quando comparados a indivíduos que eram sedentários.

Outros estudos recentes (LITY et al., 2006; RANA et al., 2007) analisaram a relação entre obesidade, atividade física, doenças crônicas degenerativas e doenças cardiovasculares. Foi evidenciado que a atividade física e a obesidade apresentaram-se como variáveis independentes para o acometimento destas patologias, sendo demonstrada a importância da manutenção do IMC em níveis normais e da prática regular de atividades físicas para prevenção dos agravos metabólicos e cardiovasculares. Nessa linha de pensamento tem sido demonstrado que a atividade física promove proteção para as CMCV em indivíduos com obesidade. (MARCHESINI et al., 2004)

No presente estudo foi evidenciado que maiores níveis de atividades físicas promovem maior proteção para as CMCV. Foi observado que mulheres obesas que praticam atividades físicas de moderada a alta intensi- 
dade adquirem um maior efeito protetor para as CMCV. Os trabalhos têm demonstrado (LEE et al., 2000), que indivíduos que praticam atividades físicas de moderada a alta intensidade ( 4 a 6 Mets e $\geq 6$ Mets, respectivamente) apresentaram uma maior proteção para a doença cardiovascular e maior longevidade. Estudo realizado por Okura e colaboradores (2003), com 90 obesos, relatou que as atividades físicas de moderada a alta intensidade promovem uma maior proteção para a doença cardiovascular do que atividades físicas realizadas em baixa intensidade.

Nesse sentido, foi evidenciado por Okura e colaboradores (2003) que a prática de atividades físicas em moderada intensidade promove um maior efeito protetor para as co-morbidades cardiovasculares. Estudo realizado por Wareham e colaboradores (2000), com 775 indivíduos entre 45 e 70 anos, demonstrou que o gasto energético está associado com redução da PA. Indivíduos com um maior gasto calórico apresentam menores níveis de pressão arterial independente da obesidade e da capacidade cardiorrespiratória.

Outro recente estudo realizado por Thompson e colaboradores (2007), que procurou analisar a associação entre IMC, aptidão cardiorrespiratória e síndrome metabólica em 200 mulheres com faixa etária entre 18 e 40 anos, demonstrou que o IMC, a aptidão cardiorrespiratória e o nível de atividade física são variáveis importantes para reduzir a prevalência e incidência da síndrome metabólica.

\section{CONCLUSÃO}

Na população estudada, a maioria das mulheres indicaram a presença das $\mathrm{CMCV}$ e foram classificadas como inativas fisicamente. Quando analisada a associação entre atividade física e CMCV, tanto bruta quanto ajustada por idade e estratificada por etnia, estado civil e IMC, evidenciou-se que a atividade física se apresentou como uma variável protetora para as CMCV. Ao se analisar o efeito dose resposta, foi evidenciado que maiores níveis de atividades físicas promovem maior proteção para as CMCV. Demonstrou-se no presente estudo que mulheres obesas classificadas como muito ativas fisicamente apresentaram maior proteção para as CMCV. Portanto, 
a atividade física deve ser sugerida para mulheres obesas visando afastar o risco para $\mathrm{CMCV}$, uma vez que a obesidade já se apresenta como um fator de risco importante para estas doenças. Aumentos gradativos no nível de atividade física também devem ser sugeridos para esta população, visando proporcionar uma maior proteção para a ausência das CMCV. A adoção de um estilo de vida ativo fisicamente deve fazer parte da rotina diária dos indivíduos com obesidade buscando uma maior qualidade de vida e longevidade.

\section{REFERÊNCIAS}

BLAIR, S. N.; MCCLOY, C. H. Research Lecture: Physical Activity, Physical Fitness and Health. Res Quart Exerc Sport., v. 64; n. 4, p. 365-376, 1993.

BLAIR, S. N. et al. Physical Fitness and all-Cause Mortality a Prospective Study of Healthy Men and Women. JAMA, v. 262, p. 2395-2401, 1989.

BROCHU M. et al. What are physical characteristics associated with a normal metobolic profile despite a high level of obesity in postmenopausal women? J. Clin. Endocrinol Metab., v. 86, n. 3, p. 1020-5, 2001.

CDC - ACSM. Physical Activity and Public Health. A recommendation from the centers for disease control and prevention and the American college of sports medicine. JAMA, v. 273, p. 402-407, 1995.

ERLICHMAN, J.; KERBEY, A. L.; JAMES, W. P. Physical activity and its impact on health outcomes. Paper 1: The impact of physical activity on cardiovascular disease and all-cause mortality: an historical perspective. Obes. Ver., v. 3, n. 4, p. 257-71, 2002.

GIACOMINI, M. C. C., SANTOS, A. L. P. e GIACOMINI, O. Comparação das análises bioquímicas em mulheres obesas submetidas a um programa de treinamento físico aeróbico. EFDeportes.com, Revista Digital, Buenos Aires, Ano 12, n. 109, jun, 2007. Disponível em: <http://www.efdeportes.com/ efd109/comparacao-das-analises-bioquimicas-em-mulheres-obesas.htm> HUBERT et al. Obesity as an independent risk factor for cardiovascular disease: a 26-year follow-up of participants in the Framingham Heart Study. Circulation, v. 67, n. 5, p. 968-77, 1983. 
HARRIS, T. B. et al. Overweight, weight loss, and risk of coronary heart disease in older women. The NHANES I Epidemiologic Follow-up Study. Am. J. Epidemiol, v. 137, n.12, p. 1318-27, 1993.

IBGE - Instituto Brasileiro de Geogrfia e Estatística. Análise da disponibilidade domiciliar de alimentos e do estado nutricional no Brasil 2002-2003. Rio de Janeiro: IBGE; 2004.

JONKER, J. T.; DE LAET, C.; FRANCO, O. H.; PEETERS, A.; MACKENBACH, J.; NUSSELDER, W. J. Physical activity and life expectancy with and without diabetes: live table analysis of the Framingham Heart Study. Diabetes Care, v. 29, p. 38-43, 2006.

KELLY, T.; YANG, W.; CHEN, C. S.; REYNOLDS, K. He J. Global burden of obesity in 2005 and projections to 2030. Int. J. Obes., v. 32, n. 9, p. 1431-7, 2008.

LAAKSONEN, D. E.; LAKKA, H. M.; SALONEN, J. T.; NISKANEN, L. K.; RAURAMAA, R. Lakkata. Low Levels of Leisure-Time Physical Activity and Cardiorespiratory Fitness Predict Development of the Metabolic Syndrome. Diabetes Care,v. 25, p. 1612-1618, 2002.

RANA, J. S.; MANSON, J. E.; WILLET, W. C.; STAMPFER, M. J.; COLDITZ, G. A.; REXRODE, K. M.; HU LITY, F. B. Obesity as compared with Physical Activity in Predicting Risk of Coronary Heart Disease in Women. Circulation, v. 113, n. 4, p. 449-506, 2006.

MARCHESINI, G. et al. Quavadis Study Group. Snoring, Hipertension and Type 2 Diabetes in Obesity. Protection by Physical Activity. J. Endocrinol Invest., v. 27, n. 2, p. 150-7, 2004.

MATSUDO, S. M. et al. Questionário Internacional de Atividade Física (IPAQ): estudo de validade e reprodutibilidade no Brasil. Rev. Bras. Ativ. Saúde, v. 6, n. 2, p. 5-18, 2001.

OKURA, T.; NAKATA, Y.; TANAKA, K. Effects of exercise intensity on physical fitness and risk factor for coronary heart disease. Obes Res, v. 11, n. 9, p. 1131-9, 2003.

PASCHOAL, M. A.; POLESSI, E. A.; SIMIONI, F. C. Avaliação da variabilidade da freqüência cardíaca em mulheres climatéricas treinadas e sedentárias. Arq. Bras. Cardiol., v., 90, n. 2, p. 80-86, 2008. 
PAFFENBARGER, R. S. et al. Physical Activity, all-cause mortality, and longevity of College Alumni. N. Engl. J. Med, v. 314, n. 10, p. 605-613, 1986.

RANA, J. S.; LITTY, Manson J. E.; HU, F. B. Adiposity Compared with Physical Inactivity and Risk of Type 2 Diabetes in Women. Diabetes Care, v. 30, n. 1, p. 53-8, 2007.

SOCIEDADE BRASILEIRA DE CARDIOLOGIA. $2^{\text {a } C o n s e n s o ~ B r a s i l e i r o ~ s o b r e ~}$ Dislipidemias. Arquivos Brasileiros de Cardiologia, v. 67, n. 2, p. 1-15, 1996.

THOMPSON, J. L et al. Associations Beteween Body Mass Index, Cardiorespiratory Fitness, Metabolic Syndrome and Impaired Fasting Glucose in Young, Urban Native American Women. Metab Syndr Relat Disord., v. 5, n. 1, p. 45-54. 2007.

WORLD HEALTH ORGANIZATION. Obesity. Preventing and Managing the Global Epidemic. Report of a WHO Consultation on Obesity. Geneva: World Health Organization, 1998.

WAREHAM, N. J. et al. Quantifying the associantion between habitual energy expenditure and blood pressure. International Journal of Epidemiology, v. 29, p. $655-660.2000$. 


\title{
Razão cintura/estatura comparado a outros indicadores antropométricos de obesidade como preditor de risco coronariano elevado
}

\author{
Danilo Ramos Haun \\ Francisco José Gondim Pitanga
}

Ines Lessa

\section{INTRODUÇÃO}

A obesidade, sobretudo a abdominal, predispõe o indivíduo a uma série de fatores de risco cardiovasculares por associar-se com grande freqüência a condições tais como dislipidemias, hipertensão arterial, resistência à insulina e diabetes que favorecem a ocorrência de eventos cardiovasculares, particularmente os coronarianos. (KANNEL et al., 2002; TONSTAD; HJERMANN, 2003) Devido os inúmeros males associados à obesidade, esta já vem sendo definida como uma doença crônica não transmissível, progressiva e recorrente. (CONSENSO LATINO-AMERICANO EM OBESIDADE, 1998) Está se tornando uma epidemia mundial (MARKS, 2004) que afeta praticamente todas as idades, grupos socioeconômicos e ameaça tanto os países desenvolvidos, quanto os subdesenvolvidos. (OMS, 2004) 
A obesidade ou até mesmo o sobrepeso, geralmente não são difíceis de serem reconhecidos, mas o diagnóstico correto requer que os níveis de risco sejam identificados e isto, freqüentemente, necessita de algumas formas de quantificação.

As técnicas de imagem, tais como ressonância magnética (ROSS et al., 1992), tomografia computadorizada (STOLK et al., 2001) e absorciometria com raios-X de dupla energia (dexa) (ERSELCAN et al., 2000) têm sido alternativas que oferecem maior precisão na avaliação do acúmulo de gordura. No entanto, muitas vezes, em razão do alto custo de seus equipamentos, da sofisticação metodológica e das dificuldades em envolver os avaliados nos protocolos de medida, sua utilização em estudos populacionais bem como diagnósticos clínicos tem sido limitada.

Nesse sentido, a simplicidade de utilização e a relativa facilidade de interpretação destacam os métodos antropométricos como bons instrumentos para avaliação do excesso de gordura corporal. Diversos índices antropométricos têm sido propostos para determinar a associação entre excesso de peso e fatores de risco cardiovascular.

O Índice de Massa Corporal (IMC) é talvez, o que tenha uma maior divulgação no que diz respeito a mensagem populacional. Seus valores limites são conhecidos por especialistas e leigos. O IMC é um bom indicador, mas não totalmente correlacionado com a distribuição da gordura corporal.

As medidas da circunferência da cintura (CC) e a relação cintura/quadril (RCQ) são os indicadores mais utilizados na aferição da distribuição centralizada do tecido adiposo em avaliações individuais e coletivas, contudo as diferenças na composição corporal dos diversos grupos etários e raciais dificultam o desenvolvimento de pontos de corte universais (OMS, 2004). O conhecimento desses pontos de corte é útil na deteç̧ão do risco de desenvolvimento de doenças, tanto na vigilância da saúde quanto em estudos de diagnóstico populacional.

Outros indicadores que vem demonstrando forte correlação com os fatores de risco cardiovascular são o índice de conicidade (Índice C) e a razão cintura/estatura (RCEst). $\mathrm{O}$ Índice $\mathrm{C}$ é determinado com as medidas do peso, da estatura e da circunferência da cintura (LEMOS-SANTOS, et al. 
2004) e apresenta associação com fatores de risco cardiovascular. Outros autores demonstram que a Razão Cintura-Estatura (RCEst) é fortemente associada a diversos fatores de risco cardiovascular e identificam os pontos de corte mais próximos deste indicador antropométrico de obesidade para discriminar o risco coronariano, em diferentes populações (PITANGA; LESSA, 2006; ASHWELL; HSIEH, 2005) sugerindo a utilização dos mesmos em estudos populacionais.

No Brasil, ainda não houve estudos que comparassem a RCEst aos demais indicadores antropométricos de obesidade. Assim, o objetivo deste estudo é comparar a RCEst com os demais indicadores de obesidade (IMC, $\mathrm{CC}, \mathrm{RCQ}$ Índice C) na predição do risco coronariano elevado (RCE).

\section{MÉTODOS}

Trata-se de um estudo transversal, de natureza quantitativa, realizado em subgrupo de 968 adultos com idade $>30$ anos, dentre 2.297 adultos que participaram do projeto Monitoramento das Doenças Cardiovasculares e da Diabetes no Brasil (MONIT), realizado na cidade de Salvador, Brasil, no ano de 2000, desenvolvido pela equipe de doenças crônicas não transmissíveis do Instituto de Saúde Coletiva (ISC) da Universidade Federal da Bahia (UFBA) e financiado pelo Ministério da Saúde do Brasil (LESSA et al., 2000). A coleta de dados foi realizada através de um censo domiciliar e aplicada por investigadores do Projeto Bahia Azul, em desenvolvimento por pesquisadores do ISC-UFBA e direcionado para outros objetivos (TEIXEIRA et al., 2002).

\section{AMOSTRA}

Segundo o Monit, a amostragem por conglomerados foi realizada em três estágios. Em primeiro lugar, os setores censitários de oito das dez bacias hidrográficas da cidade, com características sociodemográficas semelhantes, foram agrupados em 108 áreas de pesquisa, que foram classificadas por nível socioeconômico alto, misto e baixo. Ao todo, as áreas continham 16592 domicílios, com aproximadamente 83.000 habitantes com 20 anos 
ou mais. Foram sorteadas por amostra probabilística 37 áreas, proporcionalmente ao número de setores de cada nível socioeconômico. No segundo estágio foram sorteados 1.540 domicílios por amostra sistemática (intervalo $=10)$. Concordaram em participar 1.258 famílias $(81,7 \%)$ residentes em 63 setores censitários. No terceiro estágio foram sorteados os participantes, no máximo dois por domicílio, um de cada sexo. Foram programadas 2.476 entrevistas, havendo $2,9 \%$ de recusas (72) e uma perda irrecuperável de 4,3\% (107) questionários completos. Desta forma, a amostra ficou constituída por 2.297 adultos com idade entre 20 e 74 anos. Como o modelo para cálculo do indicador de risco coronariano no presente estudo foi construído com base em população de 30 a 74 anos, a amostra ficou reduzida para 1.654 adultos, sendo 711 homens e 943 mulheres. Porém, os participantes deste subgrupo etário que completaram todo o protocolo de medidas proposto e foram estudados tonalizaram 968 pessoas ( 391 homens e 577 mulheres, o que equivale a 55\% dos homens e 61\% das mulheres).

Em estudo prévio foi publicado análise de comparação entre a amostra total e a amostra utilizada no presente trabalho relatando que apesar das perdas, apenas para a variável PAS em ambos os sexos, houve diferença estatisticamente significativa entre os grupos, porém ao ser feita análise das proporções observou-se que a prevalência de níveis elevados de PAS não apresenta diferença entre os grupos. Nessa análise, apenas na variável escolaridade para o sexo feminino houve diferença estatisticamente significativa entre os grupos dos incluídos e as perdas. (PITANGA; LESSA, 2004)

\section{COLETA DE DADOS}

Todos os participantes do projeto foram entrevistados em domicílio para coleta dos dados demográficos, e tiveram a Pressão Arterial Sistólica (PAS) e Pressão Arterial Diastólica (PAD) medidas por seis vezes; as três primeiras, consecutivamente, 30 minutos após o início da entrevista, e as três seguintes após intervalo de 20 minutos, no braço esquerdo, estando o indivíduo sentado, com a bexiga vazia, sem ter fumado, tomado café ou álcool nos 30 minutos precedentes às tomadas. Das seis medidas de PAS e $\mathrm{PAD}$, as primeiras foram excluídas e analisadas a média das cinco últimas. 
A cintura foi medida com o participante na posição ereta, com o mínimo de roupa possível, na distância média entre a última costela flutuante e a crista ilíaca. As medidas de peso e estatura foram tomadas pela equipe do estudo no Centro de Saúde de cada bairro, onde também foi coletado o sangue para os exames bioquímicos após 12 horas de jejum. Foram realizadas dosagens de colesterol total (método Trinder enzimático), lipoproteína de alta densidade (HDL-C) (método Labtest) e glicemia (método Trinder enzimático). As técnicas e métodos utilizados nas determinações bioquímicas seguiram a padronização da Sociedade Brasileira de Patologia Clínica (SBPC).

Dez entrevistadores de campo e duas supervisoras, ambas nutricionistas, foram devidamente treinados para todas as etapas do trabalho. Para testes e correções dos instrumentos e técnicas, inclusive da dinâmica do trabalho de campo, 50 residências (100 participantes) foram visitadas e as entrevistas e exames realizados seguindo toda a metodologia proposta. O grupo teste não está incluído na amostra. Para verificação das técnicas e instrumentos intra e interavaliadores foram feitas comparações entre médias, desvio-padrão e coeficientes de variação para medidas de circunferência, peso e estatura.

\section{INSTRUMENTOS UTILIZADOS}

Para medida da pressão arterial, o esfignomanômetro utilizado foi o Omron HEM 705 CP, modelo eletrônico, testado e aprovado pela British Hypertension Society (BHS). A estatura foi medida com estadiômetro inglês, tipo "Leicesters", acoplado a uma base que permite medida de altura em campo, fabricado pela Child Growth Foundation (CGF). O peso corporal foi medido em balanças tipo "banheiro", marca Filizola, com capacidade máxima de $150 \mathrm{~kg}$, aferidas pelo Instituto Nacional de Metrologia (INMETRO), com certificado próprio especificando margem de erro de \pm 100 g. Para medida da circunferência da cintura foi utilizada fita métrica metálica e flexível, marca Starrett, com definição de medida de $0,1 \mathrm{~cm}$. 


\section{VARIÁVEIS DO ESTUDO}

Foram utilizadas as variáveis: idade, sexo, PAS, PAD, colesterol total, HDL-C, tabagismo e diabetes para a construção do indicador RCE representando em conjunto os fatores de risco cardiovascular analisados simultaneamente. As variáveis: peso, estatura e circunferência da cintura foram utilizadas no cálculo dos indicadores antropométricos de obesidade.

\section{CONSTRUÇÃO DO INDICADOR DE RISCO CORONARIANO}

Baseado no acompanhamento por 12 anos de 2.489 homens e $2.856 \mathrm{mu}-$ lheres de 30 a 74 anos, da coorte de Framingham, (WILSON et al., 1998), construíram o algoritmo para medida do risco coronariano que serviu de modelo para o presente estudo. Durante o acompanhamento da coorte, 383 homens e 227 mulheres desenvolveram DAC. Pela utilização do modelo de regressão de Cox, os autores elaboraram uma tabela de pontuação (algoritmo) com a inclusão das variáveis por eles selecionadas (idade, PAS, PAD, colesterol total, HDL-C, tabagismo e diabetes). Para cada variável a pontuação poderia ser positiva, quando considerado fator de risco, ou negativa, quando considerado fator de proteção, conforme descrito no estudo realizado por Pitanga e Lessa (2005).

Para determinação dos pontos, foi utilizado o coeficiente beta dos modelos de análises de regressão de Cox (WILSON P.W.F., et al., 1998). Cada participante da amostra do presente estudo teve sua pontuação calculada com base no algoritmo supracitado. Para identificação do RCE, as somas das pontuações foram colocadas em ordem crescente e determinados os percentis, selecionando-se a soma da pontuação referente ao percentil 80 como de risco coronariano elevado, que correspondeu a oito pontos para o sexo masculino e dez pontos para o sexo feminino.

\section{PROCEDIMENTO DE ANÁLISE}

As análises foram feitas através das curvas Receiver Operating Characteristic (ROC). Inicialmente foi identificada a área total sob a curva ROC entre o IMC, CC, RCQ Índice C, RCEst e o RCE. Utilizou-se intervalo de 
confiança a 95\%. Quanto maior a área sob a curva ROC, maior o poder discriminatório do indicador de obesidade para RCE. O intervalo de confiança determina se a capacidade preditiva do indicador de obesidade não é devido ao acaso e o seu limite inferior não deve ser menor do que 0,50. (SCHISTERMAN et al., 2001)

Na seqüência, foram calculadas a sensibilidade e especificidade entre os indicadores antropométricos e o RCE. Os valores indicados por meio da curva ROC constituem pontos de corte que deverão promover um equilíbrio mais adequado entre sensibilidade e especificidade para as medidas analisadas, como discriminador de RCE.

Os dados foram analisados através do programa estatístico "STATA", versão 7.0. O projeto foi aprovado na íntegra pelo Comitê de Ética do Conselho Regional de Medicina do Estado da Bahia. Todos os participantes do estudo ou seus responsáveis assinaram termo de consentimento concordando em participar da pesquisa.

\section{RESULTADOS}

A maioria das características dos indivíduos estudados apresenta-se semelhante entre os grupos, havendo diferenças estatisticamente significativas entre homens e mulheres para as variáveis: peso corporal, estatura, circunferência da cintura, PAS, PAD, colesterol total e HDL-C (Tabela 1).

As áreas sob a curva ROC para identificar a poder de preditivo entre os indicadores antropométricos apresentam o Índice $\mathrm{C}$ como melhor discriminador do RCE para ambos os sexos (tabela 2). A RCEst possui uma área sob as curvas ROC de 0,76 e o ponto de corte foi de 0,52 para homens (IC $95 \%=0,70-0,82$ ) com uma sensibilidade de $68 \%$ e especificidade de $64 \%$. O ponto de corte para as mulheres foi de 0,53 (IC95\% $=0,64-0,75)$ com sensibilidade de $67 \%$ e especificidade de $58 \%$ (tabela 2 ).

A CC obteve menor poder preditivo que a RCEst, com uma área total sob as curvas ROC de 0,73 para homens (IC95\% = 0,67 - 0,79) e 0,66 para mulheres $(\mathrm{IC95} \%=0,60-0,71)$. O ponto de corte de 0,88 para homens e 0,83 para mulheres, foi obtido pelo melhor equilíbrio entre sensibilidade (homens $=65 \%$ e mulheres $=64 \%$ ) e especificidade (homens $=67 \%$ e mulheres $=62 \%$ ) (Tabela 2 ). 
TABELA 1. Média, desvio padrão e percentuais das variáveis analisadas no estudo

\begin{tabular}{|c|c|c|c|}
\hline & Homens ( $n=391$ ) & Mulheres $(n=577)$ & $\mathrm{p}$ \\
\hline Idade (anos) & $45,34 \pm 10,44$ & $45,73 \pm 11,64$ & 0,59 \\
\hline Peso (kg) & $68,91 \pm 12,30$ & $64,20 \pm 13,84$ & $<0,001$ \\
\hline Estatura (m) & $1,68 \pm 0,07$ & $1,55 \pm 0,07$ & $<0,001$ \\
\hline Cintura (cm) & $85,64 \pm 10,11$ & $82,68 \pm 12,19$ & $<0,001$ \\
\hline Quadril (cm) & $93,73 \pm 7,46$ & $99,72 \pm 10,00$ & $<0,001$ \\
\hline PAS (mmHg) & $130,6 \pm 22,8$ & $124,8 \pm 24,6$ & $<0,001$ \\
\hline PAD (mmHg) & $81,1 \pm 14,6$ & $78,2 \pm 13,2$ & $<0,001$ \\
\hline Colesterol total (mg/dl) & $220,6 \pm 52,0$ & $232,3 \pm 52,5$ & $<0,001$ \\
\hline HDL-C (mg/dl) & $48,5 \pm 13,1$ & $51,5 \pm 13,5$ & $<0,001$ \\
\hline Glicemia (mg/dl) & $90,5 \pm 29,2$ & $92,0 \pm 34,4$ & 0,48 \\
\hline Índice C & $1,23 \pm 0,07$ & $1,18 \pm 0,09$ & $<0,001$ \\
\hline RCQ & $0,91 \pm 0,07$ & $0,83 \pm 0,08$ & $<0,001$ \\
\hline RCEst & $0,51 \pm 0,06$ & $0,53 \pm 0,08$ & $<0,001$ \\
\hline $\mathrm{CC}(\mathrm{cm})$ & $85,6 \pm 10,1$ & $82,7 \pm 12,2$ & $<0,001$ \\
\hline IMC $\left(\mathrm{kg} / \mathrm{m}^{2}\right)$ & $24,4 \pm 3,85$ & $26,54 \pm 5,39$ & $<0,001$ \\
\hline \multicolumn{4}{|l|}{ Risco coronariano } \\
\hline Não elevado & $76 \%$ & $79 \%$ & \\
\hline Elevado & $24 \%$ & $21 \%$ & 0,61 \\
\hline \multicolumn{4}{|l|}{ Escolaridade } \\
\hline Baixa & $50 \%$ & $54 \%$ & \\
\hline Média/Alta & $50 \%$ & $46 \%$ & 0,57 \\
\hline \multicolumn{4}{|l|}{ Raça } \\
\hline Brancos & $24 \%$ & $26 \%$ & \\
\hline Negros e outros & $76 \%$ & $74 \%$ & 0,74 \\
\hline
\end{tabular}

Valores contínuos foram comparados através do teste " $t$ " de student para amostras independentes e valores percentuais através do teste qui-quadrado; PAS - pressão arterial sistólica; PAD - pressão arterial distólica; HDL-C - Lipoproteína de alta densidade.

70 Danilo Haun, Francisco Pitanga e Ines Lessa 
TABELA 2. Comparação dos pontos de corte e das áreas sob as curvas ROC dos indicadores antropométricos de obesidade como discriminadores de RCE

\begin{tabular}{|c|c|c|c|c|c|}
\hline \multicolumn{6}{|l|}{ Masculino } \\
\hline $\begin{array}{l}\text { Indicadores } \\
\text { de obesidade }\end{array}$ & $\begin{array}{l}\text { Ponto } \\
\text { de Corte }\end{array}$ & Sensibilidade & Especificidade & $\begin{array}{l}\text { Área com } \\
\text { IC a } 95 \%\end{array}$ & $\mathrm{p}$ \\
\hline Índice C & 1,25 & $74 \%$ & $75 \%$ & $\begin{array}{l}0,80 \\
(0,74-0,85)\end{array}$ & \\
\hline $\mathrm{RCQ}$ & 0,92 & $74 \%$ & $65 \%$ & $\begin{array}{l}0,76 \\
(0,71-0,82)\end{array}$ & \\
\hline RCEst & 0,52 & $68 \%$ & $64 \%$ & $\begin{array}{l}0,76 \\
(0,70-0,82)\end{array}$ & \\
\hline $\mathrm{CC}$ & 0,88 & $65 \%$ & $67 \%$ & $\begin{array}{l}0,73 \\
(0,67-0,79)\end{array}$ & \\
\hline IMC & 24,0 & $67 \%$ & $53 \%$ & $\begin{array}{l}0,64 \\
(0,57-0,71)\end{array}$ & 0,0013 \\
\hline \multicolumn{6}{|l|}{ Feminino } \\
\hline Índice C & 1,18 & $73 \%$ & $61 \%$ & $\begin{array}{l}0,75 \\
(0,70-0,80)\end{array}$ & \\
\hline $\mathrm{RCQ}$ & 0,83 & $73 \%$ & $63 \%$ & $\begin{array}{l}0,75 \\
(0,70-0,80)\end{array}$ & \\
\hline RCEst & 0,53 & $67 \%$ & $58 \%$ & $\begin{array}{l}0,69 \\
(0,64-0,75)\end{array}$ & \\
\hline CC & 0,83 & $64 \%$ & $62 \%$ & $\begin{array}{l}0,66 \\
(0,60-0,71)\end{array}$ & \\
\hline IMC & 26,0 & $62 \%$ & $53 \%$ & $\begin{array}{l}0,59 \\
(0,53-0,65)\end{array}$ & $<0,001$ \\
\hline
\end{tabular}

Índice C - índice de conicidade; RCE - risco coronariano elevado; IMC - índice de massa corporal; RCQ relação cintura-quadril; CC - circunferência da cintura; RCEst - razão cintura-estatura.

Para as mulheres as áreas sob a curva ROC são semelhantes entre o Índice C e RCQ com diferenças estatisticamente significativas entre os diversos indicadores de obesidade para discriminar RCE (Tabela 2).

Com o intuito de comparar o poder discriminatório entre RCEst e os demais indicadores de obesidade foi observada a significância estatística entre as áreas sob as curvas ROC. Na comparação com o Índice C $(\mathrm{p}=0,0440)$, a CC $(\mathrm{p}=0,0104)$ e o IMC $(\mathrm{p}=0,0000)$, para pessoas do sexo masculino, houveram diferença estatisticamente significante. Quando comparado com a RCQ esta diferença não mostra significância estatística $(\mathrm{p}=0,7859)$. Para pessoas do sexo feminino a análise demonstrou diferença 
estatisticamente significante entre o valor da área sob a curva ROC da RCEst e os demais indicadores de obesidade (Tabela 3).

TABELA 3. Comparação do valor de significância entre RCEst e os outros indicadores

\begin{tabular}{l|l|l|c}
\hline & \multicolumn{1}{|c|}{$\begin{array}{l}\text { Área sob a curva ROC com } \\
\text { Intervalo de Confiança 95\% }\end{array}$} & p \\
\hline Masculino & $\begin{array}{l}0,76 \\
(0,70-0,82)\end{array}$ & $\begin{array}{l}0,80 \\
(0,74-0,85)\end{array}$ & 0.0440 \\
\hline RCEst e Índice C & $\begin{array}{l}0,76 \\
(0,70-0,82)\end{array}$ & $\begin{array}{l}0,76 \\
(0,71-0,82)\end{array}$ & 0.7859 \\
\hline RCEst e RCQ & $\begin{array}{l}0,76 \\
(0,70-0,82)\end{array}$ & $\begin{array}{l}0,73 \\
(0,67-0,79)\end{array}$ & 0.0104 \\
\hline RCEst e CC & $\begin{array}{l}0,76 \\
(0,70-0,82)\end{array}$ & $\begin{array}{l}0,64 \\
(0,57-0,71)\end{array}$ & $<0,001$ \\
\hline RCEst e IMC & $\begin{array}{l}0,69 \\
(0,64-0,75)\end{array}$ & $\begin{array}{l}0,75 \\
(0,70-0,80)\end{array}$ & 0.0063 \\
\hline Feminino & $\begin{array}{l}0,69 \\
(0,64-0,75)\end{array}$ & $\begin{array}{l}0,75 \\
(0,70-0,80)\end{array}$ & 0.0050 \\
\hline RCEst e Índice C & $\begin{array}{l}0,69 \\
(0,64-0,75)\end{array}$ & $\begin{array}{l}0,66 \\
(0,60-0,71)\end{array}$ & $<0,001$ \\
\hline RCEst e RCQ & $\begin{array}{l}0,69 \\
(0,64-0,75)\end{array}$ & $\begin{array}{l}0,59 \\
(0,53-0,65)\end{array}$ & $<0,001$ \\
\hline RCEst e CC &
\end{tabular}

Índice C - índice de conicidade; IMC - índice de massa corporal; RCQ - relação circunferência cinturaquadril; CC - circunferência da cintura; RCEst - razão cintura-estatura.

\section{DISCUSSÃO}

Diversos estudos têm demonstrado que a RCEst é um bom discriminador de obesidade abdominal relacionada a fatores de risco cardiovascular, bem como de RCE. (PITANGA; LESSA, 2006; AEKPLAKORN et al., 2007)

A análise da sensibilidade e especificidade por meio da construção de curvas ROC tem sido recomendada em estudos epidemiológicos para a determinação de pontos de corte (ERDREICH; LEE, 1981). Esse tipo de análise permite não só a identificação do melhor ponto de corte como também fornece a área sob a curva que traduz o poder de discriminação de um indicador para um determinado desfecho. Nesse estudo, todos os indi- 
cadores antropométricos analisados apresentaram capacidade preditiva para o RCE. No entanto, nota-se que a RCEst mostrou-se com bom poder de detecção para a RCE, com o segundo maior valor da área sob a curva ROC para esse desfecho, em ambos os sexos.

Diferentemente do proposto pela OMS, este estudo sugere que a CC não foi o melhor preditor de RCE, embora tenha apresentado melhor acurácia que IMC para ambos os sexos. Além disso, os melhores pontos de corte definidos por meio da análise por curva ROC, tanto para a CC, RCQ e IMC mostraram-se diferentes aos que a OMS preconiza. Outros estudos realizados no Brasil também encontraram pontos de corte diferentes dos propostos pela OMS, confirmando que estes pontos de corte universais para a CC não são eficientes quando dirigidos para esta população. (OMS, 2004; PITANGA.; LESSA, 2005; BARBOSA et al., 2006)

O padrão de distribuição da gordura e a composição corporal de forma geral variam grandemente entre grupos populacionais. (OKOSUN et al., 2003) Nos últimos anos, um grande número de publicações tem evidenciado a inadequação- de se aplicar pontos de corte definidos para populações caucasianas a outros grupos raciais. Um exemplo bastante nítido são os resultados que vêm sendo encontrados em populações asiáticas. Estudos que avaliaram os indicadores de localização de gordura em chineses e japoneses mostram claramente que os melhores pontos de corte para a detecção de diversas doenças crônicas estão abaixo daqueles recomendados pela OMS. (LIN et al., 2002; DEURENBERG-YAP et al., 2002) Além disso, tem-se observado elevado percentual de gordura corporal nesses indivíduos, apesar do IMC encontrar-se dentro dos limites de normalidade. (DEURENBERG-YAP et al., 2002) A RCEst também vem sendo uma medida de forte associação com fatores de risco cardiovascular para a população asiática. (KHAN et al., 2008)

Com relação ao Índice C, Pitanga e Lessa (2005) propõem pontos de corte de 1,25 para homens e 1,18 para mulheres. Mesmo com estas informações, não foram encontrados muitos estudos que utilizaram esta medida como referência. Os mesmos autores, em outro estudo, relatam como uma limitação para a utilização do Índice C em estudos populacionais a dificuldade de se calcular o denominador da equação proposta para 
sua determinação. (PITANGA; LESSA, 2004) A pouca informação científica disponível sobre o Índice $C$ entre as diversas populações do mundo e em diversas faixa etárias, é um outro fator que limita este indicador de se tornar uma medida adotada como referência para estudos populacionais.

Em estudo de coorte realizado na Tailândia, resultante de um acompanhamento de 17 anos com uma amostra total de 2536 homens entre 35 e 59 anos, foram comparados o IMC, CC, RCQ e RCEst para descriminar a doença arterial coronariana (DAC). Foi utilizado o mesmo modelo de regressão de Cox que utilizamos neste estudo. A RCEst foi o melhor dos quatro índices analisados para prever DAC em homens desta população. O ponto de corte sugerido neste estudo $(0,51)$ (AEKPLAKORN et al., 2007) foi muito próximo ao que encontramos $(0,52)$.

Pesquisas recentes com o intuito de determinar valores limites para RCEst em diversas populações indicaram que um ponto de corte de 0.5 é o valor mais indicado para ambos os sexos, todas as idades e diferentes populações. (PITANGA; LESSA, 2006; LIN, et al., 2002; BERTSIAS et al., 2003)

Diversos estudos têm demonstrado que a RCEst é, também, um melhor indicador para a saúde de crianças e adolescentes que outros indicadores antropométricos. E o ponto de corte de 0,5, que vem sendo proposto, está próximo aos recomendados para os adultos. (McCARTHY et al., 2006; WEILIet al., 2007)

Deve-se considerar que existem modificações na composição corporal com o processo do envelhecimento, o que poderia alterar os pontos de corte para as outras medidas antropométricas. Como a RCEst possui uma regulação direta com o crescimento e a circunferência da cintura, talvez seja esta a maior vantagem desta medida, e justifique que ela possua um mesmo valor para os pontos de corte independente da idade. Um outro fator que aparenta ser um ponto positivo desta medida é sua fácil aplicabilidade, podendo ser feita apenas com uma fita métrica - a RCEst é calculada por uma simples divisão entre as medidas da estatura e da cintura.

Considerando-se que o excesso de gordura na região central do corpo está associado ao aparecimento de doenças cardiovasculares, diabetes e mortalidade, a definição de pontos de corte para indicadores que se destacam por sua simplicidade operacional e boa acurácia permite a detecção 
dos indivíduos sob risco, sendo de grande utilidade nos serviços de atenção à saúde, além de possibilitar o conhecimento da situação de grupos populacionais específicos frente a esses riscos, quando empregados na pesquisa epidemiológica.

A abordagem populacional sobre o risco à saúde será muito mais simples se o mesmo índice antropométrico e a mesma mensagem de saúde pública forem utilizados por todas as populações. Considerando que os pontos de corte para RCEst encontrados em diversas populações esta próximo de 0,50 a mensagem populacional sugerida é que a circunferência da cintura deve ser menor que a metade da sua altura.

Uma das limitações do estudo foi a classificação do RCE usando o algaritimo proposto na coorte de Framinghan (WILSON et al., 1998) fato que gerou a exclusão da amostra de pessoas abaixo de 30 anos de idade. Além disso, a determinação dos pontos de corte para RCE estabelecido baseado no percentil 80 da distribuição amostral do estudo foi aleatória.

\section{CONCLUSÃO}

Os resultados obtidos sugerem que a RCEst é uma medida simples, com um bom poder de predição para RCE e possui ponto de corte muito próximo dos pontos obtidos em diversas populações. Seria interessante que fossem realizados no Brasil estudos que comparassem a RCEst com diferentes desfechos em ambos os sexos.

\section{REFERÊNCIAS}

AEKPLAKORN, W.; PAKPEANKITWATANA, V.; LEE, C. M.; WOODWARD, M., BARZI, F.; YAMWONG, S.; UNKURAPINUN, N.; SRITARA, P. Abdominal obesity and coronary heart disease in Thai men. Obesity (Silver Spring), v. 15, n. 4, p. 1036-1042, 2007.

ASHWELL, M.; HSIEH, S. D. Six reasons why the waist-to-height ratio is a rapid and effective global indicator for health risks of obesity and how its use could simplify the international public health message on obesity. International Journal of Food Sciences and Nutrition,v. 56, n. 5, p. 303-307, 2005. 
BARBOSA, P. J. B.; LESSA, I.; ALMEIDA FILHO, N.; MAGALHÃES, L.; ARAUJO, M. J. Critério de obesidade central em população brasileira: impacto sobre a síndrome metabólica. Arquivos Brasileiros de Cardiologia, v. 87, p. 407-414, 2006.

BERTSIAS, G.; MAMMAS, I.; LINARDAKIS, M.; KAFATOS, A. Overweight and obesity in relation to cardiovascular disease risk factors among medical students in Crete, Greece. BMC Public Health,v. 3, n. 3, p. 1-9, 2003.

CONSENSO LATINO-AMERICANO EM OBESIDADE. Convenção LatinoAmericana para Consenso em Obesidade, Rio de Janeiro, 1998.

DEURENBERG-YAP, M.; CHEW, S. K.; DEURENBERG, P. Elevated body fat percentage and cardiovascular risks at low body mass index levels among Singaporean Chinese, Malays and Indians. Obes Rev., 2002; v. 3, p. 209-15. ERDREICH, L. S.; LEE, E.T. Use of relative operating characteristic analysis in epidemiology. A method for dealing with subjective judgement. Am J Epidemiol, v. 114, p, 649-62, 1981.

ERSELCAN, T.; CANDAN, F.; SARUHAN, S.; AYCA, T. Comparison of body composition analysis methods in clinical routine. Ann Nutr. Metab, v. 44, p. 243-248, 2002.

KANNEL, W.B.; WILSON, P.W.; NAM, B.H.; D’AGOSTINO, R.B. Risk stratification of obesity as a coronary risk factor. Am J. Cardiol. v. 90, p. 697-701, 2002.

KHAN, A.; HAQ F.U. PERVEZ, M.B.;SALEHEEN, D.;FROSSARD, P. M.;ISHAQ M.; HAKEEM, A.; SHEIKH, H.T; AHMAD, U. Anthropometric correlates of blood pressure in normotensive Pakistani subjects. Int J. Cardiol. v.124, n. 2, p. 259-262, 2008.

LEMOS-SANTOS, M.G.F.; VALENTE, J. G; GONÇALVES-SILVA, R.M.V.; SICHIERI, $\mathrm{R}$. Waist circumference and waist-to-hip ratio as predictors of serum concentration of lipids in Brazilian men. Nutrition, v. 20, p. 857-62, 2004. LESSA, I. M.L; ARAÚJO, M.J; AQUINO, E; ALMEIDA FILHO, N. ProjetoMonitoramento das Doenças Crônicas Não Transmissíveis (MONIT). Relatório de Pesquisa apresentado ao Centro Nacional de Epidemiologia (CENEPI). Fundação Nacional de Saúde (MS). Brasília - DF. 2000. 
LIN, W.Y; LEE, L.T; CHEN, C,Y; LO, H., HSIA, H.H; LIU, I.L, et al. Optimal cut-off values for obesity: using simple anthropometric indices to predict cardiovascular risk factors in Taiwan. Int. J. Obes. Relat. Metab. Disord. v. 26, n. 9, p. 1232-1238, 2002.

Marks, J.B. Advances in Obesity Treatment: Clinical Highlights from the NAASO 2003 Annual Meeting. Clin. Diab. 2004; 22: 23-26.

MCCARTHY HD, ASHWELL M. A study of central fatness using waist-toheight ratios in UK children and adolescents over two decades supports the simple message--keep your waist circumference to less than half your height. Int J Obes (Lond). 2006; 30(6):988-92.

ORGANIZAÇÃO MUNDIAL DE SAÚDE - OMS. Obesidade: prevenindo e controlando a epidemia global / Relatório da consultoria da OMS. Tradução: Andréa Favano; revisão científica: Sérgio Setsuo Maeda. São Paulo: Roca, 2004.

PITANGA F.J.G., LESSA I., Indicadores Antropométricos de Obesidade como Instrumento de Triagem para Risco Coronariano Elevado em Adultos na Cidade de Salvador - Bahia. Arq. Bra. Card. v. 85, n. 1, p. 26-31, 2005. PITANGA, F.J.G.; LESSA, I. Razão cintura-estatura como discriminador do risco coronariano de adultos, Rev. Assoc. Med. Bras, v. 52, n. 3, p. 157-61. PITANGA, F.J.G.; LESSA, I. Sensibilidade e especificidade do índice de conicidade. Rev. Bras. Epidemiol, v. 7, n. 3, p. 259-269, 2004.

ROSS, R. L.; LÉGER, D.; MORRIS, J.; DE GUISE, AND R. GUARDO. Quantification of adipose tissue by MRI: relationship with anthropometric variables. J. Appl. Physiol, v. 72, p. 787-795, 1992.

SCHISTERMAN, E.F.; FARAGGI, D.; REISER, B.; TREVISAN, M. Statistical inference for the area under the receiver operating characteristic curve in the presence of random measurement error. Am. J. Epidemiol, v. 154, n. 2 , p. 174-179.

STOLK, R.P et al. Validity and reproducibility of ultrasonography for the measurement of intra-abdominal adipose tissue. Int. J. Obes. Relat. Metab. Disord,v. 25, n. 9, p. 1346-1351, 2001. 
TEIXEIRA, M.G.; BARRETO, M.L.; COSTA, M.C.N., STRINA, A, MARTINS JÚNIOR D, PRADO, M. Áreas sentinelas: uma estratégia de monitoramento em saúde pública. Cad. Saúde Pública, v. 18, n. 5, p. 1189-95, 2002.

TONSTAD, S.; HJERMANN, I. A high risk score for coronary heart disease is associated with the metabolic syndrome in 40-year-old men and women. J. Cardiovasc Risk, v. 10, p. 129-35, 2003.

WILSON, P.W.F.; DAGOSTINO, R.B.; LEVY D.; BELANGER A.M.;

SILBERSHATZ, H.; KANNEL, W.B. Prediction of coronary heart disease using risk factores categories. Circulation, v. 97, p. 1837-1847, 1998.

WEILI, Y.; HE, B.; YAO, H.; DAI, J.; CUI, J.; GE, D.; ZHENG, Y.; LI, L.; GUO, Y.; XIAO, K.; FU, X.; MA, D.. Waist-to-height ratio is an accurate and easier index for evaluating obesity in children and adolescents. Obesity (Silver Spring), v. 15, n. 3, p. 748-52, 2007. 


\section{Prevalência e fatores associados à inatividade física em adultos na cidade de Lauro de Freitas-Bahia-Brasil}

Marcela Mota Freitas

Francisco José Gondim Pitanga

\section{INTRODUÇÃO}

Com o processo da industrialização, existe um crescente número de pessoas que se tornam sedentárias com poucas oportunidades de praticar atividades físicas. O impacto da inatividade física no organismo vem acompanhado de várias doenças e condições metabólicas adversas. (PITANGA; LESSA, 2005)

Comprovam este fato a predominância atual de esforço físico de muito leve intensidade na maioria das atividades humanas, o que demanda um gasto energético inferior a 500 kcal (kilocalorias) por dia, valor este 15 vezes menor se comparado ao de nossos ancestrais que viveram há 100 mil anos, que, por serem nômades, andarilhos, caçadores e coletores de alimentos, necessitaram gastar em torno de 8000 kcal diárias com atividades de sobrevivência. (CORDAIN et al., 1998)

Como consequência dessa mudança comportamental, o sedentarismo foi elevado ao status de fator de risco secundário 
para primário (causal, variável independente) da morbimortalidade populacional por diversas doenças crônicas não-transmissíveis (DCNT). O sedentarismo encontra-se no status semelhante aos outros três grandes fatores de risco primário: tabagismo, hipertensão arterial e hipercolesterolemia. (NUNES; BARROS, 2004)

O estudo de Warburton, Nicol e Bredin (2006) tem revelado que as atividades físicas promovem reduções maiores que $5 \%$ nos fatores de risco e nas causas para desenvolvimento das doenças cardiovasculares. Um aumento no dispêndio de $1.000 \mathrm{kcal} /$ total por semana nas atividades físicas está associada a um benefício de mais de $20 \%$ nos índices de mortalidade.

A atividade física regular com gasto calórico total maior que 2000Kcal/ semana está associada à diminuição das taxas de mortalidade nos indivíduos ativos e que esses indivíduos, a partir dos 80 anos, têm aumento médio na expectativa de vida de um a dois anos comparado aos sedentários. (PAFFENBARGER; HYDE; WING, 1986) Indivíduos com esse gasto calórico apresentam risco $39 \%$ inferior para o desenvolvimento de coronariopatiascomparado aos indivíduos menos ativos. (PAFFENBARGER; HYDE; WING, 1984)

Um dos primeiros estudos sobre a associação entre o exercício físico e as doenças cardiovasculares foi realizado na Inglaterra, nos anos 1950. Os resultados mostraram que os cobradores de veículos coletivos de dois andares estavam em melhor forma física do que os motoristas e também apresentavam uma menor incidência de cardiopatia coronariana, com menos óbitos e menor mortalidade precoce em consequência de problemas do coração. (MORRIS et al., 1953)

Ao longo dos anos, os estudos vêm demonstrando que a atividade física regular no tempo livre tem efeito protetor contra doenças crônicas, incluindo hipertensão, doenças da artéria coronária, obesidade, diabete, osteoporose, câncer de cólon, depressão e ansiedade. (PITANGA; LESSA, 2003)

Assim, os estudiosos começam a perceber que a maioria da população tem um gasto energético diário muito baixo, já que a atividade no trabalho e ocupacional diária vem sendo reduzida. A avaliação da atividade física realizada no tempo livre tem sido frequentemente assumida como uma boa representação da prática de atividade física na população. (KRISKA, 1997) 
Um dos primeiros estudos que avaliou o nível de atividade física no tempo livre (AFTL) foi de Leon e colaboradores (1987), realizado com 12.138 homens durante 7 anos, e observou-se que AFTL moderada estava associada com $63 \%$ dos eventos fatais e mortes repentinas de doenças crônicas do coração e 70\% de mortes com baixo AFTL. Homens moderadamente ativos tinham taxas de mortalidade $27 \%$ menor do que os sedentários.

Estudos mais recentes como o de Vuori (2001)apresentam altos níveis de inatividade física no tempo livre na população europeia com valores de $67 \%$ na Bélgica e $83 \%$ em Portugal, além de $73 \%$ no Chile. (VIO, 2005) No Brasil também foram encontrados valores elevados; $80,7 \%$ na cidade de Pelotas (DIAS-DA-COSTA et al., 2005), 72,5\% em Salvador. (PITANGA; LESSA, 2005) Esse quadro demonstra uma situação preocupante a nível de saúde pública.

Portanto, o objetivo desse estudo foi investigar qual a prevalência e os fatores associados à inatividade física total e no tempo livre em adultos na cidade de Lauro de Freitas-BA.

\section{METODOLOGIA}

Trata-se de estudo de corte transversal realizado no município baiano de Lauro de Freitas situado no Nordeste do estado da Bahia, parte da Região Metropolitana de Salvador, com extensão territorial de 59 quilômetros quadrados. O município de Lauro de Freitas possui IDH de 0,771 e PIB per capita de R 12.046,00. De acordo com o Censo Demográfico de 2005, sua população estimada era de 138.240 habitantes. (DATASUS, 2005)

\section{Amostra}

O cálculo do "n" amostral foi baseado em Kish(1965), levando-se em consideração os seguintes parâmetros: tamanho da população de 138.240 habitantes, prevalência de atividade física de $50 \%$ por se tratar de média nacional (HALLAL et al., 2003), bem como da maior prevalência entre as variáveis analisadas no estudo, nível de confiança de 95\% de precisão e erro assumido para a prevalência esperada de $5 \%$. 
O tamanho da amostra estimada foi capaz de oferecer, com 95\% de precisão, a prevalência de variáveis de baixa ou elevada frequência populacional. Para contemplar todos os objetivos desse estudo, o " $n$ " estimado foi de 500 adultos $\geq 18$ anos, ampliado para 600 , de modo que perdas de qualquer natureza não viessem a interferir na precisão, e que recusas, quando não evitadas, não resultassem em vieses que invalidassem o trabalho.

A amostra foi probabilística, em múltiplos estágios e por conglomerados de classes sociais informados pela Secretaria de Ação Social da Prefeitura da cidade de Lauro de Freitas, a partir do poder aquisitivo dos moradores dos bairros. Inicialmente o mapa da cidade foi dividido em microrregiões de acordo com a classe social predominante para visitação dos avaliadores. Tratamos com classe A (alta e média alta), classe B (média), classe $C$ (média baixa) e classe $D$ (baixa e pobreza). Tal procedimento foi adotado para que fossem respeitados todos os níveis de comportamento, acesso a veículos de informação, lazer, transporte, sistema de saúde, educação e condição de sobrevivência. A metodologia foi desenvolvida para inclusão de uma amostra com igual número de homens e mulheres.

Em seguida foram sorteadas probabilisticamente 25 ruas da cidade de Lauro de Freitas pertencentes aos quatro níveis sociais (Classe A, B, C, D) informados pela Secretaria de Ação Social da Prefeitura. A divisão das ruas foi proporcional ao nível socioeconômico e obedeceu ao seguinte quantitativo: seis ruas em cada um dos conglomerados A, B e C e sete ruas na classe D. Em cada rua, 13 domicílios foram sorteados por amostra sistemática. O intervalo entre as casas variou de acordo com a quantidade de domicílios encontrado em cada rua. A cada residência visitada foram sorteados e entrevistados dois indivíduos adultos (sendo um do sexo masculino e outro do sexo feminino). Foram excluídas pessoas que se recusaram a responder o questionário e pessoas acamadas por problemas de saúde, pois estavam totalmente inativas não por voluntariedade, e sim por condição de vida. Também foram excluídas as residências desabitadas. Ao final da coleta de dados, a amostra ficou constituída de 522 pessoas, 220 do sexo masculino e 302 do sexo feminino. 


\section{COLETA DE DADOS}

Cinco avaliadores foram devidamente preparados e treinados para todas as etapas do trabalho. $\mathrm{O}$ índice de confiabilidade interavaliadores foi testado através do índice Kappa (PEREIRA, 1995), para aplicação do IPAQ e o erro técnico de medidas (ETM)(NORTON; OLDS, 2000), para a medida da estatura. Os valores encontrados foram 0,61 e $1,2 \%$, respectivamente, ambos considerados bons índices de concordância.

Todos os participantes da pesquisa assinaram Termo de Participação Livre e Esclarecida e foram entrevistados em domicílio. Aplicou-se o questionário IPAQ (International Physical Activity Questionnaire) versão longa, constituído de questões acerca da freqüência e duração da realização de atividades físicas realizadas na última semana desenvolvidas no Trabalho, Deslocamento, Atividades Domésticas e no Lazer. A classificação do nível de atividades físicas foi: Inativo ou Ativo através da realização dos diferentes tipos de atividades: Vigorosas, Moderadas e Caminhada.

O nível de atividade física foi classificado de forma contínua através do cálculo do gasto energético. Multiplicou-se o valor do dispêndio de energia de acordo com a atividade realizada, considerando-se a frequência semanal e a duração das mesmas (tempo médio em minutos/semana).

Os valores em METs (Equivalente Metabólico) de cada atividade realizada proposta pelo Heymsfieldet al (2005), para computar os dados do IPAQ são:

\section{Domínios}

- TRABALHO - caminhada $=3,3$ METs; atividades moderadas $=4,0$ METs; atividades vigorosas $=8,0$ METs;

- TRANSPORTE - caminhada $=3,3$ METs, Bicicleta = 6,0 METs;

- ATIVIDADES DOMÉSTICAS $=\operatorname{moderada}($ jardim ou quintal $)=4,0$ METs, moderada (dentro de casa) $=3,0$ METs, vigorosa (jardim ou quintal $)=5,5$ METs;

- TEMPO LIVRE - caminhada $=3,3$ METs, moderada $=4,0$ METs, vigorosa $=$ 8,0 METs. 
Para cada domínio multiplicou-se o valor do MET da atividade realizada pela frequência semanal e duração da mesma; depois somou-se o valor do gasto energético de cada domínio, encontrando então o gasto calórico total em MET minuto/semana. Para transformar em Kcal, multiplicou-se esse valor pelo peso do entrevistado e dividiu-se por 60 minutos (HEYMSFIELD, 2005), encontrando o valor calórico gasto na atividade em Kcal durante uma semana.

A partir desse cálculo, os indivíduos foram classificados em ativos ou inativos:

- Nível de Atividade Física( PAFFENBARGER; HYDE; WING, 1986):

$$
\begin{aligned}
& \cdot \geq 2000 \mathrm{Kcal} / \text { semana - ATIVO } \\
& \text { - }<2000 \mathrm{Kcal} \text { / semana - INATIVO }
\end{aligned}
$$

- Nível de Atividade Física no domínio Tempo livre (U.S. DEPARTAMENT OF HEALTH AND HUMAN SERVICES, 1996):

$\cdot \geq 1000 \mathrm{Kcal} / \mathrm{semana}$ - ATIVO

- $<1000 \mathrm{Kcal} /$ semana - INATIVO

No segundo momento, coletou-se, através de Questionário de Identificação, dados demográficos, assim como fatores relacionados à saúde do entrevistado. Para obtenção dos dados antropométricos utilizou-se os instrumentos:

- Fita métrica antropométrica marca Sanny (Brasil) de 2 m usada para se medir estatura. Com os indivíduos descalços, em posição ereta, com pés e calcanhares unidos e encostados na parede, braços estendidos ao longo do corpo, respiração normal seguindo o Plano de Frankfurt (linha imaginária que passa pelo ponto mais baixo do bordo inferior da órbita direita e pelo ponto mais alto do bordo superior do meato auditivo externo correspondente; esta linha deve estar paralela ao solo); a fita antropométrica foi posicionada verticalmente ao longo do corpo, e, com uma régua em posição paralela à fita na altura do vértex, mediu-se a distância até a região plantar. (PITANGA, 2004) 
- O peso foi mensurado através de balanças padrão, marca Plenna, todas aferidas pelo INMETRO, previamente ao estudo cada uma com certificado próprio (duas pesagens) com margem de erro de $\pm 100 \mathrm{gr}$. Ao entrevistado era solicitado que subisse na balança com os pés descalços, com o mínimo de roupa possível. (PITANGA, 2004)

\section{Procedimentos de Análise}

Inicialmente foi realizada a análise descritiva (média, desvio padrão e valores percentuais) da amostra. Na sequência, calculou-se a inatividade física total e no tempo livre da população estudada e nos diversos estratos de cada uma das variáveis analisadas (sexo, idade, estado civil, grau de escolaridade, classe social). Depois, calculou-se a inatividade física total e no tempo livre nos diversos estratos das variáveis analisadas, controlando por sexo. Para analisar diferenças entre as variávies contínuas (peso e estatura) foi utilizado o t-test de Student, já o teste Qui-quadrado, serviu para identificar as diferenças entre os estratos das variáveis categoriais (idade, estado civil, grau de escolaridade e classe social).

Posteriormente, calculou-se a razão de prevalência entre inatividade física total eno tempo livre e idade, grau de escolaridade, estado civil, classe social. Para esta análise, foram criadas variáveis dummiesna comparação entre o grupo de referência $=0$ e os outros estratos de cada variável estudada. As diferenças foram observadas através do teste de Mantel-Hanzel. Utilizou-se o intervalo de confiança a 95\%. Nessa fase da análise levou-se em consideração o efeito de delineamento amostral (conglomerados), sendo que a ponderação foi feita considerando a unidade amostral domicílios. Os dados foram analisados no programa estatístico STATA 7.0.

O presente estudo foi submetido ao Comitê de Ética da Faculdade Adventista de Fisioterapia (FAFIS), localizada na cidade de Cachoeira-BA, sendo aprovado através do Parecer nº 0033/2007. 


\section{RESULTADOS}

As características da amostra são apresentadas na Tabela 1. Observa-se que existem diferenças entre o sexo masculino e feminino na média do peso e estatura.

TABELA 1. Média, desvio padrão e valores percentuais analisados no estudo, Lauro de Freitas-Ba, 2007

\begin{tabular}{|c|c|c|c|}
\hline Variáveis & Homens $(n=220)$ & Mulheres $(n=302)$ & pou $x^{2}$ \\
\hline Idade (anos) & $\begin{array}{l}40,2 \pm 15,3 \\
(18-85)\end{array}$ & $\begin{array}{l}40,4 \pm 14,7 \\
(20-86)\end{array}$ & 0,880 \\
\hline Peso (Kg) & $\begin{array}{l}75 \pm 14,07 \\
(41-126)\end{array}$ & $\begin{array}{l}68 \pm 14,40 \\
(43,3-129)\end{array}$ & 0,000 \\
\hline Estatura (m) & $\begin{array}{l}1,70 \pm 0,081 \\
(1,41-1,92)\end{array}$ & $\begin{array}{l}1,58 \pm 0,073 \\
(1,36-1,82)\end{array}$ & 0,000 \\
\hline \multicolumn{4}{|l|}{ Estado Civil (\%) } \\
\hline Casado & 51,8 & 47,3 & \\
\hline Solteiro & 37,7 & 36,4 & \\
\hline Divorciado & 1,8 & 3,3 & \\
\hline Outros & 8,6 & 12,9 & 0,578 \\
\hline \multicolumn{4}{|l|}{ Grau Escolaridade (\%) } \\
\hline Analfabeto - Fund. Completo & 44,5 & 45,7 & \\
\hline Médio Incomp. - Completo & 33,6 & 39,4 & \\
\hline $\begin{array}{l}\text { Nível Superior } \\
\text { (Incom. - Pós-graduação ) }\end{array}$ & 21,8 & 14,9 & 0,574 \\
\hline \multicolumn{4}{|l|}{ Classe Social (\%) } \\
\hline A & 6,3 & 5,6 & \\
\hline B & 22,7 & 18,8 & \\
\hline C & 66,8 & 68,5 & \\
\hline D & 4,0 & 6,9 & 0,720 \\
\hline
\end{tabular}

Valores contínuos foram comparados através do teste " $t$ " de student para amostras independentes, e valores percentuais, através do teste qui-quadrado; $x 2$ = teste do qui-quadrado.

As prevalências da inatividade física total e em cada um dos estratos das diversas variáveis analisadas encontram-se na Tabela 2.

Entre as variáveis analisadas, o maior nível de inatividade física está presente nas mulheres, em indivíduos com idade $\geq 60$ anos, com maior nível de escolaridade e classe social A. Quanto ao estado civil, os casados 
apresentam maior nível de inatividade física se comparado aos outros estratos, observando-se diferenças estatisticamente significativas.

TABELA 2. Prevalência da inatividade física por fatores associados, Lauro de Freitas-Ba, 2007

\begin{tabular}{|c|c|c|c|c|c|c|c|}
\hline \multirow[t]{2}{*}{ Variáveis } & \multicolumn{3}{|c|}{ Inativos } & \multicolumn{3}{|c|}{ Ativos } & \multirow[b]{2}{*}{$\mathrm{X}^{2}$} \\
\hline & $\mathrm{n}$ & $\mathrm{p}$ & IC95\% & $\mathrm{n}$ & $\mathrm{p}$ & IC95\% & \\
\hline \multicolumn{8}{|l|}{ Sexo } \\
\hline Homens & 86 & 39,0 & $(34,8-43,1)$ & 134 & 60,9 & $(56,7-65,0)$ & \\
\hline Mulheres & 121 & 40,0 & $(35,8-44,2)$ & 181 & 59,9 & $(55,7-64,1)$ & 0,88 \\
\hline \multicolumn{8}{|l|}{ Idade (anos) } \\
\hline $18-39$ & 108 & 40,3 & $(36,1-44,5)$ & 160 & 59,7 & $(55,5-63,9)$ & \\
\hline $40-59$ & 71 & 37,3 & $(33,3-41,4)$ & 119 & 62,6 & $(58,5-66,7)$ & \\
\hline$\geq 60$ & 28 & 43,7 & $(39,5-47,9)$ & 36 & 56,2 & $(52,0-60,4)$ & 0,63 \\
\hline \multicolumn{8}{|l|}{ Estado civil } \\
\hline Casado & 104 & 40,4 & $(36,244,6)$ & 153 & 59,5 & $(55,3-63,7)$ & \\
\hline Solteiro & 77 & 39,9 & $(35,7-44,1)$ & 116 & 60,1 & $(55,9-64,3)$ & \\
\hline Divorciado & 3 & 21,4 & $(17,9-24,9)$ & 11 & 78,5 & $(75,0-82,0)$ & \\
\hline Outros & 23 & 39,6 & $(35,4-43,8)$ & 35 & 60,3 & $(56,1-64,5)$ & 0,01 \\
\hline \multicolumn{8}{|l|}{ Grau Escolaridade (\%) } \\
\hline $\begin{array}{l}\text { Analfabeto - } \\
\text { Fund. Completo }\end{array}$ & 95 & 40,2 & $(36,0-44,4)$ & 141 & 59,7 & $(55,5-63,9)$ & \\
\hline $\begin{array}{l}\text { Médio Incomp. - } \\
\text { Completo }\end{array}$ & 69 & 35,7 & $(31,6-39,8)$ & 124 & 64,2 & $(60,1-68,3)$ & \\
\hline $\begin{array}{l}\text { Nível Superior } \\
\text { (Incom. - Pós-graduação) }\end{array}$ & 43 & 46,2 & $(42,0-50,4)$ & 50 & 53,7 & $(49,5-57,9)$ & 0,49 \\
\hline \multicolumn{8}{|l|}{ Classe social } \\
\hline A & 14 & 45,1 & $(40,0-49,3)$ & 17 & 54,8 & $(50,6-59,0)$ & \\
\hline B & 41 & 38,3 & $(34,2-42,4)$ & 66 & 61,6 & $(57,5-65,7)$ & \\
\hline C & 140 & 39,5 & $(35,4-42,2)$ & 214 & 60,4 & $(56,2-64,6)$ & \\
\hline D & 12 & 40,0 & $(35,8-44,2)$ & 18 & 60,0 & $(55,8-64,2)$ & 0,78 \\
\hline TOTAL & 207 & 39,6 & $(35,4-43,8)$ & 315 & 60,3 & $(56,1-64,5)$ & \\
\hline
\end{tabular}

$\mathrm{x}^{2}$ = teste do qui-quadrado. IC95\%-Intervalo de Confiança

As prevalências da inatividade física em cada um dos estratos das diversas variáveis analisadas estratificadas por sexo estão apresentadas na Tabela 3. 
TABELA 3. Prevalência da inatividade física por fatores associados estratificados por sexo, Lauro de Freitas=Ba, 2007

\begin{tabular}{|c|c|c|c|c|c|c|c|}
\hline \multirow[t]{2}{*}{ Variáveis } & \multicolumn{3}{|c|}{ Masculino } & \multicolumn{3}{|c|}{ Feminino } & \multirow[b]{2}{*}{$X^{2}$} \\
\hline & $\mathrm{N}$ & $\mathrm{p}$ & IC95\% & $\mathrm{n}$ & $\mathrm{p}$ & IC95\% & \\
\hline \multicolumn{8}{|l|}{ Idade (anos) } \\
\hline $18-39$ & 43 & 37,0 & $(32,9-41,1)$ & 65 & 42,7 & $(38,5-46,9)$ & \\
\hline $40-59$ & 32 & 42,6 & $(38,4-46,8)$ & 39 & 33,9 & $(29,9-37,9)$ & \\
\hline$\geq 60$ & 11 & 37,9 & $(33,8-42,0)$ & 17 & 48,5 & $(44,3-52,7)$ & 0,32 \\
\hline \multicolumn{8}{|l|}{ Estado Civil } \\
\hline Casado & 45 & 39,4 & $(35,2-43,6)$ & 59 & 41,2 & $(37,0-45,4)$ & \\
\hline Solteiro & 31 & 37,3 & $(33,2-41,6)$ & 46 & 41,8 & $(37,6-46,0)$ & \\
\hline Divorciado & 2 & 50,0 & $(45,7-54,3)$ & 1 & 10,0 & $(7,50-12,5)$ & \\
\hline Outros & 8 & 42,1 & $(37,9-46,3)$ & 15 & 38,4 & $(34,3-42,5)$ & 0,00 \\
\hline \multicolumn{8}{|l|}{ Grau Escolaridade (\%) } \\
\hline Analf. - Fund. Completo & 45 & 45,9 & $(41,7-50,1)$ & 50 & 36,2 & $(32,1-40,3)$ & \\
\hline Médio Incomp. - Completo & 24 & 32,4 & $(28,4-36,4)$ & 45 & 37,8 & $(33,7-41,9)$ & \\
\hline $\begin{array}{l}\text { Nível Superior (Incom. - } \\
\text { Pós-graduação) }\end{array}$ & 17 & 35,4 & $(31,3-39,5)$ & 26 & 57,7 & $(53,5-61,9)$ & 0,06 \\
\hline \multicolumn{8}{|l|}{ Classe Social } \\
\hline A & 5 & 35,7 & $(31,6-39,8)$ & 9 & 52,9 & $(48,7-75,1)$ & \\
\hline B & 13 & 26,0 & $(22,3-29,7)$ & 28 & 49,1 & $(44,8-53,4)$ & \\
\hline C & 65 & 44,2 & $(40,0-48,4)$ & 75 & 36,2 & $(32,1-40,3)$ & \\
\hline D & 3 & 33,3 & $(29,3-37,3)$ & 9 & 42,8 & $(38,6-47,0)$ & 0,06 \\
\hline TOTAL & 86 & 39,09 & $(34,8-43,2)$ & 121 & 40,07 & $(35,8-44,2)$ & \\
\hline
\end{tabular}

$x^{2}=$ teste qui-quadrado. IC95\%-Intervalo de Confiança

A prevalência da inatividade física nas mulheres foi mais alta do que nos homens. Com relação à variável idade, os homens entre 40-59 anos são os mais inativos. Já as mulheres mais inativas têm idade $\geq 60$ anos.

Quanto ao nível de escolaridade, observa-se uma relação inversa entre os homens e mulheres. Os homens mais inativos são aqueles que têm um menor nível de escolaridade, enquanto que as mulheres mais inativas apresentam um nível de escolaridade mais alto. No que se refere à classe social, os homens mais inativos estão na classe A e C, as mulheres estão na classe A. 
Nas variáveis, idade, grau de escolaridade e classe social não houve diferença estatisticamente significativa entre os seus estratos, porém, quanto ao estado civil dessa população, observa-se que os homens divorciados são os mais inativos, enquanto que as mulheres casadas e solteiras apresentam um maior nível de inatividade física, apresentando diferenças estatisticamente significativas entre seus estratos.

As razões de prevalência da inatividade física para idade, sexo, grau de escolaridade, estado civil e classe social estratificados por sexo estão na Tabela 4.

TABELA 4. Razão de prevalência entre inatividade física, idade, sexo, grau de escolaridade, estado civil e classe social, Lauro de Freitas-BA, 2007

\begin{tabular}{l|l|l|l|l}
\hline Variáveis & Ambos os sexos & \multicolumn{1}{|c|}{ Masculino } & \multicolumn{1}{c|}{ Feminino } & \\
\hline Idade( anos) & RP (IC95\%) & RP(IC95\%) & RP (IC95\%) & p valor \\
\hline $18-39$ & 1,00 & & & \\
\hline $40-59$ & $0,82(0,70-0,97)$ & $1,30(1,00-1,70)$ & $0,61(0,50-0,75)$ & 0,00 \\
\hline$\geq 60$ & $0,74(0,58-0,93)$ & $0,86(0,58-1,28)$ & $0,67(0,51-0,89)$ & 0,31 \\
\hline Estado Civil (\%) & & & & \\
\hline Casado & 1,00 & 1,00 & 1,00 & \\
\hline Solteiro & $1,17(1,01-1,35)$ & $1,06(0,83-1,37)$ & $1,21(1,01-1,44)$ & 0,41 \\
\hline Divorciado & $0,52(0,30-0,89)$ & $1,26(0,74-2,15)$ & $0,14(0,03-0,54)$ & 0,00 \\
\hline Outros & $1,01(0,81-1,25)$ & $1,16(0,79-1,69)$ & $0,93(0,71-1,21)$ & 0,34 \\
\hline Grau Escolaridade (\%) & & & & \\
\hline Nível Superior (Inc. - Pós) & 1,00 & 1,00 & 1,00 & \\
\hline Médio Incomp. - Completo & $0,77(0,65-0,91)$ & $0,85(0,64-1,13)$ & $0,69(0,55-0,85)$ & 0,24 \\
\hline Analf. - Fund. Completo & $0,80(0,68-0,95)$ & $0,96(0,73-1,27)$ & $0,68(0,56-0,83)$ & 0,04 \\
\hline Classe Social (\%) & & & & \\
\hline A & 1,00 & 1,00 & 1,00 & \\
\hline B & $0,89(0,76-1,04)$ & $1,55(1,19-2,02)$ & $0,62(0,51-0,75)$ & 0,52 \\
\hline C & $1,05(0,86-1,28)$ & $1,27(0,84-1,91)$ & $0,89(0,71-1,12)$ & 0,02 \\
\hline D & $0,88(0,64-1,22)$ & $0,93(0,50-1,71)$ & $0,80(0,56-1,16)$ & 0,69 \\
\hline
\end{tabular}

IC95\%-Intervalo de Confiança. RP-Razão de Prevalência 
Os resultados demonstram que, entre as mulheres na idade acima de 40 anos, o fato de serem divorciadas e com os menores níveis de escolaridade, da classe social B, apresentam fator de proteção à inatividade física. Os homens da classe social B têm maiores probabilidades de se tornar inativos.

Em análise geral, pode-se afirmar que os indivíduos solteiros têm maiores possibilidades de ser inativos, porém, os divorciados, com idade maior que 40 anos e menores níveis de escolaridade, apresentam valores da RP que oferecem efeito protetor contra a inatividade física.

A prevalência da inatividade física no tempo livre por fatores sociodemográficos associados na população total do estudo encontra-se na Tabela 5. Entre as variáveis analisadas, a maior prevalência da inatividade física encontra-se nas mulheres, em indivíduos com idade $<60$ anos, com menor nível de escolaridade, solteiros e pertencentes à classe social D, observando diferenças estatisticamente significativas nas variáveis idade, grau escolaridade e classe social.

A prevalência da inatividade física no tempo livre por fatores sociodemográficos associados estratificados por sexo está apresentada na Tabela 6. Em relação à idade e grau de escolaridade, os homens mais inativos no tempo livre encontram-se na faixa etária 40-59 anos e as mulheres com idade até 39 anos. Em ambos os sexos, os indivíduos com menor grau de escolaridade são os mais inativos sem diferença estatisticamente significativa entre os diversos estratos dessas variáveis. Quanto ao estado civil, a inatividade no tempo livre predominou entre os homens divorciados e nas mulheres solteiras. Na classe social D, observa-se maior nível de inatividade em indivíduos de ambos os sexos. 
TABELA 5. Prevalência da inatividade física no tempo livre por fatores sociodemográficos associados, Lauro de Freitas-BA, 2007

\begin{tabular}{|c|c|c|c|c|c|c|c|}
\hline \multirow[t]{2}{*}{ Variáveis } & \multicolumn{3}{|c|}{ Inativos } & \multicolumn{3}{|c|}{ Ativos } & \multirow[b]{2}{*}{$X^{2}$} \\
\hline & $\mathrm{N}$ & $\%$ & IC95\% & $\mathrm{n}$ & $\%$ & IC95\% & \\
\hline \multicolumn{8}{|l|}{ Sexo } \\
\hline Homens & 168 & 76,3 & $(72,7-79,9)$ & 52 & 23,6 & $(20,0-27,2)$ & \\
\hline Mulheres & 263 & 87,0 & $(84,0-89,9)$ & 39 & 12,9 & $(10,0-15,8)$ & 0,06 \\
\hline \multicolumn{8}{|l|}{ Idade (anos) } \\
\hline 18-39 & 223 & 83,2 & $(80,0-86,4)$ & 45 & 16,7 & $(15,5-19,9)$ & \\
\hline $40-59$ & 158 & 83,1 & $(79,9-86,3)$ & 32 & 16,8 & $(13,6-20,0)$ & \\
\hline$\geq 60$ & 50 & 78,1 & $(74,6-81,0)$ & 14 & 21,8 & $(18,3-25,3)$ & 0,02 \\
\hline \multicolumn{8}{|l|}{ Estado civil } \\
\hline Casado & 207 & 80,5 & $(77,1-83,9)$ & 50 & 19,4 & $(16,0-22,8)$ & \\
\hline Solteiro & 164 & 84,9 & $(81,9-87,9)$ & 29 & 15,0 & $(12,0-18,0)$ & \\
\hline Divorciado & 11 & 78,5 & $(75,0-82,0)$ & 3 & 21,4 & $(17,9-24,9)$ & \\
\hline Outros & 49 & 84,4 & $(81,3-87,5)$ & 9 & 15,5 & $(12,4-18,6)$ & 0,58 \\
\hline \multicolumn{8}{|l|}{ Grau Escolaridade (\%) } \\
\hline $\begin{array}{l}\text { Analf. - Fund. } \\
\text { Completo }\end{array}$ & 210 & 88,9 & $(86,2-91,5)$ & 26 & 11,0 & $(10,6-18,8)$ & \\
\hline $\begin{array}{l}\text { Médio Incomp. - } \\
\text { Completo }\end{array}$ & 162 & 83,9 & $(80,8-87,0)$ & 31 & 16,0 & $(13,5-19,7)$ & \\
\hline $\begin{array}{l}\text { Nível Superior (Incom. } \\
\text { - Pós-graduação) }\end{array}$ & 59 & 63,4 & $(59,3-67,5)$ & 34 & 36,0 & $(31,9-40,1)$ & 0,00 \\
\hline \multicolumn{8}{|l|}{ Classe social } \\
\hline A & 17 & 54,8 & $(50,6-59,0)$ & 14 & 45,1 & $(40,9-49,3)$ & \\
\hline B & 72 & 67,2 & $(62,5-71,9)$ & 35 & 32,7 & $(28,7-36,7)$ & \\
\hline C & 314 & 88,7 & $(86,0-91,4)$ & 40 & 11,3 & $(8,60-14,0)$ & \\
\hline D & 28 & 93,3 & $(91,2-95,4)$ & 2 & 6,6 & $(4,50-8,70)$ & 0.00 \\
\hline TOTAL & 431 & 82,57 & $(79,2-85,7)$ & 91 & 17,43 & $(14,3-20,7)$ & \\
\hline
\end{tabular}

$x^{2}=$ teste qui-quadrado. IC95\%-Intervalo de Confiança 
TABELA 6. Prevalência da inatividade física no tempo livre por fatores sócio-demográficos associados estratificados por sexo, Lauro de Freitas-Ba, 2007

\begin{tabular}{|c|c|c|c|c|c|c|c|}
\hline \multirow[t]{2}{*}{ Variáveis } & \multicolumn{3}{|c|}{ Masculino } & \multicolumn{3}{|c|}{ Feminino } & \multirow[b]{2}{*}{$x^{2}$} \\
\hline & $\mathrm{N}$ & $\%$ & IC95\% & $\mathrm{n}$ & $\%$ & IC95\% & \\
\hline \multicolumn{8}{|l|}{ Idade (anos) } \\
\hline $18-39$ & 87 & 75 & $(71,3-78,7)$ & 136 & 89,4 & $(86,8-92,0)$ & \\
\hline $40-59$ & 60 & 80 & $(76,6-83,4)$ & 98 & 85,2 & $(82,2-88,2)$ & \\
\hline$\geq 60$ & 21 & 72,4 & $(68,6-76,2)$ & 29 & 82,8 & $(79,6-86,0)$ & 0,88 \\
\hline \multicolumn{8}{|l|}{ Estado Civil } \\
\hline Casado & 85 & 74,5 & $(70,8-88,7)$ & 122 & 85,3 & $(82,3-88,3)$ & \\
\hline Solteiro & 63 & 75,9 & $(76,6-79,5)$ & 101 & 91,8 & $(89,5-94,3)$ & \\
\hline Divorciado & 4 & 100,0 & $(0,00-0,00)$ & 7 & 70,0 & $(66,1-73,9)$ & \\
\hline Outros & 16 & 84,2 & $(81,1-87,3)$ & 33 & 84,6 & $(81,5-87,7)$ & 0,05 \\
\hline \multicolumn{8}{|l|}{ Grau Escolaridade (\%) } \\
\hline Analf. - Fund. Completo & 84 & 85,7 & $(82,7-88,7)$ & 126 & 91,3 & $(88,9-93,7)$ & \\
\hline Médio Incomp. - Completo & 59 & 79,7 & $(76,4-83,1)$ & 103 & 86,5 & $(83,6-89,4)$ & \\
\hline $\begin{array}{l}\text { Nível Superior (Incom. - } \\
\text { Pós-graduação) }\end{array}$ & 25 & 52,0 & $(47,8-56,2)$ & 34 & 75,5 & $(71,8-79,2)$ & 0,38 \\
\hline \multicolumn{8}{|l|}{ Classe Social } \\
\hline A & 5 & 35,7 & $(31,6-19,8)$ & 12 & 70,5 & $(66,6-74,4)$ & \\
\hline B & 28 & 56,0 & $(51,8-60,2)$ & 44 & 77,1 & $(73,5-80,7)$ & \\
\hline C & 127 & 86,3 & $(83,3-89,3)$ & 187 & 90,3 & $(87,8-92,8)$ & \\
\hline D & 8 & 88,8 & $(86,1-91,5)$ & 20 & 95,2 & $(93,4-97,0)$ & 0,04 \\
\hline TOTAL & 168 & 76,3 & $(72,6-79,9)$ & 26 & 387,0 & $(84,1-89,8)$ & \\
\hline
\end{tabular}

$\mathrm{x}^{2}$ = teste qui-quadrado. IC95\%-Intervalo de Confiança

Na Tabela 7 encontram-se valores referentes à Razão de Prevalência entre inatividade física no tempo livre, idade, sexo, grau de escolaridade, estado civil e classe social.

Os homens apresentam maiores chances de serem inativos na faixa etária 40-59 anos, se forem divorciados, com menor grau de escolaridade e pertencerem às menores classes sociais.

Enquanto que as mulheres, se forem solteiras, com menor grau de escolaridade e pertencerem às classes sociais mais baixas, têm mais chances de se tornarem inativas fisicamente no tempo livre. Aquelas que são divorciadas apresentam fator de proteção à inatividade física. 
TABELA 7. Razão de prevalência entre inatividade física no tempo livre, idade, sexo, grau de escolaridade, estado civil e classe social, Lauro de Freitas-Ba, 2007

\begin{tabular}{|c|c|c|c|c|}
\hline Variáveis & Ambos os sexos & Masculino & Feminino & \\
\hline & RP (IC95\%) & RP(IC95\%) & RP (IC95\%) & $\mathrm{p}$ valor \\
\hline \multicolumn{5}{|l|}{ Idade(anos) } \\
\hline $18-39$ & 1.00 & 1.00 & 1.00 & \\
\hline $40-59$ & $1.05(0.991 .13)$ & $1.17(1.03-1.34)$ & $0.96(0.90-1.03)$ & 0,00 \\
\hline$\geq 60$ & $0.96(0.871 .06)$ & $1.07(0.90-1.28)$ & $0.90(0.80-1.00)$ & 0,08 \\
\hline \multicolumn{5}{|l|}{ Estado Civil (\%) } \\
\hline Casado & 1.00 & 1.00 & 1.00 & \\
\hline Solteiro & 1.11(1.051.18) & $1.05(0.92-1.18)$ & $1.13(1.06-1.20)$ & 0,25 \\
\hline Divorciado & $0.95(0.801 .13)$ & $1.51(1.39-1.64)$ & $0.65(0.48-0.89)$ & 0,00 \\
\hline Outros & $1.10(1.011 .19)$ & 1.24(1.07-1.44) & $1.01(0.91-1.11)$ & 0,02 \\
\hline \multicolumn{5}{|l|}{ Grau Escolaridade(\%) } \\
\hline Nível Superior (Incom. - Pós) & 1.00 & 1.00 & 1.00 & \\
\hline Médio Incomp. - Completo & $1.23(1.12-1.36)$ & $1.40(1.19-1.65)$ & $1.09(0.97-1.22)$ & 0,00 \\
\hline Analfab. - Fund. Completo & $1.39(1.27-1.52)$ & $1.49(1.27-1.75)$ & $1.25(1.13-1.38)$ & 0,05 \\
\hline \multicolumn{5}{|l|}{ Classe Social (\%) } \\
\hline A & 1.00 & 1.00 & 1.00 & \\
\hline B & $1.21(1.13-1.30)$ & $1.38(1.21-1.56)$ & 1.10(1.01-1.19) & 0,11 \\
\hline C & $1.37(1.27-1.47)$ & $1.53(1.32-1.76)$ & 1.24(1.15-1.34) & 0,01 \\
\hline D & $1.70(1.35-2.13)$ & $2.48(1.50-4.12)$ & $1.34(1.08-1.68)$ & 0,01 \\
\hline
\end{tabular}

IC95\%-Intervalo de Confiança. RP-Razão de Prevalência

\section{DISCUSSÃO}

Em estudos internacionais, como no Canadá, 62\% da população não é suficientemente ativa. (KATZMARZYK; GLEDHILL; SHEPHARD, 2000) No Chile, a prevalência é de $89,8 \%$ (VIO, 2005) No Brasil, a alta prevalência também foi encontrada no estado do Rio Grande do Sul com 71,3\% (GUS; FISCHMANN; MEDINA, 2002), município de Joaçaba (SC) com 57,4\% (BARRETA; BARRETA; PERES, 2007) e João Pessoa (PB), 54,5\%. (MATSUDO et al., 2002) Valores próximos ao da presente pesquisa $(39,6 \%)$ podem ser observados em Florianópolis (SC) (44\%) e Rio de Janeiro (43,7) (MINISTÉRIO DA SAÚDE, 2004), além de São Paulo 46,5\% (MATSUDO et al., 2002) e Pelotas (RS), 41,1\%. 
(HALLAL et al., 2003) Valores mais baixos foram encontrados em Bélem (PA) $(28,2 \%)$, Porto Alegre (RS) (30,4\%), Natal (RN) (31,3\%). (MATSUDO et al., 2002)

Quando o presente estudo analisou a inatividade física no tempo livre, observou também alta prevalência (82,5\%; 79,2-85,7). Vuori (2001) revela a inatividade física no tempo livre em $57 \%$ da população européia. Dos 16 países europeus estudados, apenas Portugal, com 83\%, apresenta um valor maior no nível de inatividade no tempo livre se comparando com o encontrado no presente estudo. Os outros países apresentaram valores menores como 32\% na Suécia, 33\% na Finlândia, 56\% na Alemanha, 63\% na França e 67\% na Bélgica. Nos EUA, 68\% (MARTIN et al., 2000), Austrália 68,8\% (BURTON; TURRELL, 2000), e em Lodz (Pôlonia), 61,1\% (KALETA et al.. 2007). No Sudeste e Nordeste do Brasil, a prevalência é de $87 \%$ (MONTEIRO et al, 2003), enquanto que valores menores foram encontrados nos estudos de Pitanga e Lessa (2005), Dias-da-Costa e colaboradores (2005) e Barros e Nahas (2001).

Quanto à inatividade física total, os homens apresentaram menores percentuais se comparado com as mulheres, corroborando com os resultados dos estudos de Matsudo e colaboradores (2002), Hallal e colaboradores (2003), Barreta E., Barreta M. e Peres (2007), e Duncan e colaboradores (1993).

As mulheres se apresentam mais insuficientemente ativas do que os homens em 16 cidades pertencentes a cada estado brasileiro, com exceção de Belém (PA). No entanto, em sete das 16 cidades estudadas, Belém (PA), Natal (RN), João Pessoa (PB), Recife (PE), Aracaju (SE), Belo Horizonte (BH) e Vitória (ES) essa diferença não foi estatisticamente significativa, corroborando com os achados desse estudo. (MINISTÉRIO DA SAÚDE, 2004)

No tempo livre, as mulheres $(87 \% ; 84,0-89,9)$ também apresentaram maior prevalência de inatividade física do que os homens $(76,3 \%$; 72,779,9), corroborando com os estudos de Pitanga e Lessa (2003), Gomes, Siqueira e Sichieri (2000) e Salles-Costa e colaboradores (2003a). Uma possível justificativa para quadro de maior prevalência de inatividade no tempo livre entre as mulheres, consiste nas suas múltiplas jornadas de trabalho, que contribuem para limitação do tempo destinado ao tempo livre. (AQUINO,1996) 
Por outro lado, esse nível de inatividade física mais elevado entre as mulheres apresenta contradição. A inserção da prática de exercício físico no universo feminino está associada à manutenção de saúde e valorização dos cuidados com a imagem corporal. (LINS,1999; MESSNER, 1995)

Com relação à idade, a maior prevalência foi encontrada nos indivíduos com idade $\geq 60$ anos, observando também uma relação positiva (BARRETA, BARRETA; PERES, 2007) com a inatividade física. No tempo livre, os indivíduos mais inativos são aqueles com idade $<60$ anos. Essa associação também foi encontrada nos estudos de Salles-Costa e colaboradores (2003b), porém, os estudos de Pitanga e Lessa (2005), Gal, Santos e Barros (2005) e Martinez-Gonzalez e colaboradoresl (2001) demonstram uma relação positiva entre a inatividade física no tempo livre e idade.

Na estratificação por sexo, observa-se que os homens encontram-se mais inativos na faixa etária 40-59 anos, e as mulheres com idade $\geq 60$, corroborando com os estudos de Hallal e colaboradores (2003), Elizondo-Armendáriz, Grima e Ontoso (2005), Gal, Santos e Barros (2005) e Ministério da Saúde (2007), demonstram essa relação positiva entre idade e inatividade física independente do sexo.

Quando estratificado por sexo no tempo livre, os homens encontram-se mais inativos também na faixa etária de $40-59$ anos $(80 \%$; 76,6-83,4) e as mulheres com idade até 39 anos de idade $(89,4 \%$ : 86,8-92,0). A relação positiva entre inatividade física e idade continuaindependente do sexo (LINS,1999), mas o estudo de Pitanga e Lessa (2005) observa essa relação somente nos indivíduos do sexo masculino; nas mulheres os maiores níveis de atividade física encontram-se em idade a partir de 60 anos.

Os resultados sobre a variável idade estratificada por sexo devem sofrer várias influências socioeconômicas e culturais. Na cidade pesquisada, observa-se grande quantidade de casas e centros de assistência às pessoas de meia e terceira idade, onde são desenvolvidas diversas atividades educativas e recreacionais diariamente. A participação da população nessas atividades físicas pode ter contribuído na diminuição do nível de inatividade física encontrado nessa faixa etária, contradizendo os dados de alguns estudos. 
Quanto ao estado civil, a inatividade física foi maior nos indivíduos casados. Em relação ao sexo, são os homens divorciados e as mulheres solteiras os mais inativos. Na literatura, observam-se resultados díspares entre nível de atividade física e estado civil. No estudo de Mensink, Loose e Oomen (1997), verifica-se que mulheres e homens solteiros são mais ativos por terem maior renda e tempo disponível para a prática de atividade física.

No caso das mulheres solteiras, Aquino (1996) identificou ainda que estas têm menos responsabilidade domésticas do que aquelas casadas ou com filhos. Por outro lado, alguns autores analisaram que, quando comparadas com mulheres solteiras, as mulheres casadas (ou vivendo em união) e com filhos têm maior percepção sobre a importância da prática de exercícios para a saúde. (BRANIGAN; O’BRIEN, 1995)

A prevalência da inatividade física no tempo livre foi maior entre os solteiros $(84,9 \% ; 81,9-87,9)$. Alguns estudos encontraram maior inatividade nos indivíduos divorciados (DUNCAN et al., 1993), nos indivíduos separados, viúvos e outros (PITANGA; LESSA, 2005), nos indivíduos que vivem com companheiro. (DIAS-DA-COSTA et al., 2005)

Na estratificação por sexo, os homens divorciados (100\%) e mulheres solteiras (91,8\%: 89,5-94,3) demonstraram maior prevalência, porém, nos estudos de Pitanga e Lessa (2005), Barros e Nahas (2001), Gal, Santos e Barros (2005) encontraram essa predominância em homens e mulheres casadas.

Os indivíduos com maior grau de escolaridade têm maior nível de inatividade física, corroborando com estudo de Barreta E., Barreta M. e Peres (2007). O grupo de entrevistados com menor escolaridade apresentou percentuais menores de insuficientemente ativo em quase todas as capitais, embora estas diferenças não tenham sido estatisticamente significativas, com exceção do Distrito Federal. Vale ressaltar que o Rio de Janeiro e Porto Alegre (RS) foram as duas únicas cidades onde se observou maior percentual de insuficientemente ativos entre indivíduos de menor escolaridade, 51,1\% e 39,4\%, respectivamente. (MINISTÉRIO DA SAÚDE, 2004)

Em relação ao sexo, a maior prevalência da inatividade física encontra-se nas mulheres de maior grau de escolaridade, porém, no sexo masculino os mais inativos estão no grau de escolaridade mais baixo. Resultados 
diferentes foram encontrados na cidade do Porto (GAL; SANTOS; BARROS, 2005) onde os maiores valores de inatividade física encontram-se nos homens com maior grau de escolaridade, enquanto que nas mulheres os valores praticamente foram iguais entre aquelas que tinham menor que 5 anos e maior que 11 anos de escolaridade.

No tempo livre, observou-se que os indivíduos com menor grau de escolaridade $(88,9 \% ; 86,2-91,5)$ têm maior nível de inatividade física independente do sexo, vários estudos (DIAS-DA-COSTA et al., 2005; GOMES; SIQUEIRA; SICHIERI, 2000; MARTINEZ-GONZALEZ et al, 2001; PITANGA; LESSA, 2005) têm demonstrado essa associação. Essa tendência se justifica pelo fato de que as pessoas com menor escolaridade têm menos oportunidade de desenvolver atividade física no tempo livre. (PITANGA; LESSA, 2005)

Mesmo diante desse quadro, observou-se que a classe A tem maior prevalência da inatividade física corroborando com o estudo de Hallalet al (2003). Ao estratificar por sexo, essa relação permanece, porém, no presente estudo, apesar de confirmar entre as mulheres, nos homens, os mais inativos encontram-se na classe $C$.

Na variável tempo livre, pode-se observar maior prevalência da inatividade física nos níveis sociais mais baixos (93,3\%; 91,2-95,4), corroborando com os achados de Dias-da-Costa et al (2005). Uma explicação para menor atividade física no tempo livre por pessoas com menor escolaridade seria sua inserção em atividades pesadas e não sedentárias no trabalho, consequentes da baixa qualificação, que é dependente da escolaridade. $\mathrm{O}$ inverso ocorre para pessoas com escolaridade mais elevada e atividade sedentária no trabalho. (PITANGA; LESSA, 2005)

\section{CONCLUSÃO}

Pesquisar o nível de atividade física de uma população é uma tarefa complexa que envolve uma série de discussões acerca da metodologia a ser aplicada, o que dificulta as comparações entre os estudos. Portanto, torna-se emergencial uma padronização de instrumentos e definições para o avanço científico da área. 
Na população estudada, observa-se que os indivíduos possuem condições insuficientes para ser classificada como ativo. Sendo que esses dados variam ainda de acordo com os aspectos sociodemográficos, como gênero, idade, estado civil, classe social e grau de escolaridade.

O alto nível de inatividade física no tempo livre também vem sendo evidenciado em diversos estudos populacionais pelo mundo. Além da diminuição da atividade física no ambiente de trabalho, o decréscimo do tempo e das atividades físicas no tempo livre acaba interferindo de forma negativa na saúde. Essas alterações comportamentais no cotidiano podem ser consideradas fatores de risco para desenvolvimento de Doenças Crônicas Não-Transmissíveis.

Os valores do nível de inatividade física total $(39,6 \%)$ e no tempo livre $(82,57 \%)$ da população estudada apresentam-se bastantes próximos dos estudos similares no Brasil. É preciso que as pessoas tenham clareza quanto ao conceito de inatividade física, assim como o que é preciso fazer para não se tornar inativo. As mudanças comportamentais são responsáveis por esse nível de atividade física diário; portanto, subir as escadas ao invés do elevador, ir caminhando ao supermercado, ir à padaria da esquina ao invés do automóvel são atitudes que caracterizam alterações no nível de atividade física.

Os resultados apresentados são importantes para a saúde pública, já que demonstram os níveis de inatividade física, assim como os fatores associados a essa situação, facilitando a implantação de programas de incentivo à prática de atividades físicas mais direcionadas aos subgrupos especificamente afetados pela inatividade física. Essa estratégia poderia possibilitar que, após intervenções, fossem feitas reavaliações para determinar o impacto real dessas políticas sobre o comportamento da população.

\section{REFERÊNCIAS}

AQUINO E. Gênero, Trabalho e hipertensão arterial: um estudo de trabalhadores de enfermagem em Salvador - Bahia. 1996. Tese (Doutorado em Saúde Coletiva) - Instituto de Saúde Coletiva, Universidade Federal da Bahia, 1996. 
BARRETA, M.; PERES K. Nível de atividade física e fatores associados em adultos no Barreta Município de Joaçaba, Santa Catarina, Brasil. Cad. Saúde Pública, v. 23, p. 1595-1602.

BARROS M., NAHAS M. Comportamentos de risco, auto-avaliação donível de saúde e percepção de estresse entretrabalhadores da indústria. Rev SaúdePública, v. 35, p. 554-63,2001.

BURTON N;. TURRELL G. Occupation, hours worked and leisure-time physical activity. Prev. Med., v. 31, p. 673-81, 2000.

CORDAIN L., et. al. Physical activity, energy expenditure and fitness: an evolutionary perspective. Int. J. Sports Med., v. 19, p.328-35, 1998.

DATASUS. Dados censitários dos municípios brasileiros. 2005.Lauro de Freitas: Ministério da Saúde. Disponível em: <http:// www.datasus.gov.br.> DIAS-DA-COSTA J. .et al. Epidemiology of leisure time physical activity: a population-based study in southern Brazil. Cad Saúde Pública, v. 21, p. 275-282, 2005.

DUNCAN B., et al. Fatores de risco para doenças não-transmissíveis em área metropolitanana região sul do Brasil. Prevalência e simultaneidade. Rev Saúde Pública, v. 27, p. 143-8, 1993.

ELIZONDO-ARMENDÁRIZ J.; GRIMA F.; ONTOSO I. Prevalência de actividade física y su relación con variables sociodemográficas y estilos de vida en la población de 18 a 65 años de Pamplona. Rev Esp. Salud Pública, v. 79, p. 559-567, 2005.

GAL D.; SANTOS A., BARROS H. Leisure time versus full-day energy expenditure: a cross-sectionalstudy of sedentarism in a portuguese urban population. BMC, Public Health, v. 5, n.16, 2005.

GOMES V.; SIQUEIRA K.; SICHIERI R. Atividade física em uma amostra probabilística da população do município do Rio de Janeiro. Cad. Saúde Pública, v. 17, p. 969-976, 2000.

GUS I.; FISCHMANN A.; MEDINA C. Prevalence of Risk Factors for Coronary Artery Disease in the Brazilian State of Rio Grande do Sul. Arq.Bras.Cardiol., v. 78, p. 484-90, 2002.

HALLAL P. et al. Physical inactivity: prevalence and associated variables in Brazilian adults. Med. Sci. Sports Exerc. v. 35, p. 1894-900, 2003. 
HEYMSFIELD S. et al. Human body composition.Champaign: Human Kinetics, 2005.

KALETA D.; MAKOWIEC-DABROWSKA T.; JEGIER A. Occupational and leisure time energy expenditure and body mass índex. International Journal of Occupational Medicine and Environmental Health, v. 20, p. 9-16, 2007.

KATZMARZYK P.; GLEDHILL N.; SHEPHARD R. The Economic Burden of Physical Inactivity In Canadá. Canadian Medical Associationjournal (CMAJ), v. 163 , p. $1435-40,2000$.

KISH L. Survey sampling. New York: John Wiley and Sons. 1965.

KRISKA, A. Caspersen C. Introduction to collection of physical activity questionnaires for health-related research. Med. Sci. Sports Exerc., v. 29, p. 3-S205. 1997.

LEON A. et al. Leisure time physical activity levels and risk of coronary heart desease and death: the multiple risk factor intervention trial. JAMA, v. 258, p. 2388-2395, 1987.

LINS, A. Fatores associados ao sobrepeso em mulheres de 20 a 59 Anos no município do Rio de Janeiro. 1999 Dissertação (Mestrado em Saúde) Instituto Fernandes Figueira/Fundação Oswaldo Cruz, Rio de Janeiro; 1999.

MARTIN S., et al. Variables related to meeting the CDC/ACSM physical activity guidelines. Med Sci Sports Exerc., v. 32, p. 2087-92, 2000.

MARTINEZ-GONZALEZ M. et al.physical activity during leisure time in the European Union. Med. Sci. Sports Exerc., v. 33, p. 1142-46, 2001.

MATSUDO, S., et al. Nível de atividade física da população do Estado de São Paulo: análise de acordo com o gênero, idade, nível socioeconômico, distribuição geográfica e de conhecimento. Rev. Bras. Ciên. e Mov. v. 10, p. 41-50, 2002.

MENSINK G., LOOSE N., OOMEN C. Physical activity and its association with other lifestyle factors. European Journal of Epidemiology, v. 13, p. 771-778, 1973.

MESSNER M. Masculinities and athletic careers. In: ANDERSEN M. L; COLLINS P.H. (Ed.). Race, class and gender: an anthology. New York: Wadsworth, 1995. p. 165-179. 
MINISTÉRIO DA SAÚDE. Inquérito domiciliar sobre comportamentos de risco e morbidade referida de doenças e agravos não transmissíveis: Brasil, 15 capitais e Distrito Federal 2002-2003. Rio de Janeiro: INCA; 2004.

MINISTÉRIO DA SAÚDE. Vigilância de fatores de risco e proteção para doenças crônicas por Inquérito telefônico. VIGITEL 2006. Brasília (Distrito Federal): Secretaria de Vigilância e Saúde; 2007.

MONTEIRO C. et al. A descriptive epidemiology of leisure-time physical activity in Brazil, 1996-1997. Rev. Panam Salud Publica,v. 14, p. 246-254, 2003 MORRIS J. N. et al, Coronary heart disease and physical activity of work. Lancet ii. p. 1053-1057, 1953.

NORTON, K. Olds T. Antropometrica. Argentina: Biosystem; 2000.

NUNES J.; BARROS J. Fatores de risco associados à prevalência de sedentarismo em trabalhadores da indústria e da Universidade de Brasília. Rev. Digital, v. 10, n. 69, 2004 Disponível em: <http://www.efdeportes.com/ efd69/risco.htm.> Acesso: 28 jun. 2007.

PAFFENBARGER Jr. R. et al.A natural history of athleticism and cardiovascular health. JAMA, v. 252, n. 4, p. 491-495, 1984.

PAFFENBARGER Jr R., HYDE, R., WING, A. Physical activity, all-cause mortality, and longevity of college alumni. N. Engl. J. Med.1986; v. 314, n. 10 , p. 605-13.

PITANGA F, LESSA I. Associação entre sedentarismo no lazer e hipertensão arterial sistólica em adultos de ambos os sexos na cidade de Salvador-BA. In: $58^{\circ}$ Congresso da Sociedade Brasileira de Cardiologia; 2003. Salvador-Brasil. Gráfica Venture; 2003.

PEREIRA, M. Epidemiologia: teoria e prática. Rio de Janeiro: Editora Guanabara Koogan; 1995.

PITANGA F., LESSA I. Prevalência e fatores associados ao sedentarismo no lazer emadultos. Cad. Saúde Pública v. 21, p. 870-877, 2005.

SALLES-COSTA,R. et al. Associação entre fatores sociodemográficos e prática de atividade física de lazer no estudo pró-saúde. Cad. Saúde Pública, v. 19, p. 1095-1105, 2003a. 
SALLES-COSTA,R.et al. Gênero e prática de atividade física em lazer. Cad. Saúde Pública. v. 19, p. S325-S333, $2003 b$.

VUORI, I. Health benefits of physical activity with special reference to interaction with diet. Public Health Nutr., v. 4, p. 517-528, 2001.

WARBURTON D, NICOL C, BREDIN S. Health benefits of physical activity: the evidence. CMAJ. 2006; 174(6): 801-808. 


\section{Mecanismos de atuação do exercício nos níveis de fadiga de pacientes com câncer}

Aline da Silva Adães Motta

Aline Mendonça de Sá

Cloud Kennedy Couto de Sá

\section{INTRODUÇÃO}

O câncer está entre as principais causas de morte no mundo, e é um problema cada vez mais frequente. (INCA, 2009) Além de ser uma doença incapacitante, seus tratamentos comumente promovem efeitos colaterais que muitas vezes estão associados a uma fadiga generalizada não restaurada com o repouso. (SCHNEIDER; DENNELVY; CARTER, 2003)

Hoje em dia o tratamento do câncer busca, além da manutenção ou prolongamento da vida, promover a sobrevivência humanizada e com maior qualidade. Para tanto, atrela a qualidade de vida e a autonomia do paciente ao seu nível de aptidão física e capacidade funcional, tendo nos exercícios uma terapia alternativa para aumento das capacidades físicas e combate à fadiga relacionada ao câncer (FRC).

A este respeito, muitas evidências demonstram que o exercício pode atenuar a FRC (SCHWARTZ et al., 2001; BACKER et 
al., 2008), melhorar a qualidade de vida (OHIRA et al., 2006; HWANG et al., 2008) e diminuir os efeitos adversos vindos das terapias contra o câncer. (ADAMSEN et al., 2009; EVANS, 2007)

Boa parte desses estudos tem demonstrado que muitos dos componentes fisiológicos e psicológicos que culminam na FRC são responsivos ao aumento do nível de exercício. (IRWIN, 2004; GALVÃO et al., 2007; BATTAGLINI et al., 2007; AL-MAJID; WATERS, 2008;) Nestas evidências observam-se programas de exercícios individuais ou em grupo, realizados de forma supervisionada ou semi-supervisionada e variam entre exercício aeróbio, resistido, exercícios de flexibilidade ou uma combinação de ambos.

Embora essas evidências apresentem os efeitos benéficos dos exercícios na prevenção e controle da FRC, os mecanismos celulares e fisiológicos subjacentes à redução da FRC induzida pelo exercício ainda não foram completamente elucidados. Neste estudo, nosso objetivo foi revisar e descrever os mecanismos de atuação do exercício sobre os níveis de Fadiga Relacionada ao Câncer.

\section{METODOLOGIA}

Este estudo foi elaborado a partir da literatura de bases de dados acadêmicos como o PUBMED, SCIELO, LILACS. Foram usadas combinações das palavras-chave: exercício aeróbio, exercício resistido, fadiga relacionada ao câncer, quimioterapia, radioterapia e avaliação da fadiga, todas com suas respectivas traduções para o inglês.

Foram selecionados os estudos que priorizaram discutir os mecanismos de atuação de qualquer modalidade e intensidade de exercício sobre a FRC ou nas variáveis que interferem neste sintoma (independente do número ou da heterogeneidade das amostras). Assim foram avaliados 27 estudos, sendo 14 experimentais, 12 revisões e 1 metanálise.

Todos os estudos foram avaliados quanto aos objetivos, população (idade, gênero e tipo de câncer), intervenções (modalidade e intensidade do exercício) e desfechos (eficácia das intervenções), além de observadas suas limitações, recomendações e coerência entre proposições, métodos, resultados e conclusões. 


\section{MECANISMOS DO EXERCÍCIO NA FRC}

Embora os estudos analisados tenham mostrado uma considerável associação entre fadiga e exercício, evidenciando que exercício aeróbio e resistido podem efetivamente reduzir a FRC (LUCTKAR-FLUDE et al., 2009; MCNEELY et al., 2006), os mecanismos celulares e fisiológicos subjacentes à redução da fadiga induzida pelo exercício têm sido pouco explorados.

Em geral, programas de exercício aeróbio para indivíduos saudáveis promovem um número de positivas adaptações fisiológicas e psicológicas como o aumento do metabolismo, a melhora da resistência muscular, mudanças positivas na composição corporal, aumento do bem-estar e melhora do humor (BATTAGLINI et al, 2007; WINDSOR et al., 2009), enquanto que o exercício resistido, além de muitos destes benefícios, melhora ainda a força muscular e promove aumento de massa magra (BATTAGLINI et al., 2007), bem como atenua a perda muscular associada com a variedade de condições catabólicas. (ARGILES et al, 1999 apud AL-MAJID et al, 2001)

Alguns estudos propuseram que os mecanismos de atuação do exercício em pessoas saudáveis podem também ser relevantes para pessoas com câncer. Dentre estes mecanismos, Holloszy e Coyle (1984) mostraram que um treino regular de exercício de endurance de intensidade submáxima em sujeitos normais aumenta a resistência muscular e a resistência à fadiga pelo aumento da atividade enzimática mitocondrial, que resulta em um aumento da capacidade oxidativa dos músculos.

Postula-se também que a fadiga possui uma causa central associada ao funcionamento neural. Assim, Jager, Sleijfer e Van der Rijt (2008) sugeriram que a atividade física interfere nos níveis de fadiga por aumentar os níveis plasmáticos e cerebrais de triptofano, com decorrente aumento dos níveis sinápticos de 5-hidroxitriptamina (serotonina), neurotransmissor implicado na FRC (Figura 1).

Outras linhas ainda sugerem que exercício pode alterar o ciclo da fadiga pela melhora do perfil funcional e da eficiência neuromuscular. A este respeito, Pollock e colaboradores (1998) defendem que o exercício resistido progressivo é um potente estimulante da síntese muscular, endurance, força, sensibilidade à insulina e melhora da funcionalidade física, 
adaptações que refletem positivamente na manutenção da funcionalidade muitas vezes prejudicada pelo câncer ou pela FRC.

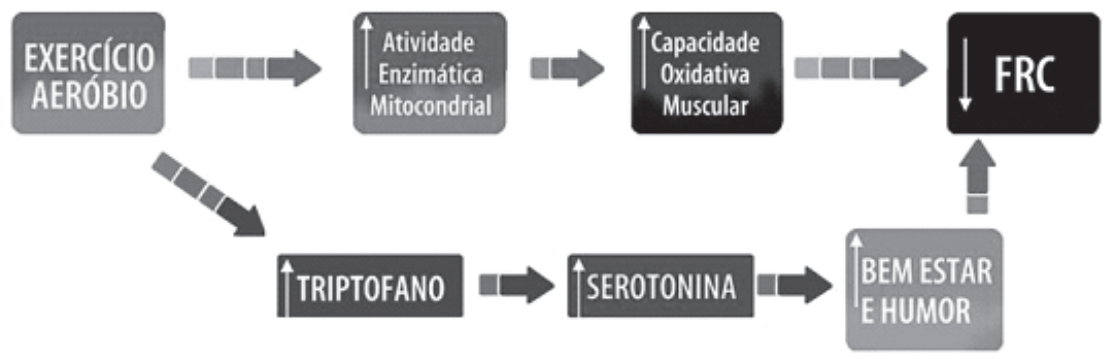

FIGURA 1. Possíveis mecanismos do efeito do Exercício Aeróbico na FRC.

Fonte: Jager, Sleijfer e Van der Rijt (2008)

Al-Majid e colaboradores (2008) e Galvão e colaboradores (2007) propuseram que o exercício resistido atenua a perda do músculo esquelético relacionada ao câncer pela supressão da atividade das citocinas pró-inflamatórias e pelo aumento da fosforilação das moléculas sinalizadoras de aminoácido intramuscular. Tal estímulo pode acarretar em maior envolvimento de células satélites com promoção de uma recuperação/estímulo à preservação da massa muscular.

Apesar dessas células se apresentarem geralmente inativas em indivíduos adultos, seu papel associa-se à recuperação e devolução de funcionalidade às células musculares que foram previamente danificadas. Alguns estudos têm mostrado que tensão, sobrecarga de estiramento e liberação de substâncias inflamatórias ou fatores de crescimento produzidos pelo exercício resistido ativam as células satélites, estimulando-as a entrar novamente no ciclo celular e a proliferar, além de suas progênies poderem funcionar para formar novas células musculares. (KADI et al., 2004; KADI et al., 2005; HAWKE; GARRY, 2001)

Outros autores referenciaram que o Fator de Necrose Tumoral (TNF-a) também está envolvido com grande perda de massa muscular. (GREIWE et al., 2001) Tal citocina é produzida por monócitos e macrófagos em resposta 
a endotoxinas e interleucina-1 (IL-1) e está relacionada com uma variedade de doenças humanas, inclusive câncer. (LOCKSLEY;, KILLEEN; LENARDO, 2001) Possuindo atividade necrotizante contra linhagens de células tumorais, ela ativa leucócitos e tem atividade antitumoral.

Greiwe e colaboradores (2001) demonstraram que esse efeito catabólico da TNF- $\alpha$ pode ser revertido através da realização de um programa de exercício resistido, que induz uma significante diminuição na expressão do RNA-m de TNF- $\alpha$ e, consequentemente, da proteína TNF- $\alpha$. Tem sido documentado ainda que contrações musculares estimulam a produção e liberação da citocina anti-inflamatória IL-6 em pessoas saudáveis (STARKIE et al., 2003 apud AL-MAJID et al., 2008) e em pessoas com câncer de próstata. (GALVÃO et al., 2007) A IL-6 inibe a produção de TNF-a e IL-1 in vitro (STARKIE et al., 2003 apud AL-MAJID et al., 2008), o que induz a diminuição da perda muscular (Figura 2). Apesar da maioria desses achados terem sido encontrados em pessoas saudáveis, eles podem ter relevância para pessoas com câncer que participam de um programa de treinamento resistido.

Recentes evidências também sugerem que treinamento resistido pode aumentar a síntese de proteína muscular pelo aumento da fosforilação da molécula sinalizadora de proteína p70S6k, responsável pelo controle da síntese protéica no aumento da massa muscular esquelética. (BOLUYT et al., 1997). Baar e Esser (1999) mostraram que uma série aguda de exercício aumentou a fosforilação da p70S6k após 6 semanas de treino.

Grande parte dessas evidências que sustentam os mecanismos do efeito do exercício sobre os níveis de fadiga quer por sinalização hormonal, por supressão de citocinas ou por aumento de fosforilação de moléculas sinalizadoras de aminoácido intramuscular, foram geradas de estudos com humanos saudáveis. Devido a isso, há ainda uma insatisfação no que se refere à possibilidade de mecanismos semelhantes acontecerem em pessoas com câncer, o que torna necessário o desenvolvimento de novos estudos para o preenchimento de tais lacunas. (HEADLEY; OWNBY; JOHN, 2004) 


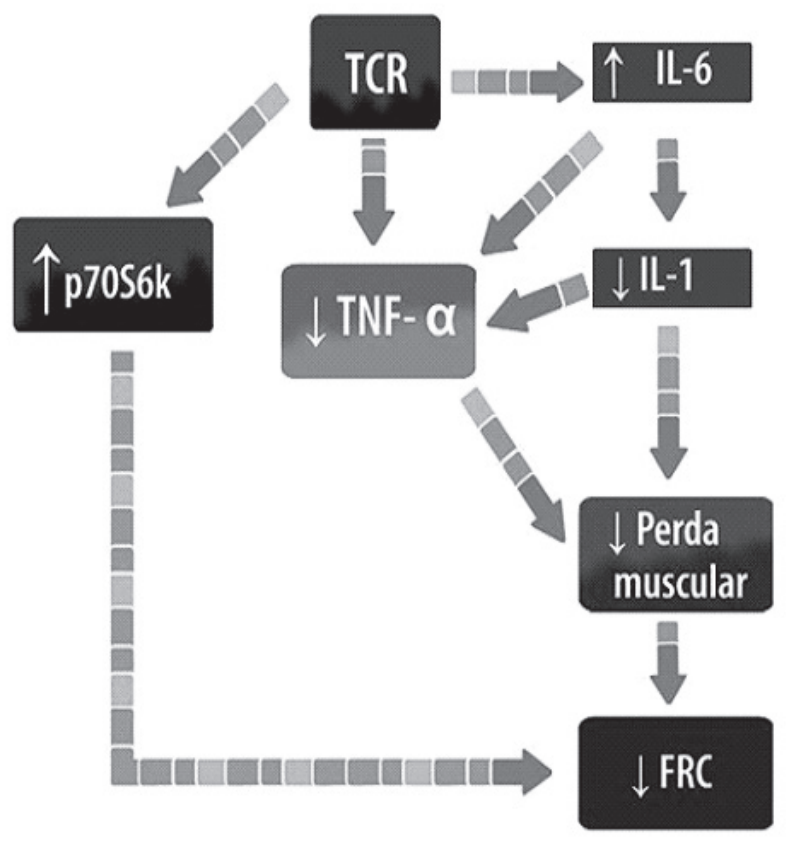

FIGURA 2. Possiveis mecanismos do Efeito do Exercício Resistido na FRC TRC: Treinamento Contra Resistência; IL-6: Interleucina-6; IL-1; TNF (x) Fator de Necrose Tumoral - (x); Fadiga Relacionada ao Cãncer.

Fonte: Jager, Sleijfer e Van der Rijt (2008)

\section{CONCLUSÃO}

A FRC é extremamente prevalente e marca de forma negativa a vida de pessoas com câncer. Devido a isso, um considerável número de evidências têm descrito sua etiologia com o fim de auxiliar os profissionais na construção de ferramentas que diminuam os efeitos desse sintoma e melhorem a qualidade de vida dos pacientes. Com o avanço dessas informações e com evidências de que a perda muscular é um dos principais promotores da FRC, o desenvolvimento de pesquisas envolvendo exercícios físicos começou a ganhar espaço e mostrar resultados promissores.

A revisão de estudos sobre exercício e FRC demonstra, de forma geral, alguns benefícios do exercício na redução dos sintomas da FRC. As inter- 
venções que usaram apenas exercícios aeróbios induziram a uma diminuição dos níveis de FRC, bem como uma melhora das variáveis que estão relacionados com o aumento do cansaço. Da mesma forma, os ensaios com intervenções apenas com exercício resistido revelaram principalmente aumento da força muscular e da massa magra. O outro grupo de estudos envolvendo combinação de exercícios mostrou significante melhora da composição corporal e da funcionalidade física.

Apesar desses desfechos positivos, nem todos os autores que publicaram sobre os efeitos do exercício resistido em pacientes com câncer fizeram relação desses resultados com variações nos níveis da FRC ou exploraram os mecanismos.

Quanto a tirar conclusões para a prática baseado nessas evidências, é importante que alguns detalhes sejam considerados prioritariamente. Um fator a ser ponderado é o limitado número de evidências e a heterogeneidade das amostras de alguns estudos, o que envolve gênero, tipo de câncer, tipo do exercício, intensidade e o tempo da intervenção. Sobre o gênero e tipo de câncer, alguns estudos não trazem essas informações especificadas adequadamente, já os outros, que tentaram homogeneizar as características da amostra, apresentaram dados apenas de mulheres com câncer de mama e/ou homens com câncer de próstata devido ao grande número de pacientes com esse agravo, o que limita a extensão dos resultados para populações com outros tipos de câncer.

Tratando-se da intervenção, não existe uma padronização dos programas de exercício, o que pode de alguma forma ter interferido no resultado de alguns estudos que usaram volumes e intensidades inadequadas, subestimando ou superestimando os efeitos das intervenções.

Outra limitação diz respeito à falta de literatura explanando os mecanismos do exercício em populações com câncer. De todos os artigos encontrados e utilizados nessa revisão, apenas um ensaio clínico analisou as respostas endócrino-metabólicas do exercício em pacientes com câncer. (GALVÃO et al., 2007) Todas as análises já feitas por outros autores sobre o tema partiram de evidências em pessoas saudáveis e conjectura-se que nem sempre o mesmo possa ocorrer em pacientes com câncer, revelando assim a necessidade de estudos para essa área. 
A fim de integrar o exercício no tratamento do câncer de forma regular e eficaz, mais provas para os diferentes parâmetros da prescrição do exercício (população, tipo de exercício, intensidade, duração e frequência), para os possíveis mecanismos do exercício (em pacientes com câncer e não em sujeitos saudáveis), para a padronização da mensuração da fadiga e para a viabilidade e segurança do exercício durante o tratamento do câncer são necessárias.

\section{REFERÊNCIAS}

ADAMSEN, L.; Andersen, C.; Møller, T. et al. Effect of a multimodal high intensity exercise intervention in cancer patients undergoing chemotherapy: randomized controlled Trial. Biomedical Medicine Journal, 2009. Disponível em: http:<//www.bmj.com/content/339/bmj.b3410>.

AL-MAJID, S.; MCCARTHY, D. O. Cancer-Induced Fatigue and Skeletal Muscle Wasting: The Role of Exercise. Biological Research for Nursing, v. 2, n. 3, p. 186-197, 2001.

AL-MAJID, S.; WATERS, H. The Biological Mechanisms of Cancer-Related Skeletal Muscle Wasting: The Role of Progressive Resistance Exercise. Biological Research for Nursing, v. 10, n. 1, p, 7-20, 2008.

BAAR, K; ESSER, K. Phosphorylation of P70s6k correlates with increased skeletal muscle mass following resistance exercise. American Journal of Physiology, v. 276, C120-7, 1999. Disponível em: <http://ajpcell.physiology. org/content/276/1/C120.full.pdf>.

BACKER I. C. Long-term follow-up after cancer rehabilitation using high-intensity resistance training: persistent improvement of physical performance and quality of life. British Journal of Cancer, v. 99, p. 30-36, 2008. BATTAGLINI, C. The effects of an individualized exercise intervention on body composition in breast cancer patients undergoing treatment.

São Paulo Medicine Journal, v. 125, n. 1, p. 22-8, 2007.

BATTAGLINI, C.L et al. Effect of exercise on the caloric intake of breast cancer patients undergoing treatment. Brazilian Journal of Medical Biological Research, v. 41, p. 709-715, 2008. 
BOLUYT, M. O. Rapamycin inhibits alpha 1-adrenergic receptorstimulatedcardiac myocyte hypertrophy but not activation of hypertrophyassociated genes. Evidence for involvement of p70 S6 kinase. Circulation Research, v. 81, p. 176-186, 1997.

BRASIL. Ministério da Saúde. Instituto Nacional de Câncer. Estimativa 2010: incidência de câncer no Brasil/Instituto Nacional de Câncer. Rio de Janeiro: INCA, 2009.

EVANS W. J.; LAMBERT, C. P. Physiological basis of fatigue. American Journal of Physical Medicine \& Rehabilitation, v. 86 (Suppl), p. S29-S46, 2007.

GALVÃO, D. A. et al. Endocrine and immune responses to resistance training in prostate cancer patients. Prostate Cancer and Prostatic Diseases. Pubmed, v. 11, n. 2, p. 160-5, 2008. Disponível em: http:<//www.ncbi.nlm. nih.gov/pubmed/17637762>.

GREIWE, J. S. et al. Resistance exercise decreases skeletal muscle tumor necrosis factor $\alpha$ in frail elderly humans. Guidelines for Evaluation and Management. The Oncologist, v. 4, p. 1-10, 2001.

HAWKE, T. J.; GARRY, D.J. Myogenic satellite cells: physiology to molecular biology. Journal of Applied Physiology, v. 91, p. 534-551, 2001.

HEADLEY J. A.; OWNBY KK; JOHN L. D. The effect of seated exercise on fatigue and quality of life in women with advanced breast cancer. Oncology Nursing Forum, v. 31, p. 977-983, 2004.

HOLLOSZY, J. O.; COYLE, E. F. Adaptations of skeletal muscle to endurance exercise and their metabolic consequences. Journal of Applied Physiology, v. 56, p. 831-838, 1984.

HWANG J. H., CHANG, H.J., SHIM, Y. H., et al. Effects of supervised exercise therapy in patients receiving radiotherapy for breast cancer. Yonsei Medicine Journal, v. 49, p. 443-450, 2008.

IRWIN ML; MCTIERNAN A; BERNSTEIN L., et al. Physical activity levels among breast cancer survivors. Medicine and Science in Sports and Exercise, v. 36, p. 1484-1491, 2004.

JAGER , A. S.; SLEIJFER, C. C. D.; VAN der RIJT. The pathogenesis of cancer related fatigue: Could increased activity of pro-inflammatory cytokines be the common denominator? European Journal of Cancer, v. 44, p. 175-181, 2008. 
KADI, F.; SCHJERLING, P.; ANDERSEN, L. L.; CHARIFI, N.; MADSEN, J. L.; CHRISTENSEN L. R., et al. The effects of heavy resistance training and detraining on satellite cells in human skeletal muscles. Journal of Physiology, v. 558, p. 1005-12, 2004.

KADI, F; CHARIFI, N; DENIS, C; LEXELL, J; ANDERSEN, JL; SCHJERLING, P., et al. The behavior of satellite cells in response to exercise: what have we learned from human studies? European Journal of Phisiology, v. 451, p. 319-27, 2005.

LOCKSLEY, R. M.; KILLEEN, N.; LENARDO, M. J. The TNF and TNF Receptor Superfamilies: Integrating Mammalian Biology. Cell, v.104, p. 487-501, 2001. LUCTKAR-FLUDE, M. et al. Fatigue and Physical Activity in Older Patients With Cancer: A Six-Month Follow-Up Study. Oncology Nursing Forum, v. 36, n. 2, 2009.

MCNEELY, M. L; et al. Effects of exercise on breast cancer patients and survivors: a systematic review and meta-analysis. Canadian Medical Association Journal, v. 175, p. 34-41, 2006.

OHIRA, T; Effects of Weight Training on Quality of Life in Recent Breast Cancer Survivors. Cancer, v. 106, p. 9, 2006.

POLLOCK, M. L. et al. The recommended quantity and quality of exercise for developing and maintaining cardiorespiratory and muscular fitness, and flexibility in healthy adults. Medicine and Science in Sports and Exercise, v. 30, p. 975-991, 1998.

SCHNEIDER, C. M.; DENNELVY, C. A.; CARTER, S. D. Exercise and Cancer Recovery. Champaign, Illinois: Human Kinetics Publishers, 2003.

SCHWARTZ, A. Exercise reduces daily fatigue in women with breast cancer receiving chemotherapy. Medicine and Science in Sports and Exercise, v. 3, n. 5, 2001.

WINDSOR, P M. et al.. Evaluation of a Fatigue Initiative: Information on Exercise for Patients Receiving Cancer Treatment. Clinical Oncology, v. 21, p. 473-482, 2009. 


\section{Contribuição do exercício resistido para prevenção e controle da osteoporose em mulheres adultas}

Antonio Dantas Júnior

Helio José Bastos Carneiro de Campos

\section{INTRODUÇÃO}

O envelhecimento populacional é uma realidade nas sociedades contemporâneas. A expectativa de vida no Brasil encontra-se aproximadamente em torno de 72 anos, segundo dados encontrados no Datasus (2009). Com o aumento da esperança de vida, principalmente da população brasileira, além dos avanços tecnológicos da medicina, bem como com a redução das taxas de mortalidade e de fecundidade, estende-se a preocupação com a qualidade de vida senil, pois, neste contexto, encontramos também uma significativa elevação das taxas de doenças crônico-degenerativas, entre elas, a osteoporose.

Em concordância com as palavras de Frazão (2006, p. 6), quando ele diz que "[...] os custos crescentes com a assistência à saúde, tem levado a considerar a osteoporose um problema relevante para aqueles que se ocupam da saúde pública mundial", é que se sinaliza a importância da pesquisa envolvendo 
as doenças relacionadas à elevação do tempo de vida da população, para que num futuro próximo possamos ao menos reduzir os altos índices de prevalência que envolvem estas enfermidades.

Diversos autores, através de seus estudos, validam a atividade física como um bom fator de proteção contra a perda de densidade mineral óssea (DMO). É Evidente que pesquisas vêm sendo realizadas com o intuito de verificar qual seria a melhor prática de exercício físico para prevenir ou controlar a osteoporose. Sabe-se, no entanto, que o desempenho de um treinamento visando dominar esta enfermidade deve ser praticado principalmente com o claro fim de interromper a perda de massa óssea, não se criando expectativas no aumento dela entre os praticantes.

No intuito de se esclarecer as principais vertentes vinculadas à DMO, é que tivemos por objeto principal deste estudo a identificação através de levantamento bibliográfico e eletrônico do papel referente ao exercício resistido na prevenção e controle da osteoporose.

Esta pesquisa consistiu em uma revisão de literatura, adotando como metodologia a leitura e interpretação de trabalhos científicos mediante consulta às principais publicações sobre o tema. O material foi identificado com auxílio das bases eletrônicas de dados bibliográficos da National Library of Medicine (MEDLINE); ${ }^{1}$ Literatura Latino-Americana em Ciências da Saúde (LILACS); ${ }^{2}$ American College of Sports Medicine (ACSM); ${ }^{3}$ e da Scientific Electronic Library On Line (SCIELO). ${ }^{4}$ Empregamos os descritores "epidemiologia", "mulheres adultas" "exercício resistido" e "osteoporose". Como critério de inclusão, apenas artigos escritos a partir de 1999 participaram do estudo. Com referência a livros e organizações governamentais ou particulares vinculadas ao tema, a norma escolhida foi a importância de suas informações e a procura de edições e/ou dados atualizados. Somente artigos publicados em português e inglês foram anexados.

\footnotetext{
http:// www.ncbi.nlm.nih.gov/pubmed/

http://www.bireme.br/

http://www.acsm.org

http://www.scielo.org/
} 


\section{EPIDEMIOLOGIA DA OSTEOPOROSE}

Existem diferentes definições para a osteoporose, mas todas gravitam em torno da adotada pelo Consenso Brasileiro, que diz: "A Osteoporose é um distúrbio osteometabólico caracterizado pela diminuição da DMO, com deterioração da microarquitetura óssea, levando a um aumento da fragilidade esquelética e do risco de fraturas”. (BARACAT et al., 2002, p. 344)

No que diz respeito à redução das taxas de mortalidade infantil e de fecundidade, no Brasil, Berbel (2009, p. 112) nos mostra que “[...] esses dois fatores [...] estimam para o ano de 2025, 34 milhões de idosos na faixa etária de 60 anos, representando 13,8\% da população". Ainda relatando dados pertinentes à nossa nação, Hashimoto (2005, p.2) é incisivo em afirmar que “[...] até 2025, o Brasil será o sexto país do mundo com maior número de pessoas idosas".

Kidde (1999 apud CARVALHO, 2004, p. 720) alerta-nos sobre o aumento da osteoporose no Brasil, que passou de 7,5 milhões em 1980 para 15 milhões no ano 2000 de pessoas acometidas (homens e mulheres). Mazo (2009, p. 2) denuncia que “[...] cerca de 15 milhões de brasileiros têm a doença. Calcula-se em 52 milhões a quantidade de mulheres acima dos 50 anos que serão atingidas pela osteoporose, em 2010, em âmbito mundial". A Secretaria de Estado de Saúde (2009) registra informações da Organização Mundial de Saúde (OMS), evidenciando que a osteoporose atinge mais de 75 milhões de pessoas na Europa, Japão e EUA, enquanto Sweet (2009, p. 193, tradução nossa) divulga que "[...] apenas nos EUA existem aproximadamente 8 milhões de mulheres e 2 milhões de homens com a doença”.

Devido a estes altos índices de prevalência, a osteoporose deve ser considerada uma importante questão de saúde pública a nível mundial, em função dos danos físicos causados, além de efeitos na esfera psicossocial e financeira nos indivíduos afetados.

\section{CUSTOS GERADOS PELA DEFINITIVA INSTALAÇÃO DO QUADRO OSTEOPORÓTICO}

Existe uma discrepância de valores referentes a internações e manutenções de pessoas em hospitais especializados. Enquanto (CARNEIRO, 1998 
apud CARVALHO, 2004, p. 720) proclama-se um gasto de mais de 1 bilhão e 300 milhões de reais por ano, os órgãos oficiais do governo brasileiro dizem que:

A cada ano, o Sistema Único de Saúde (SUS) tem gastos crescentes com tratamentos de fraturas em pessoas idosas. Em 2009, foram $\mathrm{R} \$ 57,61$ milhões com internações (até outubro) e R 24,77 milhões com medicamentos para tratamento da osteoporose. Em 2006, foram R \$ 49 milhões e R \$ 20 milhões respectivamente. A quantidade de internações aumenta a cada ano e as mulheres são as mais atingidas. Entre as mulheres foram $20.778 \mathrm{mil}$ internações em 2009 e entre eles 10.020 mil (dados até outubro). (MINISTÉRIO DA SAÚDE, 2009)

Em estudo pioneiro no Brasil, referente a custos com osteoporose, Kowalski (2001, p. 3) chegou às seguintes conclusões: “[...] Foram encontrados gastos médios de R $\$ 908,19$ por paciente analisado / ano”, o que abrangeria custos totais, sendo que: "[...] custos diretos - Relacionados às consultas, exames, tratamento, cirurgias, internações, utilização de órteses, equipamentos, adaptações no domicílio e/ou trabalho e transportes". E ainda: "[...] Custos indiretos - Perdas de dias de trabalho das pacientes e/ou acompanhantes em função dos cuidados com saúde”. Com relação à América do Norte, o "[...] custo direto atribuído à osteoporose é estimado em 38 milhões de dólares, por dia, nos Estados Unidos. Aproximadamente 1 milhão de americanos sofrem fraturas patológicas a cada ano" (YAZBEK, 2008, p.74), o que é ampliado pelos dados da Organização Mundial de Saúde citada pela Secretaria de Estado de Saúde do Distrito Federal (2009), quando diz que nos Estados Unidos da América "[...]ocorrem cerca de 1,5 milhões de fraturas por ano, resultando em 500 mil hospitalizações, 800 mil consultas aos serviços de emergência, 2,6 milhões de consultas médicas e gastos entre 12 e 18 bilhões de dólares a cada ano”. Estes custos são mais alargados por Sweet (2009, p. 193, tradução nossa) ao dizer que: “[...] Nos EUA, o custo anual de todas as fraturas osteoporóticas está em torno de 18 bilhões”. McArdle (2008, p. 62) vai mais além, e anuncia 
que os "[...] gastos nacionais diretos (hospitais e clínicas de repouso) para as fraturas osteoporóticas e correlatas foram de 21 bilhões de dólares em 2005 (51 milhões de dólares diários); esse custo poderá ultrapassar os 250 bilhões de dólares na metade do século XXI".

Fica quase evidente concluir que, assim como em qualquer processo mórbido definido, que afeta a população de uma forma tão contundente, como é o caso das enfermidades crônico-degenerativas, a prevenção é significantemente mais econômica que o tratamento da doença.

\section{CLASSIFICAÇÃO E ETIOPATOLOGIA DA OSTEOPOROSE}

Esta doença decorre de distúrbios da remodelação óssea e, portanto, conforme nos orienta Salter (2001, p. 193), “[...] há vários tipos de osteoporose baseados nos fatores mais evidentes e nas suas etiologias, ainda que a lesão esquelética resultante seja a mesma”. Este trabalho se reportou ao estudo da osteoporose involucional acometendo mulheres adultas.

Diferentes autores apresentam sugestões para explicar o surgimento da doença, porém, Porth (2004, p. 1317) nos adverte pronunciando que a patogênese da “[...] osteoporose não está clara, mas a maioria dos dados sugere desequilíbrio entre a reabsorção e a formação de osso, de forma que a reabsorção de osso excede a formação" e Carvalho (2004, p. 720) completa, dizendo: “[...] A etiologia da perda de massa óssea é complexa, multifatorial [...]". Evidente que em se tratando de sintomatologia, as fraturas (vértebra, quadril, úmero etc.) acompanhadas de dor estão em primeiro plano de investigação clínica. Seguindo esta diretriz envolvendo diversas situações precursoras da osteoporose, pudemos reunir dados dos seguintes autores: BARACAT et al., 2002, p. 345; CUMMINGS et al., 1995; FOSS, 2000, p. 382; GRAVES, 2006, p. 390; GUYTON, 2006, p. 992; HEISS et al. apud COSTA, 2003, p. 510; JORGENSEN, 2001, p. 47; LING et al., 2000 apud SEGURA, 2007, p. 54; MCARDLE, 2008, p. 61; NUNES, 2001 apud SILVA, 2007, p. 2; WILMORE, 2001, p. 595-596; WORLD HEALTH ORGANIZATION, 2004. E identificamos os seguintes fatores de risco na aquisição da osteoporose, considerados os mais prevalentes: Modificáveis - Tabagismo; Baixa ingestão de cálcio; Baixa ingestão de vitamina D; Baixa exposição solar; Sedentarismo (falta 
de estresse físico sobre os ossos); Índice de massa corpóreo baixo, e Não Modificáveis - Sexo feminino (menarca tardia e/ou menopausa precoce); População branca (asiática ou caucásica); História familiar de osteoporose; História familiar de fratura de quadril; Idade (acima de 65 anos).

\section{DIAGNÓSTICO E CONSEQUÊNCIAS DA DOENÇA}

Um grave problema a ser registrado é que na maioria das vezes em que se chega ao diagnóstico da doença, a fratura já está instalada e conforme Radominski et al. (2002, p.4) relata, “[...] este fato é incompatível com os conhecimentos atuais sobre o metabolismo e fisiologia óssea”. Às vezes, um bom exame clínico já é suficiente para se diagnosticar a osteoporose primária. Autores diversos concordam que sem dúvida a densitometria é hoje o exame de referência para o diagnóstico da osteoporose.

Com a doença já estabelecida, as sequelas são inevitáveis. Navega (2007, p. 10) apregoa que "[...] a osteoporose tem como principal consequência a fratura, que frequentemente impõe severas limitações emocionais e sociais [...]" e Costa (2003, p. 507) completa dizendo que elas “[...] ocorrem principalmente nas vértebras, punho e colo do fêmur.

\section{PARTICULARIDADES DA OSTEOPOROSE FEMININA}

Como as mulheres representam a camada populacional mais atingida pela enfermidade, procuramos esclarecer alguns fatos inerentes a este contexto, sendo que na visão de Powers (2000, p. 311) “[...] o problema é mais comum em mulheres com mais de cinquenta anos em razão da menopausa e da falta de estrogênio" e Guyton (2006, p. 1017) explica: “[...] Depois da menopausa, quase nenhum estrogênio é secretado pelos ovários. Essa deficiência leva a (1) uma maior atividade osteoclástica nos ossos, (2) diminuição da matriz óssea, e (3) menos depósito de cálcio e fosfato ósseos". Completando este raciocínio, verifica-se que "[...] a perda óssea decorrente da menopausa é caracteristicamente associada à excessiva atividade dos osteoclastos, enquanto a perda óssea associada ao envelhecimento é mais relacionada à diminuição no número de osteoblastos”. (KEATING, 2000, 
apud RADOMINSKI et al., 2002, p. 10) Todo este quadro leva ao surgimento de fraturas e Wilmore (2001, p. 595-596) esclarece que "[...] a taxa de ocorrência dessas fraturas aumenta de duas a cinco vezes após a menopausa.” E é por isso que "[...] a probabilidade de ocorrer uma fratura osteoporótica ao longo da vida é de $40 \%$ para as mulheres e $13 \%$ para os homens. (BALSAMO, 2007, p. 34)

\section{FORMAS DE TRATAMENTO DA DOENÇA}

Antes de adentrarmos ao estudo do exercício resistido e suas consequências envolvendo a osteoporose, é prudente chamarmos atenção para as afirmativas de alguns autores como, por exemplo: Carvalho (2006, p. 4) quando nos diz que "[...] a osteoporose em si é assintomática e, se conseguirmos prevenir a fratura, seria como se ela não existisse"; Berbel e colaboradores. (2009, p. 112) reforça aspectos preventivos dizendo: “[...] O foco principal das ações contra a osteoporose deve ser a prevenção, pois essa doença é considerada insidiosa, podendo evoluir, muitos anos, de forma assintomática” e continua afirmando ser a enfermidade não reversível, mas "[...] a intervenção clínica precoce pode prevenir a doença na maior parte dos casos, e a tardia, poderá alterar a progressão do quadro osteoporótico já estabelecido"; Salter (2001, p. 196) também segue esta linha de raciocínio e declara que o julgamento com maior valia "[...] de tratamento é a prevenção de mais perda óssea. A reversão da osteoporose num dado paciente é extremamente difícil de conseguir"; Hashimoto e Nunes (2005, p. 6) corrobora com as afirmações anteriores e diz não existir “[...] cura para a osteoporose, portanto, as medidas preventivas, o diagnóstico e tratamento precoce propiciam a possibilidade de evitar a principal e mais grave consequência da osteoporose, a fratura. Existem diversas formas de tratamento da osteoporose: Terapêutica de Reposição Hormonal (TRH); Bisfosfonatos; Calcitonina; Cálcio e Vitamina D; Paratormônio (PTH), sendo que neste trabalho foca-se aspectos referentes ao exercício resistido aplicado às pessoas apresentando ou não a doença. 


\section{EXERCÍCIOS RESISTIDOS - GENERALIDADES}

Na literatura encontramos fortes evidências de que a atividade física é importante para prevenção e tratamento da osteoporose. Conforme Siqueira e colaboradores (2009, p. 30) e Jovine e colaboradores (2006, p. 500), uma das maneiras de evitar esta enfermidade é promover o aumento da massa óssea na infância e na adolescência, pois esta ação, acrescenta Trindades (2007, p. 84) "[...] vai refletir na fase adulta, quando se atinge o pico de massa óssea”, situado na terceira década de vida.

Existem vários termos de funções similares, referentes a exercício resistido (treinamento resistido, treinamento de força, contra resistência, com pesos, musculação), mas todos eles servem para “[...] descrever um tipo de exercício que exige que a musculatura do corpo promova movimentos (ou tente mover) contra a oposição de uma força geralmente exercida por algum tipo de equipamento". (FLECK, 2006, p. 19)

Diversos estudiosos têm defendido em seus trabalhos o uso do exercício resistido na prevenção e controle da osteoporose, dentre eles, destacamos: Baracat e colaboradores (2002, p. 349); Wilmore (2001, p. 627); Powers (2000, p. 311); Dantas (2003, p. 138); McArdle (2008, p. 63-64); Weineck (2005, p. 371); Morais (2005, p. 132); Morais Jr. (2008, p. 3) Nóbrega (1999, p. 209); Graves (2006, p. 113); Skare (2007, p. 268), (NAVEGA; OISHI, 2007 apud MAZO, 2009, p. 3); Balsamo (2007, p. 61-63); Silva (2008, p. 90) e Lundebjerg (2001, p. 815), sendo que outros conceituados autores apenas indicam a prática de qualquer atividade para vencer o sedentarismo e expõem resultados de estudos com exercícios de um modo geral, não especificando melhorias acentuadas entre os aeróbicos e anaeróbicos. São eles: Faisal-Cury (2007, p. 8), Radominski e colaboradares (2002, p. 12); Yazbek (2008, p. 77); (DEVINE, 2004, apud BANDEIRA, 2007, p. 95); Buiate (2008, p. 7); e Porth (2004, p. 1318). Neste momento podemos analisar algumas vertentes referentes à aplicação do treinamento contra resistência e suas indicações para pessoas idosas, apresentando osteoporose, ou simplesmente sem a doença, mas na perspectiva de prevenção da mesma. 


\section{RESPOSTA ÓSSEA AO TREINAMENTO RESISTIDO}

Faz-se necessário neste instante a definição da lei de Wolf, reportada por diferentes estudiosos, como Graves (2006, p. 113-114); Salter (2001, p. 194); Silva (2007, p. 3); Segura (2007, p. 53) e Balsamo (2007, p. 33; 38), unânimes em afirmar que o tecido ósseo se forma e exprime remodelação, respondendo às forças mecânicas aplicadas sobre ele. É ainda prudente acrescentar que a estimulação osteoblástica se dá por meio da transformação de energia mecânica em elétrica (efeito piezoelétrico), que provocará um estímulo na incorporação do cálcio no osso, aumentando a densidade mineral óssea (DMO). Fisiologicamente, temos que “[...] as cargas mecânicas estimulam células ósseas nos sítios onde está sendo suportada a carga, deformam-se [...] e elevam, minutos após a aplicação da carga mecânica, a síntese de RNA [...] produzindo uma série de [...] eventos dentro dos osteoblastos e dos osteócitos, em resposta às modificações na tensão do osso [...]". (BRAVO, 1995 apud BALSAMO, 2007, p. 39-40)

A intensidade do treino é bastante comentada por Guyton (2006, p. 983); McArdle (2008, p. 63); Buiate (2008, p. 4); Balsamo (2007, p. 41) e (BOOTH, 1975 apud Foss, 2000, p. 294), pois, de acordo com estes autores, esta variável está intimamente relacionada ao ganho de DMO e consequente deposição osteoblástica, levando a uma suposta "hipertrofia óssea". As pesquisas elaboradas no sentido de se confirmar as adaptações ósseas são unânimes em concordar com a manutenção do treinamento por um longo período de tempo, pois, “[...] no momento em que a atividade física é suspensa, a massa óssea retorna a seus níveis anteriores e os efeitos benéficos são perdidos” Balsamo (2007, p. 41). Portanto, o tecido ósseo deve ser estimulado para "[...] se desenvolver no sentido de criar uma reserva óssea a qual poderá amenizar as consequências da idade sobre a arquitetura” Buiate (2008, p. 3). Evidente que os princípios científicos do treinamento devem ser obedecidos conforme nos orienta Tubino (2003, p. 93-111), Bouchard (2001, p. 446) e Dantas (2005, p. 151-154), além da análise de todas as variáveis pertinentes a cada caso analisado, consoante estudo de Uchida e colaboradores (2005, p. 5-14) e Willoughby (2001, p. 1-4).

\footnotetext{
Tradução nossa.
} 


\section{DIRETRIZES DA ACSM PARA IDOSOS}

Encontramos em nossa revisão diversos posicionamentos da American College of Sports Medicine (ACSM), sendo que, em 1990, ela oficialmente "[...] reconheceu a importância de um programa completo de aptidão física e adicionou um componente de treinamento resistido dentro de seus regimes de reabilitação por exercícios [...]”. A partir desse momento, grande parte “[...] das organizações de saúde correntemente recomendam o treinamento resistido como parte de um programa completo de exercícios" Graves (2006, p. 16). Em 2001, a ACSM recomendou que pessoas antes de se submeterem a programas de exercícios, sejam devidamente classificadas nas seguintes categorias de risco:

I. Aparentemente saudável, que apresente até um fator de risco coronariano (hipertensão, tabagismo) ou doença metabólica ou cardiopulmonar. II. Em maior risco, que apresente mais de dois fatores de risco coronariano ou sintomas de doença cardiopulmonar ou metabólica. III. Previamente diagnosticado com doenças tais como doença cardiovascular, pulmonar ou metabólica. (FLECK, 2006, p. 324)

A partir da supracitada recomendação, Fleck (2006, p. 325) apresenta-nos as características gerais dos programas de treinamento de força para adultos mais velhos (ACSM): 1) Escolha do exercício - Primeiro trabalha-se os grandes grupos musculares (4 a 6 exercícios), depois grupos musculares pequenos (3 a 5 exercícios). Utiliza-se no início, equipamentos com progressão para pesos livres, quando aplicável; 2) Ordem dos exercícios - Para sessões nas quais todo o corpo é exercitado, os exercícios podem ser alternados entre membros superiores e inferiores e entre grupos musculares antagonistas; 3) Intensidade - A mais comum faixa de percentual de carga examinada é a de 50 a $85 \%$ do 1 RM para 8 a 12 repetições. Cargas mais leves são recomendadas inicialmente; 4) Velocidade dos movimentos Leves a moderadas; 5) Número de séries - O ponto de partida inicial recomendado consiste em ao menos uma série por exercício para 8 a 10 exercícios; 6) Repouso entre as séries e os exercícios - Tipicamente, 1 a 2 minutos têm sido utilizados; 7) Frequência - 2 a 3 dias por semana. Outros autores de 
renome como Balsamo (2007, p. 26; 42) e Graves (2006, p. 24-26) também registram estes dados da ACSM, não colocados aqui para não ser repetitivo nas informações. Todos estes pesquisadores clamam por maiores necessidades de pesquisas no intuito de elaborar uma ótima relação entre treino e suas variáveis.

\section{VANTAGENS E DESVANTAGENS DO TREINAMENTO DE FORÇA}

Novamente achamos por bem considerar os estudos com as devidas explanações dos seguintes autores: Balsamo (2007, p. 20, 26); (WHARBURTON, 2001, apud BALSAMO, 2007, p. 20); Foss (2000, p. 295); Macedo (2008, p. 83); Manidi (2001, p. 87); Weineck (2005, p. 381); Rogatto (2004, p. 109); Aveiro e colaboradores (2004, p. 36); Navega (2007, p. 9) Fleck (2006, p. 124-125) e Dantas (2003, p. 201), registrando as vantagens do treino de força (desenvolve a forma musculoesquelética; melhora a saúde e os níveis de forma física; previne e reabilita lesões ortopédicas; aumenta a capacidade de desempenhar atividades da vida diária, melhorando a situação funcional, a manutenção da independência e a prevenção da incapacidade, prevenindo quedas e fraturas relativas a elas) e as desvantagens (devido à pequena componente cardiopulmonar dos trabalhos de musculação, torna-se imprescindível sua complementação com trabalhos de caráter aeróbico, podem aparecer vertigens, falte de ar severa e dores torácicas, musculares ou articulares).

\section{CONCLUSÃO}

O treinamento resistido se apresenta como uma estratégia potente na prevenção e tratamento da osteoporose e pode ser mais bem sucedido quando combinado com outras intervenções terapêuticas, como ingestão adequada de cálcio e vitamina $\mathrm{D}$, medicação e uma modificação no estilo de vida, proporcionando hábitos saudáveis. Pesquisas adicionais sobre treinamento contra resistência são necessárias para investigar o efeito da manipulação referente às variáveis de exercício, obedecendo aos seus princípios científicos na obtenção de uma melhora considerável no aumento 
da DMO. Importante ressaltar que existem na literatura diretrizes futuras para osteoporose, registradas por Junqueira (2001, p. 2), referindo-se a

1. Estratégias para maximizar o pico de massa óssea, assim como para o diagnóstico precoce de eventuais perdas. 2. Definir o impacto da carência do cálcio e da vitamina D em crianças e como revertê-las. 3. Estabelecer quais os marcadores genéticos e como aplicá-los na prática. 4. Determinar a necessidade de suplementação dietética. 5. Identificar as pacientes que necessitam de tratamento. 6. Verificar em que situações devem ser utilizados os marcadores bioquímicos de osteoporose.

Quanto às mulheres disponíveis para aplicação de atividades de força, um prévio exame médico e análise de cada caso são prudentes, avaliando fatores de risco para doenças ósteo metabólicas, pois a análise individual associada às diferentes formas de se treinar promove ao professor de Educação Física a possibilidade de êxito na promoção da saúde e controle da perda óssea, presente na osteoporose.

\section{REFERÊNCIAS}

AMERICAN COLLEGE OF SPORTS MEDICINE. Guidelines for healthy adults under age 65 and Guidelines for adults over age 65 (or adults 50-64 with chronic conditions, such as arthritis). 2007. Disponível em:<http://www.acsm.org>. Acesso em: 18 fev. 2010.

AVEIRO, Mariana C. et al. Efeitos de um programa de atividade física no equilíbrio e na força muscular do quadríceps em mulheres osteoporóticas visando uma melhoria na qualidade de vida. Revista Brasileira de Cineantropometria e Movimento. Brasília. v. 12, n. 3, p. 33-38, set. 2004. BALSAMO, Sandor; SIMÃO, Roberto. Treinamento de força para osteoporose, fibromialgia, diabetes tipo 2, artrite reumatóide e envelhecimento. 2. ed. São Paulo: Editora Phorte, 2007.

BARACAT, Edmundo et al. Consenso brasileiro de osteoporose 2002. Revista Brasileira de reumatologia, v. 42, n. 6, nov/dez, 2002. 
BERBEL, Andrea M.; CARVALHO, Daiane A. SOUZA, Vitor F. Osteoporose nas UBSs: Conhecimento e prevenção na visão dos coordenadores da subprefeitura de Pirituba - SP. Conscientiae Saúde, v. 8, n. 1, p. 111-122, 2009. BOUCHARD, Claude; RANKINEN, Tuomo. Individual differences in response to regular physical activity. American College of Sports Medicine (ACSM), march. 2001.

BUIATE, Michelle S.; GONÇALVES, Alexandre. Efeito das atividades aquáticas e treinamento de força sobre a densidade óssea: Implicações sobre a osteoporose. Revista Digital Buenos Aires, Buenos Aires, v. 13, n. 119, abr. 2008. Disponível em: <http://www.efdeportes.com>. CARVALHO, Cecília M. R. G.; FONSECA, Carla C. C.; PEDROSA. José I. Educação para a saúde em osteoporose com idosos de um programa universitário: repercussões. Cad. Saúde Pública. Rio de Janeiro, v. 20, n. 3 , p. 719-726, maio/jun. 2004.

CARVALHO, Márcio I. Osteoporose: Visão do ortopedista. Revista Brasileira de Ortopedia, v. 4, n. 4, p. 91-7, 2006.

COSTA, Lúcia P. et al. Prevalência de osteoporose em mulheres na pósmenopausa e associação com fatores clínicos e reprodutivos. Departamento de Tocoginecologia, Faculdade de Ciências Médicas - CAISM - Unicamp. Revista Brasileira de Ginecologia e Obstetrícia, Campinas, n. 25, v. 7, p. 507-512. ago. 2003.

DANTAS, Estélio H. M. Alongamento e Flexionamento. 5. ed. Rio de Janeiro: Editora Shape, 2005.

. A Prática da Preparação Física. 5. e. rev. e ampl. Rio de Janeiro: Editora Shape, 2003.

DATASUS. Banco de dados online. Disponível em:<http://www.datasus.gov.br>. Acesso em: 15 jan. 2010.

FAISAL-CURY, A.; ZACCHELLO, K. Osteoporose: Prevalência e risco em mulheres de clínica privada maiores de 49 anos de idade. Acta ortop. Bras,. São Paulo, v.15, n. 3. 2007.

FLECK, Steven J.; KRAEMER, William J. Fundamentos do Treinamento de Força Muscular. 3. ed. Porto Alegre: Editora Artmed, 2006.

FOSS, Merle L.; KETEYIAN, Steven J. Fox: bases fisiológicas do exercício e do esporte.. 6. ed. Rio de Janeiro: Editora Guanabara Koogan, 2000. 
FRAZÃO, Paulo; NAVEIRA, Miguel. Prevalência de osteoporose: uma revisão crítica. Revista Brasileira de Epidemiologia, São Paulo, v. 9, n. 2. jun. 2006.

GRAVES, James E.; FRANKLIN, Barry A. Treinamento Resistido na saúde e reabilitação. Rio de Janeiro: Livraria e Editora Revinter Ltda., 2006.

GUYTON, Arthur C.; HALL, John E. Tratado de Fisiologia Médica. Rio de Janeiro: Editora Elsevier, 2006.

HASHIMOTO, Luci A.; NUNES, Elisabete de F. P. de A. Osteoporose nas unidades básicas de saúde: Conhecimento e práticas preventivas na visão das coordenadoras no município de Cianorte, Paraná. Revista Espaço para a Saúde, Londrina, v. 7, n.1, p. 1-9. dez. 2005. Disponível em: <www.ccs.uel.br/ espacoparasaude>.

JUNQUEIRA, Paulo A. de A.; FONSECA, Angela M. da; ALDRIGHI, José M. Osteoporose: diretrizes futuras. Revista da Associação Médica Brasileira, São Paulo, v. 47, n. 1. São Paulo, jan/mar. 2001.

KOWALSKI, S. C.; SJENZFELD, M. B. F. Utilização de recursos e custos em osteoporose. Revista da Associação Médica Brasileira. v. 47, n. 4 São Paulo. Out/dez. 2001.

MAZO, Giovana Z.; SETÙBAL, Kátia C.; BALBÈ, Giovane P. Programa de osteoporose: Percepção das mulheres que praticam atividade física.

Revista digital, Buenos Aires, Año 14, n. 133, jun. 2009. Disponível em: $<$ http://www.efdeportes.com/efd110/osteoporose-percepcao-das-mulheresque-praticam-atividade-fisica.htm>.

MCARDLE, William D.; KATCH, Frank I.; KATCH, Victor L. - Fisiologia do Exercício. Energia, Nutrição e Desempenho Humano. 6. ed. Rio de Janeiro: Editora Guanabara Koogan, 2008.

MINISTÉRIO DA SAÚDE. Queda em idosos. Notícia publicada e atualizada em outubro de 2009. Disponível em: <http://portal.saude.gov.br/portal/saude>. Acesso em: 29 jan. 2010.

MORAIS, Isaías J.; ROSA, Maria T. S.; RINALDI, Wilson - O treinamento de força e sua eficiência como meio de prevenção da osteoporose. Arquivos de Ciência da Saúde Unipar, Umuarama, 9 (2), mai./ago. p. 129-134, 2005. 
NAVEGA, Marcelo T.; OISHI Jorge. Comparação da qualidade de vida relacionada à saúde entre mulheres na pós-menopausa praticantes de atividade física com e sem osteoporose. Revista Brasileira de Reumatologia, São Paulo, v. 47, n. 4, jul./ago. 2007.

PORTH, Carol M.; KUNERT, Mary P. Fisiopatologia. Editora Guanabara Koogan. 6. Ed. Rio de Janeiro, 2004.

POWERS, Scott K.; HOWLEY, Edward T. Fisiologia do Exercício. Teoria e Aplicação ao Condicionamento e ao Desempenho. 3. ed., Barueri, SP: Manole, 2000.

RADOMINSKI et al. Osteoporose em mulheres na pós-menopausa. Projeto Diretrizes. Federação Brasileira das Sociedades de Ginecologia e Obstetrícia e Sociedade Brasileira de Reumatologia. Ação conjunta da Associação Médica Brasileira e Conselho Federal de Medicina. Agosto de 2002.

ROGATTO, Gustavo P. Efeitos antropométricos e funcionais do treinamento de força sobre o sistema muscular de indivíduos idosos. Biosci. J., v. 20, n. 3, p. 105-112, set./dez. 2004.

SALTER, Robert B. Distúrbios e lesões do sistema músculo esquelético. 3. ed. Rio de Janeiro: MEDSI - Editora Médica e Científica LTDA, 2001.

SECRETARIA DE ESTADO DE SAÚDE - Osteoporose. Notícia publicada eletronicamente na quarta-feira, 22/07/09. Disponível em: <http://www. saude.df.gov.br>. Acesso em: 24 ago. 2009,

SEGURA, Dora de C. A.et al. - Relação entre atividade física e osteoporose. Arquivos de Ciência da Saúde Unipar, Umuarama, v. 11, n.1. p. 45-50, jan./abr. 2007. SILVA, Flávio C. da; BRENTANO, Michel A.; KRUEL, Luis F. M. Efeitos da dieta e do treinamento de força na saúde óssea de mulheres pósmenopáusicas: estudo de caso. Revista Brasileira de Educação Física, Esporte, Lazer e Dança, v. 3, n. 3, p. 89-101, set. 2008.

SILVA, João L. N. da; OSÒRIO, Alexsandra T.; MONTEIRO, Sara M. S. A importância do treinamento de força na profilaxia da osteoporose. In: ENCONTRO DE EDUCAÇÃO FÍSICA E ÁREAS AFINS. 2. 2007. Anais... Coordenação de Pós Graduação / Departamento de Educação Física da UFPI. 26 e 27 de outubro de 2007. 
SIQUEIRA, Fernando V. et al. Prática de Atividade Física na Adolescência e Prevalência de Osteoporose na Idade Adulta. Revista Brasileira de Medicina do Esporte, v. 15, n. 1, jan/fev., 2009.

SWEET, Mary G. et al. Diagnosis and Treatment of osteoporosis. American Family Physician. v. 79, n. 3, feb., 2009. Disponível em: www.aafp.org/afp. TRINDADES, Raquel B.; RODRIGUES, Graciele M. Exercício de resistência muscular e osteoporose em idosos. Revista Mackenzie de Educação Física e Esporte - 2007, 6 (3): 79-86.

TUBINO, Manoel J. G.; MOREIRA, Sérgio B. Metodologia Científica do Treinamento Desportivo. 13. ed. Rio Janeiro: Editora SHAPE, 2003.

UCHIDA, Marco P. et al. - Manual de Musculação: Uma abordagem teórico-prática do treinamento de força. 4. Ed, São Paulo: Editora Phorte, 2006.

WEINECK, Jürgen. Biologia do Esporte. Editora Manole. 7. ed. rev. e amp. Barueri - São Paulo, 2005.

WILLOUGHBY, Darryn S. Ph.D., CSCS, FACSM. Current comment.

Resistance training in the older adult. American College of Sports Medicine (ACSM), abr., 2001.

WILMORE, Jack H.; COSTILL, David L. Fisiologia do Esporte e do Exercício. 2. ed. Barueri-SP: Editora Manole, 2001.

YAZBEK, Michel A.; MARQUES, João F. N. Osteoporose e outras doenças osteometabólicas no idoso, São Paulo-SP. Einstein, v. 6 (Supl 1), S74 - S80, 2008. 


\section{Fatores associados à inatividade física em adolescentes: um artigo de revisão}

Carlos Fernando de Amorim Alves

Rita de Cássia Ribeiro Silva

\section{INTRODUÇÃO}

A inatividade física tem sido amplamente discutida pela comunidade científica nacional e internacional, em especial pela sua associação com as doenças crônicas não transmissíveis (DCNT) em adultos, crianças e adolescentes. (PAFFENBARGER; LEE, 1996; NIH CONSENSUS CONFERENCE, 1996; STEELE et al., 2008) Durante a adolescência, há evidências de que a atividade física traz benefícios associados à saúde esquelética (conteúdo mineral e densidade óssea), ao controle da pressão sanguínea, da dislipidemia e da obesidade. (BOUCHARD; BLAIR; HASKELL, et al., 2007; JANSSEN; LEBLANC, 2010) Contribui ainda para o aumento da habilidade motora, assim como para o desenvolvimento psicológico e o aumento das relações sociais. (BIDDLE; SMITH, 2008)

Segundo a Organização Mundial da Saúde, 60\% da população mundial não cumpre as recomendações em relação à prática de atividades físicas. (WHO, 2010) Em estudo realizado 
por Brauman e colaboradores (2009) no período de 2002 a 2004, que envolveu 20 países e utilizou o Questionário Internacional de Atividade Física (IPAQ), foi observado que a prevalência de baixos níveis de prática de atividade física entre adultos variou entre $9 \%$ e $43 \%$; no Brasil, esta prevalência foi de $30,45 \%$ entre os participantes. Os autores observaram ainda que os homens se mostravam mais ativos fisicamente do que as mulheres em 17 dos 20 países estudados. Em outro estudo, envolvendo 51 países, Guthold e colaboradores (2008) observaram que $15 \%$ dos homens e $20 \%$ das mulheres eram inativos fisicamente.

Estudando adolescentes entre 13 e 15 anos de 34 países, Guthold e colaboradores (2010) notaram que apenas $28,8 \%$ dos meninos e $15,4 \%$ das meninas cumpriam as recomendações em relação à prática de atividade física; além disso, na maioria dos paises estudados, mais de um terço das crianças assistiam a três horas ou mais de TV por dia. Em artigo de revisão, Sission e Katzmarzyk (2008), ao analisarem 28 trabalhos de pesquisa que investigaram a prevalência de atividade física, observaram os maiores índices de prática de atividade física entre meninos australianos e meninas chinesas, sendo mais inativos meninos e meninas russos.

No Brasil, não existem dados de inquéritos epidemiológicos que dimensionem os índices de inatividade física em crianças e adolescentes em todo o território nacional. Apesar disso, os resultados de alguns estudos indicam o crescente aumento das prevalências do comportamento físico inativo nesse ciclo da vida, variando de 5,3\% a 94\%. (TASSITANO et al., 2007; CESCHINNI et al., 2009; NAHAS et al., 2009; SILVA et al., 2005) A variabilidade encontrada entre os estudos pode ser atribuída à diversidade de instrumentos utilizados, faixa etária incluída e pontos de corte utilizados na classificação dos níveis de atividade física (HALLAL, 2007); essa variação também é observada em estudos de abrangência internacional. (SISSION; KATZMARZYK, 2008)

Vários são os fatores que podem influenciar os padrões de atividade física: as características individuais, incluindo motivação, habilidades motoras; as características ambientais, o acesso a espaços de lazer, barreiras arquitetônicas, disponibilidade de tempo para a prática de atividades físicas, suporte sociocultural e condição financeira. Além disso, características 
sociodemográficas como escolaridade, estado civil, sexo e idade parecem assumir-se como fatores determinantes de um estilo de vida inativo fisicamente. (SEABRA et al., 2008; OEHLSCHLAEGER, 2004; BAUER et al., 2008; BIDDLE et al, 2004)

Outro fator que pode contribuir para o aumento da inatividade física entre os jovens é a adoção de comportamentos sedentários como assistir à TV, jogar video games e usar o computador. O envolvimento excessivo em atividades intelectuais (tarefas escolares, leitura, cursos de formação), trabalho (remunerado ou não) e a ausência nas aulas de Educação Física também contribuem para tais mudanças de comportamento (SILVA et al., 2009). Os consumos de tabaco e de álcool são alguns dos fatores comportamentais que se encontram também associados à inatividade física. (OLIVEIRA et al., 2003)

Inúmeros estudos têm observado associação entre o nível de atividade física e as doenças crônicas não transmissíveis (DCNTs), em particular as doenças do aparelho circulatório (DACs). Entre as DACs, destacaram-se as doenças cerebrovasculares e as doenças isquêmicas do coração, que em 2004 compuseram mais de $47 \%$ dos óbitos por DACs no Brasil. (MINISTÉRIO DA SAÚDE, 2008)

É consenso, na literatura, que a exposição continuada aos fatores tradicionalmente de risco (estresse psicossocial, fumo e consumo abusivo do álcool) em adição ao consumo de uma dieta inadequada (pobre em frutas e vegetais), associado à inatividade física, conduzem direta ou indiretamente à patogênese de enfermidades cardiovasculares, com comprometimento precoce da vida dos indivíduos. Tem sido observado, ainda, que a inatividade física e o menor nível de aptidão física estão relacionados com fatores de risco para doenças do aparelho circulatório em crianças, independentemente da obesidade. (ANDERSEN et al., 2008) Estudos mostram que a maioria dos jovens não cumprem as recomendações sobre atividade física e redução do hábito sedentário, levando este comportamento para a fase adulta. (LARSEN,NELSON, POPKIN, 2004) A manutenção desse comportamento representa risco à saúde, na medida em que o sedentarismo tem sido associado a risco cardiovascular em adolescentes e adultos. (GOMEZ, 2010; KATZMARZYK, 2009) 
Assim, a detecção dos níveis de atividade física entre jovens, bem como dos fatores associados à inatividade física, pode contribuir para o desenvolvimento de programas de caráter preventivo que estimulem a adoção de um estilo de vida ativo fisicamente.

Diante dos poucos estudos realizados no Brasil, em especial na Região Nordeste, pretende-se com o presente trabalho dimensionar o problema, além de contribuir para o conhecimento sobre os fatores associados à inatividade física.

\section{INATIVIDADE FÍSICA EM ADOLESCENTES NO BRASIL: UMA REVISÃO SISTEMÁTICA DE ESTUDOS}

O trabalho de revisão sistemática realizado por Tassitano e colaboradores (2007), abrangendo 21 artigos resultantes de investigações sobre níveis de atividade física de crianças e adolescentes brasileiros no período de 1990 a 2005, sinaliza uma produção modesta de pesquisas nesse campo do conhecimento. Além disso, os autores observaram que apenas dois, representando aproximadamente $10 \%$ do total de artigos publicados, foram realizados na Região Nordeste e os demais foram realizados nas Regiões Sul e Sudeste.

Na Tabela 1, apresenta-se o resumo dos resultados de alguns estudos efetuados em várias cidades distribuídas nas macrorregiões do Brasil, no período de 2005 a 2009, de forma a contribuir com informações referentes ao tema. A maior parte desses trabalhos foi realizada nas Regiões Sul e Sudeste. Trata-se de estudos de delineamento transversal, realizados com amostras que variaram de 105 a 5.028 adolescentes com idade entre 10 e 19 anos, exceto o estudo executado por Silva e colaboradores (2005), cuja população alvo tinha de 7 a 17 anos, e o estudo de Nahas e colaboradores (2009), que envolveu indivíduos de 15 a 24 anos. 


\begin{tabular}{|c|c|c|c|c|c|c|c|c|c|c|c|c|c|c|}
\hline 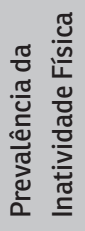 & $\begin{array}{l}\frac{*}{0} \\
\overrightarrow{0} \\
\vec{\omega}\end{array}$ & 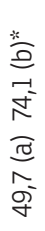 & 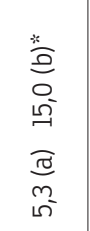 & 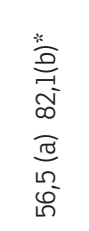 & 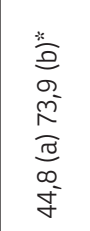 & 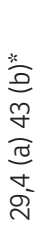 & 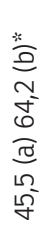 & 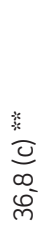 & 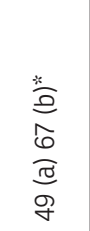 & 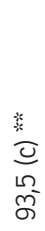 & 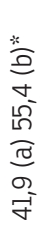 & 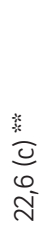 & 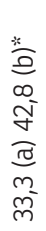 & 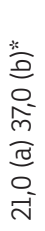 \\
\hline $\begin{array}{l}\text { 옹 } \\
\text { 은 } \\
\text { 은 }\end{array}$ & 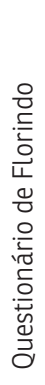 & 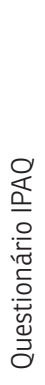 & 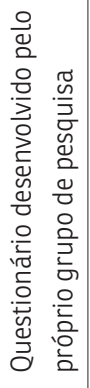 & 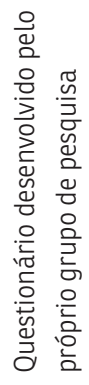 & 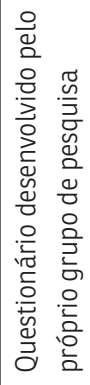 & 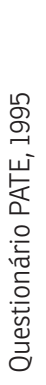 & 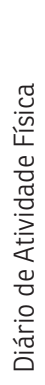 & 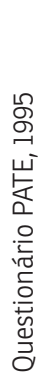 & 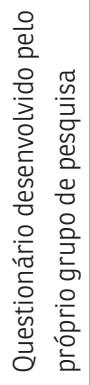 & 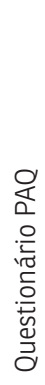 & 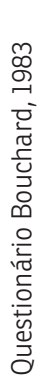 & 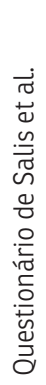 & 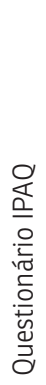 & 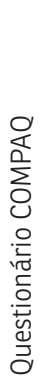 \\
\hline 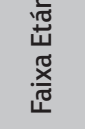 & 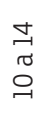 & 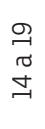 & $\begin{array}{l}\underset{\sigma}{\sigma} \\
\stackrel{\sim}{\sim}\end{array}$ & $\begin{array}{l}\stackrel{\Omega}{\rightrightarrows} \\
\text { 。 } \\
\text { 으 }\end{array}$ & $\begin{array}{l}\infty \\
\stackrel{\infty}{\sigma} \\
\stackrel{m}{-}\end{array}$ & $\begin{array}{l}\underset{\infty}{\sigma} \\
\widetilde{\sigma} \\
=\end{array}$ & $\begin{array}{l}\infty \\
\underset{\sigma}{\sigma} \\
\underset{J}{J}\end{array}$ & $\begin{array}{l}\stackrel{m}{\sim} \\
\stackrel{\sigma}{=}\end{array}$ & 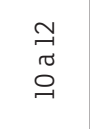 & $\begin{array}{l}\underset{1}{\sigma} \\
\stackrel{\sim}{n}\end{array}$ & $\begin{array}{l}\infty \\
\sim \\
\tilde{\sigma} \\
\stackrel{\infty}{n}\end{array}$ & $\begin{array}{l}\infty \\
\stackrel{\infty}{\sigma} \\
\underset{\sigma}{\sigma}\end{array}$ & $\begin{array}{l}\infty \\
\sim \\
\sigma \\
\stackrel{\sim}{\sigma}\end{array}$ & $\begin{array}{l}\Omega \\
\sigma \\
\stackrel{\sigma}{\sigma} \\
\stackrel{1}{n}\end{array}$ \\
\hline 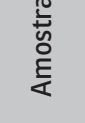 & $\stackrel{\text { เి }}{\circ}$ & $\begin{array}{l}\stackrel{\text { fo }}{\infty} \\
\text { mi }\end{array}$ & 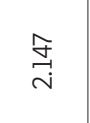 & $\stackrel{\sqrt[\hat{\infty}]{\infty}}{ }$ & 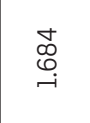 & $\stackrel{\sim}{\sim}$ & 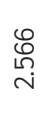 & $\underset{\pi}{\stackrel{9}{1}}$ & $\underset{\sim}{\stackrel{\text { }}{+}}$ & 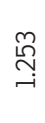 & ฟิ ชิ & 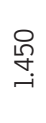 & ষ্ঠ & 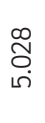 \\
\hline ) & $\begin{array}{l}0 \\
\tilde{1} \\
1 \\
\frac{0}{0} \\
\frac{\pi}{0} \\
\frac{0}{2}\end{array}$ & 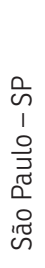 & 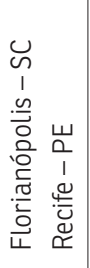 & 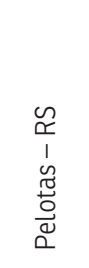 & 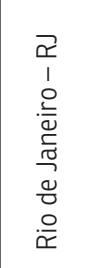 & $\begin{array}{l}\text { un } \\
1 \\
\cong \\
\frac{0}{1} \\
\frac{0}{0} \\
\frac{0}{0} \\
\frac{0}{2} \\
\frac{0}{4}\end{array}$ & 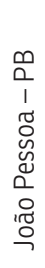 & 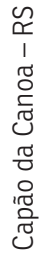 & 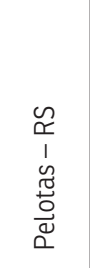 & $\begin{array}{l}\frac{1}{<} \\
! \\
: 0 \\
\frac{0}{0} \\
\frac{\pi}{2}\end{array}$ & 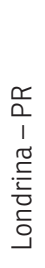 & 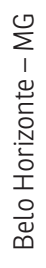 & 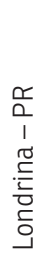 & 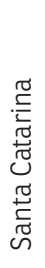 \\
\hline 䒕 & 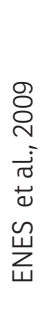 & 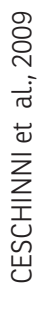 & 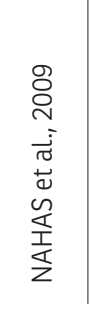 & 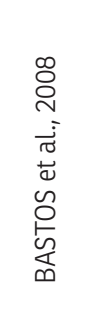 & 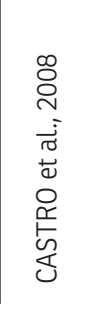 & 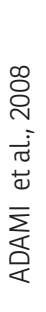 & 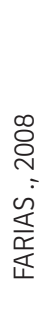 & 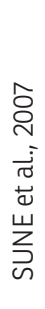 & 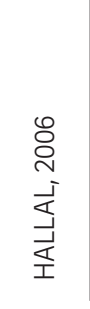 & 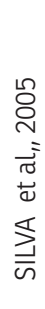 & 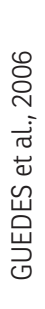 & 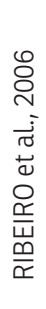 & 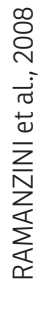 & 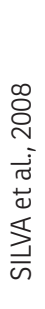 \\
\hline
\end{tabular}


Em todos os estudos apresentados, foram descritos detalhadamente os procedimentos metodológicos. Na maioria deles, os dados de prevalência foram apresentados segundo o sexo. Entre os adolescentes do sexo masculino, a prevalência de inatividade física variou de 5,3\% a 49,7\%; no sexo feminino, a variação foi de $15 \%$ a $74,1 \%$. Esta variabilidade talvez possa ser atribuída aos diferentes instrumentos utilizados: Questionário desenvolvido por Florindo (2006), Questionário de Comportamento dos Adolescentes Catarinenses (COMPAC), Questionário Internacional de Atividade Física (IPAQ), Questionário de Atividade Física (PAQ), Questionário desenvolvido por Bouchard e Tremblay (1983).

Além da variação de questionários utilizados, outro fator a ser considerado são os diferentes pontos de corte adotados para a classificação dos níveis de atividade física.

Dos instrumentos utilizados para avaliação dos níveis de atividade física, aquele adotado por Ceshinni e colaboradores (2009) e Ramanzini e colaboradores (2008) - ambos optaram pelo IPAQ - foi validado para população de brasileiros tanto para adultos jovens quanto adolescentes. (PARDINI et al., 2001; GUEDES et al., 2005) Ressalta-se que o COMPAC, utilizado por Silva e colaboradores (2008), e o Questionário desenvolvido e validado por Florindo e colaboradores (2006), utilizado por Enes, Pegolo e Silva (2009), foram desenvolvidos a partir de estudos realizados no Brasil.

O padrão de medida da atividade física observado nesses questionários foi o tempo de execução de determinadas atividades e o número de dias por semana em que estas são realizadas, tendo como ponto de corte adotado para caracterizar o estado de inatividade física: realizar menos que 300 minutos de atividades físicas por semana. (CESCHINNI et al., 2009; RAMANZINI et al., 2008; SILVA et al., 2008; HALLAL et al., 2006; ENES et al., 2009; CASTRO et al., 2008; BASTOS; ARAÚJO; HALLAL, 2008) No entanto, outros estudos utilizaram o número de sessões por semana além do tempo de participação em atividades moderadas e vigorosas, sem levar em consideração os 300 minutos. (NAHAS et al., 2009; SILVA et al., 2005, ADAMI et al., 2008; SUNE et al., 2007)

Apenas três estudos avaliaram a atividade física tendo como referência o gasto calórico diário com tais atividades. Nesse sentido, dois estudos 
consideraram como ponto de corte para caracterizar o estado de inatividade física uma demanda energética diária $\leq 37 \mathrm{kcal} / \mathrm{kg} /$ dia. (GUEDES et al., 2006; FARIAS, 2008) No estudo realizado por Ribeiro e colaboradores (2006), a demanda energética diária foi medida em METs (unidade metabólica), separando-se o resultado em quartis, e classificado como inativo quem estivesse no quartil inferior $(\mathrm{Q} 1)$, representando um gasto energético $<100 \mathrm{MET} /$ dia.

A variação na caracterização dos níveis de atividade física representa elemento complicador na comparação entre os estudos encontrados na literatura, porém, a classificação por tempo de realização das atividades, utilizando-se como ponto de corte a recomendação de 300 minutos por semana, tem sido apresentada como uma alternativa de ordem metodológica. A origem desse ponto de corte vem da recomendação encontrada na literatura sugerindo os 300 minutos como tempo mínimo semanal durante o qual crianças e adolescentes devem exercitar-se para atingir benefícios para a sua aptidão física e saúde. (PHYSICAL ACTIVITY GUIDELINES ADVISORY COMMITTEE REPORT, 2008; CAVILL; BIDDLE; SALLIS 2001; CORBIN; PANGRAZI, 2004; WHO, 2009; HEALTH CANADA, 2004; JANSSEN; LEBLANC, 2010)

Alguns autores defendem a proposta do engajamento em atividades moderadas a vigorosas três vezes ou mais por semana durante pelo menos 20 minutos (SALLIS; PATRICK, 1994), o que resultaria em um tempo menor que 300 minutos por semana. Segundo esses autores, esse tempo de treino já seria suficiente para trazer benefícios à saúde de crianças e adolescentes.

Nos estudos que investigam os fatores associados à inatividade física, os autores observam que características sociodemográficas e comportamentais contribuem para a instalação do estado de inatividade física entre jovens. (CESCHINI et al., 2009; FARIAS , 2008; HALLAL et al., 2006; SILVA et al., 2008;).

É possível que a identificação dos fatores associados à inatividade física, entre os jovens, gere subsídios para a criação de políticas públicas que tenham como objetivo a promoção de um estilo de vida mais ativo fisicamente nesse ciclo de vida. Contudo, desafios são apresentados aos 
pesquisadores no que se refere à metodologia mais adequada para mensurar os níveis de atividade física, bem como em relação ao estabelecimento dos pontos de corte e dos instrumentos mais fidedignos para determinar o nível de atividade física realizado por adolescentes.

\section{FATORES ASSOCIADOS À INATIVIDADE FÍSICA}

No Brasil, não existem estudos epidemiológicos abrangentes, que dimensionem os fatores associados à inatividade física em crianças e adolescentes em todo o território nacional. Observam-se estudos pontuais envolvendo determinada região do país ou mais especificamente uma cidade, sendo as Regiões Sul e Sudeste as que mais apresentam estudos dessa natureza. O estudo desses fatores é de suma importância para o desenvolvimento de ações que visem o combate à inatividade física e ao comportamento sedentário entre os jovens.

Para Seabra e colaboradores (2008), existem determinantes individuais, incluindo motivação, habilidade motora, além dos determinantes ambientais, integrados pelo acesso a equipamentos e espaços de lazer, custos dos programas, barreiras arquitetônicas, disponibilidade temporal e suporte sociocultural. Além disso, características sociodemográficas como escolaridade, condição financeira, estado civil, sexo e idade parecem integrar os principais fatores determinantes de um estilo de vida inativo fisicamente. (SEABRA et al., 2008; OEHLSCHLAEGER et al., 2004; BAUER et al., 2008; BIDDLE et al., 2004b)

Em relação ao gênero, alguns autores identificaram maior prevalência de inatividade física entre as meninas. (OEHLSCHLAEGER et al., 2004; SILVA et al., 2005; VELDE et al., 2007; PERSON et al., 2009a) No entanto, em estudo realizado na África, as meninas apresentaram-se mais ativas fisicamente. (NHANTUMNO et al., 2008) Nesta investigação, o tempo gasto com as atividades domésticas foi incluído na quantificação da atividade física total realizada, fato que contribuiu para a elevação do nível de atividade física total das meninas. É possível que, em sociedades em que as meninas são submetidas à realização de atividades domésticas desde a infância, o nível geral de prática de atividade física se iguale ou supere o dos meninos. 
Em investigações em que o nível de atividade física foi avaliado com base na participação em atividades esportivas no lazer, os meninos aparecem como mais ativos, em relação às meninas. É possível que fatores biológicos e socioculturais influenciem a participação dos meninos em atividades esportivas e exercícios mais vigorosos, enquanto as meninas são levadas a participar de atividades recreativas, estas de menor intensidade. (SEABRA et a.,, 2008) Alguns estudos observam uma exposição mais ascendente dos meninos às atividades como futebol, natação e atletismo. (HALLAL, 2006)

Comportamentos sedentários como assistir à TV ou utilizar computador por tempo prolongado têm sido associados à prática insuficiente de atividade física (KOEZUKA et al., 2006; HALLAL, 2006; CESCINI et al., 2009; LANNOTTI et al., 2009; FULTON et al., 2009); no entanto, Silva e colaboradores (2008) encontraram essa associação somente entre os rapazes. Para Biddle e colaboradores (2004), o comportamento sedentário não necessariamente impede a participação em atividades físicas e vice-versa. Em estudo envolvendo 1.752 adolescentes, Fernandes e colaboradores (2008) verificaram que o engajamento em atividades esportivas estava associado a outros comportamentos ativos como andar de bicicleta ou caminhar nos momentos de lazer, porém, o fato de participar de atividades esportivas não proporcionou redução no tempo dedicado a assistir à TV. Segundo Tavares e colaboradores (2007), reduzir comportamentos sedentários não garante que o tempo utilizado nessas atividades seja empregado em atividades físicas. Sendo assim, não basta reduzir ou eliminar hábitos sedentários, é preciso que exista incentivo à participação em atividades físicas.

Outro fator avaliado na determinação do comportamento inativo é a diminuição do tempo destinado à atividade física com o aumento da idade. À medida que a criança cresce, outras atribuições vão surgindo na vida dos jovens. (GUEDES et al., 2001; SEABRA et al., 2008; PEARSON et al., 2009a) É provável que o tempo gasto com atividades físicas passe a ser ocupado por atividades escolares ou pelo trabalho já em idade precoce.

A condição socioeconômica tem aparecido como um fator associado à prática de atividade física, uma vez que a situação financeira constitui elemento importante na rotina de vida das pessoas. Nesse contexto, Farias 
(2008) encontrou maior prevalência de inatividade física entre adolescentes que não trabalham e que possuem pais com um nível de escolaridade mais alto. Os autores atribuem esse fenômeno ao fato de que os meninos que trabalham se deslocam de bicicleta ou a pé até o trabalho e as meninas ajudam nas tarefas domésticas; sendo assim, os meninos são mais ativos fisicamente.

Em contrapartida, Hallal e colaboradores (2006) observaram maior participação em programas de atividades físicas estruturados, no lazer, entre jovens de classe social mais alta e cujas mães eram ativas fisicamente. Corroborando esses resultados, Pavon e colaboradores (2010) encontraram maiores índices de condição física em jovens que possuem uma melhor condição financeira. Assim, parece que a condição financeira pode atuar de forma específica nos domínios da atividade física (atividades laborais, atividades domésticas, formas de deslocamento e atividades do lazer).

$O$ fato de pertencer a um extrato social economicamente desfavorecido pode refletir em envolvimento nas atividades físicas do cotidiano, na medida em que esses adolescentes andam mais ou fazem trabalhos domésticos. Ressalta-se que muitos desses jovens deixam de participar de programas de atividade física estruturados no momento de lazer por limite do acesso a programas pagos. (SEABRA et al., 2008; FARIAS et al., 2008) Esse quadro poderá ser revertido quando programas comunitários forem disponibilizados pelo governo à população em geral, democratizando o acesso a programas estruturados de atividade física para populações mais carentes. A implantação de programas comunitários de atividades físicas pode contribuir para a redução dos níveis de inatividade física entre os jovens. Programas estruturados que envolvam as práticas esportivas, ginásticas e outras formas de exercício que possuam planejamento adequado para o desenvolvimento de componentes da aptidão física relacionada à saúde podem promover um aumento da condição física dos jovens ao praticar regularmente tais atividades. (GUEDES; GUEDES, 1995) No entanto, é possível que jovens pertencentes a famílias pobres tenham contato com atividade física no lazer pela participação em atividades espontâneas como jogos e brincadeiras na própria comunidade, por iniciativa própria, sem um caráter estrutural ou acompanhamento profissional. 
Em artigo de revisão, Davison, Wender e Lawson (2008) verificaram que adolescentes que realizam deslocamento ativo atendem às recomendações para a prática de atividades físicas, além de apresentarem maior capacidade cardiorrespiratória. No estudo conduzido por Silva e Lopes (2008), envolvendo jovens de 7 a 12 anos, os autores observaram que o deslocamento ativo para a escola se associou a uma menor prevalência de sobrepeso; além disso, os alunos oriundos de escolas públicas eram mais ativos no deslocamento comparados com os alunos de escolas privadas. Jovens mais pobres são mais ativos na medida em que utilizam caminhada e bicicleta para deslocar-se até a escola, o que não é observado entre jovens que usam meio de transporte motorizado, e por conta disso não fazem atividade física no deslocamento para a escola (HALLAL, 2006; SEABRA et al,, 2008).

Outro aspecto a ser considerado é a influência da família no nível de prática de atividade física de crianças e adolescentes. Em estudo realizado por Bauer e colaboradores (2008), os autores observaram que os adolescentes que são incentivados por seus pais a engajar-se em programas de atividade física são realmente mais ativos; além disso, nesse estudo pode ser observada a influência da mãe sobre as filhas e do pai sobre os garotos. A participação dos pais não está somente associada à possibilidade de prover o exercício físico ou incentivar os filhos; na verdade, alguns estudos mostram que, quando os pais são ativos fisicamente, as chances de os filhos também o ser aumentam. (PEARSON et al., 2009b) No estudo de Moore e colaboradores (1991 apud SEABRA et al., 2008), as crianças cujo pai era ativo fisicamente possuíam 3,4 vezes mais chance de ser ativas, quando a mãe era ativa a chance era de 2 vezes, quando os dois eram ativos a chance subia para 7,2 vezes.

Outros resultados como os de Freedson e Everson (1991 apud SEABRA et al., 2008) indicaram que o fato de os pais serem bastante ativos fisicamente fez com que 93\% a 97\% das crianças também fossem ativas. Assim, o exemplo dos pais passa a assumir um papel importante em relação à prática de exercícios das crianças. Porém, quando a ocorrência do sedentarismo entre os pais é alta, a criança tende a repetir esse comportamento. 
O aumento observado na prevalência da inatividade física entre adultos (BRAUMAN, 2009; GOUTHOLD et al., 2008) representa um elemento complicador na promoção de atividade física para crianças e adolescentes. A importância de se oferecer atividade física desde a infância reside no fato de que comportamentos em relação à prática de atividades físicas quando incorporados nessa fase da vida podem ser transferidos para a vida adulta. (MALINA, 1996) No estudo de Azevedo e colaboradores (2007), pode-se observar que, entre os 2.577 indivíduos adultos estudados, 27,5\% apresentaram níveis adequados de prática de atividade física, e 54,9\% destes reportavam regularidade na prática de atividade física na adolescência.

Rainkinen e Bouchard (2007) sugerem que aspectos genéticos podem influenciar o estado de inatividade física das pessoas, o potencial individual de treinabilidade e a resposta ao exercício. Sendo assim, as pessoas respondem de forma diferente a um determinado programa de exercícios, mesmo dentro de uma mesma família; segundo os autores, essas variações podem ser atribuídas a questões genéticas. Em relação à musculatura esquelética, as fibras do tipo 1 são utilizadas prioritariamente para atividades de menor intensidade e longa duração, enquanto as fibras do tipo 2 são utilizadas em atividades mais intensas, que requerem maior quantidade de força muscular. Indivíduos que possuem maior predominância de fibras do tipo 1 têm maior aptidão para a realização de atividades de longa duração, enquanto os indivíduos que possuem predominância das do tipo 2 desempenham melhor atividades de força. Acredita-se que o componente genético influencia a predominância do tipo de fibra muscular, apesar de o tipo de treinamento ter alguma influência sobre os subtipos de fibra. (RAIKINEN; BOUCHARD , 2007; MACLNTOSH; GARDINER; McCOMAS, 2006) Da mesma forma, o aspecto genético influencia o sistema cardiorrespiratório, uma vez que indivíduos com características semelhantes, submetidos ao mesmo treinamento por igual período de tempo, demonstram alterações diferentes no nível de consumo máximo de oxigênio (VO2 max) após a realização do programa de exercícios. (RAIKINEN; BOUCHARD, 2007) Essa diferença tem sido atribuída a variações genéticas entre os indivíduos. 
As diferenças individuais em relação à realização do exercício devem ser consideradas no estabelecimento de estratégia para o incentivo de jovens ao engajamento em programas de atividades físicas. $\mathrm{O}$ fato de possuir mais ou menos habilidade para o desenvolvimento muscular ou, ainda, maior ou menor capacidade aeróbica não pode ser encarado como barreira para a realização do exercício. É preciso que as atividades físicas propostas para os jovens tenham um caráter de promoção da saúde, independentemente da performance. Sendo assim, é preciso compreender que determinados indivíduos terão um melhor desenvolvimento em determinados aspectos da aptidão física em comparação com seus pares.

\section{HÁBITO SEDENTÁRIO}

Além da inatividade física, o hábito sedentário aparece como um fator a ser considerado, na medida em que pode influenciar a saúde dos jovens. Segundo Cillero \& Jago (2010), a cultura familiar de assistir à TV, a idade materna, o trabalho materno e a presença de TV no quarto são alguns dos fatores que contribuem para que crianças assistam mais à TV e com isso aumentem o hábito sedentário.

Alguns estudos mostram que o hábito sedentário apresenta associação negativa com autoimagem e satisfação, associando-se positivamente com agressão física e baixo nível de socialização. (LANNOTTI et al., 2009) Segundo Marshall; Golery; Biddle e colaboradores (2006), na atualidade, cerca de $28 \%$ dos jovens assistem a mais de 4 horas de TV por dia. Nos Estados Unidos, entre jovens de 6 a 11 anos e de 12 a 15 anos, a média de tempo dedicado a hábitos sedentários observada em cada grupo foi de 6,07 e 7,53 respectivamente. No Brasil, Hallal e colaboradores (2006) observaram que jovens de 10 a 12 anos assistiam à TV, em média, durante 3,3 horas por dia. Nessa direção, Atkin e colaboradores (2008) notaram um envolvimento excessivo em atividades sedentárias como utilização de computador, e TV e video game após o turno de estudo, em detrimento da prática de atividades físicas.

Hábitos sedentários têm sido associados ao aumento do percentual de gordura corporal em crianças e adolescentes (MARSHALL et al., 2004); 
estudos mostram que, independentemente da prática de atividade física, crianças que assistem mais à TV apresentam uma maior quantidade de gordura corporal. (JACKSON et al., 2009) Nesse mesmo contexto, Janssen e colaboradores (2005), em estudo envolvendo 34 países, observaram uma associação positiva entre tempo assistindo à TV e sobrepeso. Alguns estudos observam que, durante os momentos em que jovens estão assistindo à TV ou utilizando computador por períodos prolongados, aumenta o consumo de alimentos não saudáveis como refrigerantes, doces e lanches. (CARMINA et al., 2010; UTTER et al., 2003)

\section{ATIVIDADE FÍSICA, APTIDÃO FÍSICA E SAÚDE}

É preciso não somente motivar as crianças e adolescentes, mas os adultos, em uma perspectiva de tornar nossa sociedade mais saudável e ativa fisicamente. Assim, na tentativa de se estabelecer a promoção de atividade física para os diversos grupos populacionais, tem-se recorrido a modelos para a compreensão da relação entre atividade física, saúde e aptidão física. Entre eles, ressalta-se o proposto por Bouchard e Shepard (1994) (Figura 1), citado por Nahas e Barros (2003).

O modelo elaborado por Bouchard e Shepard (1994 apud NAHAS; BARROS, 2003) propõe uma rede de relações na qual a atividade física realizada no âmbito do lazer, do trabalho e demais domínios exerce influência sobre os níveis de saúde. No entanto, pode-se observar que outros elementos podem mediar esta relação, a exemplo da aptidão física relacionada à saúde, que por sua vez é representada por alterações no organismo de ordem morfológica, muscular, cardiorrespiratória e metabólica.

As alterações morfológicas representam a mudança na composição corporal como diminuição do percentual de gordura corporal e hipertrofia muscular; as alterações musculares podem ser representadas pelo aumento dos níveis de força e resistência muscular; as alterações no sistema cardiorrespiratório dizem respeito ao aumento do consumo máximo de oxigênio (VO2 max), bem como as alterações estruturais no coração como a hipertrofia concêntrica e excêntrica induzida pelo treinamento físico; as alterações metabólicas podem ser representadas por variações na sensibilidade 
à insulina e diminuição na intolerância à glicose, ou mesmo pela redução de níveis plasmáticos de triglicérides.

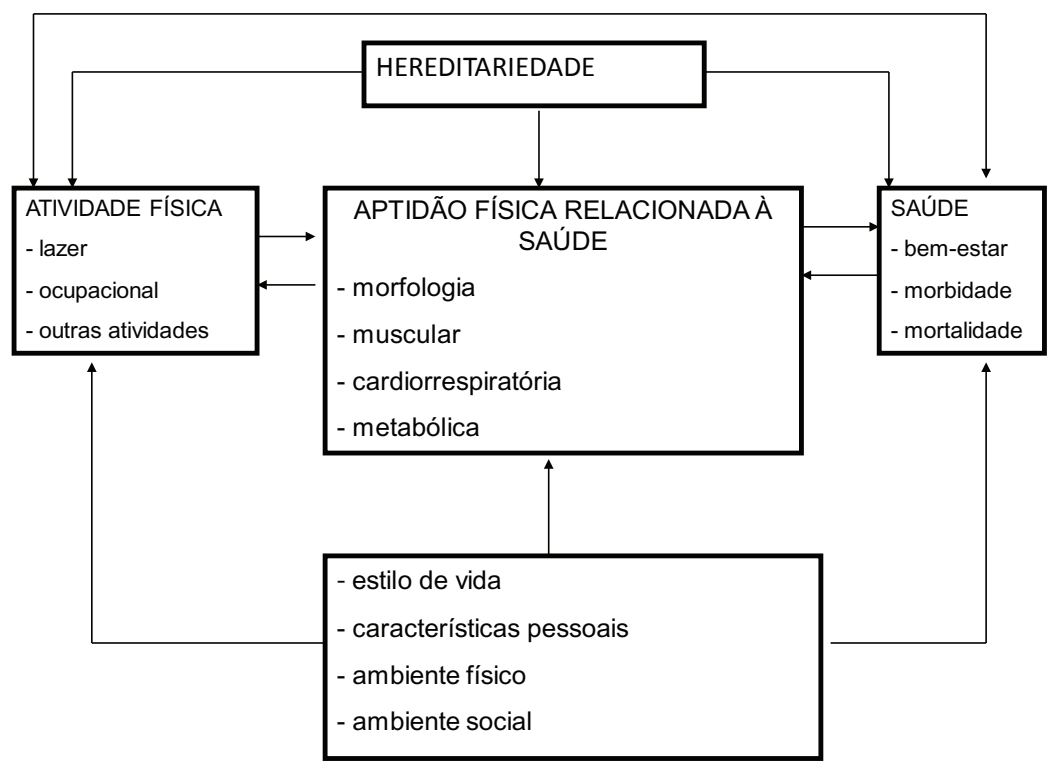

Figura 1. Modelo das relações entre atividade física, aptidão física e saúde Fonte: Adaptado de Nahas e Barros (2003).

Os autores propõem ainda um fluxo contrário mostrando a influência da saúde nos níveis de aptidão física e, por conseguinte, nos níveis de atividade física. Essa relação em mão dupla reforça a crença de que tanto a prática de atividade física tem relação com a saúde quando os níveis de saúde influenciam a atividade física praticada; além disso, esta relação pode-se estabelecer sob a mediação da aptidão física ou não, o que leva a crer que nem sempre é necessário aumento na aptidão física para se ter um bom estado de saúde ou a prática de atividade física.

Ressalta-se que os níveis de saúde, de atividade física e de aptidão física são influenciados pelo estilo de vida, pelas características pessoais, pelo ambiente físico e social, além dos fatores genéticos. Assim, é imperativa a 
compreensão de que qualquer proposta de intervenção, seja com adultos, crianças ou adolescentes, precisa levar em consideração os elementos ora referidos e as suas inter-relações. Dessa forma, os programas de incentivo à prática de atividades físicas poderão ter um caráter mais personalizado uma vez que deverão ser ajustados à realidade social das pessoas, bem como a seu nível de relação com a prática de atividades físicas. Assim sendo, é coerente pensar que os programas que tiverem essa estrutura poderão promover uma mudança de comportamento entre os indivíduos inativos fisicamente, além de estabelecer estratégias que favoreçam a manutenção do estilo de vida ativo fisicamente ao longo de todo o ciclo de vida.

\section{CONCLUSÃO}

A inatividade física é um aspecto que pode influenciar a saúde de crianças e adolescentes. Características pessoais e familiares parecem influenciar a determinação do comportamento inativo fisicamente. Sendo assim, é preciso que desde a infância seja feito um combate aos fatores que levam a esse quadro. Proporcionar a prática de atividades físicas na infância, bem como a regulação na utilização de video game, computador e TV, são iniciativas fundamentais no combate à inatividade física entre os jovens.

\section{REFERÊNCIAS}

ADAMI, Fernando et al. Insatisfação corporal e atividade física em adolescentes da região continental de Florianópolis. Psic.: Teor. e Pesq., v. 24, n. 2, p. 143-149, jun. 2008.

ANDERSEN, L. B. et al. Fitness, fatness and clustering of cardiovascular risk factors in children from Denmark, Estonia and Portugal: the european youth heart study. Internacional Journal of Pediatric Obesity, v. 3, Supl. 1, p. 58-66, 2008.

ATIKIN, A. J. ET AL. Critical hours: physical activity and sedentary behavior of adolescents after school. Pediatric Exercise Science, v. 20, n. 4, p. 446-456, nov. 2008. 
AZEVEDO, M. R. Continuidade na prática de atividade física da adolescência para a idade adulta: estudo de base populacional. Revista de Saúde Pública, v. 41, n. 1, p. 69-75, 2007.

BASTOS, J. P.; ARAUJO, C. L. P.; HALLAL, P. C. Prevalence of insufficient physical activity and associated factors in Brazilian adolescents. Journal of Physical Activity and Health, n. 5, p. 777-794, 2008.

BAUER, K. W. et al. Parental influences on adolescents physical activity and sedentary behavior: longitudinal findings from Project EAT-II. International Journal of Behavioral Nutrition and Physical Activity, n. 5, p. 12, 2008.

BIDDLE, S. J. H. et al. Physical activity and sedentary behaviours in youth: issues and controversies. The Journal of the Royal Society for the Promotion oh Health, v. 124, n. 1, p. 29-33, 2004.

BIDEDLE, S. J. H.; SMITH, A. L. Youth Physical Activity and Sedentary Behavior: challenges and solutions. Champaign, IL: Human Kinetics, 2008.

BOUCHARD, C.; TREMBLAY, A. L.; BLANC, C. A method to assess energy expenditure in children and adults. American Journal of Clinical Nutrition, v. 37, n. 3, p. 461-467, 1983.

BOUCHARD, C.; BLAIR,S.N.; HASKELL,W.L. Physical Activity and Health. Campaign. IL: Human Kinetcs, 2007.

BRAUMAN, A. et al. The international prevalence study on physical activity: results from 20 countries. International Journal of Behavioral Nutrition and Physical Activity, v. 6, n. 21, mar. 2009. Disponível em: <http//.www.ijbnpa. org/content/i/21>. Acesso em: 10 out. 2009.

CARMINA, N.; YOUNG,T. K.; COREY, P. K. Associations of television viewing, physical activity and dietary behaviours with obesity in aboriginal and nonaboriginal Canadian youth. Public Health Nutrition, v. 13. n 9: p. 1430-7. set. 2010.

CASTRO, Inês Rugani Ribeiro de et al. Vigilância de fatores de risco para doenças não transmissíveis entre adolescentes: a experiência da cidade do Rio de Janeiro, Brasil. Cad. Saúde Pública, v. 24, n. 10, p. 2279-2288, out. 2008. CAVILL, N.; BIDDLE, S.; SALLIS, F. Health enhancing physical activity for young people: Statement of the United Kingdom Expert Consensus Conference. Pediatric Exercise Science, n. 13, p. 12-25, 2001. 
CESCHINI, F. L. et al. Prevalência de inatividade física e fatores associados em estudantes do ensino médio de escolas públicas estaduais. Jornal de Pediatria, v. 85, n. 4, p. 301-306, 2009.

CILLERO, I. H.; JAGO, R. Systematic review of correlates of screen-viewing among young children. Preventive Medicine, v. 51, n. 3, p. 3-10. 2010.

CORBIN, C. B.; PANGRAZI, R. P. Physical activity for children: a statement of guidelines for children ages 5-12. Reston, VA: National Association for Sport and Physical Education, 2004.

DAVISON, K. K.; WENDER, J. L.; LAWSON, C. T. Children's active commuting to school: current knowledge and future directions. Preventing Chronic Disease, Public Health Research, Practice and Policy, v. 5, n. 3, p. 1-10, jul. 2008.

ENES, C. C.; PEGOLO, G. E.; SILVA, M. V. Influência do consumo alimentar e do padrão de atividade física sobre o estado nutricional de adolescentes de Piedade, São Paulo. Rev. Paul. Pediatr., v. 27, n. 3, p. 265-271, set. 2009.

FARIAS Jr., J. C. F. Associação entre prevalência de inatividade física e indicadores de condição socioeconômica em adolescentes. Revista Brasileira de Medicina do Esporte, v. 14, n. 2, p. 109-114, mar./abr. 2008.

FERNANDES, R. A. et al. Association between regular participation in sports and leisure time behaviors in Brazilian adolescents: a cross-sectional study. BMC Public Health, n. 8, sept. 2008. Disponível em: <http://www. biomedcentral.com/1471-2458/8/329>. Acesso em: 10 out. 2009.

FLORINDO, A. A. et al. Desenvolvimento e validação de um questionário de avaliação da atividade física para adolescentes. Revista de Saúde Pública, v. 40, n. 5, p. 802-809, 2006.

FULTON, J. E. et al. Physical activity, energy intake, sedentary behavior, and adiposity in youth. American Journal of Preventive Medicine, v. 37, Supl. 1, p. 40-49, 2009.

GOMEZ, D. M. et al. Sedentarismo, adiposidad y factores de riesgo cardiovascular en adolescentes. Estudio AFINOS. Revista Espanhola de Cardiologia, v. 63, n. 3, p. 277-285, 2010.

GUTHOLD, R. et al. Physical activity and sedentary behavior among schoolchildren: a 34-country comparison. The Journal of Pediatrics, v. 157, n. 1, p. 43-49, 2010. 
GUTHOLD, R. et al. World variability in physical inactivity a 51- country survey. American Journal of Preventive Medicine, v. 34, n. 6, p. 486-494, 2008. GUEDES, D. P. et al. Fatores de risco cardiovasculares em adolescentes: indicadores biológicos e comportamentais. Arquivos Brasileiros de Cardiologia, v. 86, n. 6 , p. 439-450, jun. 2006.

GUEDES, D. P. et al. Níveis de prática de atividade física habitual em adolescentes. Revista Brasileira de Medicina do Esporte, v. 7, n. 6, p. 187-199, nov./dez. 2001.

GUEDES, D. P.; CYNTHIA, C.; GUEDES, J. E. R. P. Reprodutibilidade e validade do questionário internacional de atividade fisica em adolescentes. Revista Brasileira de Medicina do Esporte, v. 11, n. 2, p. 151-158, mar./abr. 2005. GUEDES, D. P.; GUEDES, J. E. Exercício físico na promoção da saúde. Londrina: Midiograf, 1995.

HALLAL, P. C. et al. Evolução da pesquisa epidemiológica em atividade física no Brasil: revisão sistemática. Revista de Saúde Pública, v. 41, n. 3, p. 453-460, 2007.

HALLAL, P. C. et al. Prevalência de sedentarismo e fatores associados em adolescentes de 10-12 anos de idade. Cadernos de Saúde Pública, Rio de Janeiro, v. 22, n. 6, p. 1277-1287, jun. 2006.

HEALTH CANADA, 2004. Canada's physical activity guide for children. Retried November 1, 2004. Disponível em: <www.healthcanada.ca/paguide>. Acesso em: 10 out. 2009.

JACKSON, D. M. et al. Increased television viewing is associated with elevated body fatness but not with lower total energy expendure in children. American Journal of Nutrition Clinical, v. 89, n. 4, p. 1031-1036, Apr. 2009.

JANSSEN, I; LEBLANC, A. G. Systematic review of the health benefits of physical activity and fitness in school-aged children and yout. International Journal of Behavioral Nutrition and Physical Activity, v. 7, n. 40, 2010. Disponível em: <http//.www.ijbnpa.org/content/7/40>. Acesso em: 15 jun. 2010.

JANSSEN, I. et al. Comparation of overweight and obesity prevalence in school-aged youth from 34 countries and their relationships with physical activity and dietary patterns. Obesity Reviews, v. 6, n. 2, p. 123-132, May 2005. 
KATZMARZYK, P. T. et al. Sitting time and mortality from all causes, cardiovascular disease, and cancer. Medicine \& Science in Sports Medicine, v. 41, n. 5, p. 998-1005, May 2009.

KOEZUKA, N. et al. The relationship between sedentary activities and physical inactivity among adolescents: results from the Canadian community. Journal of Adolescent Health, v. 39, n. 4, p. 515-522, 2006.

LANNOTTI, R. J. et al. Interrelationship of adolescent physical activity, screen-based sedentary behavior, and social and psychological health. International Public Health, v. 54, p. 191-198, 2009.

LARSEN, P. G.; NELSON, M. C.; POPKIN, B. M. Longitudinal physical activity and sedentary behavior trends adolescence to adulthood. American Journal of Preventive Medicine, v. 27, n. 4, p. 277-283, 2004.

MACLNTOSH, B. R.; GARDINER, P. F.; McCOMAS, A. J. Skeletal muscle, form and function, 22. ed. Champaign, IL: Human Kinetics, 2006.

MALINA, R. Tracking of physical activity and physical fitness across the lifespan. Research Quarterly for Exercise and Sport. The American Alliance for Health, Physical Education, Recreation and Dance, v. 67, n. 3, p. 48-57, 1996.

MARSHALL, S. J.; GOLERY, T.; BIDDLE, S. J. H. A descriptive epidemiology of screen-based media use in youth: a review and critique. Journal of adolescents, v. 29, n. 3, p. 333-349, Jun. 2006.

MARSHALL, S. J.; BIDDLE, S. J. H.; GOLERY, T.; CAMERON, N.; MURDEY, I. Relationship between media use, body fatness and physical activity in children and youth: a meta-analysis. International Journal of Obesity, v. 28, n. 10, p. 1238-1246, oct. 2004.

MINISTÉRIO DA SAÚDE. Departamento de Análise de Situação de Saúde. Saúde Brasil 2008. Vinte anos do Sistema Único de Saúde no Brasil. 2008. NAHAS, M. V. et al. Physical activity and eating habits in public high schools from different regions in Brazil: the saude na boa project. Revista Brasileira de Epidemiologia, n. 12, v. 2, p. 270-277, 2009.

NAHAS, M. V.; BARROS, M. V. G. Atividade física, saúde e qualidade de vida: conceitos e sugestões para um estilo de vida ativo fisicamente. 3. ed. Londrina: Midiograf, 2003. 
NIH CONSENSUS CONFERENCE. Physical activity and cardiovascular health. Journal of the American Medical Association, v. 276, n. 3, p. 241-246, Jul. 1996.

NHANTUMBO, L.; MAIA, J.;SARANGA, S.; PRISTA, A. Atividade física em crianças e jovens residentes em uma comunidade rural moçambicana: efeitos da idade, sexo e estado nutricional. Revista Panamericana de Saúde Pública, v. 23, n. 3, p. 171-178, 2008.

OEHLSCHLAEGER, M. H. K. et al. Prevalência e fatores associados ao sedentarismo em adolescentes de área urbana. Revista de Saúde Pública, v. 30, n. 2, p. 157-63, 2004.

OLIVEIRA, M. M. C. Aspectos genéticos da atividade física: um estudo multimodal em gêmeos monozigóticos e dizigóticos. Revista Paulista de Educação Física, v. 17, n. 2, p. 104-118, jul./dez. 2003.

PAFFENBARGER, R. S.; LEE, I. M. Physical activity and fitness for health and longevity. Research Quarterly for Exercise and Sport by the American Alliance for Health Physical Education, Recreation and Dance, v. 67 , n. 3, p. 11-28, Sep. 1996.

PARDINI, R. et al. Validação do questionário internacional de nível de atividade física (IPAQ - versão 6): estudo piloto em adultos jovens. Revista Brasileira de Ciência e Movimento, v. 9, n. 3, p. 45-5, 2001.

PAVON, D. J. A. et al. Socioeconomic status influences physical fitness en European adolescents independently of body fat and physical activity: the HELENA study. Nutricion Hospitalaria, v. 25, n. 2, p. 311-316, 2010.

PERSON, N. et al. Patterns of adolescent physical activity and dietary behaviours. International Journal of Behavioral Nutrition and Physical Activity, v. 6, n. 45, 2009a. Disponível em: <http//www.ijbnpa.org/content/6/1/45>. Acesso em: 10 out. 2009.

PERSON, N. et al. Family influences on children's physical activity and fruit and vegetable consumption. International Journal of Behavioral Nutrition and Physical Activity, v. 6, n. 34, 2009b. Disponível em: <http//www.ijbnpa.org/ content/6/1/34>. Acesso em: 10 out. 2009

PHYSICAL ACTIVITY GUIDELINES ADVISORY COMMITTEE. Physical Activity Guidelines Advisory Committee Report, 2008. Washington, DC: U.S. Department of Health and Human Services, 2008. 
RANKINEN, T. S.; BOUCHARD, C. Genetic differences in the relationships among physical activity, fitness, and health. In: BOUCHARD, C.; BLAIR, S. N.; HASKELL, W. L. Physical activity and health. Champaign, IL: Human Kinetics, 2007. p. 337-357.

RAMANZINI, M. et al. Prevalência de fatores de risco cardiovascular em adolescentes. Cadernos de Saúde Pública, Rio de Janeiro, v. 24, n. 11, p. 2573-2581, nov. 2008.

RIBEIRO, R. Q. C. et al. Fatores adicionais de risco cardiovascular associados ao excesso de peso em crianças e adolescentes. O estudo do coração de Belo Horizonte. Arquivos Brasileiros de Cardiologia, v. 86, n. 6, p. 408-418, jun. 2006. SALLIS, J. F.; PATRICK, K. P. Physical activity guidelines for adolescents: consensus statement. Pediatric Exercise Science, v. 6, p. 302-314, 1994.

SEABRA, A. E. et al. Determinantes biológicos e socioculturais associados à prática de atividade física de adolescentes. Cadernos de Saúde Pública, Rio de Janeiro, v. 24, n. 4, p. 721-36, 2008.

SILVA, K. S. et al. Associação entre atividade física, índice de massa corporal e comportamentos sedentários em adolescentes. Revista Brasileira de Epidemiologia, v. 11, n. 1, p. 159-168, 2008.

SILVA, K. S. et al. Fatores associados à atividade física, comportamento sedentário e participação na Educação Física em estudantes do ensino médio em Santa Catarina, Brasil. Cadernos de Saúde Pública, v. 25, n. 10, p. 2187-2200, 2009.

SILVA, K. S.; LOPES, A. S. Excesso de peso, pressão arterial e atividade física no deslocamento à escola. Arquivos Brasileiros de Cardiologia, v. 91, n. 2, p. 93-101, 2008b.

SILVA, M. A. M. et al. Prevalência de fatores de risco cardiovascular em crianças e adolescentes da rede de ensino da cidade de Maceió. Arquivos Brasileiros de Cardiologia, v. 84, n. 5, p. 387-392, maio 2005.

SISSON, S. B.; KATZMARK, P. T. International prevalence of physical activity in youth and adults. Obesity Reviews, v. 9, n. 16, p. 606-614, nov. 2008.

STEELE, R. M. et al. Physical activity, cardiorespiratory fitness, and the metabolic syndrome in youth. J. Appl. Physiol., v. 105, n. 1, p. 342-351, Jul. 2008. 
SUNE, F. R. et al. Prevalência e fatores associados para sobrepeso e obesidade em escolares de uma cidade no sul do Brasil. Cadernos de Saúde Pública, v. 23, n. 6, p. 1361-1371, jun. 2007.

TASSITANO, R. M. et al. Atividade física em adolescentes brasileiros: uma revisão sistemática. Revista Brasileira de Cineantropometria e Desempenho Humano, v. 9, n. 1, p. 55-60, 2007.

TAVERAS, E. M. et al. Longitudinal relationship between televisionviewing and leisure-time physical activity during adolescence. Pediatrics, v. 119, n. 2, p. 314-319, Feb. 2007.

UTTER, J. SZTAINER,D.N. JEFFERY, R. Couch potatoes or french fries: are sedentary behaviors associated with body mass index, physical activity, and dietary behaviors among adolescents? Journal of The American Dietetic Assosiation. v. 103, n. 10, p. 1298-1305, 2003.

VELDE, S. J. et al. Patterns in sedentary and exercise behaviors and associations with overweight in 9-14-year-old boys and girls - a crosssectional study. BMC Public Health, v. 7, n. 16, 2007. Disponível em: <http// www.biomedcentral.com/1471-2458/7/16>. Acesso em: 10 out. 2009. WORLD HEALTH ORGANIZATION. Recommended levels of physical activity for children aged 5-17 years, 2009. Disponível em: <http://www.who.int/ dietphysicalactivity/factsheet_young_people/en/>. Acesso em: 10 out. 2009. WORLD HEALTH ORGANIZATION. Physical Activity: a global public health problem. 2010. Disponível em: <http://www.who.int/dietphysicalactivity/ factsheet_inactivity/en/>. Acesso em: 10 set. 2010. 



\title{
Participação do sistema nervoso autônomo nas alterações cardiorrespiratórias e metabólicas durante a prática competitiva do surfe
}

\author{
Marcus Vinícius Palmeira \\ Rogério Brandão Wichi \\ Helio José Bastos Carneiro de Campos \\ João Marcelo Miranda
}

\section{INTRODUÇÃO}

O surfe é uma das modalidades esportivas que atualmente mais cresce em número de praticantes em todas as regiões costeiras do mundo. Paralelo a esse fenômeno mundial, os surfistas competidores brasileiros vêm conquistando status de grande relevância no cenário esportivo mundial, sendo apontado como uma das atuais potências da modalidade. (PALMEIRA; WICHI, 2007) Os surfistas competidores brasileiros alcançaram, nos últimos anos, resultados em competições e circuitos internacionais, que surpreendem os mais otimistas visionários dos anos anteriores. Os atletas brasileiros conquistaram nove títulos mundiais do World Qualifing Series (WQS), que é divisão de acesso ao World Tour (WT), primeira divisão do surfe mundial. Além das conquistas no WQS, os atletas brasileiros 
ganharam quatro títulos no Billabong World Junior, circuito mundial para competidores até 20 anos de idade. A evolução do surfe no Brasil pode também ser verificada no World Surfing Games (edição mundial do surfe amador), que é regulamentado pela International Surfing Assossiation (ISA). Neste evento, os atletas brasileiros que se apresentavam nas últimas posições no início da década de 90 , tornaram-se campeões e vice-campeões em 2002 e 2004, respectivamente.

Evidentemente, esta evolução técnico-competitiva do surfe brasileiro vem ocorrendo em paralelo ao surgimento e desenvolvimento de pesquisas nos setores ligados à ciência do esporte, em especial na Educação Física. No entanto, poucos são os estudos voltados especificamente para a prática do surfe. Recentemente, após levantamento de dados durante o Billabong Pro Teen Series 2009, no estado da Bahia, evidenciamos a necessidade emergente da implantação do treinamento para preparação física específica dos surfistas competidores, uma vez que os dados demonstraram que 56\% dos atletas não possuíam nenhum treinamento físico paralelo ao surfe; $22 \%$ praticavam atividades físicas por conta própria; $18 \%$ possuíam apoio (bolsas) em academias sem especificidade de treinamento para a prática do surfe; e apenas $4 \%$ dos atletas afirmaram realizar treinamento voltado para o surfe realizado por um professor de educação física (dados não publicados). A ideia de que a realização de um planejamento sistematizado e um treinamento físico específico resultam na melhora da performance técnica do surfe competitivo foi confirmada através de um estudo de caso realizado com um atleta do circuito baiano de surfe profissional. Neste estudo foi demonstrado que o planejamento sistematizado do treinamento físico, bem como sua execução, elevou consideravelmente o desempenho técnico do atleta quando em competições. s competições realizadas, em todas as categorias da modalidade surfe, são organizadas em formas de baterias classificatórias, sendo que, na maioria dos eventos profissionais possuem em média duração de 25 minutos cada, composta por dois atletas, sendo que cada atleta tem direito a surfar um total de dez ondas. Notas são atribuídas em função das manobras realizadas em cada onda surfada, e o atleta é classificado conforme somatória das duas melhores notas obtidas. Assim, a execução de manobras na onda 
é o principal objetivo do atleta visando alcançar um bom desempenho na competição. No entanto, ao analisar uma bateria competitiva, observa-se que existe uma pluralidade de situações motoras, nos diversos estágios que compõe a sua prática, que podem interferir no resultado final da competição. $\mathrm{O}$ atleta ao entrar no mar precisa atravessar a arrebentação para se posicionar na área de formação das ondas (região também chamada de out-side); seguido da entrada na área funcional da onda e execução de manobras, e por fim a volta rápida ao out-side. Sendo assim, as necessidades do organismo devem ser analisadas não apenas no momento da execução das manobras, mas também durante toda a bateria competitiva, tendo em vista a diversificação motora e física que acontece em cada momento diferente da competição e que podem interferir no desempenho técnico do competidor de surfe.

Dessa forma, a execução de um planejamento de treino físico específico deve ser baseada nas exigências cardiorrespiratórias e metabólicas que são impostas ao organismo durante as diferentes fases que compõe uma bateria competitiva de surfe. Diante da carência de estudos na literatura que demonstrem tais exigências, pretendemos com esta revisão auxiliar na compreensão das adaptações cardiorrespiratórias e metabólicas durante os diferentes eventos que compõem uma bateria competitiva da modalidade do surfe, bem como, a contribuição do sistema nervoso autônomo em mediar tais alterações.

\section{INICIANDO A BATERIA: A TRANSIÇÃO DO REPOUSO AO EXERCÍCIO}

Ao iniciar uma bateria competitiva, o atleta sai do estado de repouso para o estado ativo fisicamente. Essa mudança é desencadeada a partir de um estímulo sonoro autorizando a entrada na água, isso no sistema de largada beach-start, que é o tradicional em competições de surfe, no qual a competição se inicia com a saída dos atletas a partir da areia. No sistema water-start, onde a bateria começa com o atleta já posicionado na água, também há um sinal sonoro para iniciar a competição. Em ambas as situações há uma necessidade de vários ajustes orgânicos para suprir a demanda energética necessária às exigências da competição. 
Ao entrar na água, é necessário ajuste de termorregulação para adaptar o corpo à temperatura da água, que geralmente é inferior a $37^{\circ} \mathrm{C}$. Se houver um isolamento insuficiente contra o frio, qualidades físicas relevantes para o surfista competidor, como a capacidade de desenvolver força muscular e a capacidade de realizar movimentos coordenados, podem ser afetadas. Sabe-se que a resistência muscular localizada (RML) e a força muscular, principalmente de membros superiores, são extremamente importantes neste momento, tendo em vista a atividade de remada que o atleta realiza nesta fase, visando atravessar a arrebentação e chegar ao local de formação das ondas. Esta fase pode durar aproximadamente oitenta segundos. (FONSECA, 2003) Sendo que as condições do mar, como quantidade e força das ondas podem interferir na duração e na intensidade do exercício físico realizado nesta etapa.

O ajuste da temperatura corporal é auxiliado por alterações que ocorrem no sistema cardiovascular e respiratório. Diversos estudos já demonstraram que a transição do repouso para o exercício induz aumento da frequência cardíaca (resposta cronotrópica) e da força de contração do músculo cardíaco (resposta inotrópica). O aumento do cronotropismo e do inotropoismo cardíaco promove elevação do débito cardíaco durante o exercício físico (CLAUSEN, 1969; EKBLOM et al. 1968); esse ajuste permite que maior quantidade de sangue possa ser distribuído para todo o organismo por unidade de tempo. O sistema vascular também se adapta a essa nova situação. Já foi demonstrado que durante o exercício físico ocorre vasodilatação nas áreas envolvidas com a atividade muscular e vasoconstricção em regiões menos importantes, como a região subcutânea. Essas respostas, além de possibilitar maior fluxo de nutrientes e oxigênio para as células envolvidas na contração muscular, reduz a perda de calor para o meio ambiente. Dessa forma, as alterações do sistema cardiovascular, durante a fase inicial da bateria do surfe, contribui para manter a temperatura corporal em condições estáveis, bem como para a manutenção do metabolismo celular que se apresenta aumentado.

A transição do repouso para o exercício também é evidenciada pelo aumento do metabolismo celular em especial na musculatura ativa, para suprir a demanda energética acionada pelo início da atividade de remada 
para o posicionamento inicial do atleta no out-side. A energia para a realização do exercício físico é obtida através da alimentação. Portanto, pode-se dizer que os alimentos fornecem substratos energéticos para a realização do trabalho celular. No entanto, essa energia não pode ser empregada diretamente para o trabalho celular. Primeiro, ela deve ser transferida para a molécula adenosina de trifosfato (ATP). A ATP é considerada um composto de alta energia, sendo que sua hidrólise é capaz de fornecer a energia para o trabalho celular. Sendo assim, uma série de reações químicas, conhecidas como reações metabólicas, devem ocorrer. A síntese de ATP ocorre em condições com oferta de oxigênio, nas quais o metabolismo energético utilizado para sua produção está relacionado tanto ao sistema respiratório (fosforilação oxidativa), como também na ausência do oxigênio de forma anaeróbia (sistemas fosfagênio e glicolítico anaeróbio). A ativação das diferentes vias depende de fatores como intensidade, duração do exercício físico, estado de treinamento e dieta alimentar. (SALTIN, 1987; BOOTH; THOMASON, 1991) Esta fase de entrada no mar e passagem pela rebentação deve ser realizada rapidamente, pois o atleta que primeiro se posiciona no out-side tem prioridade para a escolha da onda. Considerando que o tempo de duração desta fase é em torno de oitenta segundos, é possível que a principal via utilizada na transformação dos alimentos para a produção da ATP seja a via anaeróbia lática. (MAUGHAN; GLEESON; GREENHEFF, 2000)

\section{SURFANDO: 0 USO DA ÁREA FUNCIONAL DA ONDA}

Após o estágio inicial no qual o atleta já se localiza no out-side, é iniciada a segunda fase do surfe competitivo: a entrada e utilização da área funcional da onda. É nessa região, entre a crista e a base da onda, que o atleta executa as manobras. Esse processo exige uma série de atitudes motoras, que terão reações cardiovasculares e metabólicas inerentes a cada estágio do processo neuromuscular.

Ao se posicionar para entrar na área funcional da onda, o atleta necessita geralmente de um reflexo motor apurado. Neste momento os movimentos de remada passam a ser curtos e acelerados (sprint-alta intensidade 
e curta duração) para favorecer o aumento da aceleração e facilitar a entrada na área mais íngreme da onda. Nessa fase é imprescindível que o atleta possua uma boa velocidade de reação viso-motora para executar o movimento de mudança da posição de decúbito ventral, sobre a prancha, para posição vertical no local e momento exato que possa favorecer a utilização da área funcional útil na onda. $\mathrm{O}$ atleta que possuir essa qualidade mais evoluída tenderá a executar manobras com maior grau de dificuldade (manobras radicais) e, consequentemente, obter melhores notas por parte dos árbitros.

A realização das manobras depende do tempo no qual o atleta permanece na área funcional da onda. Estudo realizado por (FONSECA, 2003) verificou que, no Brasil, esse tempo é em média de 15 segundos. Ao realizar uma descrição funcional dos movimentos utilizados na realização das manobras executadas por um surfista, observa-se a complexidade existente nas mesmas. $\mathrm{O}$ atleta deve manter em todos os momentos o maior controle sobre sua prancha e sincronia total com a onda que estiver surfando. Os movimentos necessitam de uma combinação precisa entre a coordenação motora, agilidade, velocidade e força de explosão, dentre outras qualidades físicas.

Além do estado de aptidão física, o equilíbrio emocional e o nível de treinamento somado à tática competitiva adotada na bateria são de fundamental importância para o bom desempenho. Diante desse complexo repertório neuromotor apresentado pela prática do surfe em competições, o organismo apresenta adaptações cardiovasculares, respiratórias e metabólicas para manter a atividade neuromuscular. Sabe-se que aumento do metabolismo energético é acompanhado da elevação da frequência cardíaca e da atividade respiratória. Embora a frequência respiratória aumente, ocorre déficit de oxigênio, ou seja, período no qual o consumo de oxigênio $\left(\mathrm{VO}_{2}\right)$ fica abaixo daquele necessário para fornecer todo o ATP exigido pelo exercício. Portanto, a fase caracterizada pela entrada na área funcional e a realização de manobras (tempo médio de quinze segundos) deve utilizar predominantemente o sistema anaeróbio para a obtenção de energia. Segundo Fox e McArdle (1979) tempo de atividade física inferior a 15 segundos utilizam-se preferencialmente o sistema fosfagênio (também denomi- 
nado ATP-CP) para a ressíntese do ATP. No músculo, a fosfocreatina pode ser utilizada para ressintetizar ATP em uma taxa muito alta de energia. O desdobramento deste sistema em energia, com auxílio da enzima ATPase da miosina, libera ADP sem que se produza o ácido lático. No entanto, a quantidade de ATP formada é limitada devido à baixa quantidade de creatina fosfato que pode ser armazenada na célula muscular (BOOTH; THOMASON, 1991), o que ativa a via anaeróbia lática para suprir a demanda energética desta fase. Fonseca e colaboradores (2003), em estudo que realizou medidas de lactato sanguineo em mmol/L, logo após baterias competitivas de surfe com duração de 25 minutos, encontrou taxa média de 7,7 mmol/L de sangue, o que sugere elevada atividade do sistema glicolítico anaeróbio durante a utilização da área funcional das ondas. De acordo com Gaesser e Poole (1996), o lactato é um dos principais indicadores indiretos do metabolismo energético utilizado durante o exercício físico.

\section{O RETORNO AO OUT-SIDE}

Após surfar uma onda durante a bateria competitiva, o atleta retorna ao out-side para se posicionar novamente para a escolha de uma nova onda. Esse percurso de retorno caracteriza-se essencialmente por movimentos cíclicos de remada, associado a movimentos seguidos de rápido mergulho (passar por baixo da onda). Em estudo realizado por Fonseca (2003), foi verificado que no Brasil esse tempo de remada foi de aproximadamente 80 segundos. Nesta fase, se não houver condições de promover a ressíntese do ATP através da doação de fosfato de creatina, o organismo do atleta tende a iniciar a utilização de outra via, o sistema anaeróbio glicolítico, que é ativado depois de decorrido um tempo médio de 15 segundos da atividade. (SALTIN, 1987; BOOTH; THOMASON, 1991) Segundo Powers e Howley (1990), em atividade física de elevada intensidade com duração entre 30 e 180 segundos utiliza-se predominantemente do sistema glicolítico lático (via anaeróbia) para a obtenção da ATP. A utilização dessa via envolve a degradação da glicose ou do glicogênio em ácido pirúvico. Essa transformação ocorre através de reações químicas visando remoção dos hidrogênios contido nessas moléculas. O hidrogênio removido é transportado 
para que ocorra a formação da ATP. Duas proteínas são responsáveis por mediar esse transporte: a flavina adenina dinucleotídeo (FAD) e principalmente a nicotinamina adenina dinucleotídeo (NAD). Na presença de oxigênio, o hidrogênio transportado é lançado no interior das mitocôndrias, porém, na ausência do oxigênio, o ácido pirúvico aceita o hidrogênio transformando-se em ácido lático. Essa reação ocorre na presença da enzima lactato desidrogenase, com o objetivo de reciclar a NAD para a continuação do transporte dos hidrogênios. (booth; THOMASON, 1991; FOX; BOWERS; FOSS, 1993)

Dessa forma, a ativação dessa via tem como produto final formação do ácido láctico na célula muscular. A taxa de formação de ácido láctico depende principalmente da intensidade do exercício, em maior grau da intensidade relativa do exercício (\% VO2 máx) do que da intensidade absoluta. (MAUGHAN et al., 2000) O ácido láctico pode ser removido da célula muscular, podendo ser transportado para músculos vizinhos inativos ou migrando para o fígado para ser transformado novamente em glicogênio ou glicose por enzimas específicas, no entanto, quando a produção é maior que sua remoção, o resultado pode ser a acidose metabólica, levando à fadiga muscular ou à incapacidade de manter o processo contrátil. (BENEKE, 2003) Nesse momento, a participação do sistema respiratório é importante para manutenção do equilíbrio ácido-base do organismo. $\mathrm{O}$ aumento da frequência respiratória contribui para manutenção do equilíbrio do $\mathrm{pH}$. Além disso, o sistema cardiovascular continua com o trabalho elevado para manter o débito cardíaco alto.

A realização de atividades acíclicas e atividades físicas com intervalos irregulares que exigem ajustes rápidos do sistema cardiovascular, respiratório e no metabolismo energético celular dependem do funcionamento do sistema nervoso autônomo (SNA). Sendo que já está estabelecido que o SNA coordena o conjunto de todas essas repostas, visando à manutenção da homeostasia interna durante o repouso ou durante a prática da atividade física. 


\section{PARTICIPAÇÃO DO SISTEMA NERVOSO AUTÔNOMO NA PRÁTICÁ DO SURFE}

Já está bem estabelecida a permanente influência exercida pelo sistema nervoso autônomo (SNA) para regular o ambiente interno do corpo. Ele controla a atividade do sistema cardiovascular, respiratório, endócrino, renal e digestivo, além de participar no controle do metabolismo energético celular, tanto no repouso quanto no exercício físico. (CATAI et al., 2002)

O SNA é dividido em sistema nervoso simpático e parassimpático. A alça simpática do sistema nervoso estimula ações que mobilizam energia, permitindo ao organismo responder a situações de estresse e maior demanda energética, como nas atividades físico-desportivas. Sua atuação é evidente na prática do surfe competitivo, especificamente durante a utilização da área funcional das ondas, na execução das manobras, nas remadas para deslocamento e retorno ao out-side. De maneira antagônica, o sistema nervoso parassimpático estimula principalmente atividades que desaceleram as atividades que mobilizam energia, como as reduções do ritmo cardíaco e da pressão arterial, sendo preponderante na redução da intensidade do esforço e nos momentos de recuperação para regular o metabolismo orgânico de acordo com a necessidade apresentada (ARAÚJO; ALMEIDA, 2003), em especial durante o final do retorno do out-side e na conclusão da bateria.

As ações simpáticas agem através de neurotransmissores secretados pelos neurônios pós-ganglionares do sistema nervoso simpático, noradrenalina e a adrenalina, que têm ação direta no órgão-alvo. A ativação simpática põe em curso uma série de respostas fisiológicas conhecidas, em conjunto, como resposta de fuga-ou-luta. Durante o exercício físico, na prática do surfe, essas respostas agem sobre o sistema cardiovascular, respiratório e no metabolismo energético. No sistema cardiovascular, promove aumento da frequência cardíaca e da força de contração no músculo cardíaco, contração de vasos sanguíneos que suprem os órgãos não-essenciais, como os rins e o trato gastrointestinal e dilatação de vasos sanguíneos que suprem os músculos que participam do exercício (músculo esquelético, cardíaco, fígado e tecido adiposo). No sistema respiratório, promove aumento da amplitude e da frequência respiratórias, através da dilatação 
das vias aéreas, favorecendo uma maior captação de oxigênio. E no metabolismo energético, atua sobre os hepatócitos, no fígado, onde estimula a glicogenólise, e também sobre as células do tecido adiposo realizando a lipólise para disponibilizar os ácidos graxos e o glicerol como fonte de energia. (CATAI et al., 2002;) Tais respostas ocorrem principalmente na transição do repouso ao exercício e na entrada e realização de manobras na área funcional da onda.

A partir do momento em que o organismo identifica estímulos de conclusão da atividade na água, como por exemplo, no final do out-side, onde o atleta se posiciona e aguarda para surfar uma nova onda, ou ainda no final de bateria, inicia-se o processo de volta à calma para que a homeostase seja adquirida. Tal processo ocorre pelas ações parassimpáticas, mediadas pelo neurotransmissor acetilcolina. No metabolismo, a acetilcolina atua diretamente na redução da produção de energia. No sistema cardiovascular, reduz o ritmo cardíaco, a pressão arterial e redistribui o fluxo sanguíneo através da vasodilatação periférica. No sistema respiratório, promove redução da frequência e do volume respiratório, além de contribuir para a dissipação do calor. (CATAI et al., 2002)

Dessa forma, pode-se dizer que a ativação do sistema nervoso simpático (aumento de tônus simpático), juntamente com a inibição do sistema nervoso parassimpático (diminuição de tônus vagal) são respostas importantes para a realização das diferentes fases que compõe a bateria competitiva do surfe. Da mesma maneira que a redução do tônus simpático e aumento do tônus vagal, ativada ao término do exercício físico, possui igual relevância para reorganização da homeostase orgânica.

\section{CONCLUSÃO}

Pode-se concluir com essa revisão que o SNA é um importante mediador de todos os eventos metabólicos e cardiorrespiratórios que ocorrem durante os diferentes estágios que compõem a atividade na água e na fase de recuperação da mesma. Portanto, sua participação é decisiva para o desempenho do atleta durante as fases que compõem uma bateria competitiva de surfe. No entanto, existem poucas evidências científicas de tal 
relação na modalidade do surfe. Sugerimos que estudos específicos sejam realizados nesta modalidade para fornecimento de maior quantidade de evidências que comprovem a relação do SNA com os ajustes orgânicos durante a prática do surfe. Acreditamos que tais dados possam auxiliar no desenvolvimento da modalidade.

\section{REFERÊNCIAS}

ALMEIDA M.B.; ARAÚJO C.G.S. Efeitos do treinamento aeróbico sobre a freqüência cardíaca. Revista Brasileira de Medicina do Esporte, v. 9, n. 2, mar./abr., 2003.

BENEKE, R. Methodological aspects of maximal lactate steady stateimplications for performance testing. European Journal of Applied Physiology, Berlin, v. 89, p. 95-99, 2003.

BOOTH F. W. ; THOMASON D; B. Molecular and cellular adaptations of muscle in response to exercise: perspective of various models. Physiology Ver. v. 71, n. 2, p. 541-585, 1991.

CATAI, A. M. et al.. Effects or aerobic exercise training on heart rate variability during wakefulness and cardiorespiratory responses of young and middle-aged health men. Brazilian Journal of Medicine and Biological Research, v. 35, p. 741-752, 2002.

CLAUSEN, J. Effects of physical conditioning. A hypothesis concerning circulatory adjustment to exercise. Scand. J. Clin. Lab. Invest. v. 24, n. 305, 1969. FONSECA, C.E. Quantificação e comportamento do lactato durante uma competição de surfe profissional brasileiro. In; SIMPÓSIO INTERNACIONAL DE CIÊNCIA DO ESPORTE, 27., 2003, São Paulo. Anais... . São Paulo, 2003. FOX E. L., BOWERS R. W., AND FOSS M. L. The physiological basis for exercise and sport. Dubuque, IA: W. C. Brown, 1993.

GAESSER, G.A.; POOLE, D.C. The slow component of oxygen uptake kinetics in humans. Exercise and Sport Sciences Reviews, Baltimore, v. 24, p. 35-71, 1996. 
PALMEIRA, M. V.; WICHI R. B. Capacidades físicas utilizadas em uma bateria competitiva de surfe, Revista Integração, v. 50, n. 8, p. 271-276, jul/ago/set. 2007.

SALTIN, B. Physiologic adaptation physical conditioning. Acta med Scand Suppl., v. 711, p. 11-24, 1987. 


\section{Estudo quantitativo da produção científica sobre atividade física para promoção da saúde no banco de teses da CAPES no ano de 2008}

Ciro Oliveira Queiroz

Rogério Tosta de Almeida

\section{INTRODUÇÃO}

A atual Coordenação de Aperfeiçoamento de Pessoal de Nível Superior (CAPES) foi criada em 11 de julho de 1951, no segundo governo Vargas, pelo decreto $\mathrm{n}^{\circ} 29.741$. Tinha como objetivo "assegurar a existência de pessoal especializado em quantidade e qualidade suficientes para atender às necessidades dos empreendimentos públicos e privados que visam ao desenvolvimento do país”. Nos anos de 1970, a CAPES assumiu plenamente as funções de órgão orientador, regulador e avaliador da pós-graduação no país. Em 1981, através do Decreto $\mathrm{n}^{\circ}$ 86.791, a CAPES é reconhecida como órgão responsável pela elaboração do Plano Nacional de Pós-Graduação Stricto Sensu. (CAPES, 2006a) Editado a cada seis anos, o Plano faz um diagnóstico da pós-graduação nacional, apresentando propostas de diretrizes, cenários de crescimento do sistema, metas e orçamento para a execução de ações. 
O número de acessos ao Portal de Periódicos da CAPES vem crescendo nos últimos anos, enquanto que em 2001 foram 1.769.765 acessos, em 2009 este número aumentou para 23.386 .833 acessos nos seus textos completos. A disponibilidade de títulos no portal também aumentou, saltando de 1.882 títulos em 2001 para 22.525 em 2009. Observando a participação percentual de títulos ativos no portal por área do conhecimento, no ano de 2009, a área das Ciências da Saúde aparece em primeiro lugar com 26,03\%, seguida das Ciências Humanas (18,44\%), Ciências Sociais Aplicadas $(13,76 \%)$ e as demais áreas em menores percentuais (CAPES, 2009b).

O número de cursos de mestrado e doutorado tem aumentado no Brasil, segundo a CAPES, nos últimos sete anos, foram criados 872 novos cursos de mestrado e 492 de doutorado no país (CAPES, 2006a).

$\mathrm{Na}$ área de Educação Física existe atualmente 21 cursos de pós-graduação Stricto-Sensu reconhecidos pela CAPES no Brasil (CAPES, 2006e), o que ainda é pouco, devido à alta demanda pela formação continuada na pós-graduação no país e a necessidade de profissionais altamente qualificados para intervenção nos campos de trabalho da Educação Física. No nordeste do país, existe apenas um curso de mestrado em Educação Física, criado em 2008, fruto da parceria entre a Universidade de Pernambuco (UPE) e Universidade Federal da Paraíba (UFPB). (BARROS et al., 2010) Apesar da carência de cursos Stricto-Sensu na região, 46\% dos pesquisadores da região nordeste titularam-se especialmente em Educação Física, mas estudaram em outras regiões ou fora do país. (GAMBOA; CHAVES; TAFFAREL, 2007) No entanto, não se pode negar a contribuição destes cursos no avanço da produção científica em Educação Física no país, tanto em termos quantitativo, quanto qualitativo.

É importante salientar que o nosso entendimento é de que as pesquisas e intervenções sobre atividade física não são, e nem devem ser, privilégio da área de Educação Física ou de qualquer outra área isoladamente. Nenhuma profissão ou especialidade das ciências humanas e/ou da saúde conseguiria abarcar o conjunto da complexidade que envolve a atividade física. Portanto, reconhecemos a necessidade e importância de uma abordagem interdisciplinar entre os profissionais de saúde que trabalhem com a mesma. 
Outra questão importante diz respeito à utilização dos termos exercício físico e atividade física. Os conceitos sobre estes termos dependem da área de formação dos autores, enquanto a maioria dos autores com formação na área das ciências da saúde e biológicas diferencia os termos, conceituando atividade física como qualquer movimento corporal produzido pelos músculos esqueléticos e que resulta no gasto energético e exercício físico como um tipo de atividade física planejada, estruturada, repetitiva, que objetiva a melhoria ou a manutenção da aptidão física. (CASPERSEN; POWELL; CHRISTENSON, 1985; BARBANTI, 2003) Os autores com formação na área das ciências humanas e sociais, tendem a não diferenciar os termos, considerando-os como sinônimos. (FARIA JÚNIOR et al, 1999) A principal justificativa destes últimos estaria no fato de que, no imaginário coletivo, quando se fala em praticar atividade física, remete-se o sujeito a uma prática corporal regular diferente daquela do seu dia a dia. Portanto, espera-se que, a depender do termo utilizado para a busca de estudos em periódicos e/ou base de dados, os trabalhos selecionados apresentem características peculiares. Neste trabalho, a opção sobre a utilização do termo atividade física, inclusive no próprio título, deve-se ao entendimento mais ampliado que o mesmo nos remete, pois o exercício físico é considerado atividade física independente da área de conhecimento, mas a atividade física pode não ser considerada exercício físico a depender do olhar e do sentido de quem a analisa.

A preocupação em estudar a atividade física tem crescido bastante nos últimos anos no Brasil, numa busca com o termo "physical activity". Na base de dados Medline/Pubmed, Hallal e colaboradores (2007) identificaram aumento considerável da produção nacional sobre a temática. Entre os anos de 1950 e 1959 foram encontrados 1.033 .666 estudos na base de dados, porém, apenas 55 (0,01\%) eram brasileiros. Já entre os anos de 1990 e 1999 , de 4.289 .656 estudos encontrados, $12.693(0,30 \%)$ eram estudos brasileiros. Este crescimento pode ser justificado pelo aumento dos cursos de pós-graduação no país.

Algumas pesquisas sobre a produção do conhecimento na área da educação física e esportes têm sido desenvolvidas aqui no Brasil nos últimos anos (LUDORF, 2002; GAMBOA; CHAVES; TAFFAREL, 2007; JOB; 
ALVARENGA, 2008; FRIZZO, 2010), porém, a análise específica da produção sobre atividade física nos programas de pós-graduação stricto sensu no país é carente. Além disso, a abordagem interdisciplinar é recorrente nas orientações sobre a prática de atividade física em várias diretrizes para prevenção e proteção à saúde. (SBC, 2005; SBH et al., 2005; SPOSITO et al., 2007; SBC/SBH/SBN, 2010) Desta forma, o trabalho objetivou analisar quantitativamente a produção do conhecimento sobre atividade física voltada para promoção da saúde no banco de teses da CAPES no ano de 2008, identificando e comparando entre si os estudos com os diferentes termos (atividade física vs exercício físico) em relação as suas características metodológicas, aos seus autores, às características dos Programas de pós-graduação e às possíveis lacunas na produção.

\section{METODOLOGIA}

Trata-se de uma pesquisa exploratória tendo como fonte os dados disponíveis no Banco de Teses da Coordenação de Aperfeiçoamento de Pessoal de Nível Superior (CAPES). A busca foi feita por assunto, no ano base de 2008, através das palavras-chave atividade física e exercício físico, sendo recuperados os documentos que continham a expressão exata.

A busca inicial com o termo atividade física revelou 288 teses e dissertações e com o termo exercício físico, 169 registros. Após o confronto, a partir do nome completo do autor, 49 trabalhos foram repetidos, restando assim 120 novos estudos com o descritor exercício físico. Após leitura de todos os 408 resumos dos trabalhos encontrados, foram excluídas: 11 produções por não tratarem sobre a temática atividade física na promoção da saúde, objeto deste estudo, um trabalho apareceu duplicado, talvez em função de algum erro de registro no banco de teses e dissertações da CAPES, e 64 trabalhos relacionados a experimentos com animais. Portanto, foram analisadas 332 teses/dissertações.

As categorias estabelecidas e os critérios utilizados para análise dos trabalhos foram os seguintes: 
- Tipo ou desenho do estudo categorizado em: experimental, coorte, caso-controle, transversal, estudo de caso, qualitativo e estudo de revisão. Os ensaios clínicos, estudos quase experimentais e experimentais foram considerados experimentais, sendo subdivididos em: com controle (sendo o controle feito com sujeitos sem doença/agravo ou não submetidos ao tratamento) e sem controle (quando se comparou o efeito da intervenção pré e pós programa no mesmo grupo ou o efeito de diferentes intervenções em diferentes grupos, ou seja, não houve um grupo de sujeitos que não foram submetidos ao tratamento ou não estavam doentes). Considerou-se estudos de coorte, aqueles onde um grupo de pessoas foi acompanhado por um determinado período de vida (longitudinal), com intuito de determinar quais de seus membros desenvolveram doença/agravo. Os estudos de caso-controle foram aqueles em que a investigação partiu do "efeito" para chegar às "causas”, ou seja, pesquisa retrospectiva. Foram considerados estudos transversais, aqueles onde os dados relativos a cada indivíduo referem-se a um determinado momento da sua vida, ou seja, um recorte no tempo. Eles foram subdivididos em: analítico/ correlacional (com objetivo de analisar uma relação bem específica entre dois eventos ou de comparar diferentes grupos e estudos de validação) e descritivo/exploratório (com objetivo de descrever o que está ocorrendo no momento da coleta de dados e/ou os fatores associados a tal fenômeno). Os estudos de casos foram àqueles realizados com até três sujeitos e os estudos qualitativos e de revisão seguiram os mesmos critérios da abordagem do estudo, apresentados a seguir. Quando o estudo apresentava característica de dois delineamentos de pesquisas diferentes, ou ainda quando a tese/dissertação resultou em dois ou mais estudos, optou-se em classificá-lo a partir da hierarquia dos métodos em relação às evidências apresentadas, baseado no grau de suscetibilidade ao viés, seguindo as orientações de Fletcher e Fletcher (2006). Assim, seguiu-se a seguinte ordem: experimental, coorte, caso-controle, transversal, estudo de caso, estudo qualitativo e de revisão;

- Abordagem do estudo, classificada como: quantitativa, qualitativa, quanti-qualitativa ou estudo de revisão. Considerou-se como quali- 
tativos, aqueles estudos com o enfoque no social e na compreensão da subjetividade e do simbolismo da ação humana, e como quantitativos, os estudos com características mais objetivas de quantificação dos fenômenos, com uma linguagem estatística matemática. (MINAYO; SANCHES, 1993) Os trabalhos com os dois perfis foram classificados como quanti-qualitativos. Os estudos que não fizeram pesquisa de campo, e sim uma pesquisa bibliográfica foram classificados como estudo de revisão;

- População ou amostra estudada observando a quantidade de sujeitos (categorizados em menos de 100, entre 100 e 500, mais de 500 pessoas investigadas e outros), grupos de idade (crianças/adolescentes, adultos, idosos e diversos), grupos específicos (atletas, trabalhadores, pacientes, escolares, universitários e sem especificidade), sexo (masculino, feminino ou ambos). Em todas as situações em que as categorias especificadas acima não eram aplicáveis utilizou-se a condição "não se aplica". Quando o estudo investigou indivíduos de meia idade ( $>45$ anos) juntamente com idosos (>60 anos), classificaram-se como idosos. Os grupos diversos foram aqueles de idade diversificada, ou seja, foram estudados sujeitos de vários grupos etários. Para classificação dos grupos específicos considerou-se: Atletas (jogadores profissionais ou praticantes de algum tipo de treinamento físico-desportivo específico), trabalhadores (profissionais de diversas áreas), pacientes (indivíduos portadores de alguma doença e/ou agravo à saúde), escolares (alunos de escolas de ensino infantil, ensino fundamental e médio), universitários (alunos de ensino superior) e sem especificidade (aqueles que não se encaixavam em nenhuma das anteriores);

- Dependência administrativa do programa (Particular, Federal, Estadual ou Municipal);

- Nível de graduação do estudo (mestrado acadêmico, mestrado profissionalizante ou doutorado);

- Área de conhecimento do programa conforme classificação adotada pela CAPES para o $1^{\circ}$ nível que corresponde às grandes áreas (Ciências da saúde, Ciências humanas, Ciências biológicas, Multidisciplinar, 
Engenharias, Ciências agrárias e Ciências sociais aplicadas). As áreas das Ciências Exatas e da Terra e Linguística, Letras e Artes não tiveram nenhum estudo publicado no ano em questão.

- Área de avaliação dos programas da CAPES (saúde coletiva, educação física, enfermagem, psicologia, medicina, ciências biológicas, interdisciplinar, engenharias, ciências sociais aplicadas, educação, sociologia, farmácia, agrárias e odontologia).

As áreas de Medicina I, II e III foram todas agrupadas em Medicina, assim como as áreas de Ciências Biológicas I, II e III em Ciências Biológicas. Todas as áreas de avaliação das Ciências Agrárias foram agrupadas em Agrárias, o mesmo acontecendo nas Ciências Sociais e aplicadas e engenharias.

A pesquisa da área de avaliação dos programas foi realizada no portal da CAPES: ${ }^{1}$

- Estado do programa (Estado brasileiro onde o programa está instalado), reagrupado por grandes regiões (Norte, Nordeste, Centro-Oeste, Sudeste e Sul);

- Estado de atuação do autor do trabalho (Estado brasileiro onde o autor do estudo estava trabalhando no momento da consulta, conforme informação no seu currículo Lattes), reagrupado por grandes regiões (Norte, Nordeste, Centro-Oeste, Sudeste e Sul);

- Áreadegraduaçãodoautor(áreanaqualoautorconcluiusuagraduação no ensino superior) categorizada em grandes áreas do conhecimento, conforme classificação adotada pela CAPES;

- Área de atuação do autor (categorizada em Ensino superior ou não).

Os dados referentes aos estudos foram retirados dos resumos dos mesmos, porém, quando não foi possível identificar alguma informação referente às categorias de análise, recorreu-se ao texto completo.

<http://conteudoweb.capes.gov.br/conteudoweb/ProjetoRelacaoCursosServlet?acao=pesquisarRegiao)>. 
A busca do trabalho completo foi feita inicialmente, colocando o título do mesmo no site de busca Google, ${ }^{2}$ quando não era encontrado, recorria-se ao portal domínio público ${ }^{3}$ do Ministério da Educação. Os trabalhos não encontrados através das buscas anteriores foram procurados nas respectivas bibliotecas depositárias, sendo que 12 teses/dissertações ou não foram encontradas ou não estavam disponíveis on-line.

Com relação aos dados dos autores, foi feita uma busca pelo nome de cada autor na plataforma Lattes, que é uma base de dados de currículos desenvolvida pelo Conselho Nacional de Desenvolvimento Científico e Tecnológico (CNPq).

Foi elaborado um quadro resumo com os critérios utilizados para análise e tabulação dos dados no programa EXCEL for Windows. A análise estatística foi feita através do software SPSS versão 17.0.

Utilizou-se da estatística descritiva (frequências absolutas e relativas) para apresentação dos resultados. A comparação das características dos estudos a partir do descritor de busca, atividade física versus exercício físico, excluindo a busca com ambos os termos, foi feita através do teste qui-quadrado, e quando a frequência mínima esperada foi menor do que 5, recorreu-se ao teste exato de Fisher bi-lateral. O critério de significância estatística adotado foi $\mathrm{p} \leq 0,05$. A correlação entre o estado do programa e o estado de atuação do autor foi feita através do Coeficiente de correlação de Spearman.

\section{RESULTADOS E DISCUSSÕES}

O banco de teses e dissertações da CAPES começou a disponibilizar as pesquisas desenvolvidas nos programas de pós-graduação no país no ano de 1987. Neste ano só foram encontrados oito resumos e títulos que continham o termo atividade física e um com o termo exercício físico. Este número teve um crescimento acentuado a partir do ano de 2001 onde foram encontrados 99 e 41 trabalhos, respectivamente. De lá para cá, as pesquisas sobre atividade física e exercício físico vêm aumentando muito, em 2008 foram 288 publicações com termo atividade física e 169 com exercício

$2<$ http:<//www.google.com.br>.

3 <http://www.dominiopublico.gov.br/pesquisa/PesquisaObraForm.jsp>. 
físico (Figura 1). Vale ressaltar que alguns trabalhos se repetem quando se busca os dois termos, no ano de 2008 foram 49 trabalhos repetidos (10,7\%).

Dentre os 332 trabalhos analisados neste estudo, 219 (66\%) foram encontrados a partir do termo atividade física, $80(24,1 \%)$ com o termo exercício físico e 33 (9,9\%) com ambos.

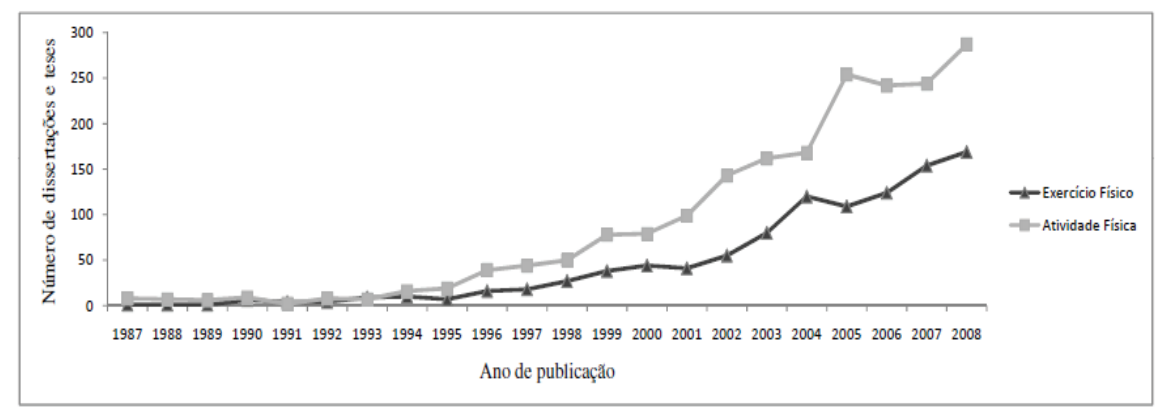

FIGURA 1. Número de teses e dissertações disponíveis na CAPES, conforme termo de busca, segundo ano de publicação. Brasil, 1987-2008

As características dos estudos em relação ao tipo, abordagem e população ou amostra estudada estão apresentadas na Tabela 1.

As maiores frequências foram de estudos transversais (43,4\%), com abordagem quantitativa (80,1\%), em amostras com quantidade menor do que 100 pessoas $(53,5 \%)$, em adultos $(39,7 \%)$, pessoas com alguma doença e/ou agravo à saúde $(33,1 \%)$ e pessoas de ambos os sexos $(68,7 \%)$. Quando analisados conforme o descritor de busca, prevalecem maiores percentuais das características anteriores, com exceção do tipo de estudo, onde aparecem os estudos experimentais em maior proporção no grupo de exercício físico (70,0\%), e os grupos específicos estudados, que a frequência maior é de sujeitos sem especificidade $(30,1 \%)$ no grupo de atividade física. Frizzo (2010), analisando a produção do conhecimento em Educação Física no programa de pós-graduação em Ciências do movimento humano da Universidade Federal do Rio Grande do Sul (UFRGS), entre os anos de 2000 e 2009, encontraram predominância de estudos experimentais comparativos $(62,5 \%)$ e descritivos interpretativos exploratórios (19\%), 
totalizando, assim, 81,5\% das teses/dissertações defendidas no programa. Resultado similar ao encontrado neste estudo, onde 75,9\% dos trabalhos foram de estudos experimentais e transversais.

Outro resultado semelhante entre os dois estudos diz respeito ao tipo de abordagem, apesar de estratégias e metodologias distintas utilizadas para análise; no programa da UFRGS, 73\% dos trabalhos apresentou um enfoque empírico-analítico, perspectiva que utiliza técnicas predominantemente quantitativas, segundo o autor.

Ludorf (2002), estudando os resumos de dissertações e teses publicados pelo Núcleo Brasileiro de Dissertações e Teses em Educação Física e Esportes (NUTESES) na década de 90, observou que 56,5\% dos trabalhos seguiam uma abordagem empírico-analítico. Para a autora,

[...]a trajetória histórica da Educação Física explica e, até certo ponto, justifica, as tendências de pesquisa desenvolvidas. As vinculações com a saúde e higiene, com o militarismo e com o esporte de rendimento, por exemplo, fartamente comentadas na literatura sobre o assunto, forneceram e ainda fornecem subsídios para discussões, principalmente nos âmbitos médico, fisiológico, antropométrico, técnico-instrumental e metodológico. (LUDORF, 2002, p. 20)

A comparação a partir dos termos utilizados para busca aponta diferenças em relação às características apresentadas. Os estudos transversais e qualitativos foram mais frequentes no grupo atividade física, e os estudos experimentais, no grupo exercício físico, sendo as diferenças estatisticamente significantes $(\mathrm{p}<0,001)$. A abordagem quantitativa foi mais frequente nos dois grupos, entretanto, comparando os grupos entre si, a abordagem qualitativa foi maior no grupo atividade física do que no grupo exercício físico $(\mathrm{p}=0,005)$, e a quantitativa, maior no grupo exercício físico $(\mathrm{p}=0,003)$.

Em relação à população estudada, os estudos com o termo atividade física tenderam a trabalhar com maior quantidade de sujeitos $(\mathrm{p}<0,001)$, pessoas com idades diversas ( $\mathrm{p}=0,003)$, escolares $(\mathrm{p}=0,001)$, trabalhadores $(\mathrm{p}=0,036)$ e grupos sem especificidade definida $(\mathrm{p}=0,029)$ e pessoas de ambos 
os sexos juntas ( $\mathrm{p}<0,001)$ em comparação ao grupo exercício físico. Já os estudos encontrados através do termo exercício físico, trabalharam com menor quantidade de sujeitos ( $\mathrm{p}=0,001)$, indivíduos adultos $(\mathrm{p}=0,001)$, pessoas com alguma doença ou agravo à saúde (pacientes) $(\mathrm{p}<0,001)$ e atletas $(\mathrm{p}=0,031)$ e com homens $(\mathrm{p}<0,001)$ e mulheres $(\mathrm{p}=0,004)$ separadamente.

Estes resultados reforçam a ideia de que as pesquisas que preferem a utilização do termo exercício físico apresentam características mais fortes de estudos clínicos e de intervenção, como por exemplo, quantidade menor de pessoas e maior especificidade dos grupos estudados, enquanto que os estudos epidemiológicos e qualitativos apresentam maior preferência pelo termo atividade física, ou seja, maior quantidade de pessoas e grupos com características mais generalizadas. Isto nos induz a pensar que os conceitos adotados por diferentes áreas do conhecimento sobre atividade física e exercício físico aparecem de alguma forma nas características dos trabalhos.

Ressalta-se a diferenciação entre os termos e a ampla utilização das definições sobre atividade física, exercício físico e aptidão física apresentadas por Caspersen, Powell e Christenson (1985), por autores brasileiros, especialmente aqueles com formação nas ciências da saúde e biológicas. Esta distinção tem sido importante para o desenvolvimento de instrumentos para a mensuração da atividade física, quer seja como exercício físico com o objetivo de melhora ou manutenção da aptidão física, quer seja como forma de deslocamento, no trabalho ou no lazer.

Desta forma, sugere-se uma devida atenção quando for utilizar um desses descritores para buscar estudos em periódicos e bases de dados, pois, em linhas gerais, o uso de um ou outro descritor pode não revelar trabalhos importantes do que se quer pesquisar. Exemplificando, se a pretensão for encontrar estudos sobre performance humana ou tipos de treinamento mais adequados para determinadas situações, seria mais interessante a utilização do termo exercício físico, já que, se o que se pretende é encontrar estudos sobre a quantidade de atividade física recomendada para a promoção da saúde individual ou coletiva ou a falta de atividade física como fator de risco para a saúde, o termo atividade física seria mais indicado. 
TABELA 1. Características dos estudos conforme descritor de busca. Brasil, 2008

\begin{tabular}{|c|c|c|c|c|c|c|c|c|c|}
\hline & \multicolumn{2}{|c|}{ Atividade física } & \multicolumn{2}{|c|}{ Exercício físico } & \multicolumn{2}{|c|}{ Ambos } & \multicolumn{2}{|c|}{ Total } & \multirow[t]{2}{*}{$p^{*}$} \\
\hline & $\mathrm{n}$ & $\%$ & $\mathrm{n}$ & $\%$ & $\mathrm{n}$ & $\%$ & $\mathrm{n}$ & $\%$ & \\
\hline \multicolumn{10}{|l|}{ Tipo de estudo } \\
\hline Transversal & 117 & 53,4 & 13 & 16,3 & 14 & 42,4 & 144 & 43,4 & $0,0001^{+}$ \\
\hline Experimental & 39 & 17,8 & 56 & 70,0 & 13 & 39,4 & 108 & 32,5 & $0,0001^{+}$ \\
\hline Qualitativo & 40 & 18,3 & 4 & 5,0 & 5 & 15,2 & 49 & 14,8 & $0,004^{+}$ \\
\hline Estudo de revisão & 9 & 4,1 & 3 & 3,8 & 1 & 3,0 & 13 & 3,9 & $1,000^{\$}$ \\
\hline Caso controle & 7 & 3,2 & 3 & 3,8 & 0 & - & 10 & 3,0 & $0,730^{\$}$ \\
\hline Coorte & 4 & 1,8 & 0 & - & 0 & - & 4 & 1,2 & $0,577 \$$ \\
\hline Estudo de caso & 3 & 1,4 & 1 & 1,3 & 0 & - & 4 & 1,2 & $1,000^{\mathbb{S}}$ \\
\hline \multicolumn{10}{|l|}{ Abordagem } \\
\hline Quantitativa & 166 & 75,8 & 73 & 91,3 & 27 & 81,8 & 266 & 80,1 & $0,003^{+}$ \\
\hline Qualitativa & 29 & 13,2 & 2 & 2,5 & 3 & 9,1 & 34 & 10,2 & $0,005^{s}$ \\
\hline Quanti-qualitativa & 15 & 6,8 & 2 & 2,5 & 2 & 6,1 & 19 & 5,7 & $0,257 \$$ \\
\hline Estudo de revisão & 9 & 4,1 & 3 & 2,8 & 1 & 3,0 & 13 & 3,9 & $1,000^{\$}$ \\
\hline \multicolumn{10}{|l|}{$\begin{array}{l}\text { População } \\
\text { ou amostra }\end{array}$} \\
\hline \multicolumn{10}{|l|}{$\begin{array}{l}\text { Quantidade } \\
\text { de sujeitos }\end{array}$} \\
\hline Menor do que 100 & 94 & 43,7 & 63 & 79,7 & 18 & 54,5 & 175 & 53,5 & $0,0001^{+}$ \\
\hline Entre 100 e 500 & 68 & 31,6 & 9 & 11,4 & 8 & 24,2 & 85 & 26,0 & $0,001^{+}$ \\
\hline $\begin{array}{l}\text { Igual ou maior do } \\
\text { que } 500\end{array}$ & 35 & 16,3 & 3 & 3,8 & 5 & 15,2 & 43 & 13,1 & $0,001^{+}$ \\
\hline Outros & 18 & 8,4 & 4 & 5,1 & 2 & 6,1 & 24 & 7,3 & $0,457 \$$ \\
\hline \multicolumn{10}{|l|}{ Grupos de idade } \\
\hline Adultos & 72 & 33,5 & 44 & 57,1 & 13 & 39,4 & 129 & 39,7 & $0,001^{+}$ \\
\hline Idosos & 48 & 21,9 & 18 & 23,4 & 5 & 15,2 & 71 & 21,8 & $0,914^{+}$ \\
\hline $\begin{array}{l}\text { Crianças/ } \\
\text { adolescentes }\end{array}$ & 52 & 24,2 & 11 & 14,3 & 2 & 6,1 & 65 & 20,0 & $0,061^{+}$ \\
\hline Diversos & 28 & 12,8 & 1 & 1,3 & 10 & 30,3 & 39 & 12,0 & $0,003^{+}$ \\
\hline Não se aplica & 15 & 7,0 & 3 & 3,9 & 3 & 9,1 & 21 & 6,5 & $0,001^{+}$ \\
\hline \multicolumn{10}{|l|}{ Grupos específicos } \\
\hline Pacientes & 48 & 22,2 & 48 & 60,0 & 13 & 39,4 & 109 & 33,1 & $0,0001^{+}$ \\
\hline Sem especificidade & 66 & 30,1 & 14 & 17,5 & 11 & 33,3 & 91 & 27,7 & $0,029^{+}$ \\
\hline Escolares & 39 & 18,1 & 2 & 2,5 & 0 & - & 41 & 12,5 & $0,001^{+}$ \\
\hline Trabalhadores & 26 & 12,0 & 3 & 3,8 & 3 & 9,1 & 32 & 9,7 & $0,036^{+}$ \\
\hline
\end{tabular}

176 Ciro Queiroz e Rogério de Almeida 


\begin{tabular}{l|l|l|l|l|l|l|l|l|l}
\hline Atletas & 7 & 3,2 & 8 & 10,0 & 1 & 3,0 & 16 & 4,9 & $0,031^{\text {\$ }}$ \\
\hline Universitários & 7 & 3,2 & 0 & - & 1 & 3,0 & 8 & 2,4 & $0,196^{\S}$ \\
\hline $\begin{array}{l}\text { Mais de uma } \\
\text { especificidade }\end{array}$ & 4 & 1,9 & 2 & 2,5 & 1 & 3,0 & 7 & 2,1 & $0,660^{\text {s }}$ \\
\hline $\begin{array}{l}\text { Indígenas/ } \\
\text { quilombolas }\end{array}$ & 4 & 1,9 & 0 & - & 0 & - & 4 & 1,2 & $0,577^{\S}$ \\
\hline Não se aplica & 15 & 6,9 & 3 & 3,8 & 3 & 9,1 & 21 & 6,4 & $0,417^{\text {s }}$ \\
\hline Sexo & & & & & & & & & \\
\hline Feminino & 27 & 12,6 & 21 & 26,9 & 4 & 12,1 & 52 & 16,0 & $0,004^{+}$ \\
\hline Masculino & 9 & 4,2 & 18 & 23,1 & 2 & 6,1 & 29 & 8,9 & $0,0001^{+}$ \\
\hline Ambos & 164 & 76,3 & 36 & 46,2 & 24 & 72,7 & 224 & 68,7 & $0,0001^{+}$ \\
\hline Não se aplica & 15 & 7,0 & 3 & 3,8 & 3 & 9,1 & 21 & 6,4 & $0,417^{\$}$ \\
\hline
\end{tabular}

*Comparação entre exercício físico e atividade física, excluindo a busca por ambos os termos. +Teste Qui-quadrado. \$Teste exato de Fisher bi-Lateral. Em negrito p $\leq 0,05$.

A Tabela 2 apresenta os estudos transversais e experimentais subdivididos em: analítico/correlacional e descritivo/exploratório e sem grupo controle e com grupo controle, respectivamente.

Entre os estudos transversais, os descritivos/exploratórios predominaram em ambos os grupos, sendo que na comparação entre os grupos, houve diferença significante, $84,6 \%$ do grupo exercício físico vs $56,4 \%$ do grupo atividade física $(\mathrm{p}=0,050)$. Uma possível explicação é que a quantidade de estudos transversais com o termo exercício físico foi pequena, apenas 13 estudos, ou ainda que alguns autores não estão preocupados ou não se atentaram para a importância da escolha adequada das palavras-chave que identificam as suas pesquisas, bem como a escrita dos seus respectivos resumos. Segundo Ferreira (2002, p. 268-269),

[...] Uma palavra excluída, substituída ou acrescentada a qualquer um dos resumos pode permitir que cada leitor faça uma apropriação diferente daquele texto, pode conduzi-lo a uma direção não prevista, pode confundi-lo na opção por um ou por outro resumo com o objetivo de escrever aspectos da produção acadêmica de uma certa área do conhecimento, pode ser responsável pela frustração do leitor-pesquisador quando buscar o original. 
Quanto às pesquisas experimentais, as maiores frequências foram de estudos sem grupo controle, não sendo a diferença significante estatisticamente na comparação entre os grupos ( $\mathrm{p}=0,173)$. No geral, os estudos sem grupo controle prevaleceram sobre os estudos com grupo controle, $63,9 \%$ vs $36,1 \%$, o que era de se esperar, haja vista que é grande a dificuldade, aqui no Brasil, da disponibilidade de voluntários para participar de pesquisas, especialmente fazendo parte de grupo controle. Alguns fatores podem ser apontados para isto: faltam consciência e clareza da população brasileira quanto à importância de pesquisas experimentais para a ciência; dificuldade de seguimento ou acompanhamento destas pessoas, principalmente, nos momentos pós-intervenção; falta retorno por parte dos pesquisadores, quando do término da pesquisa aos voluntários, criando uma resistência à participação em futuras investigações e questões éticas que limitam a experimentação de muitas situações, por exemplo, fazer com que determinadas pessoas fumem e outras não.

TABELA 2. Subdivisão dos estudos transversais e experimentais conforme descritor de busca. Brasil, 2008

\begin{tabular}{l|l|l|l|l|l|l|l}
\hline & \multicolumn{2}{|c|}{ Total } & \multicolumn{2}{c|}{ Atividade Física } & Exercício Físico & \\
\hline Tipo de estudo & $\mathbf{n}$ & $\%$ & $\mathbf{n}$ & $\%$ & $\mathbf{n}$ & $\%$ & $\mathbf{p}^{*}$ \\
\hline $\begin{array}{l}\text { Transversal analítico/ } \\
\text { correlacional }\end{array}$ & 57 & 39,6 & 51 & 43,6 & 2 & 15,4 & \\
\hline $\begin{array}{l}\text { Transversal descritivo/ } \\
\text { exploratório }\end{array}$ & 87 & 60,4 & 66 & 56,4 & 11 & 84,6 & 0,050 \\
\hline & 144 & 100,0 & 117 & 100,0 & 13 & 100,0 & \\
\hline Experimental sem controle & 69 & 63,9 & 27 & 69,2 & 31 & 55,4 & \\
\hline Experimental com controle & 39 & 36,1 & 12 & 30,8 & 25 & 44,6 & 0,173 \\
\hline & 108 & 100,0 & 39 & 100,0 & 56 & 100,0 & \\
\hline
\end{tabular}

${ }^{*}$ Teste qui-quadrado. Em negrito $p \leq 0,05$.

Em relação à dependência administrativa dos programas onde as pesquisas foram realizadas, 45,2\% eram instituições federais, 34,0\% estaduais e $20,8 \%$ particulares. A distribuição dos 2.568 programas de pós-graduação autorizados pela CAPES, e em funcionamento no país no ano de 2008 , era a seguinte: $53,7 \%$ eram de instituições federais, $25,2 \%$ de estaduais, $20,4 \%$ de particulares e 0,7\% de municipais. (CAPES, 2006d) Dos atuais 21 progra- 
mas de pós-graduação na área de Educação Física no Brasil, oito $(38,1 \%)$ são desenvolvidos em instituições federais, seis $(28,6 \%)$ em instituições estaduais e sete $(33,3 \%)$ em instituições privadas. (FRIZZO, 2010)

As informações referentes às características dos programas de pós-graduação onde os estudos foram realizados, quanto à grande área do conhecimento, ao nível de graduação e à área de avaliação, estão descritas na Tabela 3.

Como esperado, observa-se uma grande predominância de trabalhos desenvolvidos em programas da grande área das Ciências da Saúde (75,3\%), sendo que a grande maioria dos estudos foi realizada em mestrados acadêmicos (77,4\%) e, conforme área de avaliação, Educação Física e Medicina apresentaram as maiores frequências de pesquisas, 29,5\% e $25,0 \%$, respectivamente.

Segundo a CAPES, no ano de 2008, 433 (16,9\%) programas de pós-graduação eram da área das Ciências da Saúde, 366 (14,6\%) da área das Ciências Biológicas e 326 (12,7\%) da área das Ciências Sociais. (CAPES, 2006c) Apesar da maior quantidade de programas na área das ciências da saúde, isso apenas não justificaria uma diferença tão grande de trabalhos desenvolvidos sobre atividade física nesses programas. Parece que a temática atividade física, mesmo envolvendo uma complexidade de fatores, portanto, dependente de uma multiplicidade de olhares, tem encontrado ainda um maior espaço nos programas da área de saúde. O que é bastante plausível e coerente, pois as evidências científicas são cada vez mais consistentes em relacionar de alguma forma a atividade física com a saúde. Seria estranho se os programas da área das engenharias, por exemplo, apresentassem mais interesse no assunto.

Analisando as informações de acordo com os descritores de busca, os estudos com o termo exercício físico foi mais frequente na grande área das Ciências Biológicas em comparação com a atividade física ( $\mathrm{p}=0,001)$, e o termo atividade física na grande área multidisciplinar ( $\mathrm{p}=0,008)$, comparado com exercício físico. Em relação à área de avaliação, atividade física foi maior na área da saúde coletiva $(\mathrm{p}=0,002)$, e interdisciplinar $(\mathrm{p}=0,008)$ e exercício fisico, por sua vez, na área das Ciências Biológicas $(\mathrm{p}=0,001)$. 
TABELA 3. Características dos programas de pós-graduação dos estudos analisados, conforme descritor de busca. Brasil, 2008

\begin{tabular}{|c|c|c|c|c|c|c|c|c|c|}
\hline \multirow[b]{2}{*}{$\begin{array}{l}\text { Área de } \\
\text { conhecimento }\end{array}$} & \multicolumn{2}{|c|}{ Total } & \multicolumn{2}{|c|}{$\begin{array}{l}\text { Exercício } \\
\text { físico }\end{array}$} & \multicolumn{2}{|c|}{$\begin{array}{l}\text { Atividade } \\
\text { física }\end{array}$} & \multicolumn{2}{|c|}{ Ambos } & \multirow[t]{2}{*}{$p^{*}$} \\
\hline & $\mathrm{n}$ & $\%$ & $\mathrm{n}$ & $\%$ & $\mathrm{n}$ & $\%$ & $n$ & $\%$ & \\
\hline Ciências da Saúde & 250 & 75,3 & 58 & 72,5 & 165 & 75,3 & 27 & 81,8 & $0,617^{+}$ \\
\hline Ciências Humanas & 33 & 9,9 & 9 & 11,3 & 22 & 10,0 & 2 & 6,1 & $0,762^{+}$ \\
\hline Ciências Biológicas & 21 & 6,3 & 12 & 15,0 & 8 & 3,7 & 1 & 3,0 & $0,001^{+}$ \\
\hline Multidisciplinar & 18 & 5,4 & - & - & 17 & 7,8 & 1 & 3,0 & $0,008^{s}$ \\
\hline Engenharias & 5 & 1,5 & 1 & 1,3 & 3 & 1,4 & 1 & 3,0 & $1,000^{\mathrm{s}}$ \\
\hline Ciências Agrárias & 3 & 0,9 & - & - & 2 & 0,9 & 1 & 3,0 & $1,000^{s}$ \\
\hline $\begin{array}{l}\text { Ciências Sociais } \\
\text { Aplicadas }\end{array}$ & 2 & 0,6 & - & - & 2 & 0,9 & - & - & $1,000^{s}$ \\
\hline \multicolumn{10}{|l|}{ Nível de graduação } \\
\hline Mestrado acadêmico & 257 & 77,4 & 63 & 78,8 & 168 & 76,7 & 26 & 78,8 & $0,710^{+}$ \\
\hline Doutorado & 58 & 17,5 & 12 & 15,0 & 40 & 18,3 & 6 & 18,2 & $0,510^{+}$ \\
\hline $\begin{array}{l}\text { Mestrado } \\
\text { profissionalizante }\end{array}$ & 17 & 5,1 & 5 & 6,3 & 11 & 5,0 & 1 & 3,0 & $0,772^{+}$ \\
\hline \multicolumn{10}{|l|}{ Área de avaliação } \\
\hline Educação física & 98 & 29,5 & 28 & 35,0 & 59 & 26,9 & 11 & 33,3 & $0,174^{+}$ \\
\hline Medicina & 83 & 25,0 & 23 & 28,8 & 52 & 23,7 & 8 & 24,2 & $0,377^{+}$ \\
\hline Saúde coletiva & 43 & 13,0 & 2 & 2,5 & 35 & 16,0 & 6 & 18,2 & $0,002^{+}$ \\
\hline Enfermagem & 25 & 7,5 & 5 & 6,3 & 17 & 7,8 & 3 & 9,1 & $0,657^{+}$ \\
\hline Psicologia & 22 & 6,6 & 9 & 11,3 & 12 & 5,5 & 1 & 3,0 & $0,084^{+}$ \\
\hline Ciências Biológicas & 21 & 6,3 & 12 & 15,0 & 8 & 3,7 & 1 & 3,0 & $0,001^{+}$ \\
\hline Interdisciplinar & 18 & 5,4 & - & - & 17 & 7,8 & 1 & 3,0 & $0,008^{s}$ \\
\hline Educação & 8 & 2,4 & - & - & 7 & 3,2 & 1 & 3,0 & $0,196 \$$ \\
\hline Engenharia & 5 & 1,5 & 1 & 1,3 & 3 & 1,4 & 1 & 3,0 & $1,000^{s}$ \\
\hline Sociologia & 3 & 0,9 & - & - & 3 & 1,4 & - & - & $0,567 \$$ \\
\hline $\begin{array}{l}\text { Ciências Sociais } \\
\text { Aplicadas }\end{array}$ & 2 & 0,6 & - & - & 2 & 0,9 & - & - & $1,000^{\mathrm{s}}$ \\
\hline Odontologia & 2 & 0,6 & - & - & 2 & 0,9 & - & - & $1,000^{\$}$ \\
\hline Farmácia & 1 & 0,3 & - & - & 1 & 0,5 & - & - & $1,000^{\$}$ \\
\hline Agrárias & 1 & 0,3 & - & - & 1 & 0,5 & - & - & $1,000^{\$}$ \\
\hline
\end{tabular}

*Comparação entre exercício físico e atividade física, excluindo a busca por ambos os termos. + Teste Quiquadrado. \$Teste exato de Fisher bi-lateral. Em negrito $p \leq 0,05$. 
A relação das terminologias das palavras com a área de conhecimento, discutidas anteriormente talvez justifique estes resultados, acrescentando o fato de que os programas de fisiologia do esforço estão na área das ciências biológicas e se utilizam com maior frequência do termo exercício físico.

Em relação à área de graduação e atuação dos autores no ensino superior (Tabela 4), observa-se 19 áreas distintas de formação, com predominância dos estudos desenvolvidos por autores com formação em Educação Física (43,6\%) e fisioterapia (18,2\%). Quando a área de graduação foi agrupada em grandes áreas de conhecimento, conforme critérios da CAPES, 90\% dos estudos sobre atividade física foram desenvolvidos por profissionais da área de saúde, seguidos de 7,3\% de profissionais das Ciências Humanas. Estabelecendo uma relação da formação do autor com área de conhecimento dos programas, os achados podem indicar, salvo algumas exceções, que a busca de qualificação profissional dos sujeitos envolvidos na pesquisa se dá na área de conhecimento de sua formação e que as profissões que apresentam uma relação mais próxima com a prática da atividade física preocupam-se em estudá-la mais.

São vários os documentos organizados por entidades científicas, publicados em forma de diretrizes, objetivando orientar as condutas diagnósticas e terapêuticas mais adequadas e atualizadas de acordo com evidências científicas, que sugerem a prática de atividade física como parte do tratamento não-medicamentoso de Doenças Crônicas Não-Transmissíveis (DCNT). (SBC, 2005;, SBH et al., 2005; SBD, 2006; SPOSITO et al., 2007; SBC/ SBH/SBN, 2010) Existe uma recomendação por parte destas diretrizes, que o tratamento não medicamentoso, incluso a orientação de atividade física, seja acompanhado, sempre que possível, por uma equipe multiprofissional. Vale reforçar que o professor de educação física, na sua formação, deve adquirir conhecimento técnico e científico para a prescrição de exercícios físicos, no que diz respeito ao tipo, frequência e intensidade de exercícios mais adequados a cada situação, portanto, é indispensável a presença do profissional de educação física nestas equipes multiprofissional. 
TABELA 4. Distribuição da área de graduação e atuação dos autores. Brasil, 2008

\begin{tabular}{|c|c|c|}
\hline & $\mathrm{n}$ & $\%$ \\
\hline \multicolumn{3}{|l|}{ Área de graduação } \\
\hline Educação Física & 144 & 43,6 \\
\hline Fisioterapia & 60 & 18,2 \\
\hline Nutrição & 42 & 12,7 \\
\hline Enfermagem & 23 & 7,0 \\
\hline Psicologia & 22 & 6,7 \\
\hline Medicina & 17 & 5,2 \\
\hline Farmácia & 7 & 2,1 \\
\hline Ciências Biológicas & 2 & 0,6 \\
\hline Pedagogia & 2 & 0,6 \\
\hline Odontologia & 2 & 0,6 \\
\hline Eng. Biomédica & 1 & 0,3 \\
\hline Matemática & 1 & 0,3 \\
\hline Economia Doméstica & 1 & 0,3 \\
\hline Eng. Mecânica & 1 & 0,3 \\
\hline Dança & 1 & 0,3 \\
\hline Arquitetura e Urbanismo & 1 & 0,3 \\
\hline Física & 1 & 0,3 \\
\hline Terapia Ocupacional & 1 & 0,3 \\
\hline Esporte & 1 & 0,3 \\
\hline \multicolumn{3}{|c|}{ Área de graduação agrupada } \\
\hline Ciências da saúde & 297 & 90,0 \\
\hline Ciências humanas & 24 & 7,3 \\
\hline Ciências biológicas & 2 & 0,6 \\
\hline Engenharias & 2 & 0,6 \\
\hline Ciências exatas e da terra & 2 & 0,6 \\
\hline Ciências sociais aplicadas & 2 & 0,6 \\
\hline Linguística, letras e artes & 1 & 0,3 \\
\hline \multicolumn{3}{|l|}{ Atuação no Ensino Superior } \\
\hline Sim & 198 & 59,8 \\
\hline Não & 133 & 40,2 \\
\hline
\end{tabular}


Quanto à área de atuação, 59,8\% dos mestres e doutores atuam no ensino superior. Analisando esta atuação, de acordo com o tipo de curso, $82,8 \%$ daqueles que cursaram o doutorado e $55,9 \%$ do mestrado acadêmico atuam no ensino superior, sendo significante estatisticamente a diferença comparada aqueles que não atuam. Entre os autores que cursaram o mestrado profissionalizante, $58,8 \%$ não atuam no ensino superior contra $41,2 \%$ que atuam, esta diferença não apresentou significância estatística $(\mathrm{p}=0,107)$ (Tabela 5).

Apesar da maioria dos doutores e mestres que estudaram sobre atividade física em programas acadêmicos atuar no ensino superior, chama a atenção o fato da quantidade que não atua, ou seja, 17,2\% dos doutores e $44,1 \%$ dos mestres. Dois aspectos podem ser considerados, primeiro, as pessoas por livre e espontânea vontade, após se qualificarem, não têm interesse no exercício da docência, e segundo, pode não haver vagas para todos nas instituições de ensino superior. Talvez o fato de algumas instituições privadas, em função de enxugar os seus custos, optarem por profissionais menos qualificados, principalmente após o reconhecimento dos cursos pelo Ministério da Educação (MEC), diminua a quantidade de vagas para esses profissionais, principalmente nos Estados onde a oferta de cursos é maior.

A diferença entre o mestrado acadêmico e profissional é que o último "enfatiza estudos e técnicas diretamente voltadas ao desempenho de um alto nível de qualificação profissional” (CAPES, 2006d), enquanto que a proposta dos cursos stricto sensu acadêmicos é formar pesquisadores para exercício da docência, especialmente, no ensino superior.

TABELA 5. Atuação do autor no ensino superior conforme o tipo de curso

\begin{tabular}{l|c|c|c}
\hline Tipo de curso & \multicolumn{2}{|c|}{ Atuação em ensino superior } & \\
\hline & Sim & Não & p* \\
\hline Mestrado Profissionalizante & $41,2 \%$ & 58,8 & 0,107 \\
\hline Mestrado Acadêmico & 55,9 & 44,1 & 0,007 \\
\hline Doutorado & 82,8 & 17,2 & 0,0001 \\
\hline
\end{tabular}

*Teste qui-quadrado 
Na Tabela 6 estão os números de estudos sobre atividade física conforme o Estado onde o programa está alocado e sua correlação com o Estado onde o autor desenvolve suas atividades profissionais, conforme informações retiradas do currículo Lattes. Existe uma correlação moderada (rho=0,730, $\mathrm{p}<0,001)$ entre a atuação do autor e o estado alocado do programa.

Observa-se que nos programas de pós-graduação do Estado de São Paulo foram realizadas $47,3 \%$ pesquisas sobre atividade física no ano de 2008 , sendo que $36,3 \%$ dos autores atuam profissionalmente nesse estado. No Rio de Janeiro, 23 dos 25 trabalhos publicados nos programas do estado foram desenvolvidos por autores que atuam naquele perímetro estadual. Situação similar em outros estados da região sul, no Rio Grande do Sul, por exemplo, 30 das 33 publicações foram realizadas por autores do próprio estado e no Paraná 11 autores do estado para 13 trabalhos publicados. Nos estados do centro-oeste, nordeste e norte do país, a situação é a mesma, ou seja, existe uma relação entre as pesquisas desenvolvidas nos programas e os autores que trabalham no estado, só que em quantidade muito menor de estudos. Exceção para os autores que trabalham nos estados de Roraima, Acre, Tocantins, Alagoas e Piauí que desenvolveram seus estudos em outros estados.

Estes resultados, em linhas gerais, apontam que o fato dos programas estarem alocados em determinados estados facilita a qualificação das pessoas que neles residem, ou ainda, que atraem pessoas de outros estados para trabalharem naqueles.

A assimetria da distribuição geográfica dos cursos e programas de pós-graduação no país já foi apontada por outros estudos. (YAMAMOTO; SOUZA; YAMAMOTO, 1999; PRADO; SAYD, 2004; ZANELLA; TITON, 2005; MOLINA NETO et al., 2006; HALLAL et al., 2007; FRIZZO, 2010; BARROS et al., 2010) A concentração de estudos dos mais diversos assuntos em alguns estados brasileiros, especialmente os estados das regiões sudeste e sul, segue exatamente esta distribuição. São Paulo sempre aparece em primeiro lugar.

Um estudo da produção acadêmica brasileira em psicologia sobre a temática criatividade, entre 1994 e 2001, apontou que o estado de São Paulo concentrou $70 \%$ dos trabalhos, seguido de longe pelo Rio de Janeiro com 
$12 \%$ das produções, Distrito Federal 10\%, Rio Grande do Sul 7\% e Minas Gerais, 1\%. (ZANELLA; TITON, 2005)

Prado e Sayd (2004), analisando os grupos de pesquisa sobre envelhecimento humano a partir do Diretório dos Grupos de Pesquisa no Brasil do Conselho Nacional de Desenvolvimento Científico e Tecnológico (CNPq), identificaram 144 grupos com linha de pesquisa referente ao envelhecimento humano, sendo que destes, 38,9\% estavam no estado de São Paulo, $18,1 \%$ no Rio Grande do Sul, $14,6 \%$ no Rio de Janeiro e os demais distribuídos em outros estados. De acordo com região geográfica, a região sudeste concentrou $59,7 \%$ dos grupos, a Sul $21,5 \%$, a nordeste $13,9 \%$ e a centro-oeste $4,9 \%$, na região norte não foi encontrado nenhum grupo.

$\mathrm{Na}$ análise por região (Tabela 7), observa-se que $60,9 \%$ dos estudos foram desenvolvidos em programas na região sudeste, $20,6 \%$ na região sul, $9,4 \%$ na região nordeste, $8,5 \%$ na centro-oeste e apenas $0,6 \%$ no norte do país. A correlação entre a região do programa e a região de atuação profissional do autor foi de $0,748(\mathrm{p}<0,001)$.

Como dito anteriormente, as disparidades regionais em relação à oferta de cursos de pós-graduação stricto sensu já é conhecida e denunciada por outros estudos. Hallal e colaboradores (2007), em estudo de revisão sobre pesquisa epidemiológica em atividade física no Brasil, observaram que entre os 42 trabalhos revisados, $43 \%$ foram realizados na região Sudeste, $36 \%$ na Sul e os demais foram distribuídos entre as regiões Nordeste (11\%), Norte (5\%) e Centro-Oeste (5\%).

A análise de seis periódicos brasileiros de circulação nacional, editados entre 1990 e 1997, especializados em Psicologia, feita por Yamamoto; Souza; Yamamoto (1999) revelou que dos 749 artigos distribuídos pelas 80 edições, a maior parte dos artigos nos periódicos pesquisados originou-se da região sudeste, com uma participação expressiva também da região sul, justamente em função da afiliação institucional do primeiro autor ser nestas regiões geográficas do país.

É preciso superar o desequilíbrio regional referente à concentração de programas de pós-graduação no Brasil. As regiões Nordeste, Norte e Centro-Oeste do país urgem de investimento e desenvolvimento da pesquisa nos seus estados. Para tal é necessário, acima de tudo, a formação 
de mais doutores, com envolvimento, compromisso e ousadia com esta causa nestes estados, aliados a políticas públicas consistentes e efetivas de financiamento para os programas existentes e criação de novos cursos e programas de pós-graduação nestas regiões.

TABELA 7. Quantidade de estudos conforme

Região do programa e atuação atual do autor. Brasil, 2008

\begin{tabular}{|c|c|c|c|c|c|c|c|}
\hline \multirow{8}{*}{ 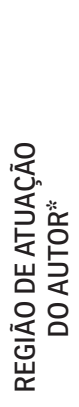 } & \multicolumn{7}{|c|}{ REGIÃO DO PROGRAMA* } \\
\hline & & Sudeste & Sul & Nordeste & $\begin{array}{l}\text { Centro- } \\
\text { oeste }\end{array}$ & Norte & Total \\
\hline & Sudeste & 170 & 2 & 1 & 5 & & 178 \\
\hline & Sul & 17 & 60 & & & & 77 \\
\hline & Nordeste & 4 & 4 & 30 & 2 & & 40 \\
\hline & Centro-oeste & 8 & 2 & & 20 & & 30 \\
\hline & Norte & 2 & & & 1 & 2 & 5 \\
\hline & Total & 201 & 68 & 31 & 28 & 2 & 330 \\
\hline
\end{tabular}

* Coeficiente de correlação de Spearman $=0,748(p<0,001)$

\section{CONSIDERAÇÕES FINAIS}

Apesar de encontrados estudos em sete áreas de conhecimento distintas, as pesquisas relacionadas à atividade física, publicadas no Banco de Teses da CAPES no ano 2008, predominantemente, aconteceram nos programas de pós-graduação da área das ciências da saúde, com razoável participação das ciências humanas e biológicas. Entre os 19 tipos de graduação dos autores, a formação em educação física merece destaque, 43,6\% dos autores graduaram-se nesta área.

No que tange à distribuição geográfica dos programas, os resultados desta pesquisa fazem eco com o que já foi apontado por outros estudos, ou seja, existe no país uma concentração na produção do conhecimento nas regiões sudeste e sul, especialmente no Estado de São Paulo. Parece-nos imprescindível atentarmos para este fato, no sentido de equacionarmos tal situação, vislumbrando uma política de ciência mais justa e realmente democrática, o que pode significar um importante avanço científico para o país nos mais diversos campos, em relação à atividade física inclusive. 
Chama-se a atenção em relação à escolha dos termos atividade física ou exercício físico como descritores de busca em periódicos e bases de dados, os achados nos induz a pensar que em função dos conceitos adotados por diferentes áreas de conhecimento e características próprias das pesquisas que cada terminologia carrega, os pesquisadores que pretendem encontrar trabalhos sobre performance humana ou tipos de treinamento físico mais adequados para determinadas situações, utilizem o termo exercício físico, e aqueles que quiserem pesquisar sobre os aspectos mais gerais da relação entre a falta de atividade física e os fatores de risco para a saúde, usem o descritor atividade física.

Espera-se ainda que este trabalho ajude a conhecer melhor as características das pesquisas em atividade física no Brasil e seus autores e estimule novas estratégias metodológicas para a quantificação destes estudos. Pode-se pensar, por exemplo, na realização de futuras pesquisas sobre as tendências das teses/dissertações defendidas nos programas de pós-graduação no país nos últimos anos.

Por fim, vale destacar que a qualidade dos resumos analisados constitui uma dificuldade para as análises exploradas. Em diversos resumos aspectos importantes dos trabalhos, como método de pesquisa utilizado, quantidade de sujeitos envolvidos, entre outros, não estavam claros. Esses problemas também foram relatados por outros estudos (FERREIRA, 2002; ZANELLA; TITON, 2005), o que pode indicar a necessidade de maior cuidado por parte dos pesquisadores na elaboração dos resumos e na utilização das palavras-chave.

\section{REFERÊNCIAS}

BARROS, M. V. G. et al. Programa associado de Pós-graduação em Educação Física UPE/UFPB. Revista Brasileira de Atividade Física \& Saúde, FALTA LOCAL v. 15, n. 3, p. 176-179, 2010.

COORDENAÇÃO DE APERFEICOAMENTO DE PESSOAL DE NÍVEL SUPERIOR (CAPES). História e Missão. 2006a. Disponível: <http://www.capes.gov.br/ sobre-a-capes/historia-e-missao>. Acesso em: 28 out. 2009a. 
. Estatística de uso. 2006b. Disponível: <http://www.periodicos.capes.gov. br/portugues/index.jsp>. Acesso em: 28 out. 2009.

COORDENAÇÃO DE APERFEICOAMENTO DE PESSOAL DE NÍVEL SUPERIOR (CAPES). Estatísticas (GeoCapes). 2006c..Disponível: <http:/geocapes. capes.gov.br/geocapesds/\#app=c501\&da7a-selectedIndex=0\&5317selectedIndex=0\&82e1-selectedIndex=0 > . Acesso em: 11 jul. 2011.

. Pós-graduação. Qual é a diferença entre o mestrado acadêmico e o mestrado profissional? 2006d...Disponível: <http://www.capes.gov.br/duvidasfrequentes/62-pos-graduacao/2376-qual-e-a-diferenca-entre-o-mestradoacademico-e-o-mestrado-profissional>. Acesso em: 11 jul. 2011.

. Relações dos cursos recomendados e reconhecidos. 2006e. Disponível: <http://www.capes.gov.br/cursos-recomendados>. Acesso em: 08 nov. 2009. FERREIRA, N. S. A. As pesquisas denominadas "estado da arte”. Educação e Sociedade, v. 23, n. 79, p. 257-272, ago. 2002.

FLETCHER, R. H.; FLETCHER, S. W. Epidemiologia Clínica: elementos essenciais. 4. ed. Porto Alegre: Artmed, 2006.

FRIZZO, G. F. E. A produção do conhecimento da Educação Física no programa de pós-graduação em ciências do movimento humano da UFRGS. Pensar a prática, v. 13, n. 3, p. 1-16, 2010.

GAMBOA, S. S.; CHAVES, M.; TAFFAREL, C. A pesquisa em Educação Física no nordeste brasileiro (Alagoas, Bahia, Pernambuco e Sergipe), 1982-2004: Balanço e perspectivas. Rev. Bras. Ciênc. Esporte, v. 29, n. 1, p. 89-106, 2007. HALLAL, P. C. et al. Evolução da pesquisa epidemiológica em atividade física no Brasil: revisão sistemática. Rev. Saúde Pública, v. 41, n. 3, p. 453-460, 2007.

JOB, I.; ALVARENGA, L. Citações presentes em teses e perfis de pesquisadores: fontes de indícios para se estudar a área da Educação Física. Perspect. Ciênc. Inf., v. 13, n. 3, p. 151-166, 2008.

LUDORF, S. M. A. Panorama da pesquisa em Educação Física na década de 90: análise dos resumos de dissertações e teses. Rev. da Educação Física, v. 13, n. 2, p. 19-25, 2002. 
MINAYO, M. C. S.; SANCHES, O. Quantitativo-Qualitativo: Oposição ou complementaridade? Cad. Saúde Públ., v. 9, n. 3, p. 239-262, 1993.

MOLINA NETO, V. et al. Reflexão sobre a produção do conhecimento em Educação Física e Ciências do Esporte. Rev. Bras. Ciênc. Esporte, v. 28, n. 1, p. 145-165, 2006.

PRADO, S. D.; SAYD, J. D. A pesquisa sobre envelhecimento humano no Brasil: grupos e linhas de pesquisa. Ciênc. Saúde Coletiva, v. 9, n. 1, p. 57-68, 2004.

SBC - SOCIEDADE BRASILEIRA DE CARDIOLOGIA. Diretriz de Reabilitação Cardíaca. Arq. Bras. Cardiol., v. 84, n. 5, p. 431-440, mai. 2005.

SBC - SOCIEDADE BRASILEIRA DE CARDIOLOGIA; SBH - SOCIEDADE BRASILEIRA DE HIPERTENSÃO; SBN - SOCIEDADE BRASILEIRA DE NEFROLOGIA. VI Diretrizes Brasileiras de Hipertensão. Arq. Bras. Cardiol., v. 95 n.1 supl.1, p. 1-51. 2010.

SBD - SOCIEDADE BRASILEIRA DE DIABETES. Tratamento e acompanhamento do Diabetes mellitus: Diretrizes da Sociedade Brasileira de Diabetes. Editora Diagrafic: 2006.

SBH - SOCIEDADE BRASILEIRA DE HIPERTENSÃO et al. I Diretriz Brasileira de Diagnóstico e Tratamento da Síndrome Metabólica.

Arq. Bras. Cardiol., v. 84, suppl. 1, p. 3-28, abr. 2005.

SPOSITO, A. C. et al. IV Diretriz Brasileira sobre Dislipidemias e Prevenção da Aterosclerose: Departamento de Aterosclerose da Sociedade Brasileira de Cardiologia. Arq. Bras. Cardiol., v. 88 supl.1, p. 2-19, abr. 2007.

YAMAMOTO, O. H.; SOUZA, C. C.; YAMAMOTO, M. E. A produção científica na psicologia: uma análise dos periódicos brasileiros no período 1990-1997. Psicol. Reflex. Crit., v. 12, n. 2, p. 549-565, 1999.

ZANELLA, A. V.; TITON, A. P. Análise da produção científica sobre criatividade em programas brasileiros de pós-graduação em psicologia (1994-2001). Psicologia em Estudo, v. 10, n. 2, p. 305-316, mai./ago. 2005. 



\section{Práticas corporais desenvolvidas com idosas participantes do projeto Educar Para a Atividade Física (EPAF) da Universidade do Estado da Bahia e variáveis da aptidão física}

Cíntia Guimarães Rosário

Maurício Maltez Ribeiro

Valter Abrantes Pereira da Silva

\section{INTRODUÇÃO}

Pesquisas (BRASIL, 2010) recentes registraram o crescimento progressivo da população brasileira nas últimas décadas, embora tenha sido observada uma redução da taxa de fecundidade e mortalidade no país, com consequente aumento da expectativa de vida desses indivíduos.

Segundo a Organização Pan-Americana da Saúde (OPAS) (2005), até 2025 o número de pessoas com 60 anos ou mais terá aumentado em aproximadamente 70\%, principalmente nos países em desenvolvimento, causando um aumento das demandas sociais e econômicas em todo o mundo, como a implementação de políticas e programas de envelhecimento ativo que permitam a essas pessoas continuarem a trabalhar de acordo 
com suas capacidades e preferências à medida que envelhecem, prevenindo e/ou minimizando incapacidades e doenças crônicas.

Comungando dessa mesma preocupação e demanda social, Matsudoe colaboradores (2001, p. 51) ressaltam ainda que

[...] torna-se imprescindível uma mobilização de vários setores e órgãos competentes ligados à área de saúde e bem-estar, com intuito de alertar, esclarecer e educar a população como um todo em especial os idosos da importância e manutenção da saúde e da qualidade de vida para se ter uma velhice bem sucedida diminuindo o risco de doenças e outros problemas que levariam a um estado de morbidade ou até a mortalidade.

Doenças Crônicas Não Transmissíveis (DCNT), como as doenças cardiovasculares, neoplasias, doenças respiratórias crônicas, diabetes, doenças músculo-esqueléticas, entre outras, são um problema emergente, reflexo desse cenário, responsável por 66\% das mortes no mundo, especialmente em países em desenvolvimento (WHO, 2004), e que vem despertando a atenção do Ministério da Saúde no sentido de elaborar estratégias que promovam uma melhor qualidade de vida, de modo a minimizar os fatores de risco a elas associados e reduzir as despesas com a saúde pública. (BRASIL, 2008)

Segundo a Organização Pan-Americana da Saúde (2005), em todos os países, e especialmente nos países em desenvolvimento, medidas para ajudar pessoas mais velhas a se manterem saudáveis e ativas são uma necessidade, não um luxo. As políticas e programas devem ser baseados nos direitos, necessidades, preferências e habilidades das pessoas mais velhas, incluindo, também, uma perspectiva de curso de vida que reconheça a importante influência das experiências de vida para a maneira como os indivíduos envelhecem.

Nesse sentido, a Organização Mundial da Saúde adotou o termo "envelhecimento ativo", que "é o processo de otimização das oportunidades de saúde, participação e segurança, com o objetivo de melhorar a qualidade de vida à medida que as pessoas ficam mais velhas”. (OPAS, 2005, p. 13) 
A referida organização afirma que

[...] o envelhecimento ativo aplica-se tanto a indivíduos quanto a grupos populacionais. Permite que as pessoas percebam o seu potencial para o bem-estar físico, social e mental ao longo do curso da vida, e que essas pessoas participem da sociedade de acordo com suas necessidades, desejos e capacidades; ao mesmo tempo, propicia proteção, segurança e cuidados adequados, quando necessários. (OPAS, 2005, p.13)

Estudos (MATSUDO et al., 2003; MATSUDO, 2002; PAIN et al., 2001; MAZZEO et al., 1998) evidenciam a importância da participação de pessoas idosas em programas de atividade física regular e a adoção de um estilo de vida ativo como forma de prevenir e controlar doenças crônicas não-transmissíveis e de manter a independência funcional durante o processo de envelhecimento, devendo fazer parte desses programas atividades aeróbicas de baixa intensidade e exercícios de força muscular, especialmente com peso.

Desta forma, atendendo a essa necessidade emergente local, foi criado o projeto Educar para a Atividade Física (EPAF). Este projeto foi desenvolvido a partir do desejo de discentes do curso de Licenciatura em Educação Física em atuar na comunidade, atrelada especificamente ao Programa Saúde da Família (PSF) e Núcleo de Atendimento à Saúde da Família (NASF) do município de Alagoinhas. O EPAF surgiu a partir da sistematização do projeto de extensão da Universidade do Estado da Bahia, enquadrado na linha de pesquisa Atividade Física e Saúde, estando seus colaboradores engajados numa nova proposta de intervenção do professor de educação física neste espaço e junto à comunidade que o frequenta, mais especificamente os idosos.

No projeto são realizadas atividades que contribuem para uma melhor qualidade de vida das suas participantes, proporcionando mudanças positivas nas capacidades físicas e funcionais, como exercícios resistidos, caminhadas, danças, lutas, e na autoestima, como a convivência com outras pessoas, atividades lúdicas e recreativas, estabelecendo relações da 
afetividade. Incluindo, também, orientação a respeito da importância e benefícios da prática regular de atividade física, entendendo-a como um dos principais aliados para um estilo de vida saudável e com qualidade.

Nesse sentido, surge a proposta da referida pesquisa que objetiva estudar os efeitos das práticas corporais desenvolvidas com idosas participantes do projeto Educar para a Atividade Física (EPAF) da Universidade do Estado da Bahia sobre variáveis da aptidão física (morfológicas e neuromotoras), comparando o comportamento das variáveis estudadas com os valores obtidos através das avaliações trimestrais.

\section{METODOLOGIA}

Caracterizado como um estudo longitudinal, o presente trabalho configura-se como uma pesquisa-ação, pois visa avaliar os impactos das ações metodológicas realizadas no projeto EPAF sobre variáveis da patidão física das participantes ao longo de 28 semanas, cujo método de coleta de dados empregado foi o instrumento de teste, utilizado para obtenção de dados quantitativos. (MATTOS; ROSSETTO JÚNIOR; BLECHER, 2008)

Foi utilizado como critério de participação na pesquisa mulheres com idade a partir de 60 (sessenta) anos, participantes ativas do Projeto Educar para a Atividade Física e que tinham acompanhamento médico do Posto de Saúde da Família (PSF) do seu bairro. Foram adotados como critério de exclusão qualquer patologia que colocasse em risco a saúde das voluntárias e a baixa frequência (maior do que $25 \%$ das aulas) e/ou saída do projeto EPAF. A amostra foi composta por 8 (oito) participantes voluntárias, com média de idade de 69,75 \pm 7,44 (60 a 82 anos), as quais foram previamente informadas acerca dos objetivos da pesquisa e convidadas a assinar o termo de consentimento livre e esclarecido, conforme previsto na resolução 196/96 do Conselho Nacional da Saúde.

No projeto EPAF são desenvolvidas atividades como caminhadas, dança, lutas, musculação, atividades lúdicas e recreativas, as quais são oferecidas aleatoriamente uma vez por semana com duração de duas horas por dia, sendo realizadas nas dependências da Universidade do Estado da Bahia - UNEB, Campus II. 
Foram realizadas três avaliações com um intervalo de três meses entre as mesmas, sendo a primeira realizada em fevereiro de 2011, a segunda em maio de 2011 e a terceira e última em agosto de 2011, sempre no início de cada mês. As variáveis avaliadas foram: o índice de massa corpórea (IMC), circunferência da cintura (CC), razão circunferência cintura-quadril (RCC/Q), força muscular e flexibilidade de membros superiores e inferiores.

Como instrumento para avaliação do IMC, da circunferência da cintura e da relação circunferência cintura/quadril foram utilizados uma balança antropométrica digital da marca Welmy e uma fita métrica metalizada e flexível, com graduação em milímetros.

Para a avaliação das variáveis neuromotoras foram utilizados os seguintes testes: a) força muscular dos membros superiores: foi utilizado o instrumento RESISFOR da bateria de testes American Alliance for Health Physical Education, Recreation and Dance (AAHPERD) (1990), composta por cinco testes motores e que utiliza um halter pesando $1,8 \mathrm{~kg}$ para mulheres; $\mathrm{b}$ ) força muscular dos membros inferiores: foi utilizado o teste de levantar da cadeira em 30 segundos, conforme padronização proposta por Rikli e Jones (1999); c) flexibilidade dos membros superiores: foi utilizado o Teste de Flexibilidade do Ombro (MATSUDO, 2010), cujo material utilizado foi uma régua; d) flexibilidade do tronco e membros inferiores: foi utilizado o teste "Sentar e Alcança" (MATSUDO, 2010), também conhecido como Banco de Wells, o material utilizado foi um banco de madeira de $35 \mathrm{~cm}$ de altura e largura, $40 \mathrm{~cm}$ de comprimento com uma régua padrão na parte superior ultrapassando em $15 \mathrm{~cm}$ a superfície de apoio dos pés.

A análise estatística dos dados foi formatada pela análise de variância de hum (1) fator para medidas repetidas (one-way ANOVA) que comparou as diferenças entre IMC, circunferência da cintura, relação circunferência cintura/quadril (RCC/Q), força muscular de membros superiores e inferiores e flexibilidade de membros superiores e inferiores das idosas, durante o acompanhamento das avaliações a cada 3 (três) meses. Foi analisado o comportamento das variáveis e os efeitos da intervenção estabelecendo o nível de significância de $\mathrm{p}<0,05$. 


\section{RESULTADOS}

Os resultados obtidos através da avaliação das variáveis morfológicas e neuromotoras estão apresentados separadamente através das Tabelas 1 e 2 , respectivamente, e os valores encontrados são expressos em média \pm desvio-padrão, com as correspondentes comparações entre os três momentos da coleta de dados e a análise estatística realizada através da análise de variância de hum (1) fator para medidas repetidas (one-way ANOVA).

Na Tabela 1, são apresentados os valores do IMC, da Circunferência da Cintura (CC) e da Razão da Circunferência da Cintura-Quadril (RCCQ). É possível observar que não houve variação estatística significativa das variáveis morfológicas no período analisado $(P>0,05)$.

TABELA 1. Valores de IMC, CC e RCC/Q expressos em média \pm desvio-padrão (DP), com as correspondente comparações entre os três momentos da coleta de dados e a análise estatística

\begin{tabular}{l|c|c|c|c|c|c|c|}
\hline & \multicolumn{2}{|c|}{$1^{\mathrm{a}}-\mathrm{FEV} / 2011$} & \multicolumn{2}{c|}{$2^{\mathrm{a}}-\mathrm{MAI} / 2011$} & \multicolumn{2}{c|}{$3^{\mathrm{a}}-\mathrm{AGO} / 2011$} & \\
\hline & Média & DP & Média & DP & Média & DP & $\mathrm{P}$ \\
\hline $\mathrm{IMC}^{*}$ & $35,0 \pm$ & 3,55 & $34,5 \pm$ & 3,18 & $34,5 \pm$ & 3,46 & 0,96 \\
\hline $\mathrm{CC}^{* *}$ & $102,5 \pm$ & 1,41 & $104,3 \pm$ & 3,18 & $100,3 \pm$ & 4,24 & 0,74 \\
\hline $\mathrm{RCCQ}^{* *}$ & $0,9 \pm$ & 0,04 & $0,9 \pm$ & 0,02 & $0,9 \pm \pm$ & 0,02 & 0,48 \\
\hline
\end{tabular}

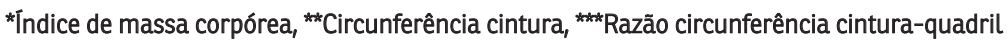

Com relação aos resultados das variáveis neuromotoras, apresentados na Tabela 2, os valores mantiveram-se estáveis tanto para a força muscular quanto para flexibilidade, não havendo variação estatística significativa $(P>0,05)$ no período analisado, à exceção da força muscular dos membros superiores a qual apresentou uma variação estatística positiva $(P<0,05)$, sendo que, da primeira para a segunda avaliação, a variação estatística foi de $P=0,88$, da segunda para a terceira $P=0,07$ e da primeira para a terceira $P=0,02$, ou seja, esta variável seguiu uma progressão estatística positiva. 
TABELA 2. Valores de Força Muscular e Flexibilidade expressos em média \pm desvio-padrão (DP), com as correspondente comparações entre os três momentos da coleta de dados e a análise estatística realizada

\begin{tabular}{|c|c|c|c|c|c|c|c|c|}
\hline \multirow[b]{3}{*}{ Força Muscular MS** } & \multicolumn{2}{|c|}{$1^{\mathrm{a}}-\mathrm{FEV} / 2011$} & \multicolumn{2}{|c|}{$2^{\mathrm{a}}-\mathrm{MAI} / 2011$} & \multicolumn{3}{|c|}{$3^{a}-A G 0 / 2011$} & \multirow[b]{2}{*}{$\mathrm{P}$} \\
\hline & Média & DP & Média & $\mathrm{DP}$ & Médic & & DP & \\
\hline & 9,5 & 0,71 & 9,5 & 0,71 & 12 & \pm & 0,00 & $0,02^{*}$ \\
\hline Força Muscular Ml*** & 12,0 & 1,41 & 9,0 & 4,24 & 11,0 & \pm & 4,24 & 0,25 \\
\hline Flexibilidade MS & $(-) 23,8 \pm$ & 5,3 & $(-) 28,3 \pm$ & 0,35 & $(-) 19,5$ & \pm & 0,35 & 0,60 \\
\hline Flexibilidade MI*** & 18,8 & 5,3 & 26,0 & 1,41 & 24,8 & \pm & 1,77 & 0,48 \\
\hline
\end{tabular}

* diferença da $1^{\mathrm{a}}$ para a $3^{\mathrm{a}}$ avaliação, **Membros superiores *** Membros inferiores

\section{DISCUSSÃO}

O processo de envelhecimento é um fenômeno extremamente complexo, por depender de uma série de fatores biopsicossociais interrelacionados (TEIXEIRA et al., 2007), e está diretamente relacionado à incidência e prevalência das DCNTs cujo fatores de risco estão associados em grande parte ao estilo de vida dos indivíduos, sendo classificados em

'Não modificáveis' (sexo, idade e herança genética) e 'comportamentais' (tabagismo, alimentação, inatividade física, consumo de álcool e outras drogas). Os fatores de risco comportamentais são potencializados pelos fatores condicionantes socioeconômicos, culturais e ambientais. (BRASIL, 2008, p. 16)

Estudos (FERREIRA et al., 2010; PEREIRA; BARRETO; PASSOS, 2008) evidenciaram a prevalência da dieta inadequada, hipertensão arterial, obesidade e inatividade física como principais fatores de risco cardiovascular em idosos, com predominância em mulheres.

Segundo a Organização Mundial de Saúde (2004, p. 4),

Dietas não saudáveis e inatividade física estão, portanto, entre as principais causas das doenças não-transmissíveis, incluindo doenças cardiovasculares, diabetes tipo 2 e certos tipos de câncer, e contribuem substancialmente para a carga global de doenças, morte e invalidez. 
Uma pesquisa (GIROTTO; ANDRADE; CABRERA, 2010) epidemiológica realizada com hipertensos na faixa etária de 20 a 79 anos residentes na cidade de Londrina no Paraná, evidenciou a prevalência de obesidade abdominal identificada pela RCCQ em $68,1 \%$ dos idosos ( $\geq 60$ anos) que participaram da pesquisa, com prevalência no sexo feminino.

Existem variações significativas relacionadas ao estado de saúde, participação e níveis de independência entre pessoas mais velhas que possuem a mesma idade (OPAS, 2005) e que estão ligadas, também, ao nível de atividade física e qualidade de vida dessas pessoas.

Segundo Matsudo (2002), uma das mais evidentes alterações que acontecem com o aumento da idade cronológica é a mudança nas dimensões corporais, principalmente na estatura, no peso e na composição corporal. $O$ aumento do peso é uma alteração corporal que geralmente começa em torno dos 45 a 50 anos e se estabiliza aos 70, quando começa a declinar até os 80. Ainda conforme a autora, esse parece ser o padrão mais provável de comportamento da adiposidade corporal no decorrer dessa fase da vida.

Em virtude das alterações no peso e estatura sofridas pelo indivíduo com o decorrer dos anos, há uma consequente variação nos índices do IMC. Nesse sentido, Matsudo (2002) ressalta a importância dessa medida no processo de envelhecimento, pois valores acima da normalidade (26-27) estão relacionados com incremento da mortalidade por doenças cardiovasculares e diabetes, enquanto índices abaixo desses valores têm relação com aumento da mortalidade por câncer, doenças respiratórias e infecciosas.

Segundo a Sociedade Brasileira de Endocrinologia e Metabologia (SBEM) (2004, p. 6), o IMC é um bom indicador da gordura corporal, no entanto, a sua associação com a medida da circunferência abdominal "pode oferecer uma forma combinada de avaliação de risco e ajudar a diminuir as limitações de cada uma das avaliações isoladas”. Pesquisas (GLANER; PELEGRINI.; NASCIMENTO, R, 2011; MOLARIUS et al., 1999) apontam a circunferência da cintura como o melhor indicador antropométrico do tecido adiposo na região abdominal.

Outro indicador antropométrico de obesidade apontado como melhor preditor para doenças cardiovasculares e cardíaca coronariana é a Razão da Circunferência Cintura-Quadril (RCCQ) (OLIVEIRA et al., 2010; PITANGA, 
2008; PITANGA; LESSA, 2005), contudo, para que seja determinado de fato um diagnóstico faz-se necessário a realização de exames mais específicos e acompanhamento de demais fatores de risco associados a tais patologias.

Estudos que analisaram os efeitos de um programa de atividade física sobre variáveis morfológicas no período de 22 meses (PAIN et al., 2001) e de 2 anos (SILVA JÚNIOR et al., 2011) encontram resultados semelhantes, embora a frequência de realização das atividades tenham sido de 2 e 3 vezes na semana, respectivamente. O recomendável é que seja realizado exercício físico moderado, se possível, todos os dias da semana com duração de 30 a 40 minutos, e os exercícios mais intensos realizados de duas a três vezes na semana (SAFONS; PEREIRA, 2007; CARVALHO et al., 2001), no entanto, os resultados encontrados reforçam o fato de que mesmo as atividades sendo realizadas uma vez durante a semana ainda é melhor que a inatividade física, garantindo assim a manutenção das variáveis da aptidão física relacionadas à morfologia corporal.

Responsável pela deterioração na mobilidade e na capacidade funcional do indivíduo que está envelhecendo, a perda do desempenho da força muscular torna-se aparente somente a partir dos 50 a 60 anos de idade e pode ser explicada, também, pelas mudanças nas propriedades intrínsecas das fibras musculares. (MATSUDO, 2002) Esta tende a sofrer um decréscimo em decorrência da perda de massa muscular resultante, em grande parte, de uma redução da síntese protéica que ocorre com o envelhecimento e a perda de unidades motoras das fibras de contração rápida, e/ou da diminuição da atividade física (WILMORE; COSTILL, 2001), ocasionando dificuldade de locomoção e equilíbrio, aumentando o risco de quedas, o que contribui também para o risco de doenças crônicas, como o diabetes e a osteoporose. (MATSUDO et al., 2003)

Outra variável, cujo pico de amplitude máxima de movimento acontece por volta dos vinte anos de idade, declinando significativamente a partir de então (SAFONS; PEREIRA, 2004) e que exerce influência direta na agilidade, é a flexibilidade, a qual pode ser um fator limitante no desempenho da marcha, especialmente de pessoas idosas, em virtude da atrofia da musculatura flexora do quadril, que compromete o desempenho da mobilização articular. (CRISTOPOLISKI et al., 2008) 
Estudos (CIPRIANI, 2010; PAULI, 2009; PAIN et al, 2001; ROGATTO; GOBBI, 2001) semelhantes que analisaram o comportamento das variáveis neuromotoras de uma população idosa durante um período maior ou igual a 7 meses, participantes ativas de um programa de atividade física para a terceira idade, cuja atividades eram realizadas no mínimo duas vezes na semana, encontraram resultados análogos. No entanto, foi encontrado também pesquisas onde foi observado melhoras significativas no que diz respeito à força muscular para membros superiores (SILVA JÚNIOR et al., 2011) e inferiores. (TEIXEIRA et al., 2007)

Um dos aspectos fundamentais para proporcionar uma velhice independente e com maior qualidade de vida é a realização regular de atividade física (GOMES; ZAZÁ, 2009), seja de forma autônoma, com orientação de um profissional da área, ou através da participação em programas que incentivem essa prática.

Estudos (SILVA JÚNIOR et al., 2011; CIPRIANI et al., 2010; MAZO et al., 2009; MATSUDO et al. ,2003; PAIN et al., 2001) concluem que a prática de atividade física regular, que inclua principalmente atividades aeróbicas e de força muscular, promove melhora significativa nas funções físicas e manutenção da independência do idoso, permitindo-o realizar com mais eficácia atividades da rotina diária e de lazer.

Em maio de 2004, a Organização Mundial de Saúde (OMS) desenvolveu a Estratégia Global sobre Alimentação, Atividade Física e Saúde com o objetivo de reduzir os fatores de risco das doenças não-transmissíveis, aumentar a consciência e entendimento sobre o impacto positivo de uma boa alimentação e da prática regular de atividade física na saúde, e incentivar o desenvolvimento, fortalecimento e implementação de políticas e ações que fortaleçam esse comportamento. (WHO, 2004)

Advogando desta mesma ideia, Pitanga (2004) descreve um modelo piramidal para análise da atividade física e exercício físico, estando na base da pirâmide atividades físicas do cotidiano, as quais deveriam ser incentivadas para todas as pessoas através de aumento no gasto energético diário, sendo compostas por atividades no trabalho, atividades domésticas, deslocamentos, entre outras. 


\section{CONCLUSÃO}

Apesar de ter sido observado alterações estatísticas positivas apenas na força muscular dos membros superiores, o fato dos valores das demais variáveis analisadas terem se mantido estáveis ao longo dos estudos, com atividades físicas sendo realizadas apenas 1 (uma) vez na semana, é considerado como positivo em se tratando de uma população cuja a tendência é um declínio dessas funções e que os programas de atividade física destinados aos gerontes contribuem para a manutenção da aptidão física dos mesmos, atenuando os efeitos deletérios do envelhecimento.

Os resultados alcançados no período são reflexo positivo das atividades realizadas no projeto Educar para a Atividade Física, como as práticas corporais e as ações educativas, como palestras educativas, que visam conscientizar as participantes sobre a importância da atividade física para a redução dos riscos de doenças cardiovasculares, além de promover a socialização e ensinar a automonitorização do exercício físico.

Esses resultados reforçam a necessidade de continuidade das atividades realizadas no projeto e da elaboração e execução de políticas públicas que propiciem a essa população melhores condições de vida. A importância desse tipo de programa se dá também ao proporcionar-lhes experiências que explorem suas capacidades e o contato/convivência com outras pessoas.

Essa visão é um passo importante para o processo de manutenção e conquista da autonomia e independência durante o processo de envelhecimento, sendo de fundamental importância a participação e colaboração de todos os envolvidos direta ou indiretamente a esse processo, como os parentes, governantes e profissionais de diversas áreas.

É imprescindível que o profissional de Educação Física interessado nesta área esteja atualizado com as alterações anatomo-fisiológicas e funcionais do envelhecimento, sabendo discernir com máxima precisão os efeitos naturais deste processo e das alterações produzidas pelas inúmeras afecções que podem acometer o idoso, e consciente a cerca da importância e contribuição dos aspectos/questões sociais no desenvolvimento de suas atividades e para o êxito dos seus trabalhos. 


\section{REFERÊNCIAS}

BRASIL. Ministério da Saúde. Diretrizes e recomendações para o cuidado integral de doenças crônicas não-transmissíveis: promoção da saúde, vigilância, prevenção e assistência. Brasília: Secretaria de Vigilância em Saúde, Secretaria de Atenção à Saúde, 2008. (Série B. Textos Básicos de Saúde. Série Pactos pela Saúde 2006), v. 8.

BRASIL. Ministério do Planejamento, Orçamento e Gestão. Sinopse do Censo Demográfico. 2010. Instituto Brasileiro de Geografia e Estatística - IBGE. Disponível em: <http://www.ibge.gov.br/home/presidencia/noticias/noticia visualiza.php?id_noticia=1866\&id_pagina=1>. Acesso em: 25 ago. 2010.

CARVALHO, T. et al. Atividade Física e Saúde. Sociedade Brasileira de Medicina do Esporte. Projeto Diretrizes. Rio de Janeiro: Associação Médica Brasileira e Conselho Federal de Medicina, 2001.

CIPRIANI, N. C. S.; et al. Aptidão funcional de idosas praticantes de atividades físicas. Revista Brasileira de Cineantropometria e Desempenho Humano, v. 12, n. 21, p. 106-111, 2010.

CRISTOPOLISKI, F. et al. Efeito transiente de exercícios de flexibilidade na articulação do quadril sobre a marcha de idosas. Revista Brasileira de Medicina do Esporte, v. 14, n. 2, mar./abr., 2008.

FERREIRA, C. C. C. et al. Prevalência de Fatores de Risco Cardiovascular em Idosos Usuários do Sistema Único de Saúde de Goiânia. Arquivos Brasileiros de Cardiologia, São Paulo, v. 95, n. 5, p. 621-628, nov. 2010.

GIROTTO, E.; ANDRADE, S.M.; CABRERA, M. A. S. Prevalência de obesidade abdominal em hipertensos cadastrados em uma unidade de saúde da família. Arquivos Brasileiros de Cardiologia, São Paulo, v. 94, n. 6, p. 754-762, maio, 2010.

GLANER, M. F.; PELEGRINI, A.; NASCIMENTO, T. B. R. Perímetro do abdômen é o melhor indicador antropométrico de riscos para doenças cardiovasculares. Revista Brasileira de Cineantropometria e Desempenho Humano, v. 13, n. 1, p. 1-7, 2011.

GOMES, K. V.; ZAZÁ, D. C. Motivos de adesão a prática de atividade física em idosas. Revista Brasileira de Atividade Física \& Saúde, v. 14, n. 2, 2009. 
MATTOS, M.G.; ROSSETTO JÚNIOR, A.J.; BLECHER, S. Metodologia da Pesquisa em Educação Física: construindo sua monografia, artigos e projetos. 3. ed. rev. e ampl. São Paulo: Editora Phorte, 2008.

MATSUDO, S. M. Envelhecimento, atividade física e saúde. Revista Mineira de Educação Física, Viçosa, v. 10, n. 1, p. 195-209, 2002.

MATSUDO, S. M. et al. Evolução do perfil neuromotor e capacidade funcional de mulheres fisicamente ativas de acordo com a idade cronológica. Revista Brasileira de Medicina do Esporte, v. 9, n. 6, nov./dez. 2003.

MATSUDO, Sandra Marcela Mahecha. Avaliação do idoso: física \& funcional. 3. ed. Santo André: MALI, 2010.

MAZO, G. Z. et al. Do diagnóstico à ação: grupo de estudos da terceira idade: alternativa para a promoção do envelhecimento ativo. Revista Brasileira de Atividade Física \& Saúde. v. 14, n. 1, p. 65-70, 2009.

MAZZEO, R. S. et al. Exercício e atividade física para pessoas idosas. Revista Brasileira de Atividade Física \& Saúde, v. 3, n. 1, p. 48-78, 1998.

MOLARIUS A. et al. Varying sensitivity of waist action levels to identif y subjects with overweight or obesity in 19 populations of the WHO MONICA Project. Journal of Clinical Epidemiology, v. 52, n. 12, p. 13-24, 1999.

ORGANIZAÇÃO PAN-AMERICANA DA SAÚDE - OPAS - OMS. Envelhecimento Ativo: uma Política de Saúde. 1. ed. Brasília: OPAS-OMS, 2005.

OSNESS, W. H. et al. Functional Fitness Assessment for Adults Over 60 Years. The American Alliance For Health, Physical Education, Recreation and Dance. Association for research, administration, professional councils, and societies. Council on aging and adult development 1900. Association Drive. Reston; 1990.

PAIN, B. M. et al. Efeitos de um programa de atividade física na aptidão física e na auto-percepção da atividade física em mulheres acima de 50 anos de idade. Revista Brasileira de Atividade Física \& Saúde, v. 6, n. 3, p. 50-64, 2001.

PAULI, J. R. et al. Influência de 12 anos de prática de atividade física regular em programa supervisionado para idosos. Revista Brasileira de Cineantropometria e Desempenho Humano, v. 11, n. 3, p. 255-260, 2009. 
PEREIRA, J.C.; BARRETO, S.M.; PASSOS, V.M.A. Perfil de saúde cardiovascular dos idosos brasileiros precisa melhorar: Estudo de base populacional. Arquivos Brasileiros de Cardiologia. São Paulo, v. 91, n. 1, p. 1-10, jul. 2008. PITANGA, F. J. G. Epidemiologia da atividade física, exercício físico e saúde. 2. ed. São Paulo: Phorte, 2004.

PITANGA, F.J.G.; LESSA, I. Indicadores Antropométricos de Obesidade como Instrumento de Triagem para Risco Coronariano Elevado em Adultos na Cidade de Salvador - Bahia. Arquivos Brasileiros de Cardiologia. São Paulo, v. 85, n. 1, p. 26-31, 2005.

PITANGA, F. J. G. Testes, medidas e avaliação em educação física e esportes. 5. ed. São Paulo: Phorte, 2008.

ROGATTO, G. P.; GOBBI, S. Efeitos da atividade física regular sobre parâmetros antropométricos e funcionais de mulheres jovens e idosas. Revista Brasileira de Cineantropometria e Desempenho Humano, v. 3, n. 1, p. 63-69, 2001.

SAFONS, M. P.; PEREIRA, M. M. Princípios metodológicos da atividade física para idosos. Brasília: 2007. CREF/DF- FEF/UnB/GEPAFI.

SILVA JÚNIOR, J. P. et al. Estabilidade das variáveis de aptidão física e capacidade funcional de mulheres fisicamente ativas de 50 a 89 anos. Revista Brasileira de Cineantropometria e Desempenho Humano, v. 13, n. 1, p. 8-14, 2011.

SOCIEDADE BRASILEIRA DE ENDOCRINOLOGIA E METABOLOGIA. Sobrepeso e obesidade: diagnóstico. 2004. Associação Médica Brasileira e Conselho Federal de Medicina. Projeto Diretrizes. Disponível em: <http://www. projetodiretrizes.org.br/projeto_diretrizes/089.pdf>.

TEIXEIRA, D. C. et al. Efeitos de um programa de exercício físico para idosas sobre variáveis neuro-motoras, antropométrica e medo de cair. Revista Brasileira de Educação Física e Esporte, São Paulo, v. 21, n. 2, p. 107-20, abr./jun. 2007.

WILMORE, J. H.; COSTILL, D. L. Fisiologia do esporte e do exercício. Barueri: Manole, 2001.

WHO - WORLD HEALTH ORGANIZATION. Global strategy on diet, physical activity and health. Geneva: WHO, 2004. [Fifty-Seventh World Assembly, WHA 57. 17] 


\section{Posfácio}

A Bahia sempre esteve representada com destaque no cenário nacional na produção cultural, com reconhecida presença de atores, cantores, compositores e grande diversidade de espetáculos envolvendo o corpo em movimento, porém no que diz respeito à produção de conhecimento em pesquisa envolvendo Atividade Física e Saúde, ficávamos em tímida posição e a reboque de publicações de outras regiões do Brasil, apesar de já apresentarmos uma massa crítica considerável de pesquisadores sobre o assunto, inclusive com ótimo quantitativo de titulações Stricto Senso.

Demonstrando sensibilidade e maturidade científica, os professores Helio Campos e Francisco Pitanga decidiram reverter tal situação, e com extrema competência, iniciam uma coleta de produções textuais com autores baianos e colaboradores, sobre a atual temática da Atividade Física e Saúde. Os autores na sua totalidade ficaram envaidecidos com o convite e o dignificaram com excelentes produções sobre o tema, oriundos das suas recentes dissertações e teses em instituições nacionais e internacionais. A maioria das pesquisas apresentadas nesse livro, além de pertencerem a autores baianos, foi realizada no âmbito da população local, o que amplia o impacto científico, a relevância dos estudos e ainda aponta para indicadores na área da saúde no nosso estado, que poderão ser utilizados pelos poderes institucionalizados no sentido de 
nortear políticas públicas de lazer ativo, deslocamento ativo, combate ao sedentarismo, e educar para saúde no ambiente escolar.

O livro trata extraordinariamente da temática da Atividade Física e Saúde através de artigos bem diversificados e nos remete, pelo seu conteúdo, a desdobramento bastante amplo envolvendo outros setores importantes como o da segurança pública, urbanismo, atenção básica a saúde e obvio educação física escolar.

Penso que essa obra não tem apenas utilidade para leitura e reflexão dos seus achados científicos, mas, também é um potente instrumento de consulta, para todas as áreas de conhecimento que lida com o corpo em movimento e suas consequências para a saúde como a Educação Física, Medicina e áreas afins, assim, reintero sobre a ótima pluralidade dos estudos apresentados que transita desde a satisfação com a imagem corporal, circunferência de cintura como preditor de comorbidades, inatividade física na região metropolitana de Salvador até uma criteriosa investigação sobre a produção de conhecimento na área da Atividade Física e Saúde no Brasil.

Nesse contexto da utilidade, a coletânea se destaca por ser um veículo importantíssimo na formação dos futuros profissionais da Educação Física, e aqui ressalto a singular contribuição aos alunos do Curso de Educação Física em EAD da UNEB/UAB, posto que, são estudantes lotados em cidades do interior do Estado da Bahia as quais ainda apresentam carência ao acesso a publicações especializadas. Portanto, esta notável obra, certamente não resolverá o problema da enorme ausência de títulos sobre o tema, mas, é aquela gotinha de água que o beija-flor derrama no incêndio florestal, ajudando e, sobretudo, motivando minimizar a problemática da carência bibliográfica na área da Atividade Física e Saúde.

Também, tenho a certeza que essa obra será de grande valia para os profissionais de Educação Física que têm o foco na promoção da saúde e na qualidade de vida, pois apresenta conhecimentos específicos e bastante atualizados, além do mais, fundamentados em pesquisas de relevância científica, que por certo, ampliará a motivação para trabalhos práticos mais consistentes, produção teórica e qualificação profissional na área da Atividade Física e Saúde. 
Por fim, fico feliz por ter os professores Helio e Pitanga como ídolos e orientadores dos meus estudos, os autores como amigos e ver a publicação baiana de uma obra de qualidade que remete a pesquisas sérias e de rigor científico na área da Atividade Física e Saúde.

Luiz Alberto Bastos de Almeida Mestre em Ciência da Motricidade Humana - UCB - RJ Professor da Universidade Estadual de Feira de Santana (UEFS) Membro do NEPAFS - UEFS Professor EAD/UNEB/UAB 
COLOFÃO

Formato $16,5 \times 23 \mathrm{~cm}$

Tipologia Swift e Ronnia

Papel Acalino $75 \mathrm{~g} / \mathrm{m}^{2}$ e Duo Design $300 \mathrm{~g} / \mathrm{m}^{2}$

Impressão Edufba

Acabamento Cian Gráfica

Tiragem 600 exemplares 